\title{
A SYSTEMATIC REVIEW AND META-ANALYSIS OF EXERCISE INTERVENTIONS AND USE OF EXERCISE PRINCIPLES TO REDUCE FEAR OF FALLING IN COMMUNITY-DWELLING OLDER ADULTS
}

by

Chengying Feng

\begin{abstract}
A thesis submitted to the Department in Rehabilitation Science
In conformity with the requirements for

the degree of Master of Science
\end{abstract}

\author{
Queen's University \\ Kingston, Ontario, Canada
}

(February 2022)

Copyright (C) Chengying Feng, 2022 


\begin{abstract}
Fear of falling (FOF) contributes to activity restriction and increases fall risks and institutionalization among older adults. Exercise interventions are associated with a reduction in FOF. Adhering to exercise principles and adopting proper exercise parameters are fundamental to optimizing the effectiveness of exercise interventions. The objectives of this thesis were to describe FOF exercise interventions in community-dwelling older adults to inform future programs, evaluate the extent to which these interventions followed the exercise principles and reported exercise parameters, and finally quantify the effect of these interventions on reducing FOF.

Randomized controlled trials (RCTs) of FOF exercise interventions in older adults ( $\geq 65$ years) were identified from MEDLINE, Embase, PsycINFO, and CINAHL databases from inception to 2020. Two reviewers independently screened and assessed the relevant literature, and a third reviewer was engaged to resolve any conflicts. The methodological quality of RCTs was assessed using the PEDro scale. The qualitative data were narratively synthesized, and a random-effect model was used in the metaanalysis. Sensitivity analyses were carried out to examine the impact of trials with small sample sizes and a high risk of bias on the findings.

Seventy-five RCTs were included in this review. Most trials with a significant effect on FOF used multicomponent exercises and group-based interventions, moderate intensity, three-times-per-week frequency for 12 to 16 weeks, and 30 to 60 minutes for each exercise session. With regard to reporting exercise principles, specificity was reported in $92 \%$ of trials, progression in $72 \%$, reversibility in $32 \%$, overload in $31 \%$, diminishing return in $21 \%$, and initial value in only $8 \%$ of trials. For exercise parameters, $97 \%$ of RCTs reported exercise type, $89 \%$ reported frequency, and $85 \%$ reported time. Only $25 \%$ of trials reported the intensity of exercises. The pooled effect of exercise interventions on FOF reduction among all included studies was a standard mean difference of $-0.34(95 \% \mathrm{CI}=-0.44$ to -0.23$)$. The sensitivity analysis showed that the pooled effect size decreased after removing trials with small
\end{abstract}


sample sizes $(-0.25 ; 95 \% \mathrm{CI}=-0.37$ to -0.13$)$ and with fair methodological quality $(-0.22 ; 95 \% \mathrm{CI}=-0.36$ to -0.8$)$, but the results were still significant.

This study showed a significant small-to-moderate effect size of exercise interventions in reducing FOF among community-dwelling older adults. Most exercise principles and the intensity of exercises were not adequately reported in included trials. These inadequate reports could undermine efforts to examine the optimal dosage for exercise prescription. Researchers must give more attention to designing and reporting components of therapeutic exercise programs to facilitate evidence-based practice. 


\section{Co-Authorship}

This thesis presents the research conducted by Chengying Feng under the supervision of Dr. Mohammad Auais. Tony Adebero facilitated the screening titles, abstracts and full texts, as well as the data extraction process. Dr. Vincent DePaul and Kathleen Norman provided constructive feedback and editorial support. Dr. Afshin Vafaei was consulted for his expertise in statistical analyses. The authorship and the related publication is as follows:

\section{Related published manuscript:}

Feng C, Adebero T, DePaul VG, Vafaei A, Norman KE, Auais M. A Systematic Review and MetaAnalysis of Exercise Interventions and Use of Exercise Principles to Reduce Fear of Falling in Community-Dwelling Older Adults. Physical therapy. 2022 Jan;102(1):pzab236. 


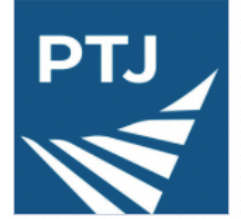

Volume 102, Issue 1 January 2022 (In Progress)

Comments (0)

<Previous Next >

\section{A Systematic Review and Meta-Analysis of Exercise Interventions and Use of Exercise Principles to Reduce Fear of Falling in Community-Dwelling Older Adults Get access ?}

Chengying Feng $\boldsymbol{M}$, Tony Adebero, Vincent G DePaul, Afshin Vafaei, Kathleen E Norman, Mohammad Auais

Physical Therapy, Volume 102, Issue 1, January 2022, pzab236,

https://doi.org/10.1093/ptj/pzab236

Published: 08 October 2021 Article history $\mathbf{v}$

66 Cite

Permissions $\prec$ Share $\boldsymbol{V}$

\section{Abstract}

Objective

Fear of falling (FOF) contributes to activity restriction and institutionalization among older adults, and exercise interventions are linked to reduction in FOF. Adhering to exercise principles and adapting optimal exercise parameters are fundamental to optimizing the effectiveness of exercise interventions. The purpose of this review was to describe FOF exercise interventions in community-dwelling older adults, evaluate the extent to which these interventions followed the exercise principles and reported exercise parameters, and quantify the effect of these interventions on reducing FOF.

\section{Methods}

Randomized controlled trials (RCTs) of FOF exercise interventions in older adults ( $\geq 65$ years) were identified from 4 databases. The methodological quality of RCTs was assessed using the Physiotherapy Evidence Database scale. A random-effect model was used in the meta-analysis.

Seventy-five RCTs were included in this review. With regard to reporting exercise principles, specificity was reported in $92 \%$ of trials, progression in $72 \%$, reversibility in $32 \%$, overload in $31 \%$, diminished return in $21 \%$, and initial value in $8 \%$. For exercise parameters, $97 \%$ of RCTs reported exercise type; $89 \%$, frequency; and $85 \%$, time. Only $25 \%$ reported the intensity. The pooled effect of exercise interventions on FOF among all included studies was a standard mean difference of $-0.34(95 \% \mathrm{CI}=-0.44$ to -0.23$)$.

\section{Conclusion}

This study showed a significant small to moderate effect size of exercise interventions in reducing FOF among community-dwelling older adults. Most exercise principles and intensity of exercises were not adequately reported in included trials.

\section{Impact}

These inadequate reports could undermine efforts to examine the optimal dosage for exercise prescription. More attention must be given to designing and reporting components of therapeutic exercise programs to facilitate evidencebased practice.

Keywords: Accidental Falls, Aged, Exercise Therapy, Geriatrics Issue Section: Review

(c) The Author(s) 2022. Published by Oxford University Press on behalf of the American Physical Therapy Association. All rights reserved. For permissions, please email:

journals.permissions@oup.com 


\section{Acknowledgements}

Words are not enough to express my gratitude to those important persons who stood next to me as I pursued my master's degree at Queen's University and completed this thesis. Nevertheless, I would like to take this opportunity to express my deepest appreciation to people who have contributed to the conclusion of my master's journey.

Dr. Mohammad Auais, you are the most important part of this undertaking. Without your generosity and kindness in providing me with a second chance for admission into the master's program, I would not have set out at all. The thesis would not be possible without your endless support, patience, and guidance. Your faith in me has encouraged me to try things I would not be confident to try on my own such as the MITACS funding application and conference presentations. Your trust in my capabilities in completing high-quality research tasks has provided me with great opportunities to develop my academic skills. As the adage goes: "Give a person a fish and they will eat for a day; teach them how to fish and they will eat for a lifetime". You have seized each possible opportunity to coach me to become a better researcher. I remember during our meetings, whenever I ask you a question, you would not give me a straightforward and easy answer, instead, you would always encourage me to find the answer on my own, and then you would step in when it was necessary. I will be always mindful of what you have taught me whenever I encounter challenges in my future academic career.

I would also like to submit my special appreciation to Drs. Vincent DePaul and Kathleen Norman for their constructive feedback, expertise, and guidance, and to Dr. Afshin Vafaei for guiding and supporting me in conducting statistical analyses.

Last but not the least, I wish to give my most sincere thanks to my family for their unconditional love and support and my friend Dr. Amir Rasooli who has been a great company in the past two years, providing academic support during difficult times and valuable tips on how to thrive in academia. 


\section{Table of Contents}

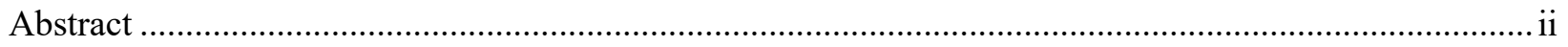

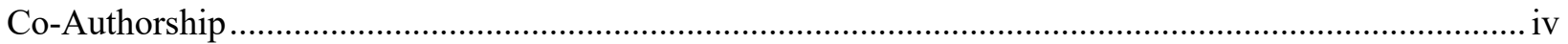

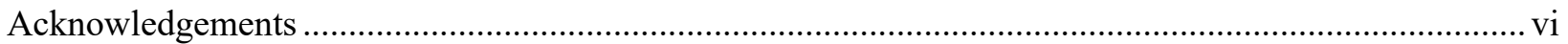

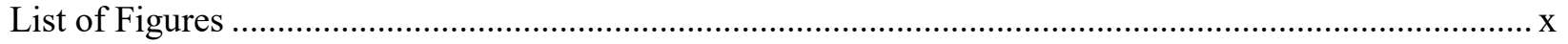

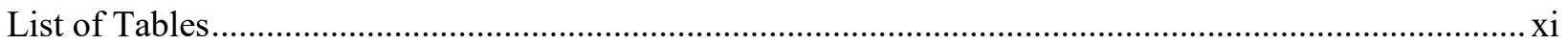

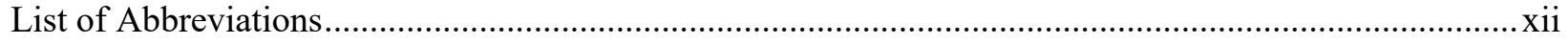

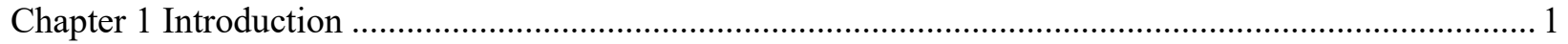

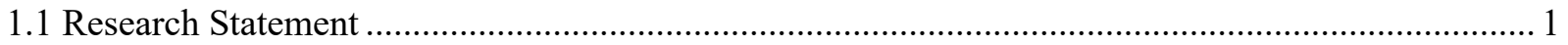

1.2 Principles of Exercise Training and Exercise Prescription Framework............................................ 3

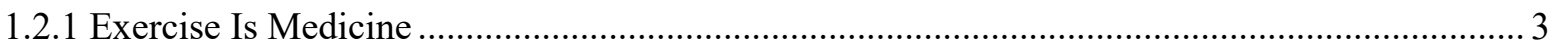

1.2.2 Distinctions of Physical Activity, Physical Exercise, Physical Training, and Exercise

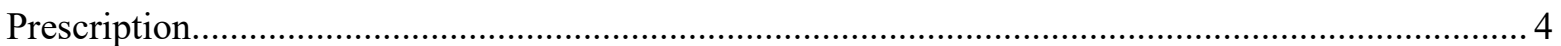

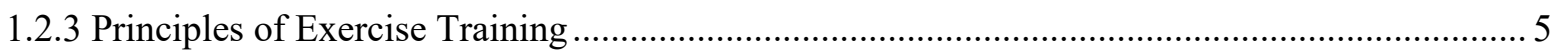

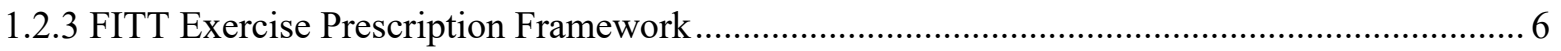

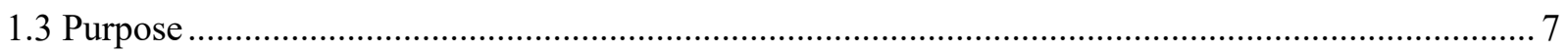

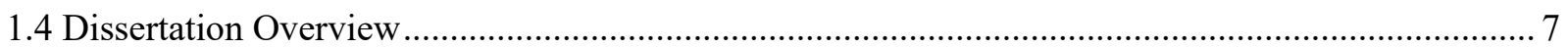

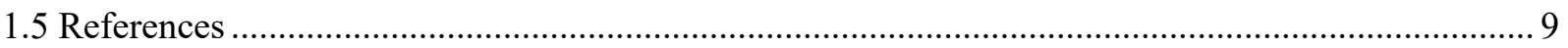

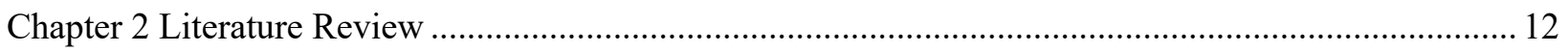

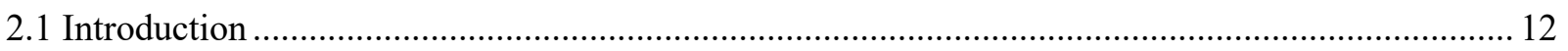

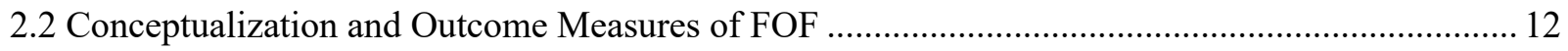

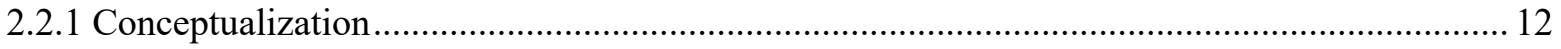

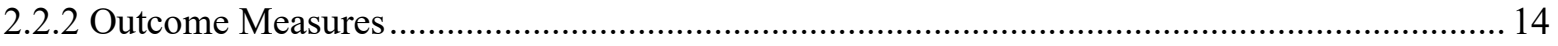

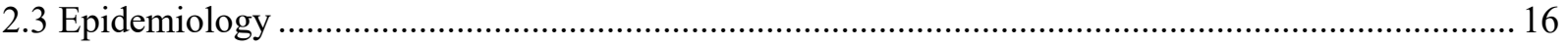

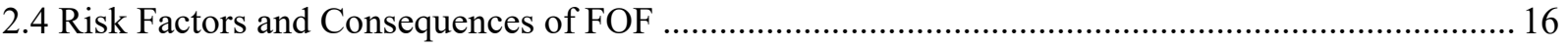

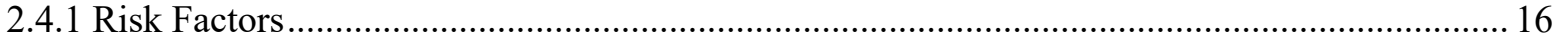

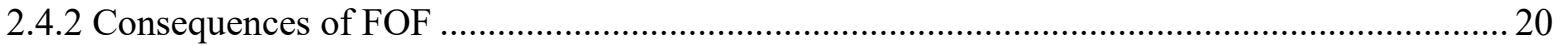

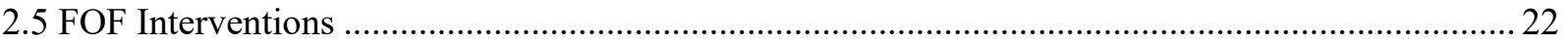

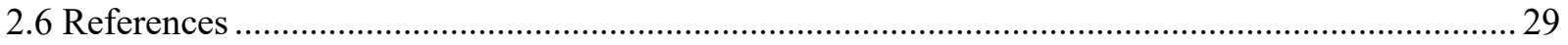

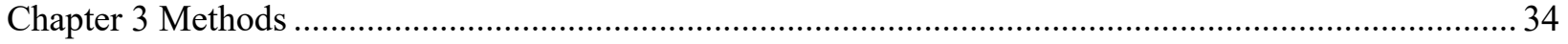

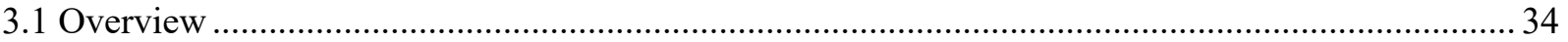

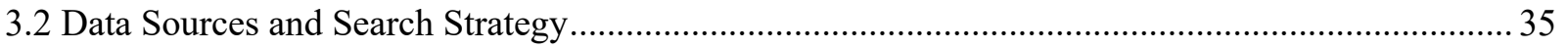

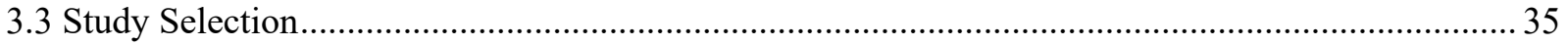




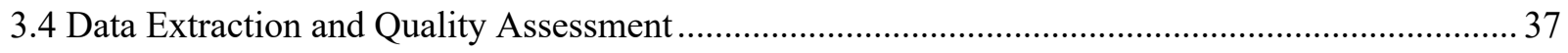

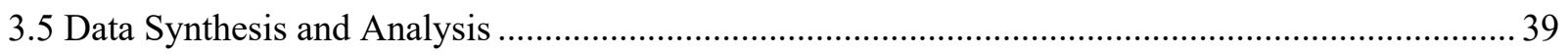

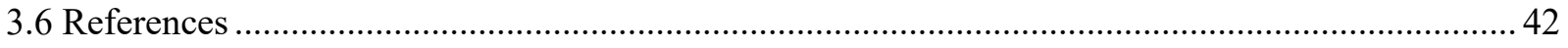

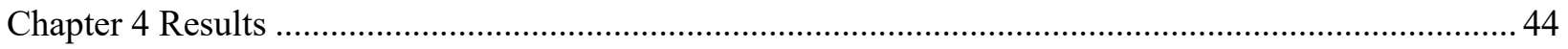

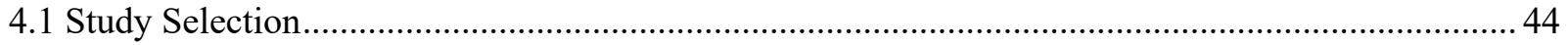

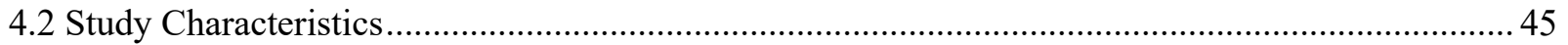

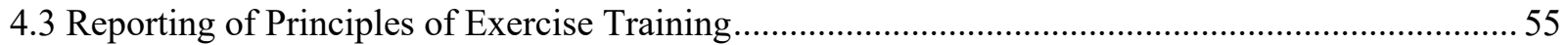

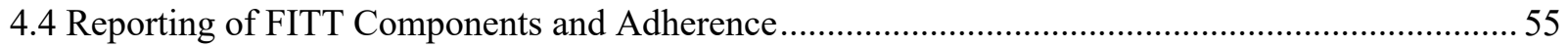

4.5 Rating of the Methodological Quality of Included RCTs ............................................................ 58

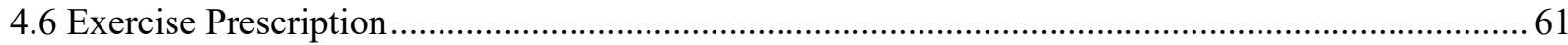

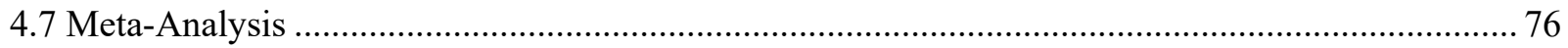

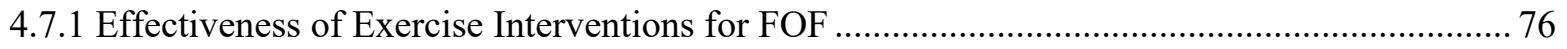

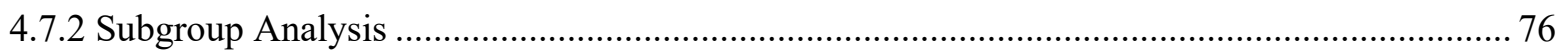

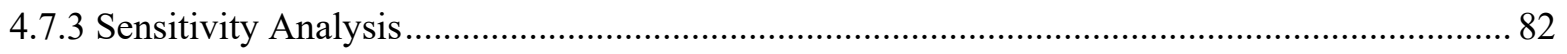

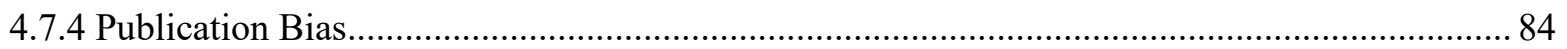

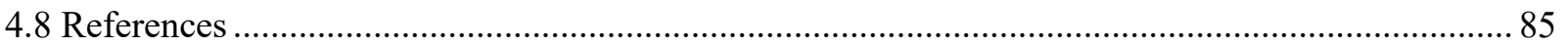

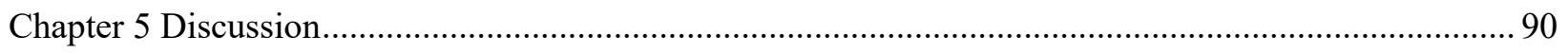

5.1 Reporting of Principles of Exercise Training and FITT Components .......................................... 90

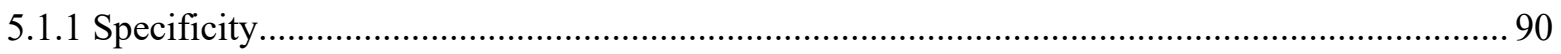

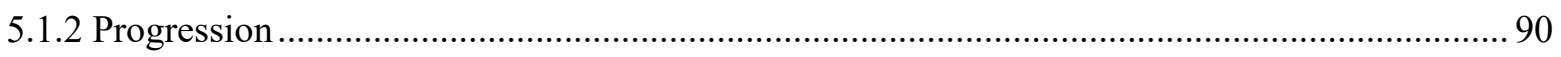

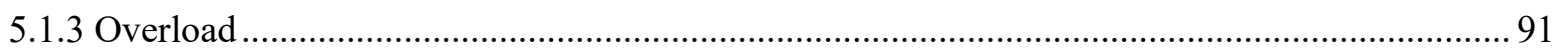

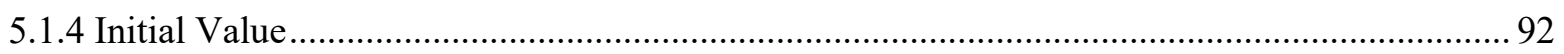

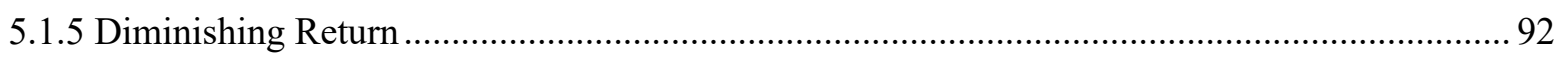

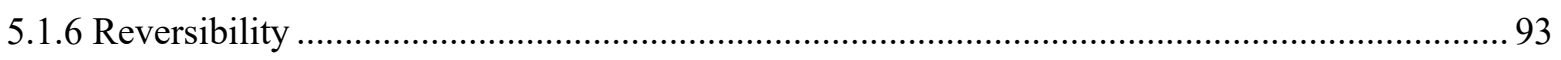

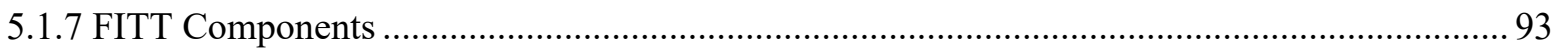

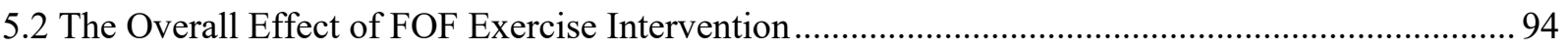

5.3 Comparing Results with Previous Reviews on FOF Intervention .............................................. 95

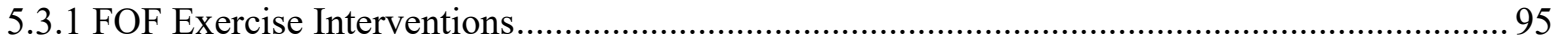

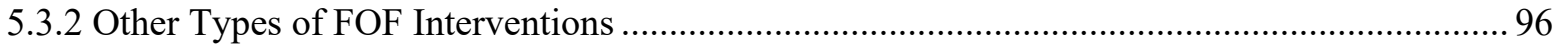

5.4 Implications for Future Research, Practice and Policy …............................................................... 98

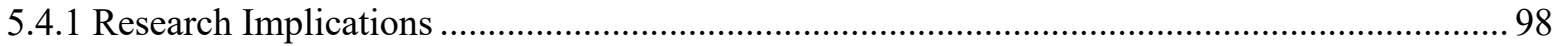

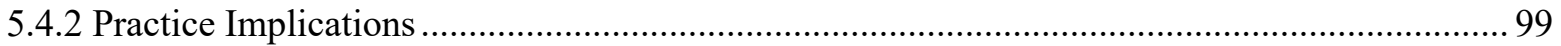

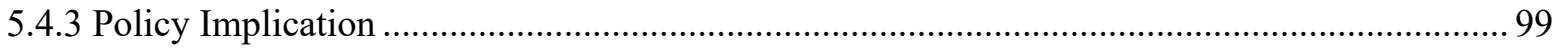

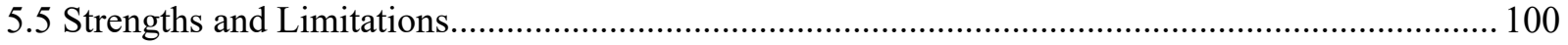




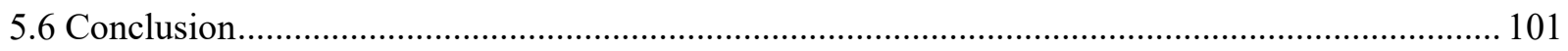

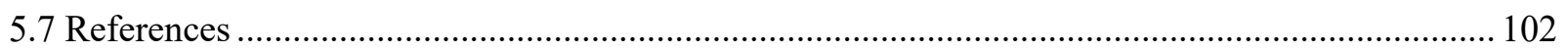

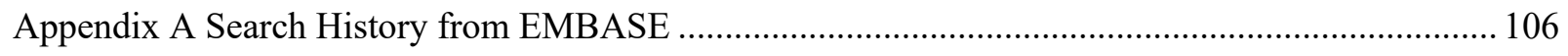

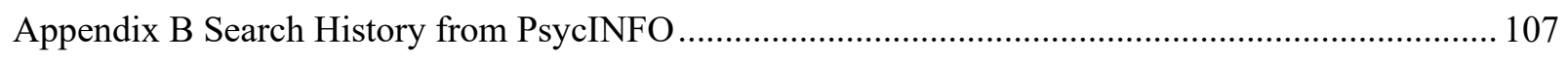

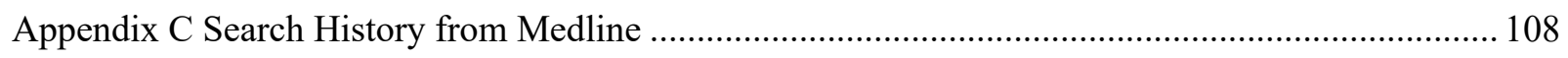

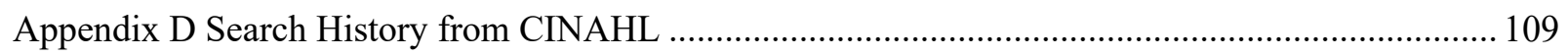

Appendix E Excluded Studies and Reasons for Exclusion ............................................................ 110

Appendix F Subgroup Analyses for Studies Using Change-from-baseline Values ............................ 116

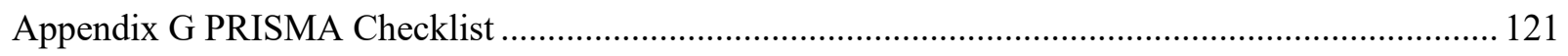

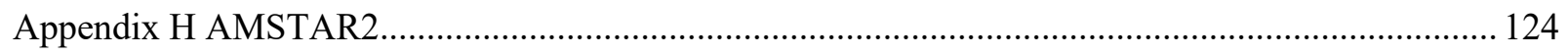




\section{List of Figures}

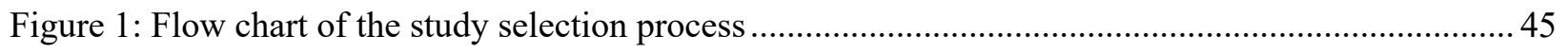

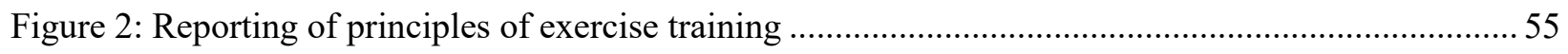

Figure 3: Reporting of FITT components and adherence …................................................................ 56

Figure 4: The pooled effect of exercise interventions on FOF using post-intervention data.................... 76

Figure 5: Subgroup analyses by outcome measures using post-intervention data ................................... 78

Figure 6: Subgroup analyses by types of exercise interventions using post-intervention data .................. 79

Figure 7: Subgroup analyses by the duration of intervention using post-intervention data....................... 80

Figure 8: Subgroup analyses by whether FOF is primary or secondary outcome measures using post-

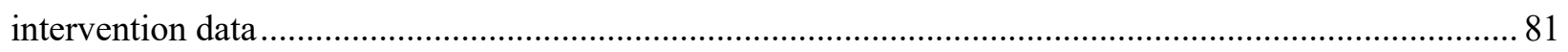

Figure 9: Subgroup analyses by whether the intervention was individual or group-based using post-

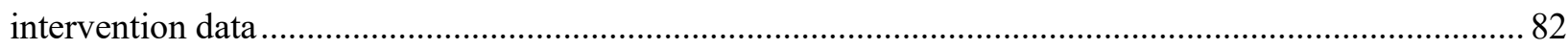

Figure 10: The pooled effect of exercise interventions on FOF using change-from-baseline values $(\mathrm{n}=52)$

(n)

Figure 11. Funnel plot using post-intervention data 84 


\section{List of Tables}

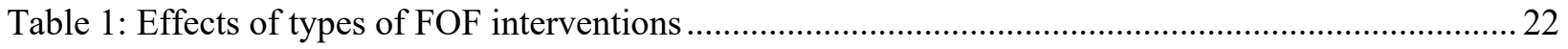

Table 2: Rating the reporting of principles of exercise training, FITT components and adherence........... 38

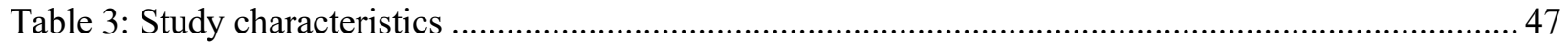

Table 4: Reporting of principles of exercise training and FITT ….......................................................56

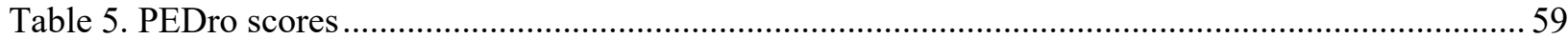

Table 6: The number ( $\%$ ) of trials meeting each criterion of PEDro scale ................................................ 61

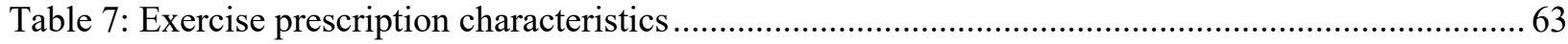

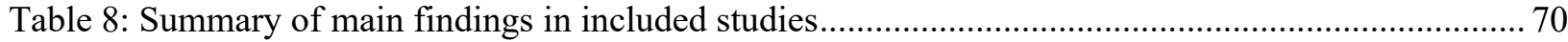




\section{List of Abbreviations}

$\mathrm{ABC}$

ACSM

ADL

AMOB/ALL

APA

CBT

CERT

CI

CONbal

$3 \mathrm{D}$

EIM

EP

FaME

FES

FES-I

FFABQ

FFQ

FITT

FOF

GFFM

IADL

ME

$\mathrm{MeSH}$

MFES

MW

OEP

OR

PEDro

RENEW

RCT

1RM
Activity-specific Balance Scale

American College of Sports Medicine

Activities of Daily Living

A Matter of Balance Volunteer Lay Leader

Anticipatory Postural Adjustments

Cognitive Behavioral Therapy

Consensus on Exercise Reporting Template

Confidence Interval

A measure of balance confidence

Three-dimensional

Exercise Is Medicine

Exercise Principles

Falls Management Exercise

Falls Efficacy Scale

Fall Efficacy Scale-International

Fear of Falling Avoidance Behavior Questionnaire

Fear of Falling Questionnaire

Frequency, Intensity, Time, and Type of exercise

Fear of Falling

Geriatric Fear of Falling Measure

Instrumental Activities of Daily Living

Maximum Exertion

Medical Subject Headings

Modified Fall Efficacy Scale

Maximum Workload

Otago Exercise Programme

Odds Ratio

Physiotherapy Evidence Database

Resistance Exercise via Negative, Eccentrically-induced Work

Randomized Controlled Trials

1 Repetition Maximum 
ROM

RPE

SAFE

SF-36

SMD

TUG

USA

VAS

UK
Range of Motion

Rating of Perceived Exertion

Survey of Activities and Fear of Falling in the Elderly

36-Item Short Form Survey

Standardized Mean Difference

Timed Up and Go

United States of America

Visual Analog Scale

United Kingdom 


\section{Chapter 1}

\section{Introduction}

\subsection{Research Statement}

Approximately one-third of older Canadians fall at least once each year. ${ }^{1}$ Falls are the number one cause of injury-related hospitalization and premature death among Canadians over 65 years of age. ${ }^{2}$ Falls and their related injuries threaten older individuals' psychological and physical health, such as the increased risk of fear of falling and depression, reduced quality of life, and loss of independence. ${ }^{2}$ Falls also place significant pressure on government finances and the healthcare system. According to the Public Health Agency of Canada, an estimated 2 billion dollars in direct healthcare costs are associated with senior falls annually. ${ }^{2}$ The costs will rise exponentially as the ageing population $(65+)$ in Canada continues to grow faster, from 6.8 million in 2020 to 11 million by $2036 .^{2}$

Despite the severe consequences of falls at both individual and social levels, there have been issues related to older adults' perception of the risk of falling. Over $30 \%$ of older Canadians reported being concerned about a future fall, with a third of them having had fall experiences in the previous year. ${ }^{3}$ Exaggerated concern about falling, termed "Fear of Falling" (FOF), is an risk factor of falling itself and associated with social and physical activity restrictions. Around $44 \%$ of older Canadians with FOF reported that they had ceased participating in some of the activities they used to enjoy because of their falling concerns. ${ }^{3}$ The FOF induced activity restriction promotes a downward spiral of physically diminished function and falls, which in turn aggravates FOF. ${ }^{4,5}$ In addition to the physical impact, FOF leads to adverse psychosocial outcomes such as low self-efficacy, ${ }^{6}$ poor life satisfaction, ${ }^{7}$ and high risks of anxiety, ${ }^{8}$ depression ${ }^{8}$, and social isolation. ${ }^{9}$ 
Due to multifactorial causes (e.g., poor balance and depression) and biopsychosocial impacts (e.g., loss of independence and social isolation) of FOF in older adults, various types of FOF interventions have been developed to address this complex issue. These interventions include (1) exercise interventions such as balance, strength, and Tai Chi exercises, (2) psychological interventions including cognitive behavior therapy and education, and (3) other interventions such as environmental modification and nutritional supplementation. ${ }^{10}$ Exercises appear to be a single-factor intervention that is effective and broadly investigated among all FOF interventions. ${ }^{11}$ In particular, research has shown that exercise interventions can enhance older adults' falls-related self-efficacy and balance confidence by improving their muscle strength, mobility, endurance, gait patterns, and static and dynamic balance. For example, communitybased exercise programs, such as Tai Chi, ${ }^{12,13}$ balance and resistance training, ${ }^{14}$ and multicomponent home-based exercise programs,${ }^{15}$ have shown effectiveness in increasing balance confidence and reducing FOF. Several systematic reviews provide an insight into the influence of various exercise interventions on FOF. ${ }^{11,16-18}$ For example, a systematic review and metaanalysis ${ }^{11}$ that included 30 trials found a small to moderate effect size of exercise interventions on reducing FOF immediately after intervention in older adults.

However, FOF exercise interventions vary across studies, and there is no unified consensus on the recommendations of type and "dosage" of FOF exercise interventions (i.e., intensity, duration, and frequency) for community-dwelling older adults. Experts and researchers often recommend exercise as an essential intervention for preventing certain health conditions such as falls and FOF in community-dwelling older adults. However, they do not provide guidelines on precise exercise prescription for those purposes. ${ }^{19}$

In the field of rehabilitation, exercise prescription is a process to develop a proper regimen with a specific purpose through evaluating and interpreting clinical information. ${ }^{20}$ To enhance the chance of successful training effect and minimize side effects, exercise prescription 
has to follow well-established principles of exercise training, including specificity, progression, overload, initial value, reversibility and diminishing return. ${ }^{21}$ Disregarding these principles may lead to an inadequate intervention design, which in turn can put studies are at risk of drawing unreliable conclusions regarding their outcomes of interest. Furthermore, frequency, intensity, time, and type of exercise (FITT) are the main variables that can be manipulated to assure the application of exercise principles and maximize the benefit of exercise training. ${ }^{21}$ Arnold et al. point out that there is a need for a clear understanding of optimal frequency, intensity, type and duration of exercise for fall prevention programs. ${ }^{22}$ As part of exercise training studies, both applications of exercise principles and FITT components should be reported so that the peer reviewers can critically appraise the effectiveness of exercise interventions and replicate the interventions in clinical settings. Without this information, clinicians attempting to implement an effective, evidence-based effective exercise program for older adults with FOF would encounter an enormous challenge. Although numerous reviews have examined the effect of FOF exercise interventions, ${ }^{23}$ no reviews have examined the measures of exercise prescription or taken them into account in their appraisal. This gap has the potential to create risks for knowledge mobilization. When the actual exercise dosage is unknown, there is a risk that exercise programs that were shown to be effective may be rendered ineffective with low fidelity in their implementation to the original programs. Therefore, an in-depth investigation of FOF exercise interventions in the current literature based on the established principles of exercise training and exercise prescription framework is key to scientific reproducibility and successful translation of evidence to clinical practice.

\subsection{Principles of Exercise Training and Exercise Prescription Framework}

\subsubsection{Exercise Is Medicine}

Exercise as a medicine is an old concept but only gained acceptance in the $20^{\text {th }}$ century. Hippocrates in ancient Greece was among the first to advocate exercise, stating: "if we could give 
every individual the right amount of nourishment and exercise, not too little and not too much, we would have found the safest way to health". ${ }^{24}$ It was not until the $19^{\text {th }}$ century that a physician named Mckenzie began considering exercise as a technique to rehabilitate people with disabling injuries. ${ }^{25}$ Gradually, exercise specialists became aware of the rationales for medically directed exercise in a wide array of conditions. Extensive evidence supports exercise as playing a significant role in the primary and secondary prevention of cancer, ${ }^{26}$ hypertension, ${ }^{27}$ coronary artery disease, ${ }^{28}$ depression, ${ }^{29}$ osteoporosis,${ }^{30}$ and dementia. ${ }^{31}$ In November 2007, Exercise Is Medicine (EIM) was initiated by the American College of Sports Medicine (ACSM) in conjunction with the American Medical Association. Specifically, the missions of EIM were to ensure physical activity assessment and promotion as a standard of medical care and encourage physicians and other healthcare providers to refer patients to qualified exercise professionals. EIM has since expanded globally to more than 40 countries in just two years. ${ }^{32}$

\subsubsection{Distinctions of Physical Activity, Physical Exercise, Physical Training, and Exercise Prescription}

The terms "physical activity", "physical exercise", "exercise training”, and "exercise prescription" describe different concepts that are sometimes used interchangeably. Physical activity refers to any body movements that involve skeletal muscle contraction and energy expenditure. ${ }^{33}$ Physical activity consists of a broad range of household, occupational, recreational, and conditioning activities. Physical exercise, however, is a subset of physical activity that is specific, planned, and structured. ${ }^{34}$ Physical exercise includes various types such as strength, endurance, flexibility, and balance exercises. Physical exercise can be performed casually or repetitively with non-specific or specific goals. A regularly planned and structured exercise to maintain and enhance fitness is a form of physical training. ${ }^{34}$ According to ACSM, exercise prescription is a recommended physical activity program that is designed in a systematic and personalized manner, considering the frequency, intensity, time and type of exercise. ${ }^{35}$ In the field of rehabilitation, exercise prescription is a process of evaluating and interpreting clinical 
information and using the principles of exercise training and appropriate dosage to determine whether a regimen is appropriate for achieving the outcomes of interests. ${ }^{36}$

\subsubsection{Principles of Exercise Training}

Principles of exercise training (i.e., specificity, overload, progression, initial values, reversibility and diminishing returns) are fundamental components for prescribing an exercise training program because they impact the effectiveness of exercise training. ${ }^{37}$ Inconsistency in applying principles of exercise training in exercise intervention studies might lead to nonsignificant results due to the inappropriate exercise prescriptions, resulting in the misinterpretation of the training effect. ${ }^{38}$ Exercise principles include specificity, progression, overload, progression, initial values, reversibility and diminishing returns. The specificity requires us to prescribe an exercise training program that is tailored to a specific organ system(s)

or muscle(s) to elicit the desired adaptation(s). ${ }^{34}$ For example, resistance exercise targeting lower limb muscles is a more appropriate intervention than aerobic exercise for a person who has developed atrophy in lower limb muscles. The progression of exercise dose ensures that new adaptations occur when our body has adapted to the previous dosage. ${ }^{34}$ Progression of exercise training involves increasing any of the FITT components depending on an individual's health status, training response, and training goals. For example, an inactive adult who initiated an aerobic exercise program at a light-to-moderate intensity is recommended to increase exercise time/duration by five to ten minutes per session every one to two weeks over the first four to six weeks of an exercise training program. ${ }^{35}$ The overload refers to an appropriate training stimulus that must exceed the individual's current exercise capacity. ${ }^{34}$ This stimulus is the proper combination of FITT components. For example, to produce muscle hypertrophy in a new health adult trainee, an intensity of $70-85 \%$ of $1 \mathrm{RM}$, eight to 12 repetitions with one to three sets for each muscle or muscle group is recommended by ACSM. ${ }^{35}$ The Initial values indicate that individuals with lower initial values will experience more significant improvements following a 
training program than individuals with higher initial values. ${ }^{39}$ Finally, the principles of reversibility and diminishing return are associated with the long-term effects of exercise training. In respect to reversibility, as soon as the exercise stimulus is removed, a de-adaptational process will occur and will eventually return to the baseline fitness level. ${ }^{34}$ In respect to diminishing return, a deceleration of improvements can be expected after a period of time as trainees reach a higher fitness level. ${ }^{39}$

\subsubsection{FITT Exercise Prescription Framework}

To achieve therapeutic goals, an exercise prescription resembling a drug prescription should specify the exercise dose. ${ }^{40}$ The essential part of exercise dose consists of exercise parameters. They are frequency, intensity, time, and type of exercises (FITT). Frequency gives information on the number of training sessions across a specific time interval. ${ }^{34}$ They can be performed several times a day or less frequently, perhaps a few times per week. For example, patients after total hip arthroplasty are recommended to perform a range of motion exercise program several times a day. Older adults should perform vigorous exercise no more than three times a week to minimize the risks of injuries and cardiac events. Intensity represents the degree of strenuousness or challenge level of a specific exercise or a training session. Intensity is commonly measured by the maximal heart rate, maximal oxygen consumption, metabolic equivalents or rate of perceived exertion. ${ }^{34}$ Time or duration of exercises is a period of a specific exercise or a training session. ${ }^{41}$ The time is often indicated by the minutes per session for aerobic exercises, while the number of repetitions and sets is indicative of time for resistance exercises. ${ }^{41}$ Exercises can be categorized into different types (i.e., aerobic, resistance, flexibility, neuromotor exercise) depending on their effect on physical function. ${ }^{41}$ Aerobic or endurance exercise aims at improving cardiovascular function by engaging large muscle groups and consuming more oxygen than the body would while resting. Resistance or strength exercise is any exercise that involves contracting the muscles against an external resistance to increase muscle strength, power, 
hypertrophy or endurance. Flexibility exercise stretches muscles, ligaments, or joint capsules to maintain optimal muscle length and joint mobility. Neuromotor exercise integrates several motor skills to target functions of balance, coordination, gait, agility, and proprioception. ${ }^{35}$ Some exercises combining resistance, neuromotor and flexibility such as Tai Chi, yoga, and Pilates are called three-dimensional (3D) exercises in the present study.

Each FITT component is indispensable when designing and prescribing an exercise training program since all of them together provide a clear structure for the training guideline based on a specific population, medical condition, and outcome of interest. For example, the ACSM recommends that in general older adults ( $\geq 65$ years) should perform 30 to 60 minutes of aerobic exercise with moderate intensity five or more times a week. ${ }^{35}$

In summary, manipulation of FITT components by following the principles of exercise training is the key to the success of designing and prescribing an effective exercise training program. Meanwhile, using them as criteria to critically appraise the quality of exercise interventions will provide better insight into the actual efficacy of those exercise interventions in studies.

\subsection{Purpose}

The purposes of this thesis are to (1) describe FOF exercise interventions in communitydwelling older adults that have been reported in the peer-reviewed literature in terms of the extent to which they followed the principles of exercise training and reported FITT components; (2) provide evidence on the magnitude of the effect of exercise interventions in reducing FOF in community-dwelling older adults; (3) explore variables that might impact the effect size of included exercise interventions.

\subsection{Dissertation Overview}

The thesis consists of five chapters. Chapter 1 is an introduction in which I state the background information, rationales, key concepts and measures of exercise prescription and the 
purposes of this thesis. Chapter 2 is a general literature review, in which I provide an overview of FOF conceptualizations, outcome measures, epidemiology, risk factors, consequences, and relevant interventions. Chapter 3 to Chapter 5 are methods, results, and discussion, respectively. 


\subsection{References}

1. Stinchcombe A, Kuran N, Powell S. Report summary-seniors' falls in Canada: second report: key highlights. Chronic Diseases and Injuries in Canada. 2014;34(2-3).

2. Public Health Agency of Canada. Seniors' falls in Canada: second report [Internet]. Ottawa (ON): Public Health Agency of Canada. 2014. [cited 2021 Dec 4]. Available from: http://www.phac-aspc.gc.ca/seniors -aines/publications/public/index-eng.ph

3. Pearson C, Geran L, St-Arnaud J. Understanding seniors' risk of falling and their perception of risk. Ottawa: Statistics Canada. 2014.

4. Bertera EM, Bertera RL. Fear of falling and activity avoidance in a national sample of older adults in the United States. Health \& Social Work. 2008;33(1):54-62.

5. Jørstad EC, Hauer K, Becker C, Lamb SE, Group P. Measuring the psychological outcomes of falling: a systematic review. Journal of the American Geriatrics Society. 2005;53(3):501-510.

6. Tinetti ME, Powell L. Fear of falling and low self-efficacy: a cause of dependence in elderly persons. Journal of Gerontology.1993.

7. Oh E, Hong G-RS, Lee S, Han S. Fear of falling and its predictors among communityliving older adults in Korea. Aging \& Mental Health. 2017;21(4):369-378.

8. van Haastregt JCM, Zijlstra GAR, van Rossum E, van Eijk JTM, Kempen GIJM. Feelings of anxiety and symptoms of depression in community-living older persons who avoid activity for fear of falling. The American Journal of Geriatric Psychiatry. 2008;16(3):186-193.

9. Painter JA, Allison L, Dhingra P, Daughtery J, Cogdill K, Trujillo LG. Fear of falling and its relationship with anxiety, depression, and activity engagement among communitydwelling older adults. The American Journal of Occupational Therapy. 2012;66(2):169176.

10. Kruisbrink M, Delbaere K, Kempen GI, et al. Intervention characteristics associated with a reduction in fear of falling among community-dwelling older people: a systematic review and meta-analysis of randomized controlled trials. The Gerontologist. 2021;61(6):e269-e282.

11. Kumar A, Delbaere K, Zijlstra G, et al. Exercise for reducing fear of falling in older people living in the community: Cochrane systematic review and meta-analysis. Age and ageing. 2016;45(3):345-352.

12. Li F, Harmer P, Chou LS. Dual-task walking capacity mediates Tai Ji Quan impact on physical and cognitive function. Med Sci Sports Exerc. 2019;51(11):2318-2324.

13. Iliffe S, Kendrick D, Morris R, et al. Multicentre cluster randomised trial comparing a community group exercise programme and home-based exercise with usual care for people aged 65 years and over in primary care. Health Technology Assessment. 2014;18(49):vii.

14. Zhao Y, Chung PK, Tong TK. Effectiveness of a community-based exercise program on balance performance and fear of falling in older nonfallers at risk for falling: a randomized, controlled study. Journal of Aging \& Physical Activity. 2016;24(4):516-524.

15. van Haastregt JC, Diederiks JP, van Rossum E, de Witte LP, Voorhoeve PM, Crebolder HF. Effects of a programme of multifactorial home visits on falls and mobility impairments in elderly people at risk: randomised controlled trial. $B M J$. 2000;321(7267):994-998.

16. Kendrick D, Kumar A, Carpenter H, et al. Exercise for reducing fear of falling in older people living in the community. Cochrane Library. 2014;2015(11):CD009848CD009848. 
17. Logghe IH, Verhagen AP, Rademaker AC, et al. The effects of Tai Chi on fall prevention, fear of falling and balance in older people: a meta-analysis. Preventive Medicine. 2010;51(3-4):222-227.

18. Kruisbrink M, Delbaere K, Kempen GI, et al. Intervention characteristics associated with a reduction in fear of falling among community-dwelling older people: a systematic review and meta-analysis of randomized controlled trials. The Gerontologist. 2020;61(6): e269-e282.

19. Haas R, Maloney S, Pausenberger E, et al. Clinical decision making in exercise prescription for fall prevention. Physical Therapy. 2012;92(5):666-679.

20. Sasso JP, Eves ND, Christensen JF, Koelwyn GJ, Scott J, Jones LW. A framework for prescription in exercise-oncology research. J Cachexia Sarcopenia Muscle. 2015;6(2):115-124.

21. Ammann BC, Knols RH, Baschung P, de Bie RA, de Bruin ED. Application of principles of exercise training in sub-acute and chronic stroke survivors: a systematic review. $B M C$ Neurology. 2014;14(1):167.

22. Arnold CM, Sran MM, Harrison EL. Exercise for fall risk reduction in communitydwelling older adults: a systematic review. Physiotherapy Canada. 2008;60(4):358-372.

23. Kumar A, Delbaere K, Zijlstra GAR, et al. Exercise for reducing fear of falling in older people living in the community: Cochrane systematic review and meta-analysis. Age and Ageing. 2016;45(3):345-352.

24. Hippocrates A. Genuine works of translated from the greek with a preliminary discourse and annotations v. 2. 123456789/1251. 1849.

25. Boerigter RJ. A history of the American College of Sports Medicine. The University of Utah; 1978.

26. Hojman P, Gehl J, Christensen JF, Pedersen BK. Molecular mechanisms linking exercise to cancer prevention and treatment. Cell Metabolism. 2018;27(1):10-21.

27. Pescatello LS, Franklin BA, Fagard R, Farquhar WB, Kelley GA, Ray CA. Exercise and hypertension. Medicine \& Science in Sports \& Exercise. 2004;36(3):533-553.

28. Morris JN. Exercise in the prevention of coronary heart disease: today's best buy in public health. Medicine and Science in Sports and Exercise. 1994;26(7):807-814.

29. Harvey SB, Øverland S, Hatch SL, Wessely S, Mykletun A, Hotopf M. Exercise and the prevention of depression: results of the HUNT cohort study. American Journal of Psychiatry. 2018;175(1):28-36.

30. Senderovich H, Kosmopoulos A. An insight into the effect of exercises on the prevention of osteoporosis and associated fractures in high-risk individuals. Rambam Maimonides Medical Journal. 2018;9(1).

31. Alty J, Farrow M, Lawler K. Exercise and dementia prevention. Practical Neurology. 2020;20(3):234-240.

32. Lobelo F, Stoutenberg M, Hutber A. The exercise is medicine global health initiative: a 2014 update. British Journal of Sports Medicine. 2014;48(22):1627-1633.

33. Caspersen CJ, Powell KE, Christenson GM. Physical activity, exercise, and physical fitness: definitions and distinctions for health-related research. Public Health Reports. 1985;100(2): 126.

34. Herold F, Müller P, Gronwald T, Müller NG. Dose-response matters-a perspective on the exercise prescription in exercise-cognition research. Frontiers in Psychology. 2019;10:2338.

35. American College of Sports Medicine. ACSM's Guidelines for Exercise Testing and Prescription, 8th Ed + ACSM's Certification Review, 3rd Ed. Philadelphia, PA, USA: Lippincott Williams \& Wilkins; 2010. 
36. Brody LT. Effective therapeutic exercise prescription: the right exercise at the right dose. Journal of Hand Therapy. 2012;25(2):220-232.

37. Cosaburi R. Principles of exercise training. Chest. 1992;101(5):263S-267S.

38. Schlagheck ML, Joisten N, Walzik D, et al. Systematic review of exercise studies in persons with multiple sclerosis: exploring the quality of interventions according to the principles of exercise training. Neurology and Therapy. 2021;10(2):585-607.

39. Pfister PB, de Bruin ED, Tobler-Ammann BC, Maurer B, Knols RH. The relevance of applying exercise training principles when designing therapeutic interventions for patients with inflammatory myopathies: a systematic review. Rheumatology International. 2015;35(10):1641-1654.

40. Sallis R. Exercise is medicine: a call to action for physicians to assess and prescribe exercise. The Physician and Sportsmedicine. 2015;43(1):22-26.

41. Mazzeo RS, Tanaka H. Exercise prescription for the elderly. Sports Medicine. 2001;31(11):809-818. 


\section{Chapter 2}

\section{Literature Review}

\subsection{Introduction}

Fear of Falling (FOF) is a multidimensional construct with multifactorial etiology. It has a significant adverse impact on biopsychosocial outcomes of community-dwelling older adults in addition to substantial healthcare utilization and costs. ${ }^{1}$ Implementing effective interventions to address this complex issue is, therefore, of vital importance. This chapter is a literature review composed of five main sections. Section one outlines the content of each subsequent section. Section two provides an overview of FOF conceptualizations and outcome measures related to FOF constructs. Section three reviews epidemiological findings on FOF. Section four synthesizes what we know regarding the risk factors and consequences of FOF. Section five outlines the findings about FOF interventions for older adults. Together, the reviews in all these sections facilitate an in-depth understanding of how and why different FOF interventions were developed as well as the mechanisms of various interventions used in reducing FOF. The reviews also help identify the gaps in the current FOF interventions, providing the foundation for this thesis.

\subsection{Conceptualization and Outcome Measures of FOF}

\subsubsection{Conceptualization}

FOF has been conceptualized in many ways. Marks and Bebbington in 1970 used "space phobia" to describe patients who had intense fear when standing without visuospatial cues of support nearby. ${ }^{2}$ They also argued that this space phobia was an unrecognized syndrome that was distinct from agoraphobia (excessive fear of certain environments such as open spaces, public transit, and shopping center). ${ }^{2}$ The term "ptophobia" was coined in 1982 to describe a distinct psychological problem characterized by an intense fear of standing or walking following an accidental fall unrelated to 
agoraphobia. ${ }^{3}$ Subsequently, Murphy and Isaacs in 1982 described what they called "post-fall syndrome" as a consequence of fall experience. ${ }^{4}$ However, the post-fall syndrome is different from the concept of FOF in that FOF has been reported among older adults who had never experienced falls., ${ }^{5,6}$

In 1990, Tinetti, Richman, and Powell operationalized FOF as "low perceived self-efficacy in avoiding falls during essential, nonhazardous activities of daily living." ${ }^{77}$ However, Tinetti and Powell in 1993 re-defined FOF as "a lasting concern about falling that leads to an individual avoiding activities that he/she remains capable of performing." "This definition changed the words "low perceived self-efficacy" to "a lasting concern" and introduced the behavior consequence of FOF, which is activity avoidance. Powell et al. later defined FOF as "an individual's confidence in their ability to maintain balance during activities of daily living". 9

The concepts of self-efficacy and balance confidence are based on Bandura's self-efficacy theory, which posits that a person's belief or confidence about their capability to perform certain activities impact their behaviors. ${ }^{10}$ A person's belief or confidence, according to Bandura, is based on (1) enactive mastery experience, (2) vicarious experience, (3) verbal persuasion and (4) physiological and affective states. ${ }^{10}$ Particularly, older adults' confidence or beliefs about their ability to avoid falling and maintain balance when performing some physical activities are influenced by (1) their past fall-management experience, (2) their observation of similar others managing their fall experience, (3) other's verbal encouragement, and (4) physiological feedbacks such as pain and injuries as well as affective states such as mood and anxiety. ${ }^{10}$ As a result of the cognitive appraisal process of one's ability to do an activity, an individual will either participate or avoid a particular activity because of fear. For example, individuals might avoid an activity if they have low confidence in performing it.

The use of falls-related self-efficacy or balance confidence as a proxy of FOF construct has led to fruitful research evidence and encouraged interchangeability across fear/concern/worry about falling in relation to falls-related self-efficacy/balance confidence. ${ }^{11}$ However, more recent literature underlines that falls-related self-efficacy/balance confidence and fear/concern/worry about falling are associated but distinct constructs with different theoretical origins. ${ }^{11}$ Falls-related self-efficacy refers to confidence in 
one's capability to overcome falls, while fear/concern/worry about falling describes a state of apprehension towards the risk of falls. ${ }^{12}$

Overall, FOF is now dominantly conceptualized in the literature in two ways. First, FOF is an umbrella term that contains cognitive constructs such as self-efficacy and balance confidence and affective constructs such as fear, concern or worries about falling. Second, fear/concern/worry about falling is a theoretically distinct but related construct to falls-related self-efficacy and balance confidence. Despite the difference between these two theoretical conceptualizations of FOF constructs, they are often operationally combined, given that studies have consistently shown high correlations across the components forming FOF. ${ }^{13}$ Therefore, FOF in this thesis refers to an umbrella term including fear/concern/worry about falling and falls-related self-efficacy/balance confidence.

\subsubsection{Outcome Measures}

Although more than 20 self-reported outcome measures related to FOF were identified in Jorstad et al.'s systematic review, ${ }^{5}$ many are variants of the same measures and assess the same constructs of FOF. Here, the key approaches to FOF measurement based on the different constructs of FOF are reviewed. Several outcome measures have been created to explore the affective construct of FOF including fear, concern or worry about falling. ${ }^{5,14}$ Others draw on the theory of self-efficacy to assess the cognitive construct of FOF, such as falls-related self-efficacy, or balance confidence. ${ }^{7,9}$ Finally, a few measurement tools combine the affective construct with behavioral changes to examine FOF-induced activity avoidance. ${ }^{15,16}$

The simplest method to measure the affective construct (fear, concern and worry about falling) of FOF is single-item measures including a dichotomous yes/no response, a 4-point Likert-type rating scale and a visual analogue scale for FOF., 5 , Some sample single-item questions include "Are you afraid/worried about falling?" or "Do you have a fear of falling?". This type of measure may help quickly identify the prevalence of FOF in epidemiology but demonstrates low sensitivity to change in the research and does not measure FOF-related behavior consequences. ${ }^{18}$ 
Grounded in social cognitive theory, two common outcome measures were established based on Bandura's theory of self-efficacy. The first one is the Falls Efficacy Scale (FES), which measures the level of confidence in performing ten basic activities of daily living (ADLs) (e.g., getting in or out of chair or bed, dressing, light housekeeping) without falling using a 10-point rating scale of confidence from 0 (no confidence) to 10 (complete confidence). ${ }^{7}$ The FES presented a ceiling effect among older adults with higher physical function, despite its good reliability and validity. ${ }^{9}$ To address this gap, another commonly used measure was established. Powell and Myers developed the Activities-Specific Balance Scale (ABC) in 1995 by including activities at a broad continuum of difficulty. ${ }^{9}$ Specifically, the ABC is a 16-item scale that assesses an individual's confidence to maintain balance while performing both basic ADLs and instrumental activities of daily living (IADLs) with higher levels of difficulty such as walking in the crowded mall and on icy sidewalks. Powell and Myers pointed out that the ABC might be more appropriate for more active individuals. Furthermore, the $\mathrm{ABC}$ uses a scale ranging from $0 \%$ (no confidence) to $100 \%$ (complete confidence), which makes it difficult to respond accurately. ${ }^{18}$

Another frequently used outcome measure related to the affective construct of FOF is the fall efficacy scale-international (FES-I) developed by Yardley et al.in 2005. ${ }^{14}$ The FES-I was developed based on the FES; however, it includes more challenging social activities. Unlike the FES which measures falls-related self-efficacy, the FES-I measures the level of concern about falling when performing physical and social activities using a 4-point Likert-type scale ranging from 1 (not at all concerned) to 4 (very concerned).

To assess both the affective construct (worry about falling) and the behavioral change (activity restriction) elements of FOF, the Survey of Activities and Fear of Falling in the Elderly (SAFE) was developed. ${ }^{16}$ The items of the SAFE contain five ADLs and IADLs, nine mobility activities and three social activities and are rated on a 4-point scale of 0 (not at all worried) to 3 (very worried). The SAFE can also identify the activities that are avoided due to worry about falling. For example, it includes questions like "do you currently do the activity?", "if you do not do the activity, do you not do it because you are worried?". ${ }^{16}$ Similarly, Landers and colleagues developed the fear of falling avoidance behavior 
questionnaire (FFABQ) to quantify FOF-induced activity/participation avoidance based on the fearavoidance model of pain. ${ }^{15}$ It contains items of ADLs (e.g., showering, going up and downstairs), IADLs (e.g., preparing meals, and doing housework), and social activities (e.g., recreational activities and volunteer work) and uses a 5-point Likert-type scale ranging from completely disagree to completely agree in order to rate FOF induced activity avoidance.

\subsection{Epidemiology}

The prevalence of FOF among community-dwelling older adults varies across epidemiological studies, ranging from $3 \%$ to $85 \% .{ }^{19}$ According to a systematic review by Scheffer and colleagues, all included studies had prevalence between $21 \%$ and $85 \%$ (except one study where the prevalence of FOF among non-dizzy community-dwelling older adults was 3\%). ${ }^{19}$ The prevalence of FOF among community-dwelling older adults also differs across countries with $34 \%$ in Canada, ${ }^{20}$ from $29 \%$ to $60 \%$ in the USA,${ }^{21,22} 48.2 \%$ in Israel, ${ }^{23} 53.4 \%$ in Taiwan, ${ }^{24} 57.9 \%$ in Japan, ${ }^{25} 64.73 \%$ in Hong Kong, ${ }^{26} 76.6 \%$ in Korea,${ }^{27}$ and $86.6 \%$ in Turkey. ${ }^{28}$ The great variability of FOF prevalence could be explained by the variations in population characteristics, study settings and measurement tools. ${ }^{29}$

Several studies reported the incidence of FOF. According to Rivasi et al., $18 \%$ of participants $(\geq$ 60 years) developed FOF in a 2.1 year period. ${ }^{30}$ They also found that FOF was more likely to occur in individuals who were older, frailer, had a history of falls, had worse performance in balance and physical function tests and needed a walking aid during the assessment. ${ }^{30}$ In Lach's study, $22.5 \%$ of older adults over the age of 65 developed FOF after two years. ${ }^{31}$ Based on their study, the incidence of FOF was associated with having two or more falls, feeling unsteady, and having fair or poor health status. ${ }^{31}$ Murphy and colleagues' study examined the incidence of FOF among women aged 72 and older and revealed that $27 \%$ of women developed FOF at a 1 -year follow-up. ${ }^{32}$

\subsection{Risk Factors and Consequences of FOF}

In this section, I will first discuss the major risk factors of FOF, followed by the consequences of FOF in this section.

\subsubsection{Risk Factors}


FOF has a multifactorial etiology among community-dwelling older adults that includes fall history and sociodemographic, physical, psychological and environmental factors.

\section{Fall history}

Although FOF occurs in non-fallers, FOF is more prevalent among older adults who have falling experiences. ${ }^{5,23,29,33-35} \mathrm{Up}$ to $92 \%$ of community-dwelling older adults who fell in the previous year experienced FOF ${ }^{5,35}$ According to Frankenthal et al., FOF was about twice as likely to occur among those who had fallen in the previous year than among those who had not. ${ }^{23}$ Furthermore, dominant evidence has indicated that fall history is a significant predictor of FOF. According to systematic reviews by Denkinger et al.'s and Scheffer et al., the significant versus insignificant association ratio between fall history and FOF-related outcomes was 26 to 19 , indicating that $73 \%$ of FOF-related outcomes were significantly associated with fall history in the literature they reviewed. ${ }^{11,19}$ Similar findings were also reported in recent studies. $^{23,28}$

\section{Sociodemographic factors}

In terms of sociodemographic factors, robust evidence has shown that age and gender were the main risk factors associated with FOF. As shown in Martinez et al.'s study, older adults greater than 75 years are two times more likely to have high FOF. ${ }^{36}$ Likewise, an older age ( $\geq 80$ years) in Zijlstra et al.'s study $^{37}$ and ( $\geq 85$ years) in Park et al.'s study ${ }^{38}$ was independently associated with the increased level of FOF. Furthermore, the female gender was a strong predictor of FOF in many studies. ${ }^{23,27,36-43}$ Particularly, results from these studies showed that FOF was 1.64 to 5.55 times more likely to occur in women than in men. ${ }^{27,36}$ Another study examined the relationship between the female gender and FOF among older adults with and without fall history. ${ }^{42}$ The researchers found that, when compared with men, older female adults in the fall history group had a five-times greater likelihood of having a high FOF level. Those without a fall history had a three-times greater likelihood of having a high FOF level than men in the same category. ${ }^{42}$

Evidence is less robust regarding the association between FOF and other sociodemographic factors such as ethnicity, marital status, education level, and socioeconomic status. For example, Kumar 
and colleagues found that the odds of FOF were significantly increased among community-dwelling older adults who were African American, had lower household income, and had a lower educational level. ${ }^{44}$ Similarly, low income was found to be an independent risk factor for FOF-related activity restriction and a lower-level education was identified as an independent predictor of FOF. ${ }^{38,45}$ Nevertheless, these factors (i.e., ethnicity, education level and socioeconomic status) were not significant determinants of FOF in other studies. ${ }^{36,39,40,46,47}$

\section{Physical function}

FOF has been primarily attributed to poor physical function, specifically mobility disability, ADL and IADL impairments, reduced balance capacity and lower limb muscle strength. By systematically reviewing publications from January 2006 to October 2012, Denkinger et al. found that the use of a walking aid, walking disability, mobility disability, IADL and ADL impairments were most associated with increased FOF across all domains. ${ }^{11}$ Numerous studies that were published before 2006 and after 2012 produced similar evidence. Particularly, studies have identified the impairment of IADLs and ADLs as a significant predictor of a high level of FOF., ${ }^{6,23,27,34,43,47-50}$ Likewise, Curcio and colleagues found that participants with a high level of mobility disability were 6.3 times more likely to develop FOF compared to participants with a low level of mobility disability. ${ }^{51}$ Kumar et al. demonstrated that the use of a walking aid, difficulty in using public transport, poorer perceived physical health, and self-reported balance problems were factors significantly increasing the odds of FOF. ${ }^{44}$ Furthermore, FOF is also associated with balance and lower limb muscle strength. According to Hoang et al, a high level of FOF was significantly correlated with poor mobility, and balance measured by the Timed Up and Go (TUG) test, Functional Reach Test, and Tandem Gait Test. ${ }^{48}$ Tomita et al. found that women with less muscle strength in lower extremities measured by the Five Times chair stand times were more likely to have FOF. ${ }^{29}$ Similarly, Kumar et al. also found that inability to rise from a chair of knee height increased the chance of having a high level of FOF. ${ }^{44}$

\section{Psychological factors}


A growing number of recent studies worldwide appear to confirm that depression is a significant determinant of FOF. For example, Mane and colleagues found FOF was significantly correlated to depression among older adults above 60 years in an urban area of Karnataka, India. ${ }^{52}$ Similarly, Hoang and colleagues found that depression was significantly and positively related to FOF in older adults. ${ }^{48}$ Rivasi et al.'s study revealed that a higher burden of depressive symptoms at baseline were predictors for developing FOF among community-dwelling older adults. ${ }^{30}$ Moreover, both depressive and anxiety symptoms were found to be associated with FOF in Liu et al.’s study. ${ }^{26}$ However, findings from Denkinger et al.'s systematic review showed that there had been conflicting results for the association between FOF and anxiety. ${ }^{11}$ Findings on this variable from Denkinger et al.'s study were only based on three studies. A systematic review and meta-analysis of 20 studies by Payette et al. yielded an opposite conclusion from Denkinger et al.'s systematic review regarding the relationship between anxiety and FOF. ${ }^{12}$ Payette et al. found a significant moderate association between anxiety and FOF. ${ }^{12}$

\section{Environmental factors}

A few studies have identified environmental factors as predictors of FOF. The findings from Curl et al.'s study suggested that perceived accessibility and difficulties with walking in the local neighbourhood were independent predictors of FOF. ${ }^{53}$ Cho et al. compared the prevalence of FOF in urban communities to that in rural communities with respect to social demographics, health status, and functional level. ${ }^{34}$ They implied that FOF was more prevalent among rural residents when compared with urban residents who were from lower-income or educational backgrounds, were physical workers or unemployed, and were free of chronic medical morbidity or functionally independent. ${ }^{34}$ Based on Filiatrault et al.'s study, older adults living in a smaller city or rural area were more likely to be affected by FOF than older adults living in a larger city. ${ }^{39}$

\section{Additional risk factors}

While the prior outlined factors have been increasingly identified as significant predictors, there are additional risk factors that have less robust evidence to date and need further investigation. These additional factors include cognitive impairment, living status, health status and perceived general health. 
Some studies found that impaired cognitive performance was associated with FOF ${ }^{54-56}$ However, other studies did not find cognitive impairment to be associated with FOF. ${ }^{1,40,49,57}$ Additionally, living alone was found to be a predictor of FOF in some studies, ${ }^{39,41,55}$ but not in other studies. ${ }^{36,37,49,58}$ Finally, Lach et al. and Zijlstra et al. found that poor health status and perceived general health were associated with FOF, but few other studies had the same finding. ${ }^{37,59}$

\subsubsection{Consequences of FOF}

Research on FOF has become increasingly important due to its adverse biopsychosocial consequences such as a decline in physical function and mental health, restriction of physical and social participation, increase in fall risks, and mortality. ${ }^{60}$ A systematic review by Scheffer and colleagues analyzed 28 studies published between 1990 and 2006. They examined the relationship between FOF and possible health consequences among community-dwelling older adults. ${ }^{19}$ Among their reviewed studies, FOF contributed to activity restriction, a decrease in physical activity and quality of life, increased fall risks, balance and gait impairment, and depression. ${ }^{19}$

FOF contributes to activity and social participation restriction. Many studies have explored the impact of FOF-induced activity and participation restrictions on health outcomes. A recent systematic review found that FOF was an independent predictor of physical and psychological impairments, and these impairments were partially mediated by FOF-induced activity restriction. ${ }^{33}$ Additionally, Deshpande and colleagues found that $75 \%$ of participants in their study experiencing FOF reported moderate to severe activity restriction. ${ }^{1}$ This FOF-induced moderate and severe activity restriction was significantly associated with worsening ADL disability and decline in lower extremity performance at the three-year follow-up. ${ }^{1}$ Finally, Auais and colleagues investigated the relationship between FOF and life-space mobility among 1841 older adults from four different countries. ${ }^{61}$ They found that FOF was strongly associated with a reduction in life-space mobility. ${ }^{61}$ Individuals' life-space mobility is determined by the specific area they negotiate on a daily basis and is indicative of their activity and social participation status; restricted life-space mobility leads to or exacerbates existing poor physical function, frailty, disability and mortality. ${ }^{62-64}$ 
FOF contributes to poor physical function. FOF is linked to poor balance, postural control, and risk of falling. Yong et al. signified that FOF was associated with adapting a "stiffening strategy" for postural control, which compromises balance performance during dynamic and highly demanding activities such as dual tasks. ${ }^{65}$ Similarly, Holtzer and colleagues found that FOF in older adults was associated with higher and inefficient activation of the prefrontal cortex during dual-task walking. ${ }^{66}$ Lavedan and colleagues explored whether FOF contributes to falls and found that FOF was a predictor of the incidence of falls at 25-months follow-up. ${ }^{67}$ Moreover, FOF might predict the incidence of mobility disability and poor physical performance. For example, Auais and colleagues conducted a longitudinal study to examine the contribution of FOF on the incidence of functional disability over a 2-year period among community-dwelling older adults across four sites. ${ }^{68}$ Their findings showed that increasing the FES-I by one point at baseline increased the risk of developing mobility disability and poor physical performance by $4 \%$ and $3 \%$ respectively, two years later. ${ }^{6}$

FOF contributes to decreased quality of life and mental health and increased mortality. A recent systematic review found that increased FOF is a strong predictor of decreased quality of life. ${ }^{33}$ Chang and colleagues also found that FOF was a major risk factor in predicting poor physical and mental components of health-related quality of life measured by the 36-Item Short Form Survey (SF-36). ${ }^{69}$ Furthermore, Hajek et al.'s study showed that FOF was associated with increased depressive symptoms, lower life satisfaction and perceived autonomy. ${ }^{70}$ Finally, according to Kim and colleagues, participants with a high level of FOF had significantly higher mortality as compared to those with a low level of FOF. $^{71}$

In summary, FOF has a multifactorial etiology comprising non-modifiable and modifiable risk factors. As demonstrated in many research findings, fall history, older age, and female gender were common non-modifiable risk factors of FOF. Mobility disability, poor balance and muscle strength, depression and anxiety, and poor accessibility of the local neighborhood were the modifiable risk factors associated with a high prevalence and level of FOF. 
In many cases, a mild degree of FOF can prevent older adults from engaging in dangerous physical activities, ${ }^{72}$ but becomes dysfunctional when it grows to the level that prevents them from doing normal physical and social activities, potentially leading to an escalating vicious cycle of activity restriction, deconditioning, and more falls. ${ }^{15}$ To break this vicious cycle, various types of interventions targeting those modifiable FOF risk factors have been investigated. ${ }^{73-76}$ I will provide an overview of different types of FOF interventions by reviewing existing reviews in the next section.

\subsection{FOF Interventions}

A total of 11 data synthesis studies (5 systematic reviews with meta-analyses, 3 systematic reviews, 1 scoping, 1 updated review and 1 meta-analysis) published between 2007 and 2020 have been identified from the current literature on FOF interventions. These studies investigated the effectiveness of broad categories of FOF interventions among community-dwelling older adults. Table 1 summarizes the main findings of these reviews.

Given the different constructs (i.e., cognitive and affective construct) and multi-dimensional modifiable risk factors (i.e., physical, psychological, and environmental factors) linked to FOF, existing FOF interventions in the literature can be categorized as exercise, psychological, environmental, and other interventions. Exercise interventions consist of different exercise types such as balance, strength, aerobic, Tai Chi and multi-component exercises (e.g., a combination of balance and strength exercise). The psychological interventions include cognitive behavioral therapy (CBT), education, and mental imagery. The environmental intervention focuses on environmental assessment and modification. The other interventions include wearing hip protectors, fall risk assessment, and multifactorial interventions (e.g., a combination of physical and psychological intervention).

\section{Table 1: Effects of types of FOF interventions}

\begin{tabular}{|c|c|c|c|c|}
\hline $\begin{array}{l}\text { First } \\
\text { author of } \\
\text { the }\end{array}$ & $\begin{array}{l}\text { Type of the } \\
\text { review (\# of } \\
\text { included } \\
\text { studies) }\end{array}$ & $\begin{array}{l}\text { Type(s) of } \\
\text { interventions }\end{array}$ & $\begin{array}{l}\text { Types of } \\
\text { studies } \\
\text { included in } \\
\text { the review }\end{array}$ & Main findings \\
\hline
\end{tabular}




\begin{tabular}{|c|c|c|c|c|}
\hline $\begin{array}{l}\text { review } \\
\text { (year) }\end{array}$ & & & & \\
\hline \multicolumn{5}{|c|}{ Reviews on all types of FOF interventions } \\
\hline $\begin{array}{l}\text { Zilstra } \\
(2007)^{77}\end{array}$ & $\begin{array}{l}\text { Systematic } \\
\text { review } \\
(\mathrm{n}=19)\end{array}$ & $\begin{array}{l}\text { Exercise, Fall- } \\
\text { related } \\
\text { multifactorial } \\
\text { intervention, } \\
\text { CBT }\end{array}$ & RCTs & $\begin{array}{l}\text { Eleven trials reported a statistically } \\
\text { significant reduction of FOF, and they } \\
\text { were fall-related multifactorial programs } \\
(\mathrm{n}=5) \text {, community-based Tai Chi } \\
\text { programs ( } \mathrm{n}=3) \text {, home-based multi- } \\
\text { component exercise programs }(\mathrm{n}=2) \text {, and } \\
\text { a hip protector program }(\mathrm{n}=1)\end{array}$ \\
\hline $\begin{array}{l}\text { Bula } \\
(2011)^{78}\end{array}$ & $\begin{array}{l}\text { Updated } \\
\text { systematic } \\
\text { review } \\
(\mathrm{n}=46)\end{array}$ & $\begin{array}{l}\text { Exercise, CBT, } \\
\text { Education, } \\
\text { Environmental } \\
\text { adaptation, } \\
\text { Nutritional } \\
\text { intervention, } \\
\text { Vision } \\
\text { correction, Hip } \\
\text { protector }\end{array}$ & RCTs & $\begin{array}{l}\text { Exercises containing strengthening and } \\
\text { balance components and Tai Chi were the } \\
\text { most frequently used interventions and } \\
\text { showed the most consistent positive } \\
\text { effect on balance confidence. }\end{array}$ \\
\hline $\begin{array}{l}\text { Whipple } \\
(2018)^{79}\end{array}$ & $\begin{array}{l}\text { Scoping } \\
\text { review } \\
(n=26)\end{array}$ & $\begin{array}{l}\text { Exercise, CBT, } \\
\text { Guided } \\
\text { relaxation, } \\
\text { Virtual reality } \\
\text { trainer, Fall- } \\
\text { related } \\
\text { multifactorial } \\
\text { intervention }\end{array}$ & RCTs & $\begin{array}{l}\text { Exercise interventions such as walking, } \\
\text { water-based training, and Tai Chi aimed } \\
\text { at improving strength, balance, agility } \\
\text { and flexibility alone or in combination } \\
\text { and psychological interventions such as } \\
\text { CBT, guided relaxation and virtual reality } \\
\text { training were effective in reducing FOF. }\end{array}$ \\
\hline $\begin{array}{l}\text { Kruisbrin } \\
\mathrm{k}(2020)^{74}\end{array}$ & $\begin{array}{l}\text { Systematic } \\
\text { review } \\
(\mathrm{n}=62) \text { and } \\
\text { meta- } \\
\text { analysis( } \mathrm{n}=5 \\
0)\end{array}$ & $\begin{array}{l}\text { Exercise, CBT, } \\
\text { Assess-based } \\
\text { home care and } \\
\text { modification, } \\
\text { Education, } \\
\text { Nutritional }\end{array}$ & $\mathrm{RCTs}$ & $\begin{array}{l}\text { The pooled estimate of SMD of fifty } \\
\text { study arms was - } 0.36 \text { ( } 95 \% \mathrm{CI} \text { - }-0.48 ;- \\
0.24) \text {, indicating that interventions } \\
\text { resulted in a significant small-to- } \\
\text { moderate reduction in FOF }\end{array}$ \\
\hline
\end{tabular}




\begin{tabular}{|c|c|c|c|c|}
\hline & & $\begin{array}{l}\text { supplementatio } \\
\text { n, Mental } \\
\text { imagery, A } \\
\text { referral } \\
\text { protocol for } \\
\text { emergency } \\
\text { ambulance } \\
\text { visits }\end{array}$ & & \\
\hline \multicolumn{5}{|c|}{ Reviews on fall prevention programs } \\
\hline $\begin{array}{l}\text { Sjosten } \\
(2008)^{76}\end{array}$ & $\begin{array}{l}\text { Systematic } \\
\text { review }(n=24)\end{array}$ & $\begin{array}{l}\text { Fall prevention } \\
\text { programs }\end{array}$ & $\mathrm{RCTs}$ & $\begin{array}{l}\text { The fall prevention interventions appear } \\
\text { to be effective in reducing FOF since } \\
\text { around } 70 \% \text { of trials yielded significant } \\
\text { results in FOF reduction. }\end{array}$ \\
\hline $\begin{array}{l}\text { Yoshikaw } \\
\text { a }(2020)^{13}\end{array}$ & $\begin{array}{l}\text { Systematic } \\
\text { review } \\
(n=17) \text { and } \\
\text { meta- } \\
\text { analysis } \\
(n=13)\end{array}$ & $\begin{array}{l}\text { Fall prevention } \\
\text { program } \\
(\mathrm{AMOB} / \mathrm{ALL})\end{array}$ & $\begin{array}{l}\text { RCTs, } \\
\text { Quasi- } \\
\text { experiment } \\
\text { al studies }\end{array}$ & $\begin{array}{l}\text { The effect size of AMOB/ALL fall } \\
\text { prevention program on FOF measured by } \\
\text { affective construct was an SMD of }-0.29 \\
\text { ( } 9 \text { studies, CI: }-0.4,-0.19 \text { ) and on FOF } \\
\text { measured by cognitive construct was } \\
\text { SMD of } 0.51 \text { ( } 10 \text { studies, CI: } 0.42,0.60) \text {, } \\
\text { meaning that AMOB/ALL fall prevention } \\
\text { program has a small-to-moderate effect in } \\
\text { managing FOF. }\end{array}$ \\
\hline \multicolumn{5}{|c|}{ Reviews on CBT interventions } \\
\hline $\begin{array}{l}\text { Liu } \\
(2018)^{80}\end{array}$ & $\begin{array}{l}\text { Systematic } \\
\text { review }(\mathrm{n}=6) \\
\text { and meta- } \\
\text { analysis } \\
(\mathrm{n}=5)\end{array}$ & CBT & RCTs & $\begin{array}{l}\text { CBT interventions have significant } \\
\text { immediate }(\mathrm{SMD}=0.25,95 \% \mathrm{CI} 0.09 \text {, } \\
0.41) \text { and long-term }(\leq 12 \text { month }) \text { effects } \\
(\mathrm{SMD}=0.37,95 \% \mathrm{CI} 0.21,0.53) \text { on } \\
\text { reducing FOF }\end{array}$ \\
\hline $\begin{array}{l}\text { Chua } \\
(2019)^{75}\end{array}$ & $\begin{array}{l}\text { Systematic } \\
\text { review } \\
(\mathrm{n}=15) \text { and } \\
\text { meta- }\end{array}$ & $\begin{array}{l}\text { CBT-based } \\
\text { multifactorial } \\
\text { interventions }\end{array}$ & RCTs & $\begin{array}{l}\text { The pooled immediate CBT-based } \\
\text { multifactorial intervention effect was an } \\
\text { SMD of }-0.28 \text { ( } 95 \% \text { CI }-0.35,-0.21) \text {, the } \\
\text { pooled short-term ( } \leq 6 \text { month) intervention } \\
\text { effect was an SMD of }-0.32 \text { ( } 95 \% \text { CI - }\end{array}$ \\
\hline
\end{tabular}




\begin{tabular}{|c|c|c|c|c|}
\hline & $\begin{array}{l}\text { analysis } \\
(\mathrm{n}=15)\end{array}$ & & & $\begin{array}{l}0.49,-0.15) \text { and the pooled long-term } \\
(>6 \text { month) intervention effect was an } \\
\text { SMD of }-0.30(95 \% \text { CI }-0.45,-0.14) \text {. }\end{array}$ \\
\hline \multicolumn{5}{|c|}{ Reviews on exercise interventions } \\
\hline $\begin{array}{l}\text { Harling } \\
(2008)^{81}\end{array}$ & $\begin{array}{l}\text { Systematic } \\
\text { review }(\mathrm{n}=7)\end{array}$ & $\begin{array}{l}\text { Exercise (Tai } \\
\text { Chi) }\end{array}$ & RCTs & $\begin{array}{l}\text { Of seven included RCTs, five trials with } \\
\text { high methodological quality } \\
\text { demonstrated a significant effect of Tai } \\
\text { Chi exercise in FOF reduction. }\end{array}$ \\
\hline $\begin{array}{l}\text { Logghe } \\
(2010)^{82}\end{array}$ & $\begin{array}{l}\text { Meta- } \\
\text { analysis } \\
(\mathrm{n}=21)\end{array}$ & $\begin{array}{l}\text { Exercise (Tai } \\
\text { Chi) }\end{array}$ & $\mathrm{RCTs}$ & $\begin{array}{l}\text { The pooled estimate of SMD of three } \\
\text { trials on FOF reduction was an SMD of } \\
0.37 \text {. }\end{array}$ \\
\hline $\begin{array}{l}\text { Kumar } \\
(2016)^{73}\end{array}$ & $\begin{array}{l}\text { Systematic } \\
\text { review } \\
(n=30) \text { and } \\
\text { meta- } \\
\text { analysis } \\
(n=25)\end{array}$ & $\begin{array}{l}\text { Exercise (all } \\
\text { types) }\end{array}$ & $\begin{array}{l}\text { RCTs, } \\
\text { Quasi- } \\
\text { experiment } \\
\text { al studies }\end{array}$ & $\begin{array}{l}\text { The pooled estimate of SMD of } 24 \text { trials } \\
\text { on FOF reduction was an SMD of } 0.37 \text {. }\end{array}$ \\
\hline
\end{tabular}

Note. RCTs: Randomized Controlled Trials; CBT: Cognitive Behavioral Therapy; SMD: Standardized Mean Difference; CI: Confidence Interval; AMOB/ALL: A Matter of Balance Volunteer Lay Leader; \#/n: numbers.

Among identified reviews, four studies reviewed all types of FOF interventions in communitydwelling older adults. ${ }^{74,77-79}$ Findings from Zilstra and colleagues' systematic review revealed that fallrelated multifactorial programs, community-based Tai Chi programs, home-based multi-component exercise programs, and a hip protector program were effective in reducing FOF among communitydwelling older adults. ${ }^{77}$ According to Bula et al.'s review, programs containing strengthening and balance exercises or Tai Chi were the most frequently used interventions and showed the most consistent positive effect on balance confidence. ${ }^{78}$ In Whipple et al.'s scoping review, no clear consensus has been established regarding the best type of FOF intervention. However, the authors noted that interventions comprised of exercise and CBT are consistently superior to standard care. ${ }^{79}$ A recent systematic review and meta-analysis of RCTs aimed to explore the relationship between effective FOF interventions for community-dwelling older adults and overarching characteristics of FOF interventions such as type of 
supervisor, delivery method, and settings. ${ }^{74}$ The meta-regression analyses in this review showed that holistic exercises (i.e., Tai Chi, yoga, ving tsun, or pilates), a Tai Chi program supervised by an instructor and interventions delivered in a community setting were characteristics that were associated with a significant effect of interventions on FOF reduction. ${ }^{74}$

Two studies reviewed the effectiveness of fall prevention programs on reducing FOF. ${ }^{13,76}$ Fall prevention programs include both single-factorial and multifactorial fall prevention programs targeting one or multiple risk factors of falls such as poor balance, impaired muscle strength, FOF, side-effects of medication and environmental hazards. Sjosten and colleagues found that fall prevention interventions appear to be effective in reducing FOF since around $70 \%$ of trials yielded significant results in FOF reduction. ${ }^{76}$ In Yoshikawa et al.'s systematic review and meta-analysis, a community-based fall prevention program called A Matter of Balance Volunteer Lay Leader (AMOB/ALL) model had a smallto-moderate effect size in reducing FOF. ${ }^{13}$ However, I should note that most of the included studies in this review used a quasi-experimental design. Potential selection bias, maturation bias and historical bias might limit the study's ability to identify the true program effect.

Two studies reviewed the effectiveness of CBT in reducing FOF. ${ }^{75,80} \mathrm{CBT}$ as a psychotherapeutic intervention to manage FOF through modifying individuals' thoughts, and behaviors has increasingly gained attention in the past decade. In Liu et al.'s systematic review and meta-analysis, CBT interventions have significant immediate and long-term ( $\leq 12$ months) effects on reducing FOF. ${ }^{80}$ They also found that individual-based CBT interventions were more effective than group-based interventions in FOF reduction. ${ }^{80}$ Chua and colleagues looked at the effectiveness of CBT-based multicomponent interventions on FOF reduction among community-dwelling older adults at risk of falling. ${ }^{75}$ The results implied that interventions involving CBT as part of a biopsychosocial intervention program have positive short- and long-term effects on reducing FOF among community-dwelling older adults with fall risks. ${ }^{75}$

Three studies reviewed the effectiveness of exercise interventions in reducing FOF ${ }^{81,82}$ Exercise of all types has been the most common intervention to reduce FOF due to its benefits on improving balance, muscle strength, and stamina. Harling et al., in 2008, systematically reviewed RCTs that used 
Tai Chi as interventions to reduce FOF among older adults 60 years and older, living in the community or in institutions. ${ }^{81}$ Of seven included RCTs, five trials with high methodological quality demonstrated a significant effect of Tai Chi exercise on FOF reduction. ${ }^{81}$ Among these five trials, four trials used Tai Chi exercise alone as intervention and one trial incorporated Tai Chi with resistance and functional-balance training. ${ }^{81}$ Though they concluded that the Yang style Tai Chi appears to offer the greatest benefits, there was insufficient information regarding how Tai Chi exercise programs have been implemented in the research and what were the frequency, duration, and intensity of Tai Chi exercises. Therefore, we should interpret the findings with caution since different implementation methods and doses may alter the effectiveness of Tai Chi interventions.

A meta-analysis was performed by Logghe et al. in 2010 to evaluate the effectiveness of Tai Chi as a single-component intervention on FOF, fall rate and balance in healthy adults aged 50 years or older. ${ }^{82}$ They found that compared with non-exercise controls, Tai Chi participants showed a significant reduction in FOF ${ }^{82}$ Nevertheless, due to the limited number of analyzed trials ( 3 trials analyzed), evidence is insufficient to conclude that Tai Chi effectively reduces FOF in people over the age of 50.

In Kumar's Cochrane systematic review and meta-analysis on the effect of exercise intervention in reducing FOF in community-dwelling older adults ( $\geq 65$ years), 30 trials published up to 2013 were included in the qualitative synthesis and 25 in the quantitative synthesis. ${ }^{73}$ Among a total of 36 interventions in 30 trials, most of the interventions were in respect to gait, balance, coordination, and functional training (53\%), were supervised (75\%), delivered in group settings $(56 \%)$, lasted $\leq 12$ weeks $(61 \%)$ and had a frequency of 1 to 3 times per week (89\%). ${ }^{73}$ Findings from the meta-analysis demonstrated a small-to-moderate effect size ( $\mathrm{SMD}=0.37 ; 95 \% \mathrm{CI}=0.18$ to 0.56$)$ of exercise interventions on FOF reduction in community-dwelling older adults immediately following the exercise interventions. ${ }^{73}$ However, most of their included trials were appraised to have a high risk of bias (i.e., performance and detection bias). The variables such as the intensity and types of exercise that may impact the effect of exercise interventions are yet to be clarified. Many important trials in this field have been published after 2013, necessitating an updated and more comprehensive review. 
To conclude, the current evidence drawn from existing reviews shows that exercise interventions such as Tai Chi and multi-component exercises or exercises incorporated with CBT as a multifactorial intervention can effectively reduce FOF among community-dwelling older adults. Despite the essential role of exercise interventions in reducing FOF among community-dwelling older adults, no reviews have taken the essential step to report the measures of exercise prescription. Reporting the measures of exercise prescription according to the principles of exercise training and the FITT exercise prescription framework is valuable for readers with different backgrounds in order to critically appraise the actual effectiveness of different exercise interventions in reducing FOF. Such reporting also facilitates the real-world application of evidence and provides policymakers with strategies for developing FOF exercise program guidelines. Therefore, this thesis aims to examine the extent to which FOF exercise interventions followed the principles of exercise training and reported FITT components, to pool the effect size of exercise interventions in reducing FOF in community-dwelling older adults, and to explore variables that might impact the effect size of included exercise interventions. 


\subsection{References}

1. Deshpande N, Metter EJ, Bandinelli S, Lauretani F, Windham BG, Ferrucci L. Psychological, physical and sensory correlates of fear of falling and consequent activity restriction in the elderly: the InCHIANTI Study. American Journal of Physical Medicine \& Rehabilitation/Association of Academic Physiatrists. 2008;87(5):354.

2. Marks I, Bebbington P. Space phobia: syndrome or agoraphobic variant? $\mathrm{Br} \mathrm{Med} J$. 1976;2(6031):345-347.

3. Bhala RP, O'Donnell J, Thoppil E. Ptophobia: phobic fear of falling and its clinical management. Physical Therapy. 1982;62(2):187-190.

4. Murphy J, Isaacs B. The post-fall syndrome. Gerontology. 1982;28(4):265-270.

5. Jørstad EC, Hauer K, Becker C, Lamb SE, Group obotP. Measuring the psychological outcomes of falling: a systematic review. Journal of the American Geriatrics Society. 2005;53(3):501-510.

6. Suzuki M, Ohyama N, Yamada K, Kanamori M. The relationship between fear of falling, activities of daily living and quality of life among elderly individuals. Nursing \& Health Sciences. 2002;4(4):155-161.

7. Tinetti ME, Richman D, Powell L. Falls efficacy as a measure of fear of falling. Journal of Gerontology. 1990;45(6):P239-P243.

8. Tinetti ME, Powell L. Fear of falling and low self-efficacy: a cause of dependence in elderly persons. Journal of Gerontology. 1993.

9. Powell LE, Myers AM. The Activities-specific Balance Confidence (ABC) scale. The Journals of Gerontology: Series A. 1995;50A(1):M28-M34.

10. Bandura A. Self-efficacy determinants of anticipated fears and calamities. J Pers Soc Psychol.1983;45:464

11. Denkinger MD, Lukas A, Nikolaus T, Hauer K. Factors associated with fear of falling and associated activity restriction in community-dwelling older adults: a systematic review. The American Journal of Geriatric Psychiatry. 2015;23(1):72-86.

12. Payette M-C, Belanger C, Léveillé V, Grenier S. Fall-related psychological concerns and anxiety among community-dwelling older adults: systematic review and meta-analysis. PLoS one. 2016;11(4):e0152848.

13. Yoshikawa A, Ramirez G, Smith ML, Lee S, Ory MG. Systematic review and metaanalysis of fear of falling and fall-related efficacy in a widely disseminated communitybased fall prevention program. Archives of Gerontology and Geriatrics. 2020;91:104235.

14. Yardley L, Beyer N, Hauer K, Kempen G, Piot-Ziegler C, Todd C. Development and initial validation of the Falls Efficacy Scale-International (FES-I). Age and Ageing. 2005;34(6):614-619.

15. Landers MR, Durand C, Powell DS, Dibble LE, Young DL. Development of a scale to assess avoidance behavior due to a fear of falling: the Fear of Falling Avoidance Behavior Questionnaire. Phys Ther. 2011;91(8):1253-1265.

16. Lachman ME, Howland J, Tennstedt S, Jette A, Assmann S, Peterson EW. Fear of Falling and Activity Restriction: The Survey of Activities and Fear of Falling in the Elderly (SAFE). The Journals of Gerontology: Series B. 1998;53B(1):P43-P50.

17. Scheffer AC, Schuurmans MJ, VanDijk N, Van Der Hooft T, De Rooij SE. Reliability and validity of the visual analogue scale for fear of falling in older persons. Journal of the American Geriatrics Society. 2010;58(11):2228-2230.

18. Greenberg SA. Analysis of measurement tools of fear of falling for high-risk, community-dwelling older adults. Clinical Nursing Research. 2012;21(1):113-130. 
19. Scheffer AC, Schuurmans MJ, van Dijk N, van der Hooft T, de Rooij SE. Fear of falling: measurement strategy, prevalence, risk factors and consequences among older persons. Age and Ageing. 2008;37(1):19-24.

20. Pearson C, St-Arnaud J, Geran L. Understanding seniors' risk of falling and their perception of risk. Ottawa: Statistics Canada; 2017.

21. Uemura K, Yamada M, Nagai K, Tanaka B, Mori S, Ichihashi N. Fear of falling is associated with prolonged anticipatory postural adjustment during gait initiation under dual-task conditions in older adults. Gait \& Posture. 2012;35(2):282-286.

22. Rahman M. Prevalence and risk factors of fear of falling among elderly: a review. Medical Journal of Clinical Trials \& Case Studies. 2018;2.

23. Frankenthal D, Saban M, Karolinsky D, et al. Falls and fear of falling among Israeli community-dwelling older people: a cross-sectional national survey. Israel Journal of Health Policy Research. 2021;10(1):1-8.

24. Chang H-T, Chen H-C, Chou P. Factors associated with fear of falling among community-dwelling older adults in the Shih-Pai study in Taiwan. PLoS One. 2016;11(3):e0150612.

25. Sakurai R, Fujiwara Y, Yasunaga M, et al. Association of confidence in motor function and fear of falling with physical ability in community-dwelling older people. Nihon Ronen Igakkai Zasshi Japanese Journal of Geriatrics. 2013;50(3):369-376.

26. Liu JYW. Fear of falling in robust community-dwelling older people: results of a crosssectional study. Journal of Clinical Nursing. 2015;24(3-4):393-405.

27. Kim S, So W-Y. Prevalence and correlates of fear of falling in Korean communitydwelling elderly subjects. Experimental Gerontology. 2013;48(11):1323-1328.

28. Simsek H, Erkoyun E, Akoz A, Ergor A, Ucku R. Falls, fear of falling and related factors in community-dwelling individuals aged 80 and over in Turkey. Australasian Journal on Ageing. 2020;39(1):e16-e23.

29. Tomita Y, Arima K, Tsujimoto R, et al. Prevalence of fear of falling and associated factors among Japanese community-dwelling older adults. Medicine (Baltimore). 2018;97(4):e9721-e9721.

30. Rivasi G, Kenny RA, Ungar A, Romero-Ortuno R. Predictors of incident fear of falling in community-dwelling older adults. Journal of the American Medical Directors Association. 2020;21(5):615-620.

31. Lach HW. Incidence and risk factors for developing fear of falling in older adults. Public Health Nurs. 2005;22(1):45-52.

32. Murphy SL, Dubin JA, Gill TM. The Development of fear of falling among communityliving older women: predisposing factors and subsequent fall events. The Journals of Gerontology: Series A. 2003;58(10):M943-M947.

33. Schoene D, Heller C, Aung YN, Sieber CC, Kemmler W, Freiberger E. A systematic review on the influence of fear of falling on quality of life in older people: is there a role for falls? Clinical Interventions in Aging. 2019;14:701.

34. Cho H, Seol SJ, Do Hyun Yoon MJK, Choi BY, Kim T. Disparity in the fear of falling between urban and rural residents in relation with socio-economic variables, health issues, and functional independency. Annals of Rehabilitation Medicine. 2013;37(6):848.

35. Evitt CP, Quigley PA. Fear of falling in older adults: a guide to its prevalence, risk factors, and consequences. Rehabilitation Nursing. 2004;29(6):207.

36. Martínez IP, Bravo BN, Pretel FA, Muñoz J, Molina R, Hidalgo J. Fear of falling in elderly community-dwelling individuals. Gaceta Sanitaria. 2010;24(6):453-459.

37. Zijlstra G, Van Haastregt J, Van Eijk JTM, van Rossum E, Stalenhoef PA, Kempen GI. Prevalence and correlates of fear of falling, and associated avoidance of activity in the 
general population of community-living older people. Age and Ageing. 2007;36(3):304309.

38. Park J-I, Yang J-C, Chung S. Risk factors associated with the fear of falling in community-living elderly people in Korea: role of psychological factors. Psychiatry Investigation. 2017;14(6):894.

39. Filiatrault J, Desrosiers J, Trottier L. An exploratory study of individual and environmental correlates of fear of falling among community-dwelling seniors. Journal of Aging and Health. 2009;21(6):881-894.

40. Oh-Park M, Xue X, Holtzer R, Verghese J. Transient versus persistent fear of falling in community-dwelling older adults: incidence and risk factors. Journal of the American Geriatrics Society. 2011;59(7):1225-1231.

41. da Costa EM, Pepersack T, Godin I, Bantuelle M, Petit B, Levêque A. Fear of falling and associated activity restriction in older people. results of a cross-sectional study conducted in a Belgian town. Archives of Public Health. 2012;70(1):1-8.

42. Lee S, Oh E, Hong G-RS. Comparison of factors associated with fear of falling between older adults with and without a fall history. International Journal of Environmental Research and Public Health. 2018;15(5):982.

43. Curcio C-L, Gomez F, Reyes-Ortiz CA. Activity restriction related to fear of falling among older people in the Colombian Andes mountains: are functional or psychosocial risk factors more important? Journal of Aging and Health. 2009;21(3):460-479.

44. Kumar A, Carpenter H, Morris R, Iliffe S, Kendrick D. Which factors are associated with fear of falling in community-dwelling older people? Age and Ageing. 2014;43(1):76-84.

45. Curcio C-L, Wu YY, Vafaei A, et al. A regression tree for identifying risk factors for fear of falling: the International Mobility in Aging Study (IMIAS). The Journals of Gerontology: Series A. 2020;75(1):181-188.

46. Ramulu PY, Van Landingham SW, Massof RW, Chan ES, Ferrucci L, Friedman DS. Fear of falling and visual field loss from glaucoma. Ophthalmology. 2012;119(7):13521358.

47. Shin KR, Kang Y, Kim MY, et al. Impact of depression and activities of daily living on the fear of falling in Korean community-dwelling elderly. Nursing \& health sciences. 2010;12(4):493-498.

48. Hoang OTT, Jullamate P, Piphatvanitcha N, Rosenberg E. Factors related to fear of falling among community-dwelling older adults. Journal of Clinical Nursing. 2017;26(12):68-76.

49. Kempen GI, van Haastregt JC, McKee KJ, Delbaere K, Zijlstra GR. Socio-demographic, health-related and psychosocial correlates of fear of falling and avoidance of activity in community-living older persons who avoid activity due to fear of falling. BMC Public Health. 2009;9(1):1-7.

50. Patil R, Uusi-Rasi K, Kannus P, Karinkanta S, Sievänen H. Concern about falling in older women with a history of falls: associations with health, functional ability, physical activity and quality of life. Gerontology. 2014;60(1):22-30.

51. Curcio C, Wu Y, Vafaei A, et al. A regression tree for identifying risk facots for fear of falling: the International Mobility In Aging Study (IMIAS). Innovation in Aging. 2018;2:891-891.

52. Mane AB, Sanjana T, Patil PR, Sriniwas T. Prevalence and correlates of fear of falling among elderly population in urban area of Karnataka, India. Journal of Mid-life Health. 2014;5(3):150.

53. Curl A, Fitt H, Tomintz M. Experiences of the built environment, falls and fear of falling outdoors among older adults: an exploratory study and future directions. International Journal of Environmental Research and Public Health. 2020;17(4):1224. 
54. Fletcher PC, Guthrie DM, Berg K, Hirdes JP. Risk factors for restriction in activity associated with fear of falling among seniors within the community. Journal of Patient Safety. 2010;6(3):187-191.

55. Austin N, Devine A, Dick I, Prince R, Bruce D. Fear of falling in older women: a longitudinal study of incidence, persistence, and predictors. Journal of the American Geriatrics Society. 2007;55(10):1598-1603.

56. Yardley L, Smith H. A prospective study of the relationship between feared consequences of falling and avoidance of activity in community-living older people. The Gerontologist. 2002;42(1):17-23.

57. Rossat A, Beauchet O, Nitenberg C, Annweiler C, Fantino B. Risk factors for fear of falling: A cross-sectional population-based study. Journal of the American Geriatrics Society. 2009;57(7):1304-1306.

58. van Haastregt JC, Zijlstra GR, van Rossum E, van Eijk JTM, Kempen GI. Feelings of anxiety and symptoms of depression in community-living older persons who avoid activity for fear of falling. The American Journal of Geriatric Psychiatry. 2008;16(3):186-193.

59. Lach HW. Incidence and risk factors for developing fear of falling in older adults. Public Health Nursing. 2005;22(1):45-52.

60. Trombetti A, Reid K, Hars M, et al. Age-associated declines in muscle mass, strength, power, and physical performance: impact on fear of falling and quality of life. Osteoporosis International. 2016;27(2):463-471.

61. Auais M, Alvarado B, Guerra R, et al. Fear of falling and its association with life-space mobility of older adults: a cross-sectional analysis using data from five international sites. Age and Ageing. 2017;46(3):459-465.

62. Boyle PA, Buchman AS, Barnes LL, James BD, Bennett DA. Association between life space and risk of mortality in advanced age. Journal of the American Geriatrics Society. 2010;58(10):1925-1930.

63. Xue Q-L, Fried LP, Glass TA, Laffan A, Chaves PH. Life-space constriction, development of frailty, and the competing risk of mortality: the Women's Health And Aging Study I. American Journal of Epidemiology. 2008;167(2):240-248.

64. James BD, Boyle PA, Buchman AS, Barnes LL, Bennett DA. Life space and risk of Alzheimer disease, mild cognitive impairment, and cognitive decline in old age. The American Journal of Geriatric Psychiatry. 2011;19(11):961-969.

65. Young WR, Williams AM. How fear of falling can increase fall-risk in older adults: applying psychological theory to practical observations. Gait \& Posture. 2015;41(1):712.

66. Holtzer R, Kraut R, Izzetoglu M, Ye K. The effect of fear of falling on prefrontal cortex activation and efficiency during walking in older adults. GeroScience. 2019;41(1):89100.

67. Lavedán A, Viladrosa M, Jürschik $\mathrm{P}$, et al. Fear of falling in community-dwelling older adults: A cause of falls, a consequence, or both? PLoS One. 2018;13(3):e0194967.

68. Auais M, French S, Alvarado B, Pirkle C, Belanger E, Guralnik J. Fear of falling predicts incidence of functional disability 2 years later: a perspective from an international cohort study. The Journals of Gerontology: Series A. 2017;73(9):1212-1215.

69. Chang N-T, Chi L-Y, Yang N-P, Chou P. The impact of falls and fear of falling on health-related quality of life in Taiwanese elderly. Journal of Community Health Nursing. 2010;27(2):84-95.

70. Hajek A, König HH. What are the psychosocial consequences when fear of falling starts or ends? Evidence from an asymmetric fixed effects analysis based on longitudinal data 
from the general population. International Journal of Geriatric Psychiatry.

2020;35(9):1028-1035.

71. Kim J-H, Bae SM. Association between Fear of Falling (FOF) and all-cause mortality. Archives of Gerontology and Geriatrics. 2020;88:104017.

72. WHO. WHO global report on falls prevention in older age. Geneva, Switzerland: World Health Organization; 2008.

73. Kumar A, Delbaere K, Zijlstra G, et al. Exercise for reducing fear of falling in older people living in the community: Cochrane systematic review and meta-analysis. Age and Ageing. 2016;45(3):345-352.

74. Kruisbrink M, Delbaere K, Kempen GI, et al. Intervention characteristics associated with a reduction in fear of falling among community-dwelling older people: a systematic review and meta-analysis of randomized controlled trials. The Gerontologist. 2020.

75. Chua CHM, Jiang Y, Lim DS, Wu VX, Wang W. Effectiveness of cognitive behaviour therapy-based multicomponent interventions on fear of falling among communitydwelling older adults: A systematic review and meta-analysis. Journal of Advanced Nursing. 2019;75(12):3299-3315.

76. Sjösten N, Vaapio S, Kivelä S-L. The effects of fall prevention trials on depressive symptoms and fear of falling among the aged: a systematic review. Aging and Mental Health. 2008;12(1):30-46.

77. Zijlstra GR, Van Haastregt JC, Van Rossum E, Van Eijk JTM, Yardley L, Kempen GI. Interventions to reduce fear of falling in community-living older people: a systematic review. Journal of the American Geriatrics Society. 2007;55(4):603-615.

78. Büla CJ, Monod S, Hoskovec C, Rochat S. Interventions aiming at balance confidence improvement in older adults: an updated review. Gerontology. 2011;57(3):276-286.

79. Whipple MO, Hamel AV, Talley KM. Fear of falling among community-dwelling older adults: A scoping review to identify effective evidence-based interventions. Geriatric Nursing. 2018;39(2):170-177.

80. Liu T-W, Ng GY, Chung RC, Ng SS. Cognitive behavioural therapy for fear of falling and balance among older people: a systematic review and meta-analysis. Age and Ageing. 2018;47(4):520-527.

81. Harling A, Simpson JP. A systematic review to determine the effectiveness of Tai Chi in reducing falls and fear of falling in older adults. Physical Therapy Reviews. 2008;13(4):237-248.

82. Logghe IH, Verhagen AP, Rademaker AC, et al. The effects of Tai Chi on fall prevention, fear of falling and balance in older people: a meta-analysis. Preventive Medicine. 2010;51(3-4):222-227. 


\section{Chapter 3}

\section{Methods}

\subsection{Overview}

A systematic review synthesizes results and summarizes empirical evidence from all available studies in a particular area. It involves a comprehensive plan, detailed search strategy and rigorous data selection process that is derived a priori to the study. ${ }^{1}$ A meta-analysis in medical research often uses statistical approaches, integrating data from available studies into a single quantitative estimate to assess the strength of the evidence presented on a type of intervention or treatment. ${ }^{2}$ A rigorous systematic review and meta-analysis are considered the highest level and most trustworthy source of evidence in the evidence-based medical literature when assessing interventions. ${ }^{1,3}$

The present thesis study leveraged a systematic review methodology in order to describe the FOF exercise interventions with respect to the measures of exercise prescription and to investigate the extent to which these FOF exercise interventions in existing RCTs adhered to the principles of exercise training and reported FITT components. A meta-analysis technique was then used to examine the magnitude of the effect of FOF exercise interventions in reducing FOF among community-dwelling older adults and to explore the impact of potential variables regarding the measures of exercise prescription on the effect size of exercise interventions on FOF reduction. The systematic review was conducted with guidance from the Preferred Reporting Items for Systematic Reviews and Meta-Analyses (PRISMA) ${ }^{4}$ and AMSTAR2 checklists (Appendix G and H). ${ }^{5}$ The Cochrane Handbook for Systematic Reviews of Interventions was followed for conducting meta-analysis. ${ }^{6}$ 
The following sections provide a detailed description of methods that were used in conducting this systematic review and the meta-analysis, including the development of search strategies, identification and selection of studies, data extraction and quality assessment, and data synthesis and analysis.

\subsection{Data Sources and Search Strategy}

The search strategy was developed and performed with the help of a health science librarian using MEDLINE, Embase, PsycINFO, and CINAHL databases from the inception of each database until December 31, 2019. An AutoAlert was set up for each database for a weekly update, and all studies received before the data extraction phase (July 1, 2020) were also examined for eligibility. To supplement the electronic searching, reference lists of relevant systematic reviews were examined manually. Both medical subject headings $(\mathrm{MeSH})$ and free text words were used as search terms according to the recommendations of each database. A detailed search strategy for each database can be found in appendices A to D. No language or publication date restrictions were implemented in the search process.

\subsection{Study Selection}

Two reviewers (C.F. and T.A.) independently screened and assessed the relevant literature based on the inclusion and exclusion criteria. Disagreements were resolved through discussion between the two reviewers. A third reviewer (M.A.) was consulted for unresolved disagreements to make the final decisions. The inclusion and exclusion criteria are as follows:

Study design. Only Randomized Controlled Trials (RCTs) were included in this systematic review. Quasi-randomization studies were excluded. In rehabilitation research, randomized controlled trials (RCTs) are the gold standard for investigating the causal relationship between exercise interventions and their effects. The superiority of RCT design lies in its ability to minimize confounding impacts of other factors that might misrepresent the effect of 
interventions. ${ }^{7}$ It has been recognized that a systematic review of RCTs can provide the best evidence on the effectiveness of therapeutic interventions. ${ }^{8}$

Participants. The participants in included trials were community-dwelling older adults who were at least 65 years old. Trials that targeted specific clinical populations such as people with stroke, Parkinson's disease, dementia, or living dependently in any institutions were excluded from our study. The inclusion of articles focused on specific populations would have jeopardized the external validity of the results (i.e., reduced the applicability of findings to the general population).

Intervention. Trials in which exercise of any type was used as either the main intervention or as a secondary intervention were included in this study.

Comparator/control. RCTs with any type of the comparison group(s) (e.g., usual care, exercise, cognitive therapy) were included in the qualitative review.

Outcome measures. Included studies were required to use at least one FOF-related outcome measure, including a single-item question on the FOF, FOF-related visual analog scale, ${ }^{9}$ Falls Efficacy Scale (FES), ${ }^{10}$ FES-International (FES-I), ${ }^{11}$ Short FES-I, ${ }^{12}$ Activities-Specific Balance Confidence Scale (ABC), ${ }^{13}$ Survey of Activities and Fear of Falling in the Elderly (SAFE), ${ }^{14}$ Geriatric Fear of Falling Measure (GFFM), ${ }^{15}$ Fear of Falling Questionnaire (FFQ), ${ }^{16}$ and a measure of balance confidence (CONFbal). ${ }^{17}$

The additional inclusion criterion for the meta-analysis. In the meta-analysis, RCTs directly comparing at least one exercise arm with an inactive control arm (e.g., usual care, education class, or low-intensity exercise program that is not designed to modify the risk of falling or FOF) were included. Studies that compared two arms with active exercise were excluded from the meta-analysis. 


\subsection{Data Extraction and Quality Assessment}

Purpose-designed data extraction sheets were created based on several previously published systematic reviews ${ }^{18-20}$. The topic-specific information included in the data extraction sheets was determined by consensus among three reviewers (C.F., T.A., and M.A.). A pilot review of three articles was conducted independently by two reviewers (C.F. and T.A.) using the initial data extraction sheets, and modifications were made to create the final version of the data extraction tool.

Rating the reporting of principles of exercise training (Table. 2). The following operational definitions were used:1) specificity: interventions targeted specific body systems or body parts, 2) progression: the dose (FITT) of exercise progressed over time, 3) overload: exercise dose was prescribed individually in a way that challenges participants beyond their baseline levels of performance 4) initial value: the magnitude of intervention-induced changes were compared between participants with low baseline values and participants with high baseline values, 5) reversibility: there was at least one follow-up assessment after the intervention was completed to evaluate the long-term effect of exercise intervention, 6) diminishing return: there was at least one mid-intervention assessment and the magnitude of intervention-induced changes between pre, mid and post-intervention assessments within the group were compared.

Rating the reporting of FITT components and adherence (Table. 2). For each trial, reviewers answered the following questions: did the author clearly describe the 1) frequency: how often (e.g., times per week) were the participants instructed to perform the exercise? 2) intensity: at what intensity did participants exercise? 3) time: how long was each exercise session (e.g., minutes as well as repetitions and sets)? and 4) type: what kind of exercises were prescribed (e.g., balance, resistance exercises)? Adherence to exercise interventions was defined as the percentage or number of the total exercise sessions attended. ${ }^{21}$ 
If each exercise principle, FITT components, and adherence were reported in the trials, "y" (for "yes") was marked; if not, then "n" (for "not reported") was indicated, and "Unclear" was marked when they were mentioned but not clearly described.

\section{Table 2: Rating the reporting of principles of exercise training, FITT components and adherence}

\begin{tabular}{|c|c|}
\hline Principles & Rating criteria \\
\hline Specificity & $\begin{array}{l}\text { The prescribed exercises have to align with the participant's specific needs and } \\
\text { desired outcomes. }\end{array}$ \\
\hline Progression & $\begin{array}{l}\text { A gradual and systematic increase of the exercise dose over time is required to } \\
\text { cause sustainable physiological adaptation. }\end{array}$ \\
\hline Overload & $\begin{array}{l}\text { The given exercise dose is greater than the dosage that the individual has adapted } \\
\text { to. }\end{array}$ \\
\hline Initial value & $\begin{array}{l}\text { Participants with lower initial values have more potential to improve than } \\
\text { participants with higher initial values. }\end{array}$ \\
\hline Reversibility & $\begin{array}{l}\text { The beneficial effect of exercise training will gradually decrease once the training } \\
\text { ceases, and the downward trend can be reversed once training is resumed. }\end{array}$ \\
\hline $\begin{array}{l}\text { Diminishing } \\
\text { return }\end{array}$ & $\begin{array}{l}\text { The magnitude of exercise-caused improvements will decelerate when } \\
\text { participants reach a relatively high fitness level. }\end{array}$ \\
\hline Frequency & How often exercise is performed. \\
\hline Intensity & The magnitude of effort required to perform the exercise. \\
\hline Time & The duration of exercise in each training session. \\
\hline Type & $\begin{array}{l}\text { Exercise types included, e.g., resistance, endurance, aerobic, balance, and } \\
\text { flexibility training. }\end{array}$ \\
\hline Adherence & The percentage or number of the total exercise sessions attended \\
\hline
\end{tabular}


Rating the methodological quality of RCTs. The Physiotherapy Evidence Database (PEDro)

scale was applied to assess the methodological quality of each of the RCTs included in the review. ${ }^{22}$ The PEDro scale is comprised of 11 yes-or-no questions and has been shown to be valid and reliable. One point was given to each criterion satisfied (except the first one, which examines the external validity) for a total of 10 points. The cutoff scores for the PEDro Scale (a score of 9 or $10=$ "excellent," scores of 6 to 8 $=$ "good," a score of 4 or 5 = "fair," and a score of $<4=$ "poor") were used to define the quality of included RCTs. In studies in which the relevant criteria were not explicitly reported, the corresponding authors of relevant studies were consulted for clarifications.

All rating scales for included RCTs were rated independently by two reviewers (C.F. and T.A.); when discrepancies arose, they were solved by a discussion between C.F. and T.A. and arbitration by a third reviewer (M.A.).

\subsection{Data Synthesis and Analysis}

For qualitative data, the extracted data were narratively synthesized. ${ }^{23}$ The number and percentage of the studies which reported the principles of exercise training and FITT components were calculated. The inter-rater agreement of each rating scale between the two reviewers (C.F. and T.A.) before the discussion was calculated using Cohen's kappa coefficient (Cohen $\kappa$.). The level of reliability of the $\kappa$ values was evaluated on the basis of the classification of Landis and Koch $(\geq 0.81=$ "almost perfect," 0.61 to $0.81=$ "substantial," 0.41 to $0.6=$ "moderate," 0.21 to $0.4=$ "fair," and 0 to $0.2=$ “poor"). ${ }^{24}$

As recommended by the Cochrane Handbook, post-intervention values were entered into Review Manager to estimate the Standardized Mean Difference (SMD) or Hedges $g$ with $95 \%$ CIs for each study with continuous data. ${ }^{25}$ To allow for the variability across studies, a random effect model was applied. In trials with more than one exercise intervention arm, we combined interventions to create a single pairwise comparison according to the recommendations by Higgins et al. ${ }^{26}$ Heterogeneity of trials was assessed with the $\chi^{2}$ test and $I^{2}$ statistics. The $I^{2}$ represents the percentage of overall variation across studies that is 
caused by heterogeneity rather than by chance. ${ }^{26}$ The $I^{2}$ is calculated by the flowing statistic where $\mathrm{Q}$ is the chi-squared statistic and df is its degree of freedom. ${ }^{26}$

$$
I^{2}=\left(\frac{Q-d f}{Q}\right) \times 100 \%
$$

In terms of missing data, the first authors of the studies were contacted. If missing data were not obtained from the first author of any study, available data were used to calculate the missing data and complete the analysis if possible. If medians and ranges of the outcome were the only available data, the sample means and SDs were estimated following the method of Hozo et al. ${ }^{27}$

In most trials, higher scores of FOF measures were indicative of higher FOF. In the few trials in which higher scores of FOF were indicative of lower FOF because of the FOF measure used, the scores were multiplied by -1 to ensure consistency in the interpretation of outcomes before entering data into the meta-analysis. ${ }^{6,28}$

A series of subgroup analyses were conducted according to FOF outcome measures, types of exercise, duration of interventions in weeks and whether a FOF measure was a primary or secondary outcome. In subgroup analysis, if the studies had multiple intervention arms (e.g., $\geq 2$ exercise intervention arms with one inactive control arm), each exercise intervention arm was compared separately with the control.

Sensitivity analyses were conducted to examine the impact of trials with a small sample size $(\mathrm{N}<$ 100 at randomization), and a high risk of bias (PEDro Scale score of $<6$ ) on effect sizes. Moreover, although post-intervention values were used to estimate the intervention effects in this study, the use of change-from-baseline values is another common approach to produce effect estimates of the mean difference. According to Fu and Haley, estimating the effect size using the post-intervention values versus the change-from-baseline values may lead to discrepancies in conclusions. ${ }^{29}$ Therefore, to examine the robustness of the SMD estimates, we also conducted a second meta-analysis using change-from-baseline values. ${ }^{29}$ If the change-from-baseline values were not reported in the included studies and not obtained from the first authors, the OpenMetaAnalyst were used to calculate them from the available data. ${ }^{30}$ The 
OpenMetaAnalyst uses a correlation coefficient to impute a standard deviation of the change-frombaseline value: ${ }^{30}$

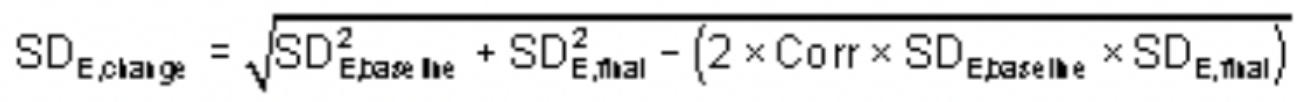

A funnel plot was conducted to detect potential publication bias. 


\subsection{References}

1. Uman LS. Systematic reviews and meta-analyses. J Can Acad Child Adolesc Psychiatry. 2011;20(1):57-59.

2. Haidich A-B. Meta-analysis in medical research. Hippokratia. 2010;14(Suppl 1):29.

3. Impellizzeri FM, Bizzini M. Systematic review and meta-analysis: a primer.

International Journal of Sports Physical Therapy. 2012;7(5):493.

4. Liberati A, Altman DG, Tetzlaff J, et al. The PRISMA statement for reporting systematic reviews and meta-analyses of studies that evaluate health care interventions: explanation and elaboration. Journal of Clinical Epidemiology. 2009;62(10):e1-e34.

5. Shea BJ, Reeves BC, Wells G, et al. AMSTAR 2: a critical appraisal tool for systematic reviews that include randomised or non-randomised studies of healthcare interventions, or both. BMJ. 2017;358.

6. Higgins J, Thomas J, Chandler J. Cochrane Handbook for Systematic Reviews of Interventions version 6.1. Updated September 2020.

7. Kendall JM. Designing a research project: randomised controlled trials and their principles. Emerg Med J. 2003;20(2):164-168.

8. Maher CG, Sherrington C, Herbert RD, Moseley AM, Elkins M. Reliability of the PEDro scale for rating quality of randomized controlled trials. Phys Ther. 2003;83(8):713-721.

9. Scheffer AC, Schuurmans MJ, VanDijk N, Van Der Hooft T, De Rooij SE. Reliability and validity of the visual analogue scale for fear of falling in older persons. Journal of the American Geriatrics Society. 2010;58(11):2228-2230.

10. Tinetti ME, Richman D, Powell L. Falls efficacy as a measure of fear of falling. Journal of Gerontology. 1990;45(6):P239-P243.

11. Yardley L, Beyer N, Hauer K, Kempen G, Piot-Ziegler C, Todd C. Development and initial validation of the Falls Efficacy Scale-International (FES-I). Age and Ageing. 2005;34(6):614-619.

12. Kempen GIJM, Yardley L, Van Haastregt JCM, et al. The Short FES-I: a shortened version of the falls efficacy scale-international to assess fear of falling. Age and Ageing. 2007;37(1):45-50.

13. Powell LE, Myers AM. The Activities-specific Balance Confidence (ABC) Scale. The Journals of Gerontology: Series A. 1995;50A(1):M28-M34.

14. Lachman ME, Howland J, Tennstedt S, Jette A, Assmann S, Peterson EW. Fear of Falling and Activity Restriction: The Survey of Activities and Fear of Falling in the Elderly (SAFE). The Journals of Gerontology: Series B. 1998;53B(1):P43-P50.

15. Huang T-T. Geriatric fear of falling measure: development and psychometric testing. International Journal of Nursing Studies. 2006;43(3):357-365.

16. Dayhoff N, Baird C, Bennett S, Backer J. Fear of falling: measuring fear and appraisals of potential harm. Rehabilitation Nursing Research. 1994;3(3):97-104.

17. Simpson JM, Worsfold C, Fisher KD, Valentine JD. The CONFbal scale: a measure of balance confidence - a key outcome of rehabilitation. Physiotherapy. 2009;95(2):103109.

18. Ammann BC, Knols RH, Baschung P, de Bie RA, de Bruin ED. Application of principles of exercise training in sub-acute and chronic stroke survivors: a systematic review. $B M C$ Neurology. 2014;14(1):167.

19. Neil-Sztramko SE, Winters-Stone KM, Bland KA, Campbell KL. Updated systematic review of exercise studies in breast cancer survivors: attention to the principles of exercise training. British Journal of Sports Medicine. 2019;53(8):504.

20. Baschung Pfister P, de Bruin ED, Tobler-Ammann BC, Maurer B, Knols RH. The relevance of applying exercise training principles when designing therapeutic 
interventions for patients with inflammatory myopathies: a systematic review. Rheumatology International. 2015;35(10):1641-1654.

21. Hawley-Hague H, Horne M, Skelton D, Todd C. Review of how we should define (and measure) adherence in studies examining older adults' participation in exercise classes. $B M J .2016 ; 6(6): \mathrm{e} 011560$.

22. Blobaum P. Physiotherapy Evidence Database (PEDro). J Med Libr Assoc. 2006;94(4):477-478.

23. Prictor M, Hill S. Cochrane consumers and communication review group: leading the field on health communication evidence. Journal of Evidence-Based Medicine. 2013;6(4):216-220.

24. Landis JR, Koch GG. The Measurement of observer agreement for categorical data. Biometrics. 1977;33(1):159-174.

25. Cochrane Collaboration. Review Manager (RevMan). Version 4.2 for Windows. Oxford, England: The Cochrane Collaboration; 2002.

26. Higgins JP, Thomas J, Chandler J, et al. Cochrane handbook for systematic reviews of interventions. John Wiley \& Sons; 2019.

27. Hozo SP, Djulbegovic B, Hozo I. Estimating the mean and variance from the median, range, and the size of a sample. BMC Medical Research Methodology. 2005;5(1):13.

28. Kendrick D, Kumar A, Carpenter H, et al. Exercise for reducing fear of falling in older people living in the community. Cochrane Library. 2014;2015(11):CD009848CD009848.

29. Fu R, Holmer HK. Change score or followup score? An empirical evaluation of the impact of choice of mean difference estimates. 2015.

30. Wallace BC, Dahabreh IJ, Trikalinos TA, Lau J, Trow P, Schmid CH. Closing the gap between methodologists and end-users: R as a computational back-end. Journal of Statistical Software. 2012;49(1):1-15. 


\section{Chapter 4}

\section{Results}

\subsection{Study Selection}

A total of 582 studies were identified through systematic searching. After removing 138 duplicates, 444 studies remained. Eleven additional studies were identified through AutoAlert. Fifty-six studies were identified through manually searching the reference lists of identified relevant articles and systematic reviews. In the abstract and title screening, 353 out of 511 studies were excluded because they did not meet the eligibility criteria. This yielded 158 studies for the full-text review. At this stage, 78 additional studies were excluded because participants were younger than 65 years old (31 studies), lived in a supported-living environment such as a nursing home (18 studies), the study design was not RCT $(n=24)$, interventions were not exercises $(n=4)$, or there was no FOF related outcome measure $(n=1)$. During the data extraction, two studies were excluded due to non-RCT study design and three due to identical data sources (duplication of data from other RCTs). There were three articles and two articles in each group reporting on the same trials, and the earliest publications among them were included. ${ }^{1,2} \mathrm{~A}$ total of 75 trials were included in the qualitative review, out of which 50 trials were eligible and had enough postintervention data for the meta-analysis (Figure 1). 


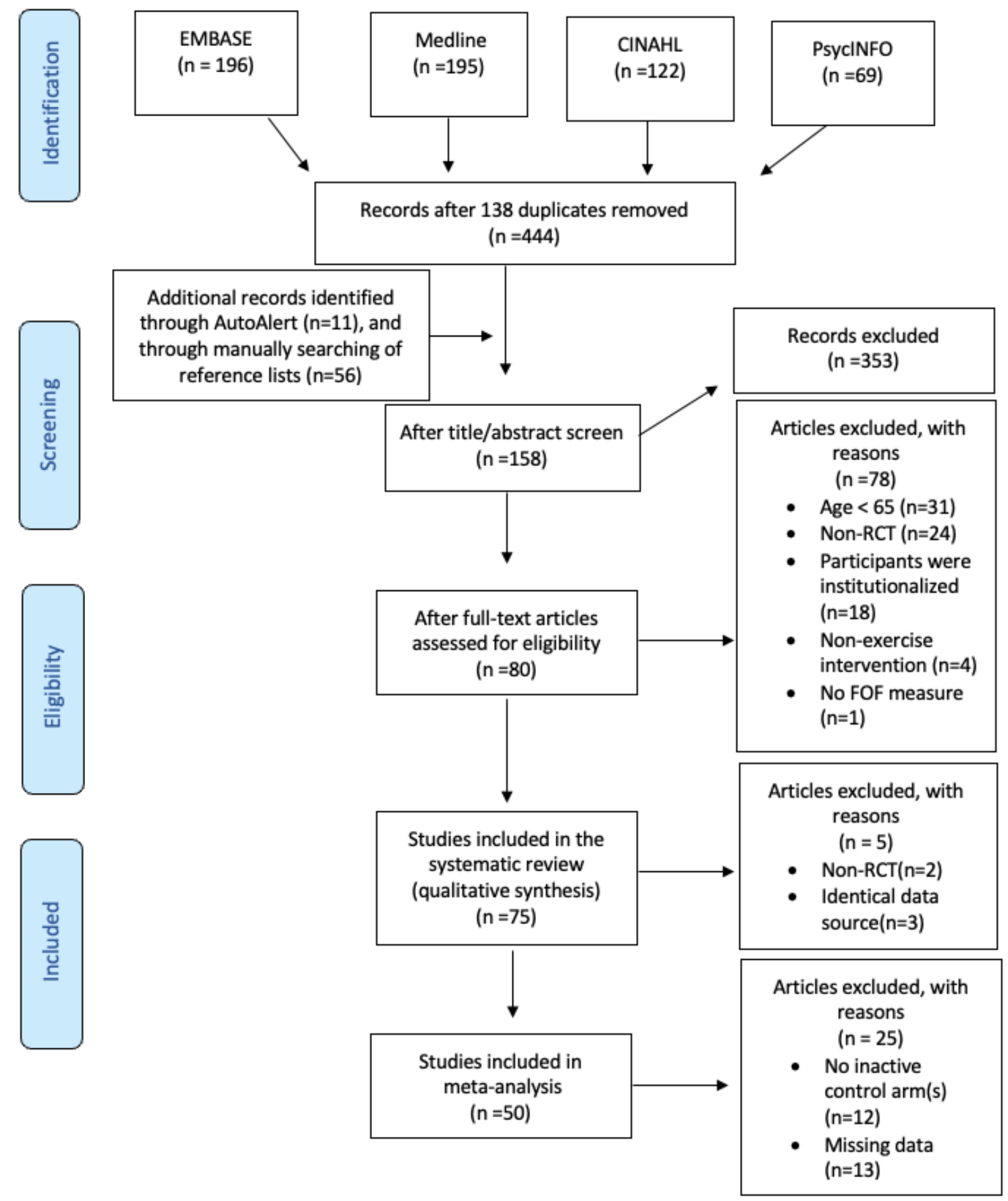

Figure 1: Flow chart of the study selection process

\subsection{Study Characteristics}

The 75 included studies were published between 1997 and 2019, and the trials were most frequently conducted in the United States (25\%), Australia (16\%), and Germany (6.4\%). The 
sample sizes of the trials ranged from 6 participants to 1254 participants (median $=80$

[interquartile range $=45-239]$ ), and the mean age of the participants was 77 years. Women represented more than half of the participants in 56 trials. Forty-two trials assessed FOF as the primary outcome measure. The median duration of the interventions and full studies were 12 (interquartile range $=10-24)$ and 24 (interquartile range $=12-48)$ weeks, respectively (Table 3 ). Twenty-six trials used the Activities-specific Balance Confidence Scale (ABC) as a FOF outcome measure; the Falls Efficacy Scale-International (FES-I) and FES were used in 19 and 17 trials, respectively. Additional FOF measures used in less than $10 \%$ of the trials included a single-item question, ${ }^{3-7}$ a measure of balance confidence (CONFbal), ${ }^{1}$ a visual analog scale (VAS),${ }^{8-10}$ and the Survey of Activities and Fear of falling in the Elderly (SAFE). ${ }^{11,12}$ 


\section{Table 3: Study characteristics}

\begin{tabular}{|c|c|c|c|c|c|c|c|c|c|}
\hline \multirow[b]{2}{*}{$\begin{array}{l}\text { First Authors } \\
\text { (year) }\end{array}$} & \multirow[b]{2}{*}{ Country } & \multirow[b]{2}{*}{$\begin{array}{c}\text { Mean } \\
\text { age }\end{array}$} & \multirow[b]{2}{*}{$\begin{array}{c}\text { Sample } \\
\text { size }\end{array}$} & \multirow[b]{2}{*}{$\begin{array}{c}\text { Women } \\
\%\end{array}$} & \multirow[b]{2}{*}{ Design } & \multicolumn{3}{|c|}{ Duration } & \multirow[b]{2}{*}{$\begin{array}{c}\text { \# of } \\
\text { assessments } \\
\text { during } \\
\text { study }\end{array}$} \\
\hline & & & & & & $\begin{array}{l}\text { Is FOF } \\
\text { primary } \\
\text { outcome }\end{array}$ & $\begin{array}{c}\text { of } \\
\text { intervent } \\
\text { ion } \\
\text { (Weeks) }\end{array}$ & $\begin{array}{c}\text { Duration of } \\
\text { study } \\
\text { (weeks) }\end{array}$ & \\
\hline Arai, T $(2007)^{13}$ & Japan & 74.1 & 171 & $\mathrm{n}$ & 2-arms single-blind & $\mathrm{y}$ & 12 & 12 & 2 \\
\hline $\begin{array}{c}\text { Arantes, M } \\
(2015)^{14}\end{array}$ & Brazil & 73.05 & 30 & $100 \%$ & 2-arms single-blind & $\mathrm{y}$ & 12 & 12 & 2 \\
\hline $\begin{array}{c}\text { Arkkukangas, } \\
\text { M (2015) }\end{array}$ & Sweden & 83 & 45 & $71 \%$ & 3-arms single-blind & $\mathrm{y}$ & 12 & 12 & 2 \\
\hline $\begin{array}{l}\text { Arkkukangas, } \\
\text { M (2019) }\end{array}$ & Sweden & 83 & 175 & $70 \%$ & 3-arms single-blind & $\mathrm{y}$ & 12 & 96 & 4 \\
\hline $\mathrm{Bao}, \mathrm{T}(2018)^{17}$ & USA & 75.6 & 12 & $66 \%$ & 2-arms single blind & $\mathrm{y}$ & 8 & 8 & 3 \\
\hline $\begin{array}{l}\text { Barban, F } \\
(2017)^{18}\end{array}$ & $\begin{array}{l}\text { Italy, } \\
\text { Greece, } \\
\text { Spain, } \\
\text { Serbia }\end{array}$ & 75 & 481 & $65 \%$ & 4-arms single-blind & $\mathrm{y}$ & 12 & 24 & 3 \\
\hline $\begin{array}{c}\text { Barnett, A } \\
(2003)^{3}\end{array}$ & Australia & 74.9 & 163 & $66 \%$ & 2-arms single-blinded & $\mathrm{n}$ & 48 & 48 & 3 \\
\hline $\begin{array}{l}\text { Beyer, N } \\
(2007)^{19}\end{array}$ & UK & 78.1 & 65 & $100 \%$ & 2-arms open & $\mathrm{y}$ & 24 & 48 & 3 \\
\hline
\end{tabular}




\begin{tabular}{|c|c|c|c|c|c|c|c|c|c|}
\hline \multirow[b]{2}{*}{$\begin{array}{l}\text { First Authors } \\
\text { (year) }\end{array}$} & \multirow[b]{2}{*}{ Country } & \multirow[b]{2}{*}{$\begin{array}{l}\text { Mean } \\
\text { age }\end{array}$} & \multirow[b]{2}{*}{$\begin{array}{c}\text { Sample } \\
\text { size }\end{array}$} & \multirow[b]{2}{*}{$\begin{array}{c}\text { Women } \\
\%\end{array}$} & \multirow[b]{2}{*}{ Design } & \multicolumn{3}{|c|}{ Duration } & \multirow[b]{2}{*}{$\begin{array}{c}\text { \# of } \\
\text { assessments } \\
\text { during } \\
\text { study }\end{array}$} \\
\hline & & & & & & $\begin{array}{l}\text { Is FOF } \\
\text { primary } \\
\text { outcome }\end{array}$ & $\begin{array}{c}\text { of } \\
\text { intervent } \\
\text { ion } \\
\text { (Weeks) }\end{array}$ & $\begin{array}{c}\text { Duration of } \\
\text { study } \\
\text { (weeks) }\end{array}$ & \\
\hline $\begin{array}{l}\text { Boogird } \\
(2017)^{20}\end{array}$ & Thailand & 74.37 & 439 & $82 \%$ & 2-arms single blinded & $\mathrm{n}$ & 48 & 48 & 5 \\
\hline $\begin{array}{c}\text { Brouwer, B } \\
(2003)^{21}\end{array}$ & Canada & 77.55 & 34 & $74 \%$ & 2-arms single blinded & $\mathrm{y}$ & 8 & 8 & 3 \\
\hline $\begin{array}{c}\text { Campbell, A. J } \\
(1997)^{22}\end{array}$ & $\begin{array}{c}\text { New } \\
\text { Zealand }\end{array}$ & 84.1 & 233 & $100 \%$ & 2-arms single-blind & $\mathrm{n}$ & 48 & 48 & 3 \\
\hline $\begin{array}{c}\text { Clemson, L } \\
(2012)^{23}\end{array}$ & Australia & 83.4 & 317 & $55 \%$ & 3-arms single-blind & $\mathrm{n}$ & 24 & 48 & 3 \\
\hline $\begin{array}{c}\text { Clemson, L } \\
(2010)^{24}\end{array}$ & Australia & 81.53 & 34 & $47 \%$ & 2-arms single-blind & $\mathrm{n}$ & 24 & 24 & 3 \\
\hline $\begin{array}{c}\text { Cockayne, S } \\
(2017)^{25}\end{array}$ & UK & 78.1 & 1010 & $58 \%$ & 2-arms double blinded & $\mathrm{n}$ & 48 & 48 & 4 \\
\hline $\begin{array}{l}\text { Covill, L } \\
(2017)^{26}\end{array}$ & USA & 73.74 & 48 & $78 \%$ & 2-arms open & $\mathrm{y}$ & $\mathrm{n}$ & $\mathrm{n}$ & 4 \\
\hline $\begin{array}{c}\text { Cyarto, E. V } \\
(2008)^{27}\end{array}$ & Australia & 78.7 & 167 & $81 \%$ & 3-arms single blinded & $\mathrm{y}$ & 20 & 20 & 2 \\
\hline $\begin{array}{c}\text { Devereux, K } \\
(2005)^{28}\end{array}$ & Australia & 73.3 & 50 & $100 \%$ & 2-arms open & $\mathrm{y}$ & 10 & 10 & 2 \\
\hline $\begin{array}{l}\text { Donath, L } \\
(2014)^{29}\end{array}$ & $\begin{array}{c}\text { Switzerlan } \\
\text { d }\end{array}$ & 72.3 & 18 & $94 \%$ & 2-arms open & $\mathrm{y}$ & 6 & 6 & 2 \\
\hline
\end{tabular}




\begin{tabular}{|c|c|c|c|c|c|c|c|c|c|}
\hline \multirow[b]{2}{*}{$\begin{array}{l}\text { First Authors } \\
\text { (year) }\end{array}$} & \multirow[b]{2}{*}{ Country } & \multirow[b]{2}{*}{$\begin{array}{l}\text { Mean } \\
\text { age }\end{array}$} & \multirow[b]{2}{*}{$\begin{array}{c}\text { Sample } \\
\text { size }\end{array}$} & \multirow[b]{2}{*}{$\begin{array}{c}\text { Women } \\
\%\end{array}$} & \multirow[b]{2}{*}{ Design } & \multicolumn{3}{|c|}{ Duration } & \multirow[b]{2}{*}{$\begin{array}{c}\text { \# of } \\
\text { assessments } \\
\text { during } \\
\text { study }\end{array}$} \\
\hline & & & & & & $\begin{array}{l}\text { Is FOF } \\
\text { primary } \\
\text { outcome }\end{array}$ & $\begin{array}{c}\text { of } \\
\text { intervent } \\
\text { ion } \\
\text { (Weeks) }\end{array}$ & $\begin{array}{l}\text { Duration of } \\
\text { study } \\
\text { (weeks) }\end{array}$ & \\
\hline $\begin{array}{l}\text { Duque, G } \\
(2013)^{11}\end{array}$ & Australia & 76.84 & 70 & $61 \%$ & 2-arms single-blind & $\mathrm{y}$ & 6 & 36 & 3 \\
\hline $\begin{array}{l}\text { El-Khoury, F } \\
\qquad(2015)^{30}\end{array}$ & France & 79.7 & 706 & $100 \%$ & 2-arms open & $\mathrm{n}$ & 96 & 96 & 3 \\
\hline $\begin{array}{l}\text { Freiberger, E } \\
\qquad(2013)^{31}\end{array}$ & Germany & 78.1 & 378 & $75 \%$ & 2-arms open & $\mathrm{y}$ & 16 & 96 & 4 \\
\hline $\begin{array}{l}\text { Freiberger, E } \\
\qquad(2012)^{32}\end{array}$ & Germany & 76.1 & 280 & $44 \%$ & 4 arms single blinded & $\mathrm{y}$ & 16 & 96 & 4 \\
\hline $\begin{array}{l}\text { Gallo, E } \\
(2018)^{33}\end{array}$ & USA & 75 & 35 & $46 \%$ & 2-arms open & $\mathrm{n}$ & 26 & 26 & 4 \\
\hline $\begin{array}{l}\text { Gine-Garriga, } \\
\text { M }(2013)^{34}\end{array}$ & Spain & 84 & 51 & $30 \%$ & 2-arms open & $\mathrm{y}$ & 12 & 36 & 3 \\
\hline $\begin{array}{l}\text { Gitlin,L.N } \\
(2006)^{35}\end{array}$ & USA & 79 & 319 & $81 \%$ & 2-arms open & $\mathrm{y}$ & 24 & 48 & 3 \\
\hline $\begin{array}{l}\text { Gschwind, Y } \\
(2015)^{36}\end{array}$ & $\begin{array}{l}\text { German, } \\
\text { Spain, } \\
\text { Australia }\end{array}$ & 74.7 & 153 & $61 \%$ & 2-arms open & $\mathrm{y}$ & 16 & 24 & 2 \\
\hline $\begin{array}{c}\text { Haines,T.P } \\
(2009)^{37}\end{array}$ & Australia & 80.6 & 53 & $60 \%$ & 2-arms single blinded & $\mathrm{y}$ & 24 & 24 & 3 \\
\hline
\end{tabular}




\begin{tabular}{|c|c|c|c|c|c|c|c|c|c|}
\hline \multirow[b]{2}{*}{$\begin{array}{l}\text { First Authors } \\
\text { (year) }\end{array}$} & \multirow[b]{2}{*}{ Country } & \multirow[b]{2}{*}{$\begin{array}{c}\text { Mean } \\
\text { age }\end{array}$} & \multirow[b]{2}{*}{$\begin{array}{c}\text { Sample } \\
\text { size }\end{array}$} & \multirow[b]{2}{*}{$\begin{array}{c}\text { Women } \\
\%\end{array}$} & \multirow[b]{2}{*}{ Design } & \multicolumn{3}{|c|}{ Duration } & \multirow[b]{2}{*}{$\begin{array}{c}\text { \# of } \\
\text { assessments } \\
\text { during } \\
\text { study }\end{array}$} \\
\hline & & & & & & $\begin{array}{l}\text { Is FOF } \\
\text { primary } \\
\text { outcome }\end{array}$ & $\begin{array}{c}\text { of } \\
\text { intervent } \\
\text { ion } \\
\text { (Weeks) }\end{array}$ & $\begin{array}{c}\text { Duration of } \\
\text { study } \\
\text { (weeks) }\end{array}$ & \\
\hline $\begin{array}{l}\text { Halvarsson, A } \\
\qquad(2011)^{38}\end{array}$ & Sweden & 77 & 59 & $71 \%$ & 2-arms single blinded & $\mathrm{y}$ & 12 & 12 & 2 \\
\hline $\begin{array}{l}\text { Hauer, K } \\
(2001)^{39}\end{array}$ & Germany & 82.2 & 57 & $100 \%$ & 2-arms single-blind & $\mathrm{n}$ & 12 & 24 & 3 \\
\hline $\begin{array}{c}\text { Henwood, T. R } \\
(2008)^{40}\end{array}$ & Australia & 68.56 & 67 & $54 \%$ & 3 arms open & $\mathrm{n}$ & 24 & 24 & 3 \\
\hline Iliffe, S $(2014)^{1}$ & UK & 72.94 & 1254 & $62 \%$ & 3 arms open & $\mathrm{n}$ & 24 & 96 & 5 \\
\hline $\begin{array}{c}\text { Jagdhane, S } \\
(2016)^{41}\end{array}$ & USA & 73.3 & 6 & $83 \%$ & 2-arms open & $\mathrm{n}$ & 4 & 4 & 2 \\
\hline $\begin{array}{l}\text { Jeon,M.Y } \\
(2014)^{42}\end{array}$ & Korea & 69.24 & 62 & $100 \%$ & 2-arms single blinded & $\mathrm{y}$ & 12 & 12 & 2 \\
\hline $\begin{array}{l}\text { Josephs, S } \\
(2016)^{43}\end{array}$ & USA & 75.1 & 24 & $75 \%$ & 2-arms single blinded & $\mathrm{y}$ & 12 & 12 & 2 \\
\hline $\begin{array}{l}\text { Kapan, A } \\
(2016)^{44}\end{array}$ & Austria & 82.74 & 80 & $84 \%$ & 2-arms open & $\mathrm{y}$ & 12 & 12 & 2 \\
\hline $\begin{array}{c}\text { Karinkanta, S } \\
(2012)^{8}\end{array}$ & Finland & 72.7 & 149 & $100 \%$ & 4-arms open & $\mathrm{y}$ & 48 & 48 & 3 \\
\hline Kim, S (2009) & USA & 73.67 & 18 & $\mathrm{n}$ & 3-arms open & $\mathrm{y}$ & 8 & 8 & 2 \\
\hline
\end{tabular}




\begin{tabular}{|c|c|c|c|c|c|c|c|c|c|}
\hline \multirow[b]{2}{*}{$\begin{array}{l}\text { First Authors } \\
\text { (year) }\end{array}$} & \multirow[b]{2}{*}{ Country } & \multirow[b]{2}{*}{$\begin{array}{c}\text { Mean } \\
\text { age }\end{array}$} & \multirow[b]{2}{*}{$\begin{array}{c}\text { Sample } \\
\text { size }\end{array}$} & \multirow[b]{2}{*}{$\begin{array}{c}\text { Women } \\
\%\end{array}$} & \multirow[b]{2}{*}{ Design } & \multicolumn{3}{|c|}{ Duration } & \multirow[b]{2}{*}{$\begin{array}{c}\text { \# of } \\
\text { assessments } \\
\text { during } \\
\text { study }\end{array}$} \\
\hline & & & & & & $\begin{array}{l}\text { Is FOF } \\
\text { primary } \\
\text { outcome }\end{array}$ & $\begin{array}{c}\text { of } \\
\text { intervent } \\
\text { ion } \\
\text { (Weeks) }\end{array}$ & $\begin{array}{c}\text { Duration of } \\
\text { study } \\
\text { (weeks) }\end{array}$ & \\
\hline $\begin{array}{l}\text { Kyrdalen, I. L } \\
(2014)^{45}\end{array}$ & Norway & 82.5 & 125 & $73 \%$ & 2-arms single-blind & $\mathrm{n}$ & 12 & 24 & 3 \\
\hline $\begin{array}{l}\text { Lai, C.H } \\
(2013)^{46}\end{array}$ & Taiwan & 72.7 & 30 & $57 \%$ & 2-arms single-blind & $\mathrm{y}$ & 6 & 12 & 3 \\
\hline $\begin{array}{l}\text { LaStayo, P } \\
(2017)^{47}\end{array}$ & USA & 76.1 & 134 & $65 \%$ & 2-arms open & $\mathrm{y}$ & 12 & 48 & 4 \\
\hline $\mathrm{Li}, \mathrm{F}(2005)^{12}$ & USA & 77.48 & 256 & $\mathrm{n}$ & 2-arms open & $\mathrm{y}$ & 24 & 24 & 3 \\
\hline $\begin{array}{l}\text { Li, F\&Harmer } \\
\qquad(2005)^{48}\end{array}$ & USA & 77.8 & 256 & $70 \%$ & 2-arms open & $\mathrm{n}$ & 26 & 48 & 6 \\
\hline Li, F (2019) ${ }^{49}$ & USA & 77.7 & 670 & $65 \%$ & 2-arms single-blind & $\mathrm{y}$ & 24 & 48 & 3 \\
\hline $\begin{array}{l}\text { Lin, M.R } \\
(2007)^{9}\end{array}$ & Taiwan & 76.8 & 150 & $51 \%$ & 3-arm single blinded & $\mathrm{n}$ & 16 & 16 & 3 \\
\hline Liu, H $(2007)^{50}$ & USA & 80.73 & 26 & $64 \%$ & 2-arm double blinded & $\mathrm{y}$ & 12 & 12 & 2 \\
\hline $\begin{array}{l}\text { Liu, Y. W } \\
(2014)^{51}\end{array}$ & China & 74.5 & 122 & $87 \%$ & 2-arm single blinded & $\mathrm{y}$ & 8 & 16 & 3 \\
\hline $\begin{array}{l}\text { Liu-Ambrose, T } \\
\qquad(2004)^{52}\end{array}$ & Canada & 79 & 104 & $100 \%$ & 3-arms open & $\mathrm{y}$ & 13 & 13 & 2 \\
\hline
\end{tabular}




\begin{tabular}{|c|c|c|c|c|c|c|c|c|c|}
\hline \multirow[b]{2}{*}{$\begin{array}{l}\text { First Authors } \\
\text { (year) }\end{array}$} & \multirow[b]{2}{*}{ Country } & \multirow[b]{2}{*}{$\begin{array}{c}\text { Mean } \\
\text { age }\end{array}$} & \multirow[b]{2}{*}{$\begin{array}{l}\text { Sample } \\
\text { size }\end{array}$} & \multirow[b]{2}{*}{$\begin{array}{c}\text { Women } \\
\%\end{array}$} & \multirow[b]{2}{*}{ Design } & \multicolumn{3}{|c|}{ Duration } & \multirow[b]{2}{*}{$\begin{array}{c}\text { \# of } \\
\text { assessments } \\
\text { during } \\
\text { study }\end{array}$} \\
\hline & & & & & & $\begin{array}{l}\text { Is FOF } \\
\text { primary } \\
\text { outcome }\end{array}$ & $\begin{array}{c}\text { of } \\
\text { intervent } \\
\text { ion } \\
\text { (Weeks) }\end{array}$ & $\begin{array}{c}\text { Duration of } \\
\text { study } \\
\text { (weeks) }\end{array}$ & \\
\hline $\begin{array}{l}\text { Logghe, I. H. J } \\
\qquad(2009)^{53}\end{array}$ & $\begin{array}{c}\text { Netherland } \\
\text { s }\end{array}$ & 77 & 269 & $71 \%$ & 2-arm single blinded & $\mathrm{n}$ & 13 & 48 & 4 \\
\hline $\begin{array}{l}\text { McCormack, G } \\
(2004)^{54}\end{array}$ & Australia & 79.1 & 43 & $\mathrm{n}$ & 3-arms open & $\mathrm{y}$ & 10 & 10 & 2 \\
\hline Oh, S $(2015)^{55}$ & Korea & 71.56 & 80 & $\mathrm{n}$ & 2-arm single blinded & $\mathrm{y}$ & 10 & 10 & 2 \\
\hline $\begin{array}{l}\text { Okubo, Y } \\
(2016)^{56}\end{array}$ & Japan & 70.1 & 90 & $62 \%$ & 2-arms open & $\mathrm{n}$ & 12 & 52 & 3 \\
\hline Patil, R (2016) $)^{57}$ & Finland & 74.2 & 409 & $100 \%$ & 4-arms double blinded & $\mathrm{y}$ & 96 & 96 & 3 \\
\hline $\begin{array}{c}\text { Plummer- } \\
\text { D'Amato, P } \\
(2012)^{58}\end{array}$ & USA & 76.64 & 20 & $94 \%$ & 2-arm single blinded & $\mathrm{y}$ & 4 & 4 & 2 \\
\hline $\begin{array}{l}\text { Pollock, R. D } \\
\qquad(2012)^{59}\end{array}$ & UK & 81.01 & 77 & $32 \%$ & 2-arms single-blind & $\mathrm{n}$ & 8 & 24 & 4 \\
\hline $\begin{array}{l}\text { Roller, M } \\
(2017)^{60}\end{array}$ & USA & 77.6 & 55 & $69 \%$ & 2-arms single-blinded & $\mathrm{y}$ & 10 & 10 & 2 \\
\hline $\begin{array}{l}\text { Sattin, R. W } \\
(2005)^{61}\end{array}$ & USA & 80.86 & 311 & $94 \%$ & 2-arms single-blind & $\mathrm{y}$ & 48 & 48 & 4 \\
\hline
\end{tabular}




\begin{tabular}{|c|c|c|c|c|c|c|c|c|c|}
\hline $\begin{array}{l}\text { First Authors } \\
\text { (year) }\end{array}$ & Country & $\begin{array}{c}\text { Mean } \\
\text { age }\end{array}$ & $\begin{array}{c}\text { Sample } \\
\text { size }\end{array}$ & $\begin{array}{c}\text { Women } \\
\%\end{array}$ & Design & $\begin{array}{l}\text { Is FOF } \\
\text { primary } \\
\text { outcome }\end{array}$ & $\begin{array}{c}\text { Duration } \\
\text { of } \\
\text { intervent } \\
\text { ion } \\
\text { (Weeks) }\end{array}$ & $\begin{array}{c}\text { Duration of } \\
\text { study } \\
\text { (weeks) }\end{array}$ & $\begin{array}{c}\text { \# of } \\
\text { assessments } \\
\text { during } \\
\text { study }\end{array}$ \\
\hline $\begin{array}{c}\text { Schoene, D } \\
(2015)^{62}\end{array}$ & Australia & 81.5 & 90 & $67 \%$ & 2-arms single-blind & $\mathrm{n}$ & 16 & 16 & 2 \\
\hline $\begin{array}{l}\text { Shigematsu, R } \\
(2008)^{5}\end{array}$ & Japan & 69.04 & 39 & $46 \%$ & 2-arms open & $\mathrm{y}$ & 12 & 56 & 2 \\
\hline $\begin{array}{c}\text { Siegrist, M } \\
(2016)^{63}\end{array}$ & Germany & 78.1 & 378 & $75 \%$ & 2-arms open & $\mathrm{n}$ & 16 & 96 & 4 \\
\hline $\begin{array}{c}\text { Smulders, E } \\
(2010)^{64}\end{array}$ & $\begin{array}{c}\text { Netherland } \\
\text { s }\end{array}$ & 71 & 96 & $94 \%$ & 2-arms single-blind & $\mathrm{n}$ & 5.5 & 48 & 3 \\
\hline $\begin{array}{l}\text { Szturm, T } \\
(2011)^{65}\end{array}$ & Canada & $\mathrm{n} / \mathrm{a}$ & 30 & $\mathrm{n}$ & 2-arm single blinded & $\mathrm{y}$ & 8 & 8 & 2 \\
\hline $\begin{array}{l}\text { Ullmann, G } \\
(2010)^{66}\end{array}$ & USA & 75.6 & 47 & $70 \%$ & 2-arms open & $\mathrm{y}$ & 5 & 5 & 2 \\
\hline Vogler $(2009)^{67}$ & Australia & 80 & 180 & $79 \%$ & 3-arms single-blind & $\mathrm{n}$ & 12 & 12 & 2 \\
\hline $\begin{array}{c}\text { Voukelatos, A } \\
(2015)^{68}\end{array}$ & Australia & 73.2 & 386 & $74 \%$ & 2-arms open & $\mathrm{n}$ & 48 & 48 & 4 \\
\hline $\begin{array}{c}\text { Westlake, K. P } \\
(2007)^{69}\end{array}$ & USA & $\mathrm{n} / \mathrm{a}$ & 44 & $\mathrm{n}$ & 3 arms single blinded & $\mathrm{n}$ & 8 & 16 & 3 \\
\hline $\begin{array}{l}\text { Wetherell, J. L } \\
\qquad(2018)^{70}\end{array}$ & USA & 77.9 & 42 & $74 \%$ & 2-arms single blinded & $\mathrm{y}$ & 8 & 18 & 7 \\
\hline
\end{tabular}




\begin{tabular}{|c|c|c|c|c|c|c|c|c|c|}
\hline \multirow[b]{2}{*}{$\begin{array}{l}\text { First Authors } \\
\text { (year) }\end{array}$} & \multirow[b]{2}{*}{ Country } & \multirow[b]{2}{*}{$\begin{array}{c}\text { Mean } \\
\text { age }\end{array}$} & \multirow[b]{2}{*}{$\begin{array}{c}\text { Sample } \\
\text { size }\end{array}$} & \multirow[b]{2}{*}{$\begin{array}{c}\text { Women } \\
\%\end{array}$} & \multirow[b]{2}{*}{ Design } & \multicolumn{3}{|c|}{ Duration } & \multirow[b]{2}{*}{$\begin{array}{c}\text { \# of } \\
\text { assessments } \\
\text { during } \\
\text { study }\end{array}$} \\
\hline & & & & & & $\begin{array}{l}\text { Is FOF } \\
\text { primary } \\
\text { outcome }\end{array}$ & $\begin{array}{c}\text { of } \\
\text { intervent } \\
\text { ion } \\
\text { (Weeks) }\end{array}$ & $\begin{array}{l}\text { Duration of } \\
\text { study } \\
\text { (weeks) }\end{array}$ & \\
\hline $\begin{array}{l}\text { Wolf, B } \\
(2001)^{10}\end{array}$ & $\begin{array}{c}\text { Netherland } \\
\text { s }\end{array}$ & 84.3 & 77 & $73 \%$ & 2-arms single-blind & $\mathrm{y}$ & 6 & 48 & 4 \\
\hline $\begin{array}{l}\text { Wolf, S. L } \\
(2003)^{6}\end{array}$ & USA & 76.2 & 200 & $81 \%$ & 3-arms open & $\mathrm{n}$ & 15 & 31 & 3 \\
\hline $\begin{array}{c}\text { Wollesen, B } \\
(2017)^{71}\end{array}$ & Germany & 71.5 & 95 & $77 \%$ & 4-arms single-blind & $\mathrm{n}$ & 12 & 12 & 2 \\
\hline $\mathrm{Wu}, \mathrm{G}(2010)^{72}$ & USA & 75.4 & 64 & $\mathrm{n}$ & 3-arms open & $\mathrm{y}$ & 15 & 15 & 2 \\
\hline $\begin{array}{c}\text { Yamada, M } \\
(2011)^{7}\end{array}$ & Japan & 71.8 & 57 & $\mathrm{n}$ & 2-arms single blinded & $\mathrm{y}$ & 24 & 24 & 2 \\
\hline $\begin{array}{c}\text { Yang, X. J } \\
(2012)^{73}\end{array}$ & Australia & 85.55 & 165 & $44 \%$ & 2-arms single-blind & $\mathrm{n}$ & 24 & 24 & 2 \\
\hline $\begin{array}{l}\text { Yoo, E. J } \\
(2010)^{74}\end{array}$ & Korea & 70.1 & 21 & $\mathrm{n}$ & 2-arm open & $\mathrm{y}$ & 12 & 12 & 2 \\
\hline $\begin{array}{l}\text { Zhang, L } \\
(2014)^{75}\end{array}$ & China & 85.27 & 44 & $14 \%$ & 2-arms single-blind & $\mathrm{n}$ & 8 & 8 & 3 \\
\hline $\begin{array}{l}\text { Zhao, Y } \\
(2016)^{76}\end{array}$ & China & 70 & 61 & $69 \%$ & 2-arms single-blinded & $\mathrm{n}$ & 16 & 24 & 4 \\
\hline
\end{tabular}

Note. y: yes; n: not reported; n/a: not applicable 


\subsection{Reporting of Principles of Exercise Training}

The ratings of application principles of exercise training of all trials are listed in Table 4. None of the 75 trials reported information for all the six principles. Three trials reported five principles, 21 trials reported four, 21 trials reported three, 18 trials reported two, 11 trials reported one, and one trial reported none of them.

The specificity was reported in 69 trials, while the initial value was only reported in 6 trials. The second most frequently reported principle was progression in 54 trials. Overload and reversibility were reported in less than $50 \%$ of trials, and diminishing return was reported in $21 \%$ of trials (Figure. 2).

The agreement between the 2 reviewers (C.F. and T.A.) in rating principles of exercise training was almost perfect $(\kappa=0.94)$.

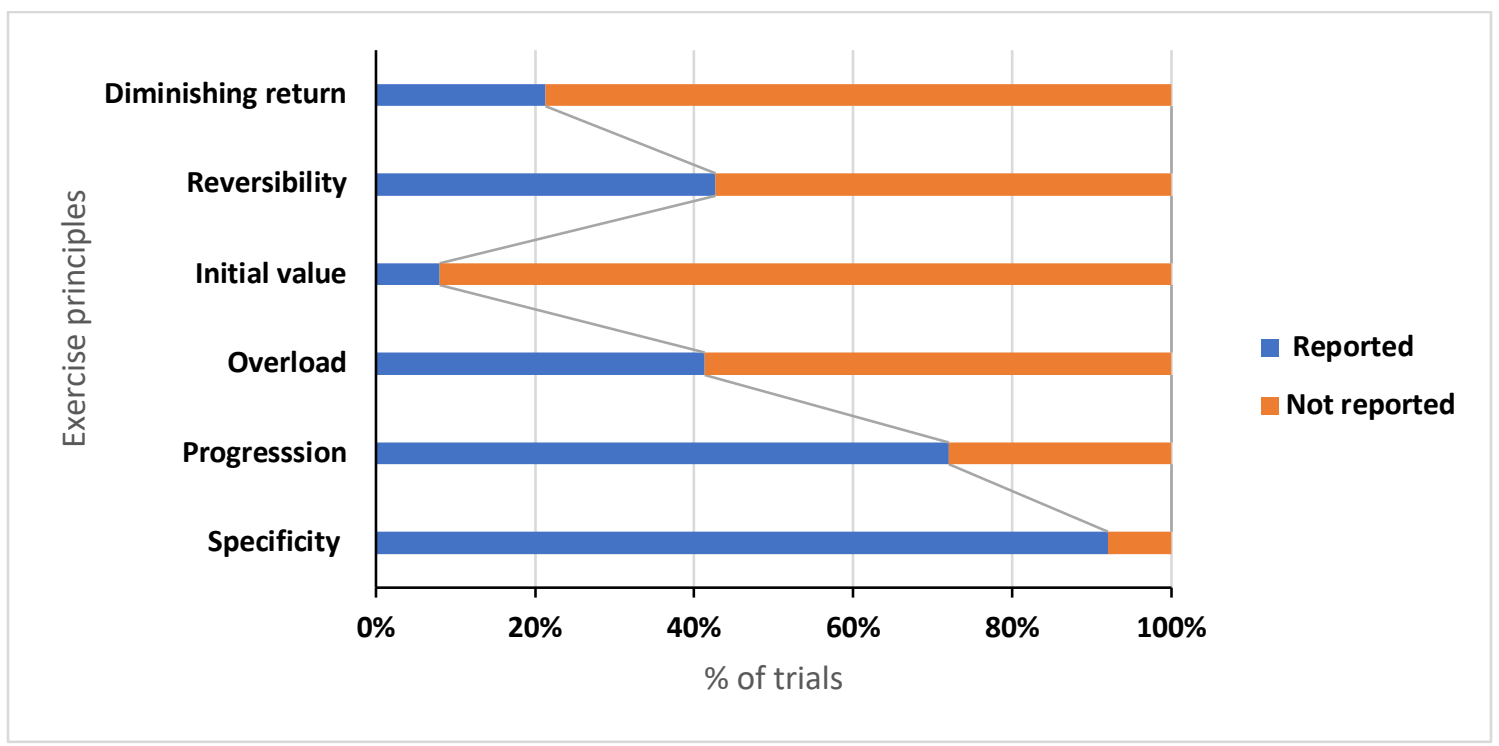

Figure 2: Reporting of principles of exercise training

\subsection{Reporting of FITT Components and Adherence}

Frequency was reported in 67 trials, intensity was reported in 19 trials, time was reported in 64 trials, the type was reported in 73 trials, and adherence to exercise interventions was reported in 47 trials (Figure. 3). 
The agreement for assessing FITT components and adherence was substantial $(\kappa=0.79)$.

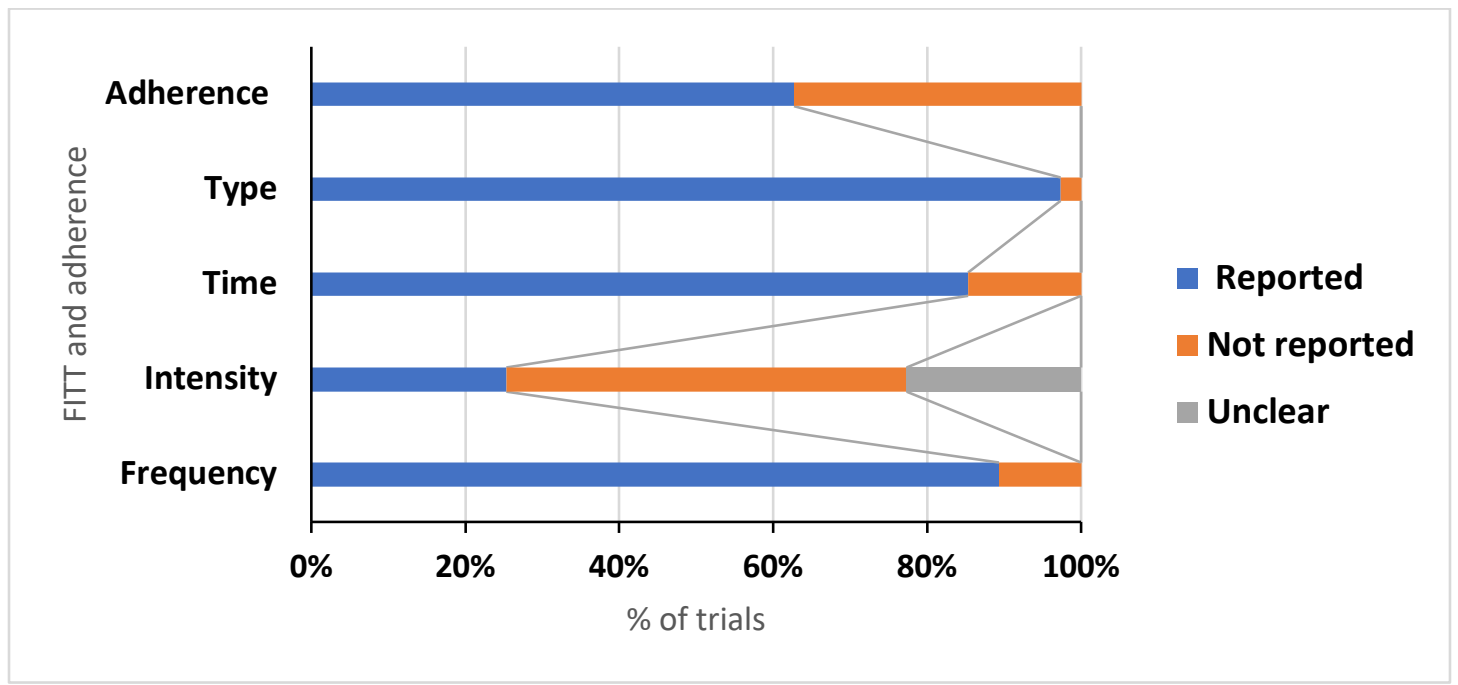

Figure 3: Reporting of FITT components and adherence

Table 4: Reporting of principles of exercise training and FITT

\begin{tabular}{|c|c|c|c|c|c|c|c|c|c|c|}
\hline Fist Author. Year & $\mathrm{Sp}$ & Pr & $\mathrm{OL}$ & IV & $\operatorname{Re}$ & DR & $\mathbf{F}$ & I & $\mathbf{T}$ & $\mathbf{T}$ \\
\hline Arai, T. 2007 & $\mathrm{y}$ & $\mathrm{y}$ & $\mathrm{y}$ & $\mathrm{y}$ & $\mathrm{n}$ & $\mathrm{n}$ & $\mathrm{y}$ & $\mathrm{y}$ & $\mathrm{y}$ & $\mathrm{y}$ \\
\hline Arantes, M. 2015 & $\mathrm{y}$ & $\mathrm{y}$ & $\mathrm{y}$ & $\mathrm{n}$ & $\mathrm{n}$ & $\mathrm{n}$ & $\mathrm{y}$ & unclear & $\mathrm{y}$ & $\mathrm{y}$ \\
\hline Arkkukangas, M.2015 & $\mathrm{y}$ & $\mathrm{y}$ & $\mathrm{y}$ & $\mathrm{n}$ & $\mathrm{n}$ & $\mathrm{n}$ & $\mathrm{y}$ & $\mathrm{n}$ & $\mathrm{y}$ & $\mathrm{y}$ \\
\hline Arkkukangas, M.2019 & $\mathrm{y}$ & $\mathrm{y}$ & $\mathrm{y}$ & $\mathrm{n}$ & $\mathrm{y}$ & $\mathrm{n}$ & $\mathrm{y}$ & unclear & $\mathrm{y}$ & $\mathrm{y}$ \\
\hline Bao, T. 2018 & $\mathrm{y}$ & $\mathrm{y}$ & $\mathrm{y}$ & $\mathrm{n}$ & $\mathrm{n}$ & $\mathrm{y}$ & $\mathrm{y}$ & $\mathrm{y}$ & $\mathrm{y}$ & $\mathrm{y}$ \\
\hline Barban, F.2017 & $\mathrm{y}$ & $\mathrm{y}$ & $\mathrm{n}$ & $\mathrm{n}$ & $\mathrm{y}$ & $\mathrm{n}$ & $\mathrm{y}$ & $\mathrm{n}$ & $\mathrm{y}$ & $\mathrm{y}$ \\
\hline Barnett, A. 2003 & $\mathrm{y}$ & $\mathrm{y}$ & $\mathrm{n}$ & $\mathrm{n}$ & $\mathrm{n}$ & $\mathrm{n}$ & $\mathrm{n}$ & $\mathrm{n}$ & $\mathrm{n}$ & $\mathrm{y}$ \\
\hline Beyer, N. 2007 & $\mathrm{y}$ & $\mathrm{y}$ & $\mathrm{y}$ & $\mathrm{n}$ & $\mathrm{y}$ & $\mathrm{y}$ & $\mathrm{y}$ & $\mathrm{y}$ & $\mathrm{y}$ & $\mathrm{y}$ \\
\hline Boongird. 2017 & $\mathrm{y}$ & $\mathrm{y}$ & $\mathrm{n}$ & $\mathrm{n}$ & $\mathrm{n}$ & $\mathrm{y}$ & $\mathrm{n}$ & $\mathrm{n}$ & $\mathrm{n}$ & $\mathrm{y}$ \\
\hline Brouwer, B. 2003 & $\mathrm{y}$ & $\mathrm{n}$ & $\mathrm{n}$ & $\mathrm{n}$ & $\mathrm{y}$ & $\mathrm{n}$ & $\mathrm{y}$ & $\mathrm{n}$ & $\mathrm{y}$ & $\mathrm{y}$ \\
\hline Campbell, A. J.1997 & $\mathrm{y}$ & $\mathrm{y}$ & $\mathrm{n}$ & $\mathrm{n}$ & $\mathrm{y}$ & $\mathrm{n}$ & $\mathrm{y}$ & unclear & $\mathrm{y}$ & $\mathrm{y}$ \\
\hline Clemson, L.2012 & $\mathrm{y}$ & $\mathrm{y}$ & $\mathrm{y}$ & $\mathrm{n}$ & $\mathrm{y}$ & $\mathrm{n}$ & $\mathrm{y}$ & unclear & $\mathrm{n}$ & $\mathrm{y}$ \\
\hline Clemson, L.2010 & $\mathrm{y}$ & $\mathrm{y}$ & $\mathrm{n}$ & $\mathrm{n}$ & $\mathrm{n}$ & $\mathrm{y}$ & $\mathrm{n}$ & $\mathrm{n}$ & $\mathrm{n}$ & $\mathrm{y}$ \\
\hline Cockayne, S. 2017 & $\mathrm{y}$ & $\mathrm{n}$ & $\mathrm{n}$ & $\mathrm{n}$ & $\mathrm{n}$ & $\mathrm{n}$ & $\mathrm{y}$ & $\mathrm{y}$ & $\mathrm{y}$ & $\mathrm{y}$ \\
\hline Covill, L. 2017 & $\mathrm{y}$ & $\mathrm{y}$ & $\mathrm{y}$ & $\mathrm{n}$ & $\mathrm{y}$ & $\mathrm{n}$ & $\mathrm{n}$ & $\mathrm{n}$ & $\mathrm{y}$ & $\mathrm{y}$ \\
\hline Cyarto, E. V. 2008 & $\mathrm{y}$ & $\mathrm{y}$ & $\mathrm{y}$ & $\mathrm{n}$ & $\mathrm{n}$ & $\mathrm{n}$ & $\mathrm{y}$ & $\mathrm{n}$ & $\mathrm{y}$ & $\mathrm{y}$ \\
\hline Devereux, K. 2005 & $\mathrm{y}$ & $\mathrm{n}$ & $\mathrm{n}$ & $\mathrm{n}$ & $\mathrm{n}$ & $\mathrm{n}$ & $\mathrm{y}$ & $\mathrm{n}$ & $\mathrm{y}$ & $\mathrm{y}$ \\
\hline Donath, L. 2014 & $\mathrm{y}$ & $\mathrm{y}$ & $\mathrm{n}$ & $\mathrm{n}$ & $\mathrm{n}$ & $\mathrm{n}$ & $\mathrm{y}$ & $\mathrm{n}$ & $\mathrm{y}$ & $\mathrm{y}$ \\
\hline
\end{tabular}




\begin{tabular}{|c|c|c|c|c|c|c|c|c|c|c|}
\hline Duque, G.2013 & $\mathrm{y}$ & $\mathrm{y}$ & $\mathrm{y}$ & $\mathrm{n}$ & $\mathrm{y}$ & $\mathrm{n}$ & $\mathrm{y}$ & $\mathrm{y}$ & $\mathrm{y}$ & $\mathrm{y}$ \\
\hline El-Khoury, F. 2015 & $\mathrm{y}$ & $\mathrm{y}$ & $\mathrm{n}$ & $\mathrm{n}$ & $\mathrm{y}$ & $\mathrm{n}$ & $\mathrm{y}$ & unclear & $\mathrm{y}$ & $\mathrm{y}$ \\
\hline Freiberger, E. 2013 & $\mathrm{y}$ & $\mathrm{y}$ & $\mathrm{n}$ & $\mathrm{n}$ & $\mathrm{n}$ & $\mathrm{n}$ & $\mathrm{y}$ & unclear & $\mathrm{y}$ & $\mathrm{y}$ \\
\hline Freiberger, E. 2012 & $\mathrm{y}$ & $\mathrm{y}$ & $\mathrm{n}$ & $\mathrm{n}$ & $\mathrm{y}$ & $\mathrm{y}$ & $\mathrm{y}$ & unclear & $\mathrm{y}$ & $\mathrm{y}$ \\
\hline Gallo, E.2018 & $\mathrm{y}$ & $\mathrm{y}$ & $\mathrm{y}$ & $\mathrm{n}$ & $\mathrm{n}$ & $\mathrm{y}$ & $\mathrm{y}$ & unclear & $\mathrm{y}$ & $\mathrm{y}$ \\
\hline Gine-Garriga, M. 2013 & $\mathrm{y}$ & $\mathrm{y}$ & $\mathrm{y}$ & $\mathrm{n}$ & $\mathrm{y}$ & $\mathrm{n}$ & $\mathrm{y}$ & $\mathrm{y}$ & $\mathrm{n}$ & $\mathrm{y}$ \\
\hline Gitlin, L. N. 2006 & $\mathrm{y}$ & $\mathrm{n}$ & $\mathrm{n}$ & $\mathrm{n}$ & $\mathrm{y}$ & $\mathrm{n}$ & $\mathrm{n}$ & $\mathrm{n}$ & $\mathrm{n}$ & $\mathrm{y}$ \\
\hline Gschwind, Y.2015 & $\mathrm{y}$ & $\mathrm{y}$ & $\mathrm{y}$ & $\mathrm{y}$ & $\mathrm{n}$ & $\mathrm{n}$ & $\mathrm{y}$ & unclear & $\mathrm{y}$ & $\mathrm{y}$ \\
\hline Haines, T. P. 2009 & $y$ & $\mathrm{y}$ & $y$ & $\mathrm{n}$ & $\mathrm{y}$ & $\mathrm{y}$ & $\mathrm{n}$ & $\mathrm{n}$ & $\mathrm{n}$ & $\mathrm{y}$ \\
\hline Halvarsson, A. 2011 & $\mathrm{y}$ & $\mathrm{y}$ & $\mathrm{y}$ & $\mathrm{y}$ & $\mathrm{n}$ & $\mathrm{n}$ & $\mathrm{y}$ & $\mathrm{n}$ & $\mathrm{y}$ & $\mathrm{y}$ \\
\hline Hauer, K.2001 & $\mathrm{y}$ & $\mathrm{y}$ & $\mathrm{y}$ & $\mathrm{n}$ & $\mathrm{y}$ & $\mathrm{n}$ & $\mathrm{y}$ & $\mathrm{y}$ & $\mathrm{y}$ & $\mathrm{y}$ \\
\hline Henwood, T. R. 2008 & $\mathrm{y}$ & $\mathrm{y}$ & $\mathrm{y}$ & $\mathrm{n}$ & $\mathrm{n}$ & $\mathrm{y}$ & $\mathrm{y}$ & $\mathrm{y}$ & $\mathrm{y}$ & $\mathrm{y}$ \\
\hline Iliffe, S. 2014 & $\mathrm{y}$ & $\mathrm{y}$ & $\mathrm{y}$ & $\mathrm{y}$ & $\mathrm{y}$ & $\mathrm{n}$ & $\mathrm{y}$ & unclear & $\mathrm{y}$ & $\mathrm{y}$ \\
\hline Jagdhane, S. 2016 & $\mathrm{y}$ & $\mathrm{y}$ & $\mathrm{n}$ & $\mathrm{n}$ & $\mathrm{n}$ & $\mathrm{n}$ & $\mathrm{y}$ & unclear & $\mathrm{y}$ & $\mathrm{y}$ \\
\hline Jeon, M. Y. 2014 & $\mathrm{y}$ & $\mathrm{n}$ & $\mathrm{n}$ & $\mathrm{n}$ & $\mathrm{n}$ & $\mathrm{n}$ & $\mathrm{y}$ & $\mathrm{n}$ & $\mathrm{y}$ & $\mathrm{y}$ \\
\hline Josephs, S. 2016 & $\mathrm{y}$ & $\mathrm{y}$ & $\mathrm{y}$ & $\mathrm{n}$ & $\mathrm{n}$ & $\mathrm{n}$ & $\mathrm{y}$ & $\mathrm{y}$ & y & $\mathrm{y}$ \\
\hline Kapan, A. 2016 & $\mathrm{y}$ & $\mathrm{n}$ & $\mathrm{n}$ & $\mathrm{n}$ & $\mathrm{n}$ & $\mathrm{n}$ & $\mathrm{y}$ & $\mathrm{n}$ & $\mathrm{y}$ & $\mathrm{y}$ \\
\hline Karinkanta, S. 2012 & $\mathrm{y}$ & $\mathrm{y}$ & $\mathrm{y}$ & $\mathrm{n}$ & $\mathrm{y}$ & $\mathrm{n}$ & $\mathrm{y}$ & $\mathrm{y}$ & $\mathrm{y}$ & $\mathrm{y}$ \\
\hline Kim, S. 2009 & $\mathrm{y}$ & $\mathrm{y}$ & $\mathrm{y}$ & $\mathrm{n}$ & $\mathrm{n}$ & $\mathrm{n}$ & $\mathrm{y}$ & $\mathrm{y}$ & $\mathrm{y}$ & $\mathrm{y}$ \\
\hline Kyrdalen, I. L.2014 & $\mathrm{y}$ & $\mathrm{y}$ & $\mathrm{y}$ & $\mathrm{n}$ & $\mathrm{y}$ & $\mathrm{n}$ & $\mathrm{y}$ & $\mathrm{n}$ & y & $\mathrm{y}$ \\
\hline Lai, C.H.2013 & $\mathrm{n}$ & $\mathrm{n}$ & $\mathrm{n}$ & $\mathrm{n}$ & $\mathrm{n}$ & $\mathrm{n}$ & $\mathrm{y}$ & $\mathrm{n}$ & $\mathrm{y}$ & $\mathrm{n}$ \\
\hline LaStayo, P. 2017 & $\mathrm{y}$ & $\mathrm{y}$ & $\mathrm{y}$ & $\mathrm{n}$ & $\mathrm{y}$ & $\mathrm{n}$ & $\mathrm{y}$ & $\mathrm{y}$ & $\mathrm{y}$ & $\mathrm{y}$ \\
\hline Li, F. 2005 & $\mathrm{y}$ & $\mathrm{n}$ & $\mathrm{n}$ & $\mathrm{n}$ & $\mathrm{n}$ & $\mathrm{y}$ & $\mathrm{y}$ & unclear & $\mathrm{y}$ & $\mathrm{y}$ \\
\hline Li, F\&Harmer.2005 & $\mathrm{y}$ & $\mathrm{n}$ & $\mathrm{n}$ & $\mathrm{n}$ & $\mathrm{y}$ & $\mathrm{y}$ & $\mathrm{n}$ & $\mathrm{n}$ & $\mathrm{n}$ & $\mathrm{y}$ \\
\hline Li, F.2019 & $\mathrm{y}$ & $\mathrm{n}$ & $\mathrm{n}$ & $\mathrm{n}$ & $\mathrm{y}$ & $\mathrm{n}$ & $\mathrm{y}$ & $\mathrm{n}$ & $\mathrm{y}$ & $\mathrm{y}$ \\
\hline Lin, M. R. 2007 & $\mathrm{y}$ & $\mathrm{y}$ & $\mathrm{y}$ & $\mathrm{n}$ & $\mathrm{y}$ & $\mathrm{n}$ & $\mathrm{y}$ & $\mathrm{n}$ & $\mathrm{y}$ & $\mathrm{y}$ \\
\hline Liu, H. 2007 & $\mathrm{y}$ & $\mathrm{y}$ & $\mathrm{y}$ & $\mathrm{n}$ & $\mathrm{n}$ & $\mathrm{n}$ & $\mathrm{y}$ & unclear & $\mathrm{y}$ & $\mathrm{y}$ \\
\hline Liu, Y. W. 2014 & $\mathrm{n}$ & $\mathrm{n}$ & $\mathrm{n}$ & $\mathrm{n}$ & $\mathrm{y}$ & $\mathrm{n}$ & $\mathrm{y}$ & $\mathrm{n}$ & $\mathrm{y}$ & $\mathrm{y}$ \\
\hline Liu-Ambrose, T. 2004 & $\mathrm{y}$ & $\mathrm{y}$ & $\mathrm{y}$ & $\mathrm{n}$ & $\mathrm{n}$ & $\mathrm{n}$ & $\mathrm{y}$ & $\mathrm{y}$ & $\mathrm{y}$ & $\mathrm{y}$ \\
\hline Logghe, I. H. J. 2009 & $\mathrm{n}$ & $\mathrm{n}$ & $\mathrm{n}$ & $\mathrm{n}$ & $\mathrm{y}$ & $\mathrm{n}$ & $\mathrm{y}$ & $\mathrm{n}$ & $\mathrm{y}$ & $\mathrm{y}$ \\
\hline McCormack, G.2004 & $\mathrm{y}$ & $\mathrm{y}$ & $\mathrm{n}$ & $\mathrm{n}$ & $\mathrm{n}$ & $\mathrm{n}$ & $\mathrm{y}$ & unclear & $\mathrm{y}$ & $\mathrm{y}$ \\
\hline Oh, S. 2015 & $\mathrm{y}$ & $\mathrm{n}$ & $\mathrm{n}$ & $\mathrm{n}$ & $\mathrm{n}$ & $\mathrm{n}$ & $\mathrm{y}$ & $\mathrm{y}$ & $\mathrm{y}$ & $\mathrm{y}$ \\
\hline Okubo, Y.2016 & $\mathrm{y}$ & $\mathrm{y}$ & $\mathrm{n}$ & $\mathrm{n}$ & $\mathrm{y}$ & $\mathrm{n}$ & $\mathrm{y}$ & $\mathrm{y}$ & $\mathrm{y}$ & $\mathrm{y}$ \\
\hline Patil, R. 2016 & $\mathrm{y}$ & $\mathrm{y}$ & $\mathrm{n}$ & $\mathrm{n}$ & $\mathrm{y}$ & $\mathrm{y}$ & $\mathrm{y}$ & $\mathrm{y}$ & $\mathrm{y}$ & $\mathrm{y}$ \\
\hline Plummer. 2012 & $\mathrm{y}$ & $\mathrm{y}$ & $\mathrm{n}$ & $\mathrm{n}$ & $\mathrm{n}$ & $\mathrm{n}$ & $\mathrm{y}$ & $\mathrm{n}$ & $\mathrm{y}$ & $\mathrm{y}$ \\
\hline Pollock, R. D.2012 & $\mathrm{y}$ & $\mathrm{y}$ & $\mathrm{n}$ & $\mathrm{n}$ & $\mathrm{y}$ & $\mathrm{y}$ & $\mathrm{y}$ & $\mathrm{n}$ & $\mathrm{y}$ & $\mathrm{y}$ \\
\hline Roller, M. 2018 & $\mathrm{y}$ & $\mathrm{y}$ & $\mathrm{y}$ & $\mathrm{n}$ & $\mathrm{n}$ & $\mathrm{n}$ & $\mathrm{y}$ & $\mathrm{n}$ & $\mathrm{y}$ & $\mathrm{y}$ \\
\hline
\end{tabular}




\begin{tabular}{|c|c|c|c|c|c|c|c|c|c|c|}
\hline Sattin, R. W. 2005 & $\mathrm{y}$ & $\mathrm{y}$ & $\mathrm{n}$ & $\mathrm{y}$ & $\mathrm{n}$ & $\mathrm{y}$ & $\mathrm{y}$ & $\mathrm{n}$ & $\mathrm{y}$ & $\mathrm{y}$ \\
\hline Schoene, D.2015 & $\mathrm{y}$ & $\mathrm{y}$ & $\mathrm{y}$ & $\mathrm{y}$ & $\mathrm{n}$ & $\mathrm{n}$ & $\mathrm{y}$ & unclear & $\mathrm{y}$ & $\mathrm{y}$ \\
\hline Shigematsu, R. 2008 & $\mathrm{y}$ & $\mathrm{y}$ & $\mathrm{n}$ & $\mathrm{n}$ & $\mathrm{n}$ & $\mathrm{n}$ & $\mathrm{y}$ & $\mathrm{n}$ & $\mathrm{y}$ & $\mathrm{y}$ \\
\hline Siegrist, M. 2016 & $\mathrm{y}$ & $\mathrm{y}$ & $\mathrm{n}$ & $\mathrm{n}$ & $\mathrm{n}$ & $\mathrm{n}$ & $\mathrm{y}$ & $\mathrm{n}$ & $\mathrm{y}$ & $\mathrm{y}$ \\
\hline Smulders, E.2010 & $\mathrm{y}$ & $\mathrm{n}$ & $\mathrm{n}$ & $\mathrm{n}$ & $\mathrm{y}$ & $\mathrm{n}$ & $\mathrm{y}$ & $\mathrm{n}$ & $\mathrm{y}$ & $\mathrm{y}$ \\
\hline Szturm, T. 2011 & $\mathrm{y}$ & $\mathrm{y}$ & $\mathrm{n}$ & $\mathrm{n}$ & $\mathrm{n}$ & $\mathrm{n}$ & $\mathrm{y}$ & $\mathrm{n}$ & $\mathrm{y}$ & $\mathrm{y}$ \\
\hline Ullmann, G. 2010 & $\mathrm{y}$ & $\mathrm{n}$ & $\mathrm{y}$ & $\mathrm{n}$ & $\mathrm{n}$ & $\mathrm{n}$ & $\mathrm{y}$ & $\mathrm{n}$ & $\mathrm{y}$ & $\mathrm{y}$ \\
\hline Vogler.2009 & $\mathrm{y}$ & $\mathrm{y}$ & $\mathrm{n}$ & $\mathrm{n}$ & $\mathrm{n}$ & $\mathrm{n}$ & $\mathrm{y}$ & $\mathrm{y}$ & $\mathrm{n}$ & $\mathrm{y}$ \\
\hline Voukelatos, A.2015 & $\mathrm{n}$ & $\mathrm{y}$ & $\mathrm{n}$ & $\mathrm{n}$ & $\mathrm{n}$ & $\mathrm{n}$ & $\mathrm{n}$ & unclear & $\mathrm{n}$ & $\mathrm{y}$ \\
\hline Westlake, K. P. 2007 & $\mathrm{y}$ & $\mathrm{y}$ & $\mathrm{n}$ & $\mathrm{n}$ & $\mathrm{y}$ & $\mathrm{n}$ & $\mathrm{y}$ & $\mathrm{n}$ & $\mathrm{y}$ & $\mathrm{y}$ \\
\hline Wetherell, J. L. 2018 & $\mathrm{y}$ & $\mathrm{n}$ & $\mathrm{n}$ & $\mathrm{n}$ & $\mathrm{y}$ & $\mathrm{y}$ & $\mathrm{y}$ & $\mathrm{n}$ & $\mathrm{y}$ & $\mathrm{y}$ \\
\hline Wolf, B.2001 & $\mathrm{y}$ & $\mathrm{n}$ & $\mathrm{n}$ & $\mathrm{n}$ & $\mathrm{y}$ & $\mathrm{n}$ & $\mathrm{y}$ & $\mathrm{n}$ & $\mathrm{y}$ & $\mathrm{y}$ \\
\hline Wolf, S. L. 2003 & $\mathrm{y}$ & $\mathrm{y}$ & $\mathrm{n}$ & $\mathrm{n}$ & $\mathrm{y}$ & $\mathrm{n}$ & $\mathrm{y}$ & $\mathrm{n}$ & $\mathrm{y}$ & $\mathrm{y}$ \\
\hline Wollesen, B. 2017 & $\mathrm{y}$ & $\mathrm{y}$ & $\mathrm{n}$ & $\mathrm{n}$ & $\mathrm{n}$ & $\mathrm{n}$ & $\mathrm{y}$ & $\mathrm{n}$ & $\mathrm{y}$ & $\mathrm{y}$ \\
\hline Wu, G. 2010 & $\mathrm{y}$ & $\mathrm{n}$ & $\mathrm{n}$ & $\mathrm{n}$ & $\mathrm{n}$ & $\mathrm{n}$ & $\mathrm{y}$ & $\mathrm{n}$ & $\mathrm{y}$ & $\mathrm{y}$ \\
\hline Yamada, M. 2011 & $\mathrm{y}$ & $\mathrm{y}$ & $\mathrm{y}$ & $\mathrm{n}$ & $\mathrm{n}$ & $\mathrm{n}$ & $\mathrm{y}$ & unclear & $\mathrm{y}$ & $\mathrm{y}$ \\
\hline Yang, X. J.2012 & $\mathrm{y}$ & $\mathrm{y}$ & $\mathrm{y}$ & $\mathrm{n}$ & $\mathrm{n}$ & $\mathrm{n}$ & $\mathrm{y}$ & $\mathrm{n}$ & $\mathrm{y}$ & $\mathrm{y}$ \\
\hline Yoo, E. J. 2010 & $\mathrm{y}$ & $\mathrm{n}$ & $\mathrm{n}$ & $\mathrm{n}$ & $\mathrm{n}$ & $\mathrm{n}$ & $\mathrm{y}$ & $\mathrm{y}$ & $\mathrm{y}$ & $\mathrm{y}$ \\
\hline Zhang, L.2014 & $\mathrm{n}$ & $\mathrm{n}$ & $\mathrm{n}$ & $\mathrm{n}$ & $\mathrm{n}$ & $\mathrm{y}$ & $\mathrm{y}$ & $\mathrm{n}$ & $\mathrm{n}$ & $\mathrm{n}$ \\
\hline Zhao, Y. 2016 & $\mathrm{y}$ & $\mathrm{n}$ & $\mathrm{n}$ & $\mathrm{n}$ & $\mathrm{y}$ & $\mathrm{y}$ & $\mathrm{y}$ & $\mathrm{y}$ & $\mathrm{y}$ & $\mathrm{y}$ \\
\hline
\end{tabular}

Note. y: yest; n: not reported; Sp: specificity; Pr: progression; OL: overload; IV: initial value; Re: reversibility; DR: diminishing return; F: frequency; I: intensity; T: time; T: type of exercise

\subsection{Rating of the Methodological Quality of Included RCTs}

No trials had excellent methodological quality. Forty-seven and 27 trials had good and fair methodological quality, respectively. One trial was rated as having poor methodological quality (Table 5).

All trials met criterion 2 (randomization), 74 trials met criterion 10 (between-group comparisons), and 72 trials followed criterion 11 (point estimates and variability). However, none of the trials masked all participants and therapists. Thirty-one trials reported concealed allocation, and 46 trials masked assessors. Finally, 42 trials measured at least one key outcome in more than $85 \%$ of participants, and 39 trials used an intention-to-treat analysis (Table 6). 
The agreement in rating the PEDro Scale between the 2 reviewers was excellent $(\kappa=$ $0.88)$.

Table 5. PEDro scores

\begin{tabular}{|c|c|c|c|c|c|c|c|c|c|c|c|c|}
\hline PEDro Criteria: & 1 & 2 & 3 & 4 & 5 & 6 & 7 & 8 & 9 & 10 & 11 & Total $\mathbf{1 0 / 1 0}$ \\
\hline Arai, T. 2007 & 1 & 1 & 0 & 1 & 0 & 0 & 1 & 0 & 0 & 1 & 1 & $5 / 10$ \\
\hline Arantes, M. 2015 & 1 & 1 & 1 & 1 & 0 & 0 & 1 & 1 & 0 & 1 & 1 & $7 / 10$ \\
\hline Arkkukangas, M.2015 & 1 & 1 & 0 & 1 & 0 & 0 & 1 & 1 & 0 & 1 & 1 & $6 / 10$ \\
\hline Arkkukangas, M.2019 & 1 & 1 & 0 & 1 & 0 & 0 & 1 & 1 & 1 & 1 & 1 & $7 / 10$ \\
\hline Bao, T. 2018 & 1 & 1 & 1 & 1 & 0 & 0 & 1 & 1 & 0 & 1 & 1 & $7 / 10$ \\
\hline Barban, F.2017 & 1 & 1 & 1 & 1 & 0 & 0 & 1 & 1 & 0 & 1 & 1 & $7 / 10$ \\
\hline Barnett, A. 2003 & 1 & 1 & 1 & 1 & 0 & 0 & 1 & 1 & 1 & 1 & 1 & $8 / 10$ \\
\hline Beyer, N. 2007 & 1 & 1 & 0 & 1 & 0 & 0 & 0 & 0 & 1 & 1 & 1 & $5 / 10$ \\
\hline Boongird. 2017 & 1 & 1 & 1 & 1 & 0 & 0 & 0 & 1 & 0 & 1 & 1 & $6 / 10$ \\
\hline Brouwer, B. 2003 & 1 & 1 & 0 & 1 & 0 & 0 & 1 & 1 & 0 & 1 & 1 & $6 / 10$ \\
\hline Campbell, A. J.1997 & 1 & 1 & 1 & 1 & 0 & 0 & 1 & 1 & 1 & 1 & 1 & $8 / 10$ \\
\hline Clemson, L.2012 & 1 & 1 & 1 & 1 & 0 & 0 & 1 & 0 & 1 & 1 & 1 & $7 / 10$ \\
\hline Clemson, L.2010 & 1 & 1 & 1 & 1 & 0 & 0 & 1 & 1 & 1 & 1 & 1 & $8 / 10$ \\
\hline Cockayne, S. 2017 & 1 & 1 & 1 & 1 & 0 & 0 & 0 & 1 & 1 & 1 & 1 & $7 / 10$ \\
\hline Covill, L. 2017 & 1 & 1 & 0 & 1 & 0 & 0 & 0 & 0 & 0 & 1 & 1 & $4 / 10$ \\
\hline Cyarto, E. V. 2008 & 1 & 1 & 1 & 0 & 0 & 0 & 1 & 1 & 1 & 1 & 1 & $7 / 10$ \\
\hline Devereux, K. 2005 & 1 & 1 & 1 & 1 & 0 & 0 & 0 & 1 & 1 & 1 & 1 & $7 / 10$ \\
\hline Donath, L. 2014 & 0 & 1 & 0 & 1 & 0 & 0 & 0 & 1 & 0 & 1 & 1 & $5 / 10$ \\
\hline Duque, G.2013 & 1 & 1 & 0 & 1 & 0 & 0 & 1 & 0 & 0 & 1 & 1 & $5 / 10$ \\
\hline El-Khoury, F. 2015 & 1 & 1 & 1 & 1 & 0 & 0 & 1 & 1 & 1 & 1 & 1 & $8 / 10$ \\
\hline Freiberger, E. 2013 & 1 & 1 & 0 & 1 & 0 & 0 & 0 & 1 & 0 & 1 & 1 & $5 / 10$ \\
\hline Freiberger, E. 2012 & 1 & 1 & 1 & 1 & 0 & 0 & 1 & 1 & 1 & 1 & 1 & $8 / 10$ \\
\hline Gallo, E.2018 & 1 & 1 & 0 & 1 & 0 & 0 & 0 & 0 & 0 & 1 & 1 & $4 / 10$ \\
\hline Gine-Garriga, M. 2013 & 1 & 1 & 0 & 1 & 0 & 0 & 0 & 0 & 1 & 1 & 1 & $5 / 10$ \\
\hline Gitlin, L. N. 2006 & 1 & 1 & 1 & 1 & 0 & 0 & 0 & 1 & 1 & 1 & 1 & $7 / 10$ \\
\hline Gschwind, Y.2015 & 0 & 1 & 0 & 1 & 0 & 0 & 0 & 1 & 1 & 1 & 1 & $6 / 10$ \\
\hline Haines, T. P. 2009 & 1 & 1 & 1 & 1 & 0 & 0 & 1 & 1 & 0 & 1 & 1 & $7 / 10$ \\
\hline Halvarsson, A. 2011 & 1 & 1 & 1 & 1 & 0 & 0 & 1 & 1 & 0 & 1 & 1 & $7 / 10$ \\
\hline Hauer, K.2001 & 1 & 1 & 0 & 1 & 0 & 0 & 1 & 0 & 1 & 1 & 1 & $6 / 10$ \\
\hline Henwood, T. R. 2008 & 1 & 1 & 0 & 1 & 0 & 0 & 0 & 0 & 0 & 1 & 1 & $4 / 10$ \\
\hline Iliffe, S. 2014 & 1 & 1 & 1 & 1 & 0 & 0 & 0 & 0 & 1 & 1 & 1 & $6 / 10$ \\
\hline
\end{tabular}




\begin{tabular}{|c|c|c|c|c|c|c|c|c|c|c|c|c|}
\hline PEDro Criteria: & 1 & 2 & 3 & 4 & 5 & 6 & 7 & 8 & 9 & 10 & 11 & Total 10/10 \\
\hline Jagdhane, S. 2016 & 0 & 1 & 0 & 1 & 0 & 0 & 0 & 0 & 0 & 1 & 1 & $4 / 10$ \\
\hline Jeon, M. Y. 2014 & 0 & 1 & 0 & 1 & 0 & 0 & 1 & 1 & 0 & 1 & 1 & $6 / 10$ \\
\hline Josephs, S. 2016 & 1 & 1 & 0 & 1 & 0 & 0 & 1 & 0 & 0 & 1 & 1 & $5 / 10$ \\
\hline Kapan, A. 2016 & 1 & 1 & 0 & 1 & 0 & 0 & 0 & 0 & 1 & 1 & 1 & $5 / 10$ \\
\hline Karinkanta, S. 2012 & 1 & 1 & 0 & 1 & 0 & 0 & 0 & 1 & 1 & 1 & 1 & $6 / 10$ \\
\hline Kim, S. 2009 & 1 & 1 & 0 & 0 & 0 & 0 & 0 & 0 & 0 & 1 & 0 & $2 / 10$ \\
\hline Kyrdalen, I. L.2014 & 1 & 1 & 0 & 1 & 0 & 0 & 1 & 0 & 1 & 1 & 1 & $6 / 10$ \\
\hline Lai, C.H.2013 & 0 & 1 & 0 & 1 & 0 & 0 & 1 & 0 & 0 & 0 & 1 & $4 / 10$ \\
\hline LaStayo, P. 2017 & 1 & 1 & 0 & 1 & 0 & 0 & 1 & 1 & 1 & 1 & 1 & $7 / 10$ \\
\hline Li, F. 2005 & 1 & 1 & 0 & 1 & 0 & 0 & 0 & 0 & 1 & 1 & 1 & $5 / 10$ \\
\hline Li, F\&Harmer.2005 & 1 & 1 & 0 & 1 & 0 & 0 & 0 & 0 & 1 & 1 & 1 & $5 / 10$ \\
\hline Li, F.2019 & 0 & 1 & 0 & 0 & 0 & 0 & 1 & 1 & 1 & 1 & 1 & $6 / 10$ \\
\hline Lin, M. R. 2007 & 1 & 1 & 0 & 1 & 0 & 0 & 1 & 0 & 0 & 1 & 1 & $5 / 10$ \\
\hline Liu, H. 2007 & 1 & 1 & 0 & 1 & 0 & 0 & 1 & 0 & 0 & 1 & 0 & $4 / 10$ \\
\hline Liu, Y. W. 2014 & 1 & 1 & 1 & 1 & 0 & 0 & 1 & 0 & 1 & 1 & 1 & $7 / 10$ \\
\hline Liu-Ambrose, T. 2004 & 1 & 1 & 0 & 1 & 0 & 0 & 0 & 1 & 0 & 1 & 1 & $5 / 10$ \\
\hline Logghe, I. H. J. 2009 & 1 & 1 & 1 & 1 & 0 & 0 & 1 & 1 & 1 & 1 & 1 & $8 / 10$ \\
\hline McCormack, G.2004 & 1 & 1 & 0 & 1 & 0 & 0 & 0 & 0 & 0 & 1 & 1 & $4 / 10$ \\
\hline Oh, S. 2015 & 1 & 1 & 0 & 1 & 0 & 0 & 1 & 0 & 0 & 1 & 1 & $5 / 10$ \\
\hline Okubo, Y.2016 & 1 & 1 & 0 & 1 & 0 & 0 & 0 & 1 & 0 & 1 & 1 & $5 / 10$ \\
\hline Patil, R. 2016 & 1 & 1 & 0 & 1 & 0 & 0 & 1 & 1 & 1 & 1 & 1 & $7 / 10$ \\
\hline Plummer. 2012 & 1 & 1 & 1 & 1 & 0 & 0 & 1 & 1 & 0 & 1 & 1 & $7 / 10$ \\
\hline Pollock, R. D.2012 & 1 & 1 & 1 & 1 & 0 & 0 & 1 & 0 & 0 & 1 & 1 & $6 / 10$ \\
\hline Roller, M. 2018 & 1 & 1 & 0 & 1 & 0 & 0 & 1 & 1 & 0 & 1 & 1 & $6 / 10$ \\
\hline Sattin, R. W. 2005 & 1 & 1 & 0 & 1 & 0 & 0 & 1 & 0 & 1 & 1 & 1 & $6 / 10$ \\
\hline Schoene, D.2015 & 1 & 1 & 0 & 1 & 0 & 0 & 1 & 1 & 1 & 1 & 1 & $7 / 10$ \\
\hline Shigematsu, R. 2008 & 1 & 1 & 0 & 1 & 0 & 0 & 0 & 1 & 1 & 1 & 1 & $6 / 10$ \\
\hline Siegrist, M. 2016 & 1 & 1 & 0 & 1 & 0 & 0 & 0 & 0 & 0 & 1 & 1 & $4 / 10$ \\
\hline Smulders, E.2010 & 1 & 1 & 1 & 1 & 0 & 0 & 1 & 1 & 1 & 1 & 1 & $8 / 10$ \\
\hline Szturm, T. 2011 & 1 & 1 & 1 & 1 & 0 & 0 & 1 & 1 & 0 & 1 & 1 & $7 / 10$ \\
\hline Ullmann, G. 2010 & 1 & 1 & 0 & 1 & 0 & 0 & 0 & 0 & 1 & 1 & 1 & $5 / 10$ \\
\hline Vogler.2009 & 1 & 1 & 1 & 1 & 0 & 0 & 1 & 1 & 1 & 1 & 1 & $8 / 10$ \\
\hline Voukelatos, A.2015 & 1 & 1 & 1 & 1 & 0 & 0 & 0 & 0 & 1 & 1 & 1 & $6 / 10$ \\
\hline Westlake, K. P. 2007 & 1 & 1 & 0 & 1 & 0 & 0 & 0 & 0 & 0 & 1 & 1 & $4 / 10$ \\
\hline Wetherell, J. L. 2018 & 1 & 1 & 1 & 1 & 0 & 0 & 1 & 1 & 1 & 1 & 1 & $8 / 10$ \\
\hline
\end{tabular}




\begin{tabular}{|c|c|c|c|c|c|c|c|c|c|c|c|c|}
\hline PEDro Criteria: & $\mathbf{1}$ & $\mathbf{2}$ & $\mathbf{3}$ & $\mathbf{4}$ & $\mathbf{5}$ & $\mathbf{6}$ & $\mathbf{7}$ & $\mathbf{8}$ & $\mathbf{9}$ & $\mathbf{1 0}$ & $\mathbf{1 1}$ & Total 10/10 \\
\hline Wolf, B.2001 & 1 & 1 & 1 & 1 & 0 & 0 & 1 & 1 & 1 & 1 & 1 & $8 / 10$ \\
\hline Wolf, S. L. 2003 & 1 & 1 & 0 & 1 & 0 & 0 & 1 & 1 & 0 & 1 & 1 & $6 / 10$ \\
\hline Wollesen, B. 2017 & 1 & 1 & 0 & 1 & 0 & 0 & 1 & 1 & 0 & 1 & 0 & $5 / 10$ \\
\hline Wu, G. 2010 & 1 & 1 & 0 & 1 & 0 & 0 & 0 & 0 & 1 & 1 & 1 & $5 / 10$ \\
\hline Yamada, M. 2011 & 1 & 1 & 1 & 1 & 0 & 0 & 1 & 1 & 0 & 1 & 1 & $7 / 10$ \\
\hline Yang, X. J.2012 & 1 & 1 & 1 & 1 & 0 & 0 & 1 & 0 & 1 & 1 & 1 & $7 / 10$ \\
\hline Yoo, E. J. 2010 & 1 & 1 & 0 & 1 & 0 & 0 & 0 & 0 & 0 & 1 & 1 & $4 / 10$ \\
\hline Zhang, L.2014 & 1 & 1 & 1 & 1 & 0 & 0 & 1 & 0 & 1 & 1 & 1 & $7 / 10$ \\
\hline Zhao, Y. 2016 & 1 & 1 & 1 & 1 & 0 & 0 & 1 & 1 & 1 & 1 & 1 & $8 / 10$ \\
\hline
\end{tabular}

Table 6: The number (\%) of trials meeting each criterion of PEDro scale

\begin{tabular}{|l|c|}
\hline \multicolumn{1}{|c|}{ PEDro criteria } & Number (\%) \\
\hline 1. eligibility criteria were specified & $69(92 \%)$ \\
\hline 2. subjects were randomly allocated to groups (in a crossover study, subjects & $75(100 \%)$ \\
\hline 3. allocation was concealed & $31(41 \%)$ \\
\hline 4. the groups were similar at baseline regarding the most important prognostic & $72(96 \%)$ \\
\hline 5. there was blinding of all subjects & $0(0 \%)$ \\
\hline 6. there was blinding of all therapists who administered the therapy & $0(0 \%)$ \\
\hline 7. there was blinding of all assessors who measured at least one key outcome & $46(61 \%)$ \\
\hline 8. measures of at least one key outcome were obtained from more than 85\% & $42(56 \%)$ \\
\hline $\begin{array}{l}\text { 9. all subjects for whom outcome measures were available received the treatment or control } \\
\text { condition as allocated or, where this was not the case, data for at least one key outcome was } \\
\text { analyzed by "intention to treat" }\end{array}$ & $39(52 \%)$ \\
\hline 10. the results of between-group statistical comparisons are reported for at least one & $74(99 \%)$ \\
\hline $\begin{array}{l}\text { 11. the study provides both point measures and measures of variability for at least one key } \\
\text { outcome }\end{array}$ & $72(96 \%)$ \\
\hline
\end{tabular}

\subsection{Exercise Prescription}

Table 7 illustrates the detailed characteristics of exercise prescription for all trials. Thirtythree trials applied multicomponent exercise interventions (e.g., balance, resistance, endurance, and coordination), 14 used balance exercises, 11 used three-dimensional (3D) exercises (i.e., Tai 
Chi and Pilates), seven used strengthening exercises, four used aerobic exercises, and six used novel exercises (i.e., water-based exercise, Feldenkrais, video games, whole-body vibration, and fall training). Fifty-two trials explicitly reported the repetition/duration and sets of the exercises, and 16 trials provided values for the intensity of the exercise interventions. The intensity was mainly measured with the 1 Repetition Maximum (1RM) for strengthening exercise; the Borg Scale for the Rating of Perceived Exertion (RPE) for strengthening, balance, and multicomponent exercises; or the Maximum Heart Rate (HR max) for aerobic exercise. No adverse effects of exercise interventions were reported in the included trials.

The exercise dosage varied across the 75 trials. The mode of exercise frequency was 3 times per week for 12 weeks. The intensity was between $30 \%$ and $85 \%$ of the $1 \mathrm{RM}$ and 7 to 14 on the RPE. The duration of each exercise session was between 15 and 135 minutes (median $=60$ [interquartile range $=45-60]$ ). The most common types of equipment used in the trials were ankle weights, resistive bands, different exercise balls (e.g., stability ball and medicine ball), and stability trainers.

Among 47 trials that showed significant intragroup or intergroup improvements in FOF outcome measures, most trials used multicomponent exercises (23 trials) and group-based interventions, moderate-intensity (a RPE of 12 or 13, an HR max of $64 \%-76 \%$, or a 1 RM of $60 \%-70 \%$ ), 3 times per week for 12 to 16 weeks, and 30 to 60 minutes for each exercise session.

Table 8 is a summary of the main findings in included studies. No patterns were observed regarding the relationship between the significant outcomes in FOF reduction and other variables (i.e., significance on physical performance outcomes, number of exercise principles reported in each study, number of FITT reported in each study, and PEDro scores). 
Table 7: Exercise prescription characteristics

\begin{tabular}{|c|c|c|c|c|c|c|c|}
\hline Fist Author. year & Type of Exercises & Reps/Min*sets & Intensity & $\begin{array}{c}\text { Frequency } \\
\text { (times*weeks) }\end{array}$ & $\begin{array}{l}\text { time(min/ } \\
\text { session })\end{array}$ & Warm Up & Cool Down \\
\hline Arai, T. 2007 & $\begin{array}{l}\text { Resistance\&balance } \\
\text { \&functional }\end{array}$ & $\mathrm{n}$ & $>60 \%$ of $1 \mathrm{RM}$ & $2 * 12$ & 90 & $10-15 \mathrm{mins}$ & $10 \mathrm{~min}$ \\
\hline Arantes, M. 2015 & Balance & $0.5 \min * 4 ; 15 * 2$ & $\begin{array}{l}\text { Maintain } \\
\text { challenging }\end{array}$ & $2 * 12$ & 60 & $\mathrm{n}$ & $\mathrm{n}$ \\
\hline Arkkukangas, M.2015 & OEP & $\mathrm{n}$ & $\mathrm{n}$ & $3 * 12$ & 30 & $\mathrm{n}$ & $\mathrm{n}$ \\
\hline Arkkukangas, M.2019 & OEP & $\mathrm{n}$ & unclear & $3 * 12$ & 30 & $\mathrm{n}$ & $\mathrm{n}$ \\
\hline Bao, T. 2018 & Balance exercises & $30 \mathrm{~s} * 6$ & VAS of 3 & $3 * 8$ & 45 & $\mathrm{n}$ & $\mathrm{n}$ \\
\hline Barban, F.2017 & Balance\&Gait & $\mathrm{n}$ & $\mathrm{n}$ & $2 * 12$ & 60 & $\mathrm{y}$ & $\mathrm{n}$ \\
\hline Barnett, A. 2003 & $\begin{array}{c}\text { Balance\&Coordination\&Aer } \\
\text { obic\&Strength }\end{array}$ & $\mathrm{n}$ & $\mathrm{n}$ & $\mathrm{n}$ & $\mathrm{n}$ & $5-10 \mathrm{~min}$ & $10 \mathrm{~min}$ \\
\hline Beyer, N. 2007 & Strength\&Balance & 10 reps $* 3$ & $70-75 \% 1 \mathrm{RM}$ & $2 * 24$ & 60 & $10 \mathrm{~min}$ & $5 \mathrm{~min}$ \\
\hline Boogird. 2017 & Modified-OEP & $\mathrm{n}$ & $\mathrm{n}$ & $\mathrm{n}$ & $\mathrm{n}$ & $\mathrm{n}$ & $\mathrm{n}$ \\
\hline Brouwer, B. 2003 & Low-resistance & $\mathrm{n}$ & $\mathrm{n}$ & $1 * 8$ & 60 & $10 \mathrm{~min}$ & $10 \mathrm{~min}$ \\
\hline Campbell, A. J.1997 & Strength\&Balance & $\mathrm{n}$ & unclear & $3 * 48$ & 30 & $\mathrm{n}$ & $\mathrm{n}$ \\
\hline Clemson, L.2012 & Balance\&Strength & $\mathrm{n}$ & unclear & $3 * 48$ & $\mathrm{n}$ & $\mathrm{n}$ & $\mathrm{n}$ \\
\hline
\end{tabular}




\begin{tabular}{|c|c|c|c|c|c|c|c|}
\hline Fist Author. year & Type of Exercises & Reps/Min*sets & Intensity & $\begin{array}{c}\text { Frequency } \\
\text { (times*weeks) }\end{array}$ & $\begin{array}{l}\text { time }(\mathrm{min} / \\
\text { session })\end{array}$ & Warm Up & Cool Down \\
\hline Clemson, L.2010 & Balance\&Strength & $\mathrm{n}$ & $\mathrm{n}$ & $\mathrm{n}$ & $\mathrm{n}$ & $\mathrm{n}$ & $\mathrm{n}$ \\
\hline Cockayne, S. 2017 & Foot and ankle exercises & $10 * 3$ & $\mathrm{n}$ & $3 * 24$ & 30 & $\mathrm{n}$ & $\mathrm{n}$ \\
\hline Covill, L. 2017 & Tai Chi & $\mathrm{n}$ & $\mathrm{n}$ & $\mathrm{n}$ & $30-40$ & $5-10 \mathrm{~min}$ & $5 \mathrm{~min}$ \\
\hline Cyarto, E. V. 2008 & $\begin{array}{l}\text { Group resistance } \\
\text { Home balance }\end{array}$ & $\begin{array}{c}n \\
5-15^{* 2}\end{array}$ & $\mathrm{n}$ & $2 * 20$ & 60 & $\mathrm{y}$ & $10 \mathrm{~min}$ \\
\hline Devereux, K. 2005 & Water-based exercise & $\mathrm{n}$ & $\mathrm{n}$ & $2 * 10$ & $50 \mathrm{~min}$ & $\mathrm{n}$ & $\mathrm{n}$ \\
\hline Donath, L. 2014 & Fall-training & $\mathrm{n}$ & $\mathrm{n}$ & $2 * 6$ & 60 & $10 \mathrm{~min}$ & $5 \mathrm{~min}$ \\
\hline Duque, G.2013 & Balance & $\mathrm{n}$ & 15 levels & $2 * 6$ & 30 & $\mathrm{n}$ & $\mathrm{n}$ \\
\hline El-Khoury, F. 2015 & Balance & $\mathrm{n}$ & $\begin{array}{l}\text { Increase in } \\
\text { intensity }\end{array}$ & $1 * 96$ & 60 & $\mathrm{n}$ & $\mathrm{n}$ \\
\hline Freiberger, E. 2013 & $\begin{array}{c}\text { Strength\&Balance\&Enduran } \\
\text { ce }\end{array}$ & $\mathrm{n}$ & RPE & $1 * 16$ & 60 & $10 \mathrm{~min}$ & $5-10 \mathrm{~min}$ \\
\hline Freiberger, E. 2012 & $\begin{array}{c}\text { Strength\&Balance\&Enduran } \\
\text { ce }\end{array}$ & $\mathrm{n}$ & RPE & $1 * 16$ & 60 & $10 \mathrm{~min}$ & $10 \mathrm{~min}$ \\
\hline Gallo, E.2018 & Balance\&Gait & $\mathrm{n}$ & unclear & $5 * 26$ & 24 & $\mathrm{n}$ & $\mathrm{n}$ \\
\hline Gine-Garriga, M. 2013 & Functional balance & unclear*4 & $\mathrm{n}$ & $1 * 12$ & $\mathrm{n}$ & $10 \mathrm{~min}$ & $5 \mathrm{~min}$ \\
\hline
\end{tabular}




\begin{tabular}{|c|c|c|c|c|c|c|c|}
\hline Fist Author. year & Type of Exercises & Reps/Min*sets & Intensity & $\begin{array}{c}\text { Frequency } \\
\text { (times*weeks) }\end{array}$ & $\begin{array}{l}\text { time(min/ } \\
\text { session })\end{array}$ & Warm Up & Cool Down \\
\hline & -strength & $6-8-15$ reps $* 1-2$ & RPE 12-14 & $1 * 12$ & $\mathrm{n}$ & & \\
\hline Gitlin,L.N. 2006 & Balance\&Strength & $\mathrm{n}$ & $\mathrm{n}$ & $\mathrm{n}$ & $\mathrm{n}$ & $\mathrm{n}$ & $\mathrm{n}$ \\
\hline Gschwind, Y.2015 & Balance\&Strength & $10-15$ reps $* 2-3$ & unclear & $6 * 16$ & 60 & $\mathrm{n}$ & $\mathrm{n}$ \\
\hline Haines, T.P. 2009 & Strength\&Balance & $3-10$ reps*1 & $\mathrm{n}$ & $\mathrm{n}$ & $\mathrm{n}$ & $\mathrm{n}$ & $\mathrm{n}$ \\
\hline Halvarsson, A. 2011 & $\begin{array}{l}\text { Balance with dual or multi- } \\
\text { tasks }\end{array}$ & $\mathrm{n}$ & $\mathrm{n}$ & $3 * 12$ & 45 & $\mathrm{y}$ & $\mathrm{y}$ \\
\hline Hauer, K.2001 & Resistance\&Balance & $10-15$ reps $* 2-3$ & $79-90 \% \mathrm{MW}$ & $3 * 12$ & 135 & $10 \mathrm{~min}$ & $\mathrm{n}$ \\
\hline \multirow{3}{*}{ Henwood, T. R. 2008} & Conditioning & \multirow{3}{*}{$8 * 3$} & $65 \%-70 \% 1 \mathrm{RM}$ & & \multirow{3}{*}{60} & \multirow{3}{*}{$10 \mathrm{~min}$} & \multirow{3}{*}{$\mathrm{y}$} \\
\hline & Strength & & $75 \% 1 \mathrm{RM}$ & $2 * 24$ & & & \\
\hline & High-velocity & & $40-75 \% 1 \mathrm{RM}$ & & & & \\
\hline \multirow{3}{*}{ Iliffe, S. 2014} & FaME & & More intense & $3 * 24$ & 90 & \multirow{3}{*}{$\mathrm{n}$} & \multirow{3}{*}{$\mathrm{n}$} \\
\hline & & $\mathrm{n}$ & than OEP & & & & \\
\hline & OEP & & Moderate & $3 * 24$ & 30 & & \\
\hline Jagdhane, S. 2016 & APA-focused training & $10 \min * 3-4$ & unclear & $3 * 4$ & 60 & $5-7 \mathrm{~min}$ & $5-7 \mathrm{~min}$ \\
\hline Jeon,M.Y. 2014 & $\begin{array}{c}\text { Strength\&Endurance\&Balan } \\
\text { ce }\end{array}$ & $\mathrm{n}$ & $\mathrm{n}$ & $3 * 12$ & 80 & $\mathrm{n}$ & $\mathrm{n}$ \\
\hline
\end{tabular}




\begin{tabular}{|c|c|c|c|c|c|c|c|}
\hline Fist Author. year & Type of Exercises & Reps/Min*sets & Intensity & $\begin{array}{c}\text { Frequency } \\
\text { (times*weeks) }\end{array}$ & $\begin{array}{l}\text { time(min/ } \\
\text { session) }\end{array}$ & Warm Up & Cool Down \\
\hline \multirow{3}{*}{ Josephs, S. 2016} & Pilates & 10rep*1 & \multirow{3}{*}{ RPE12-14 } & \multirow{3}{*}{$2 * 12$} & \multirow{3}{*}{60} & \multirow{3}{*}{$\mathrm{n}$} & \multirow{3}{*}{$\mathrm{n}$} \\
\hline & & & & & & & \\
\hline & Resistance\&Balance & Individualized & & & & & \\
\hline Kapan, A. 2016 & Balance\&Strength & $12-15$ reps $* 2$ & $\mathrm{n}$ & $2 * 12$ & 60 & $10 \mathrm{~min}$ & $\mathrm{n}$ \\
\hline \multirow{4}{*}{ Karinkanta, S. 2012} & Resistance & $10-15 * 2$ & $50-80 \% 1 \mathrm{RM}$ & \multirow{4}{*}{$3 * 48$} & \multirow{4}{*}{$40-50$} & \multirow{4}{*}{$7-10 \mathrm{~min}$} & \multirow{4}{*}{$8-10 \mathrm{~min}$} \\
\hline & & Or $8-10 * 3$ & RPE18-20 & & & & \\
\hline & Balance-jumping & $\mathrm{n}$ & $\mathrm{n}$ & & & & \\
\hline & $\begin{array}{l}\text { Resistance\&Balance- } \\
\text { jumping training }\end{array}$ & $\mathrm{n}$ & $\mathrm{n}$ & & & & \\
\hline \multirow{3}{*}{ Kim, S. 2009} & Balance & $\mathrm{n}$ & $\mathrm{n}$ & \multirow{3}{*}{$3 * 8$} & \multirow{3}{*}{50 to 60} & \multirow{3}{*}{$\mathrm{n}$} & \multirow{3}{*}{$\mathrm{n}$} \\
\hline & & & & & & & \\
\hline & Strength & $10 * 3-7 * 3$ & $50 \%-85 \% \mathrm{ME}$ & & & & \\
\hline Kyrdalen, I. L.2014 & OEP & $\mathrm{n}$ & $\mathrm{n}$ & $2 * 12$ & 45 & $\mathrm{n}$ & $\mathrm{n}$ \\
\hline Lai, C.H.2013 & $\begin{array}{l}\text { interactive video-game } \\
\text { based (IVGB) training }\end{array}$ & $\mathrm{n}$ & $\mathrm{n}$ & $3 * 6$ & 30 & $\mathrm{n}$ & $\mathrm{n}$ \\
\hline \multirow{3}{*}{ LaStayo, P. 2017} & TRAD resistance & $15 * 3:$ & $60-70 \% 1 \mathrm{RM}$ & \multirow{3}{*}{$3 * 12$} & \multirow{3}{*}{60} & \multirow{3}{*}{$\mathrm{n}$} & \multirow{3}{*}{$\mathrm{n}$} \\
\hline & & & & & & & \\
\hline & RENEW & $3-15 \min$ & RPE7-13 & & & & \\
\hline Li, F. 2005 & Tai chi & $\mathrm{n}$ & $\mathrm{n}$ & $3 * 26$ & 60 & $5-10 \mathrm{~min}$ & $5-10 \mathrm{~min}$ \\
\hline
\end{tabular}




\begin{tabular}{|c|c|c|c|c|c|c|c|}
\hline Fist Author. year & Type of Exercises & Reps/Min*sets & Intensity & $\begin{array}{c}\text { Frequency } \\
\text { (times*weeks) }\end{array}$ & $\begin{array}{l}\text { time(min/ } \\
\text { session) }\end{array}$ & Warm Up & Cool Down \\
\hline & Stretching & & Low intensity & & & $\mathrm{n}$ & $\mathrm{n}$ \\
\hline Li, F\&Harmer.2005 & Tai Chi & $\mathrm{n}$ & $\mathrm{n}$ & $3 * 26$ & $\mathrm{n}$ & $5-10 \mathrm{~min}$ & $5-10 \mathrm{~min}$ \\
\hline \multirow[b]{2}{*}{ Li, F.2019 } & Tai Ji Quan & $4-5$ reps $* 3-6$ & \multirow[b]{2}{*}{$\mathrm{n}$} & \multirow[b]{2}{*}{$2 * 24$} & \multirow[b]{2}{*}{60} & \multirow[b]{2}{*}{$\mathrm{n}$} & \multirow[b]{2}{*}{$\mathrm{n}$} \\
\hline & $\begin{array}{c}\text { Multimodal (Aerobics, } \\
\text { Balance, Strength, } \\
\text { Flevihilitv) }\end{array}$ & 4-30rep*1 & & & & & \\
\hline Lin, M.R. 2007 & Strength\&Balance & $\mathrm{n}$ & $\mathrm{n}$ & $3 * 16$ & 50 & 10 & 10 \\
\hline \multirow{2}{*}{ Liu, H. 2007} & Resistance\&Balance & $10 * 1-2$ & individualized & \multirow{2}{*}{$3 * 12$} & \multirow{2}{*}{60} & \multirow{2}{*}{$5 \mathrm{~min}$} & \multirow{2}{*}{$10-15 \mathrm{~min}$} \\
\hline & $\mathrm{ROM}$ & $5-10 * 2$ & Same intensity & & & & \\
\hline Liu, Y. W. 2014 & Tai chi & $\mathrm{n}$ & $\mathrm{n}$ & $1 * 8$ & 60 & 5 & 5 \\
\hline \multirow{4}{*}{ Liu-Ambrose, T. 2004} & Resistance & $10-15 * 2-6-8 * 2$ & $50-85 \% 1 \mathrm{RM}$ & \multirow{4}{*}{$2 * 13$} & \multirow{4}{*}{50} & \multirow{4}{*}{$\mathrm{n}$} & \multirow{4}{*}{$\mathrm{n}$} \\
\hline & Agility & & & & & & \\
\hline & & $\mathrm{n}$ & $\mathrm{n}$ & & & & \\
\hline & Stretching & & & & & & \\
\hline Logghe, I. H. J. 2009 & Tai chi & $\mathrm{n}$ & $\mathrm{n}$ & $2 * 13$ & 60 & $\mathrm{y}$ & $\mathrm{y}$ \\
\hline
\end{tabular}




\begin{tabular}{|c|c|c|c|c|c|c|c|}
\hline Fist Author. year & Type of Exercises & Reps/Min*sets & Intensity & $\begin{array}{c}\text { Frequency } \\
\text { (times*weeks) }\end{array}$ & $\begin{array}{l}\text { time(min/ } \\
\text { session) }\end{array}$ & Warm Up & Cool Down \\
\hline McCormack, G.2004 & Strength & $\mathrm{n}$ & Low intensity & $2 * 10$ & $30-45$ & $\mathrm{y}$ & $\mathrm{y}$ \\
\hline Oh, S. 2014 & $\begin{array}{l}\text { Water-based } \\
\text { Land-based }\end{array}$ & $\mathrm{n}$ & RPE 4/10 & $3 * 10$ & 60 & $10 \mathrm{~min}$ & $10 \mathrm{~min}$ \\
\hline Okubo, Y.2016 & Brist walking & $\mathrm{n} / \mathrm{a}$ & $\begin{array}{c}\text { light-somewhat } \\
\text { hard }\end{array}$ & $3-5 * 12$ & $30-50$ & $10-15 \mathrm{~min}$ & $10-15 \mathrm{~min}$ \\
\hline & OEP\&Tai Chi & 10-20rep & $\mathrm{n}$ & $3-5 * 12$ & $45-60$ & $\mathrm{n}$ & $\mathrm{n}$ \\
\hline Patil, R. 2016 & $\begin{array}{l}\text { Resistance\&Balance\& } \\
\text { Agility\&mobility }\end{array}$ & $8-12 * 2$ & $\begin{array}{c}\text { 30-75\%1RM; } \\
\text { RPE14-18 }\end{array}$ & $2 * 48-1 * 48$ & 60 & $10 \mathrm{~min}$ & $\mathrm{n}$ \\
\hline Plummer. 2012 & Balance\&Gait\&Agility & $\mathrm{n}$ & $\mathrm{n}$ & $1 * 4$ & 45 & $\mathrm{n}$ & $\mathrm{n}$ \\
\hline Pollock, R. D.2012 & $\begin{array}{c}\text { Strength\&Balance\&Functio } \\
\text { nal mobility }\end{array}$ & $\mathrm{n}$ & $\mathrm{n}$ & $3 * 8$ & 60 & $\mathrm{n}$ & $\mathrm{n}$ \\
\hline Roller, M. 2017 & Pilates & $10 * 1$ & $\mathrm{n}$ & $1 * 10$ & 45 & $\mathrm{n}$ & $\mathrm{n}$ \\
\hline Sattin, R. W. 2005 & Tai Chi & $\mathrm{n}$ & $\mathrm{n}$ & $2 * 48$ & $60-90$ & $\mathrm{y}$ & $\mathrm{y}$ \\
\hline Schoene, D.2015 & Balance & $\mathrm{n}$ & unclear & $3 * 16$ & 20 & $\mathrm{n}$ & $\mathrm{n}$ \\
\hline Shigematsu, R. 2008 & $\begin{array}{c}\text { Square-stepping } \\
\text { Strength\&Balance }\end{array}$ & $10 * 3$ & $\mathrm{n}$ & $2 * 12$ & 70 & $15 \mathrm{~min}$ & $15 \mathrm{~min}$ \\
\hline
\end{tabular}




\begin{tabular}{|c|c|c|c|c|c|c|c|}
\hline Fist Author. year & Type of Exercises & Reps/Min*sets & Intensity & $\begin{array}{c}\text { Frequency } \\
\text { (times*weeks) }\end{array}$ & $\begin{array}{l}\text { time(min/ } \\
\text { session) }\end{array}$ & Warm Up & Cool Down \\
\hline Siegrist, M. 2016 & $\begin{array}{c}\text { Strength\&Power\&Balance\& } \\
\text { gait }\end{array}$ & $\mathrm{n}$ & $\mathrm{n}$ & $1 * 16$ & 60 & $\mathrm{n}$ & $\mathrm{n}$ \\
\hline Smulders, E.2010 & Weight-bearing\&walking & $\mathrm{n}$ & $\mathrm{n}$ & $2 * 5.5$ & $15-60$ & $\mathrm{n}$ & $\mathrm{n}$ \\
\hline Szturm, T. & Balance & $\mathrm{n}$ & $\mathrm{n}$ & $2 * 8$ & 45 & $\mathrm{n}$ & $\mathrm{n}$ \\
\hline Ullmann, G. 2010 & Feldenkrais & $\mathrm{n}$ & $\mathrm{n}$ & $3 * 5$ & 60 & $\mathrm{n}$ & $\mathrm{n}$ \\
\hline Vogler.2009 & $\begin{array}{l}\text { Seated exercise } \\
\text { Weight bearing }\end{array}$ & $10-12$ reps & $10-12 \mathrm{RM}$ & $3 * 12$ & $\mathrm{n}$ & $\mathrm{n}$ & $\mathrm{n}$ \\
\hline Voukelatos, A.2015 & Walking & $\mathrm{n}$ & unclear & $\mathrm{n}$ & $\mathrm{n}$ & $\mathrm{n}$ & $\mathrm{n}$ \\
\hline Westlake, K. P. 2007 & Balance & $\mathrm{n}$ & $\mathrm{n}$ & $3 * 8$ & 60 & $\mathrm{n}$ & $\mathrm{n}$ \\
\hline Wetherell, J. L. 2018 & Strength\&Balance & $\mathrm{n}$ & $\mathrm{n}$ & $1 * 8$ & 60 & $\mathrm{n}$ & $\mathrm{n}$ \\
\hline Wolf, B.2001 & Balance & $\mathrm{n}$ & $\mathrm{n}$ & $2-3 * 4-6$ & 30 & $\mathrm{n}$ & $\mathrm{n}$ \\
\hline \multirow[b]{2}{*}{ Wolf, S. L. 2003} & Tai Chi & & & $14 * 15$ & $>15$ & & \\
\hline & Balance & $\mathrm{n}$ & $\mathrm{n}$ & $\mathrm{n}$ & $\mathrm{n}$ & $\mathrm{n}$ & $\mathrm{n}$ \\
\hline Wollesen, B. 2017 & Dual task & $\mathrm{n}$ & $\mathrm{n}$ & $1 * 12$ & 60 & $\mathrm{n}$ & $\mathrm{n}$ \\
\hline
\end{tabular}


Wu, G. 2010

Tai Chi

Rhythmic stepping

Strength\&Balance

Walking

Whole-body vibration

Balance

Zhao, Y. 2016

Yoo, E. J. 2010

Zhang, L.2014

Note. n: not reported; 1RM:1 repetition maximum; VAS: visual analogue scale; RPE: rating of perceived exertion; ME: maximum exertion; MW: maximum workload; OEP: Otago exercise programme including leg muscle strengthening and balance exercises; FaME: falls management exercise including balance, strength, endurance, flexibility, functional floor skills, and adapted Tai Chi; APA: anticipatory postural adjustments; TRAD: traditional resistance exercise; RENEW: resistance exercise via negative, eccentrically-induced work; ROM: range of motion.

Table 8: Summary of main findings in included studies

\begin{tabular}{|c|c|c|c|c|c|c|c|}
\hline Fist Author. Year & $\begin{array}{c}\text { FOF } \\
\text { measure }\end{array}$ & $\begin{array}{c}\text { Is FOF primary } \\
\text { outcome } \\
\text { measure }\end{array}$ & $\begin{array}{l}\text { Significant reduction } \\
\text { in FOF outcomes }\end{array}$ & $\begin{array}{l}\text { Significance on } \\
\text { physical } \\
\text { performance } \\
\text { measures }\end{array}$ & $\begin{array}{l}\text { No. of EP } \\
\text { reported }\end{array}$ & $\begin{array}{l}\text { No. of FITT } \\
\text { reported }\end{array}$ & PEDro score \\
\hline Arai, T. 2007 & FES & $\mathrm{y}$ & $\mathrm{n}$ & $\mathrm{y}$ & 4 & 4 & 5 \\
\hline Arantes, M. 2015 & FES-I & $\mathrm{y}$ & $\mathrm{y}$ & $\mathrm{y}$ & 3 & 3 & 7 \\
\hline
\end{tabular}




\begin{tabular}{|c|c|c|c|c|c|c|c|}
\hline Fist Author. Year & $\begin{array}{c}\text { FOF } \\
\text { measure }\end{array}$ & $\begin{array}{c}\text { Is FOF primary } \\
\text { outcome } \\
\text { measure }\end{array}$ & $\begin{array}{l}\text { Significant reduction } \\
\text { in FOF outcomes }\end{array}$ & $\begin{array}{c}\text { Significance on } \\
\text { physical } \\
\text { performance } \\
\text { measures }\end{array}$ & $\begin{array}{l}\text { No. of EP } \\
\text { reported }\end{array}$ & $\begin{array}{l}\text { No. of FITT } \\
\text { reported }\end{array}$ & PEDro score \\
\hline Arkkukangas, M.2015 & FES & $\mathrm{y}$ & $\mathrm{n}$ & $\mathrm{n}$ & 3 & 3 & 6 \\
\hline Arkkukangas, M.2019 & FES & $\mathrm{y}$ & $\mathrm{n}$ & $\mathrm{n}$ & 4 & 3 & 7 \\
\hline Bao, T. 2018 & $\mathrm{ABC}$ & $\mathrm{n}$ & $\mathrm{n}$ & $\mathrm{y}$ & 4 & 4 & 7 \\
\hline Barban, F.2017 & FES-I & $\mathrm{y}$ & $\mathrm{y}$ & $\mathrm{y}$ & 3 & 3 & 7 \\
\hline Barnett, A. 2003 & Single item & $\mathrm{n}$ & $\mathrm{n}$ & $\mathrm{y}$ & 2 & 1 & 8 \\
\hline Beyer, N. 2007 & $\mathrm{ABC}$ & $\mathrm{y}$ & $\mathrm{n}$ & $\mathrm{y}$ & 5 & 4 & 5 \\
\hline Boongird. 2017 & FES-I & $\mathrm{y}$ & $\mathrm{y}$ & $\mathrm{n}$ & 3 & 1 & 6 \\
\hline Brouwer, B. 2003 & $\mathrm{ABC}$ & $\mathrm{y}$ & $\mathrm{y}$ & $\mathrm{y}$ & 2 & 3 & 6 \\
\hline Campbell, A. J.1997 & FES & $\mathrm{n}$ & $\mathrm{y}$ & $\mathrm{y}$ & 3 & 3 & 8 \\
\hline Clemson, L.2012 & $\mathrm{ABC}$ & $\mathrm{n}$ & $\mathrm{y}$ & $\mathrm{y}$ & 4 & 2 & 7 \\
\hline Clemson, L.2010 & ABC/MFES & $\mathrm{n}$ & $\mathrm{y}$ & $\mathrm{y}$ & 3 & 1 & 8 \\
\hline Cockayne, S. 2017 & Short-FES-I & $\mathrm{n}$ & $\mathrm{n}$ & $\mathrm{n} / \mathrm{a}$ & 2 & 4 & 7 \\
\hline Covill, L. 2017 & $\mathrm{ABCI}$ & $\mathrm{n}$ & $\mathrm{n}$ & $\mathrm{y}$ & 4 & 2 & 4 \\
\hline Cyarto, E. V. 2008 & $\mathrm{ABC}$ & $\mathrm{y}$ & $\mathrm{y}$ & $\mathrm{y}$ & 3 & 3 & 7 \\
\hline Devereux, K. 2005 & MFES & $\mathrm{y}$ & $\mathrm{n}$ & $\mathrm{y}$ & 1 & 3 & 7 \\
\hline Donath, L. 2014 & FES-I & $\mathrm{y}$ & $\mathrm{n}$ & $\mathrm{n}$ & 2 & 3 & 5 \\
\hline Duque, G.2013 & SAFE & $\mathrm{y}$ & $\mathrm{y}$ & $\mathrm{y}$ & 4 & 4 & 5 \\
\hline El-Khoury, F. 2015 & FES-I & $\mathrm{n}$ & $\mathrm{n}$ & $\mathrm{y}$ & 3 & 3 & 8 \\
\hline
\end{tabular}




\begin{tabular}{|c|c|c|c|c|c|c|c|}
\hline Fist Author. Year & $\begin{array}{c}\text { FOF } \\
\text { measure }\end{array}$ & $\begin{array}{c}\text { Is FOF primary } \\
\text { outcome } \\
\text { measure }\end{array}$ & $\begin{array}{l}\text { Significant reduction } \\
\text { in FOF outcomes }\end{array}$ & $\begin{array}{c}\text { Significance on } \\
\text { physical } \\
\text { performance } \\
\text { measures }\end{array}$ & $\begin{array}{l}\text { No. of EP } \\
\text { reported }\end{array}$ & $\begin{array}{l}\text { No. of FITT } \\
\text { reported }\end{array}$ & PEDro score \\
\hline Freiberger, E. 2013 & FES-I & $\mathrm{y}$ & $\mathrm{y}$ & $\mathrm{y}$ & 2 & 3 & 5 \\
\hline Freiberger, E. 2012 & $\mathrm{ABC}$ & $\mathrm{y}$ & $\mathrm{n}$ & $\mathrm{y}$ & 4 & 3 & 8 \\
\hline Gallo, E.2018 & $\mathrm{ABC}$ & $\mathrm{n}$ & $\mathrm{y}$ & $\mathrm{y}$ & 4 & 3 & 4 \\
\hline Gine-Garriga, M. 2013 & $\mathrm{ABC}$ & $\mathrm{y}$ & $\mathrm{y}$ & $\mathrm{n} / \mathrm{a}$ & 4 & 3 & 5 \\
\hline Gitlin, L. N. 2006 & FES & $\mathrm{n}$ & $\mathrm{y}$ & $\mathrm{y}$ & 2 & 1 & 7 \\
\hline Gschwind, Y.2015 & Icon-FES & $\mathrm{y}$ & $\mathrm{n}$ & $\mathrm{y}$ & 4 & 4 & 6 \\
\hline Haines, T. P. 2009 & $\mathrm{ABC}$ & $\mathrm{y}$ & $\mathrm{n}$ & $\mathrm{n}$ & 5 & 1 & 7 \\
\hline Halvarsson, A. 2011 & FES-I & $\mathrm{y}$ & $\mathrm{y}$ & $\mathrm{y}$ & 4 & 3 & 7 \\
\hline Hauer, K.2001 & $\begin{array}{l}\text { Subjective } \\
\text { rating of } \\
\text { FOF }\end{array}$ & $\mathrm{n}$ & $\mathrm{y}$ & $\mathrm{y}$ & 4 & 4 & 6 \\
\hline Henwood, T. R. 2008 & $\mathrm{ABC}$ & $\mathrm{n}$ & $\mathrm{n}$ & $\mathrm{y}$ & 4 & 4 & 4 \\
\hline Iliffe, S. 2014 & $\begin{array}{c}\text { FES- } \\
\text { I/CONFbal }\end{array}$ & $\mathrm{n}$ & $\mathrm{y}$ & $\mathrm{n}$ & 5 & 3 & 6 \\
\hline Jagdhane, S. 2016 & $\mathrm{ABC}$ & $\mathrm{n}$ & $\mathrm{n}$ & $\mathrm{y}$ & 2 & 3 & 4 \\
\hline Jeon, M. Y. 2014 & FES & $\mathrm{y}$ & $\mathrm{y}$ & $\mathrm{y}$ & 1 & 3 & 6 \\
\hline Josephs, S. 2016 & $\mathrm{ABC}$ & $\mathrm{y}$ & $\mathrm{y}$ & $\mathrm{y}$ & 3 & 4 & 5 \\
\hline Kapan, A. 2016 & FES-I & $\mathrm{y}$ & $\mathrm{y}$ & $\mathrm{y}$ & 1 & 3 & 5 \\
\hline
\end{tabular}




\begin{tabular}{|c|c|c|c|c|c|c|c|}
\hline Fist Author. Year & $\begin{array}{c}\text { FOF } \\
\text { measure }\end{array}$ & $\begin{array}{c}\text { Is FOF primary } \\
\text { outcome } \\
\text { measure }\end{array}$ & $\begin{array}{l}\text { Significant reduction } \\
\text { in FOF outcomes }\end{array}$ & $\begin{array}{c}\text { Significance on } \\
\text { physical } \\
\text { performance } \\
\text { measures }\end{array}$ & $\begin{array}{l}\text { No. of EP } \\
\text { reported }\end{array}$ & $\begin{array}{l}\text { No. of FITT } \\
\text { reported }\end{array}$ & PEDro score \\
\hline Karinkanta, S. 2012 & VAS & $\mathrm{y}$ & $\mathrm{n}$ & $\mathrm{n} / \mathrm{a}$ & 4 & 4 & 6 \\
\hline Kim, S. 2009 & Single item & $\mathrm{y}$ & $\mathrm{y}$ & $\mathrm{n} / \mathrm{a}$ & 3 & 4 & 2 \\
\hline Kyrdalen, I. L.2014 & FES-I & $\mathrm{n}$ & $\mathrm{y}$ & $\mathrm{y}$ & 4 & 3 & 6 \\
\hline Lai, C.H.2013 & MFES & $\mathrm{y}$ & $\mathrm{y}$ & $\mathrm{y}$ & 0 & 2 & 4 \\
\hline LaStayo, P. 2017 & $\mathrm{ABC}$ & $\mathrm{y}$ & $\mathrm{y}$ & $\mathrm{n}$ & 4 & 4 & 7 \\
\hline Li, F. 2005 & $\mathrm{ABC}$ & $\mathrm{y}$ & $\mathrm{y}$ & $\mathrm{n} / \mathrm{a}$ & 2 & 3 & 5 \\
\hline Li, F\&Harmer.2005 & SAFE & $\mathrm{n}$ & $\mathrm{y}$ & $\mathrm{y}$ & 3 & 1 & 5 \\
\hline Li, F.2019 & $\mathrm{ABC}$ & $\mathrm{y}$ & $\mathrm{y}$ & $\mathrm{y}$ & 3 & 3 & 6 \\
\hline Lin, M. R. 2007 & VAS & $\mathrm{n}$ & $\mathrm{y}$ & $\mathrm{y}$ & 4 & 3 & 5 \\
\hline Liu, H. 2007 & FES & $\mathrm{y}$ & $\mathrm{y}$ & $\mathrm{y}$ & 3 & 3 & 4 \\
\hline Liu, Y. W. 2014 & FES-I & $\mathrm{y}$ & $\mathrm{y}$ & $\mathrm{n}$ & 1 & 3 & 7 \\
\hline Liu-Ambrose, T. 2004 & $\mathrm{ABC}$ & $\mathrm{y}$ & $\mathrm{y}$ & $\mathrm{n}$ & 3 & 4 & 5 \\
\hline Logghe, I. H. J. 2009 & FES & $\mathrm{y}$ & $\mathrm{n}$ & $\mathrm{n}$ & 1 & 3 & 8 \\
\hline McCormack, G.2004 & MFES & $\mathrm{y}$ & $\mathrm{y}$ & $\mathrm{n} / \mathrm{a}$ & 1 & 3 & 4 \\
\hline Oh, S. 2015 & MFES & $\mathrm{y}$ & $\mathrm{y}$ & $\mathrm{y}$ & 1 & 4 & 5 \\
\hline Okubo, Y.2016 & FES & $\mathrm{n}$ & $\mathrm{y}$ & $\mathrm{y}$ & 3 & 4 & 5 \\
\hline Patil, R. 2016 & FES-I & $\mathrm{y}$ & $\mathrm{n}$ & $\mathrm{n}$ & 4 & 4 & 7 \\
\hline Plummer. 2012 & $\mathrm{ABC}$ & $\mathrm{n}$ & $\mathrm{n}$ & $\mathrm{y}$ & 2 & 3 & 7 \\
\hline
\end{tabular}




\begin{tabular}{|c|c|c|c|c|c|c|c|}
\hline Fist Author. Year & $\begin{array}{c}\text { FOF } \\
\text { measure }\end{array}$ & $\begin{array}{c}\text { Is FOF primary } \\
\text { outcome } \\
\text { measure }\end{array}$ & $\begin{array}{l}\text { Significant reduction } \\
\text { in FOF outcomes }\end{array}$ & $\begin{array}{c}\text { Significance on } \\
\text { physical } \\
\text { performance } \\
\text { measures }\end{array}$ & $\begin{array}{l}\text { No. of EP } \\
\text { reported }\end{array}$ & $\begin{array}{l}\text { No. of FITT } \\
\text { reported }\end{array}$ & PEDro score \\
\hline Pollock, R. D.2012 & FES-I & $\mathrm{n}$ & $\mathrm{y}$ & $\mathrm{y}$ & 4 & 3 & 6 \\
\hline Roller, M. 2018 & $\mathrm{ABC}$ & $\mathrm{y}$ & $\mathrm{n}$ & $\mathrm{y}$ & 3 & 3 & 6 \\
\hline Sattin, R. W. 2005 & $\mathrm{ABC}$ & $\mathrm{y}$ & $\mathrm{y}$ & $\mathrm{n} / \mathrm{a}$ & 4 & 3 & 6 \\
\hline Schoene, D.2015 & icon-FES & $\mathrm{n}$ & $\mathrm{y}$ & $\mathrm{y}$ & 4 & 3 & 7 \\
\hline Shigematsu, R. 2008 & Single item & $\mathrm{n}$ & $\mathrm{n}$ & $\mathrm{y}$ & 2 & 3 & 6 \\
\hline Siegrist, M. 2016 & FES-I & $\mathrm{n}$ & $\mathrm{y}$ & $\mathrm{y}$ & 2 & 3 & 4 \\
\hline Smulders, E.2010 & $\mathrm{ABC}$ & $\mathrm{n}$ & $\mathrm{y}$ & $\mathrm{y}$ & 2 & 2 & 8 \\
\hline Szturm, T. 2011 & $\mathrm{ABC}$ & $\mathrm{n}$ & $\mathrm{y}$ & $\mathrm{y}$ & 2 & 3 & 7 \\
\hline Ullmann, G. 2010 & FES & $\mathrm{y}$ & $\mathrm{y}$ & $\mathrm{y}$ & 2 & 3 & 5 \\
\hline Vogler.2009 & MFES & $\mathrm{n}$ & $\mathrm{n}$ & $\mathrm{y}$ & 2 & 3 & 8 \\
\hline Voukelatos, A.2015 & FES-I & $\mathrm{n}$ & $\mathrm{n}$ & $\mathrm{y}$ & 1 & 1 & 6 \\
\hline Westlake, K. P. 2007 & $\mathrm{ABC}$ & $\mathrm{n}$ & $\mathrm{n}$ & $\mathrm{y}$ & 3 & 3 & 4 \\
\hline Wetherell, J. L. 2018 & FES-I & $\mathrm{y}$ & $\mathrm{y}$ & $\mathrm{n} / \mathrm{a}$ & 3 & 3 & 8 \\
\hline Wolf, B.2001 & VAS & $\mathrm{y}$ & $\mathrm{n}$ & $\mathrm{y}$ & 2 & 3 & 8 \\
\hline Wolf, S. L. 2003 & Single item & $\mathrm{n}$ & $\mathrm{y}$ & $\mathrm{y}$ & 3 & 3 & 6 \\
\hline Wollesen, B. 2017 & FES-I & $\mathrm{n}$ & $\mathrm{n}$ & $\mathrm{y}$ & 2 & 3 & 5 \\
\hline Wu, G. 2010 & $\mathrm{ABC}$ & $\mathrm{n}$ & $\mathrm{y}$ & $\mathrm{y}$ & 1 & 3 & 5 \\
\hline Yamada, M. 2011 & Single item & $\mathrm{y}$ & $\mathrm{y}$ & $\mathrm{y}$ & 2 & 3 & 7 \\
\hline
\end{tabular}




\begin{tabular}{|c|c|c|c|c|c|c|c|}
\hline Fist Author. Year & $\begin{array}{c}\text { FOF } \\
\text { measure }\end{array}$ & $\begin{array}{c}\text { Is FOF primary } \\
\text { outcome } \\
\text { measure }\end{array}$ & $\begin{array}{l}\text { Significant reduction } \\
\text { in FOF outcomes }\end{array}$ & $\begin{array}{c}\text { Significance on } \\
\text { physical } \\
\text { performance } \\
\text { measures }\end{array}$ & $\begin{array}{l}\text { No. of EP } \\
\text { reported }\end{array}$ & $\begin{array}{l}\text { No. of FITT } \\
\text { reported }\end{array}$ & PEDro score \\
\hline Yang, X. J.2012 & MFES & $\mathrm{n}$ & $\mathrm{n}$ & $\mathrm{y}$ & 3 & 3 & 7 \\
\hline Yoo, E. J. 2010 & FES & $\mathrm{y}$ & $\mathrm{y}$ & $\mathrm{y}$ & 1 & 4 & 4 \\
\hline Zhang, L.2014 & $\mathrm{ABC}$ & $\mathrm{n}$ & $\mathrm{y}$ & $\mathrm{y}$ & 1 & 1 & 7 \\
\hline Zhao, Y. 2016 & FES-I & $\mathrm{y}$ & $\mathrm{y}$ & $\mathrm{y}$ & 3 & 4 & 8 \\
\hline
\end{tabular}

Note. n: no; y: yes; n/a: not applicable. EP: exercise principles. 


\subsection{Meta-Analysis}

\subsubsection{Effectiveness of Exercise Interventions for FOF}

According to the post-intervention data, the pooled estimate of the SMD in 50 studies with continuous data was $-0.34(95 \% \mathrm{CI}=-0.44$ to -0.23$)$, with a substantial level of heterogeneity $\left(I^{2}=\right.$ $75 \%)^{77}$ (Figure 4).

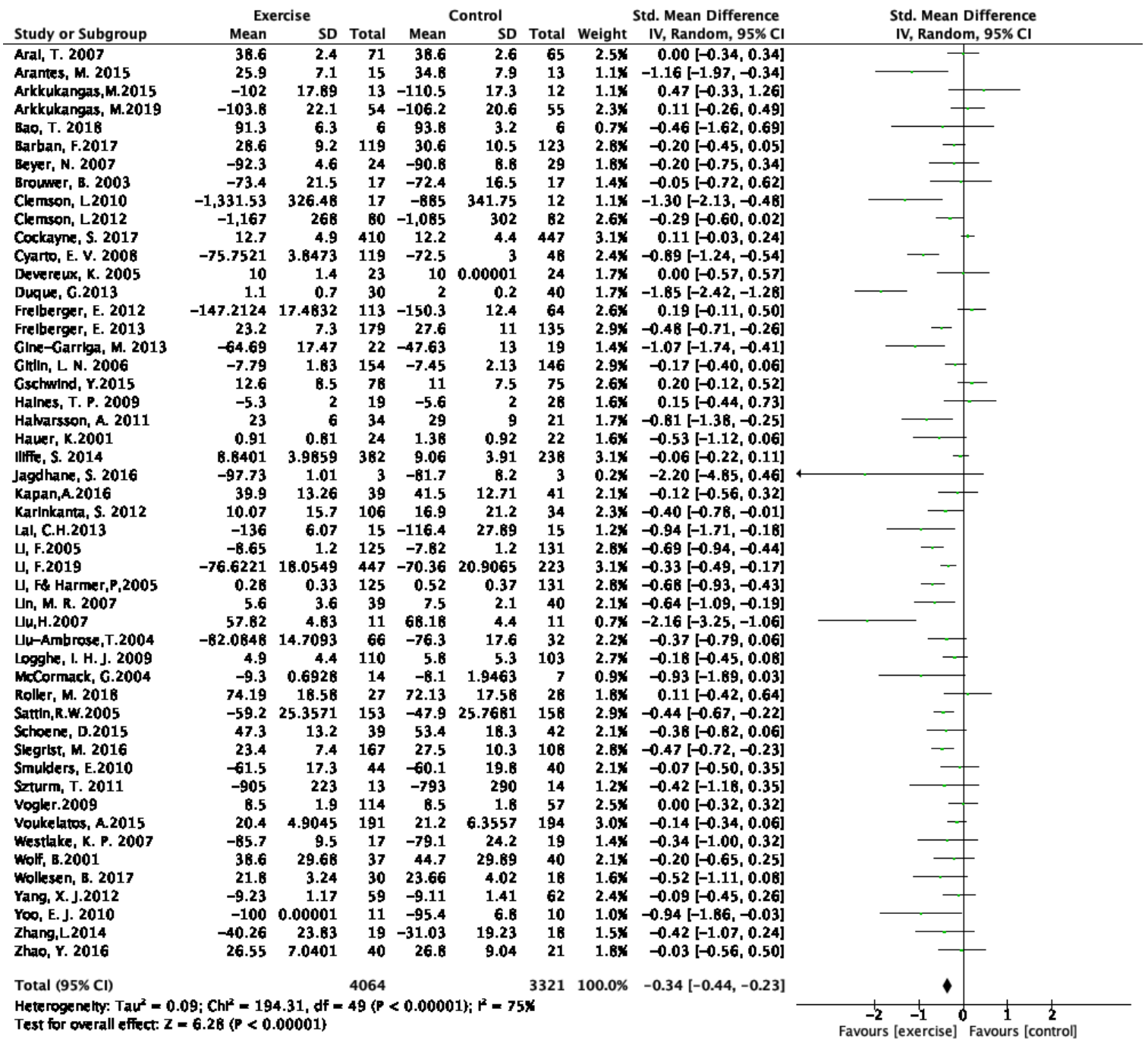

Figure 4: The pooled effect of exercise interventions on FOF using post-intervention data

\subsubsection{Subgroup Analysis}

Figure 5 to 9 illustrated the subgroup analyses for studies entered with post-intervention values. There was no statistically significant effect on any subgroups on the basis of type of exercise $\left(\chi^{2}=10.45 ; \mathrm{P}=0.06\right)$, duration of interventions $\left(\chi^{2}=1.90 ; P=0.39\right)$, FOF as primary or secondary outcome measures $\left(\chi^{2}=0.5 ; P=0.48\right)$, and individual- or group-based exercises $\left(\chi^{2}=0.24 ; P=0.62\right)$. 
However, studies that used balance exercise interventions (19 studies: $\mathrm{SMD}=-0.62 ; 95 \% \mathrm{CI}=-0.93$ to -0.31) had the largest effect size in comparison to the studies that used other types of exercise interventions, while both were significant; studies that used FOF as a primary outcome measure (30 studies: $\mathrm{SMD}=-0.37 ; 95 \% \mathrm{CI}=-0.52$ to -0.22 ) had a larger effect size than studies that used FOF as a secondary outcome (20 studies: $\mathrm{SMD}=-0.29 ; 95 \% \mathrm{CI}=-0.43$ to -0.15$)$; and studies that delivered exercise interventions in group settings ( 30 studies: $\mathrm{SMD}=0.38 ; 95 \% \mathrm{CI}=-0.51$ to -0.26 ) had a larger effect size than studies with individual delivery of exercise interventions (22 studies: SMD $=-0.33 ; 95 \% \mathrm{CI}=-0.52$ to -0.14$)$, but both were significant. 


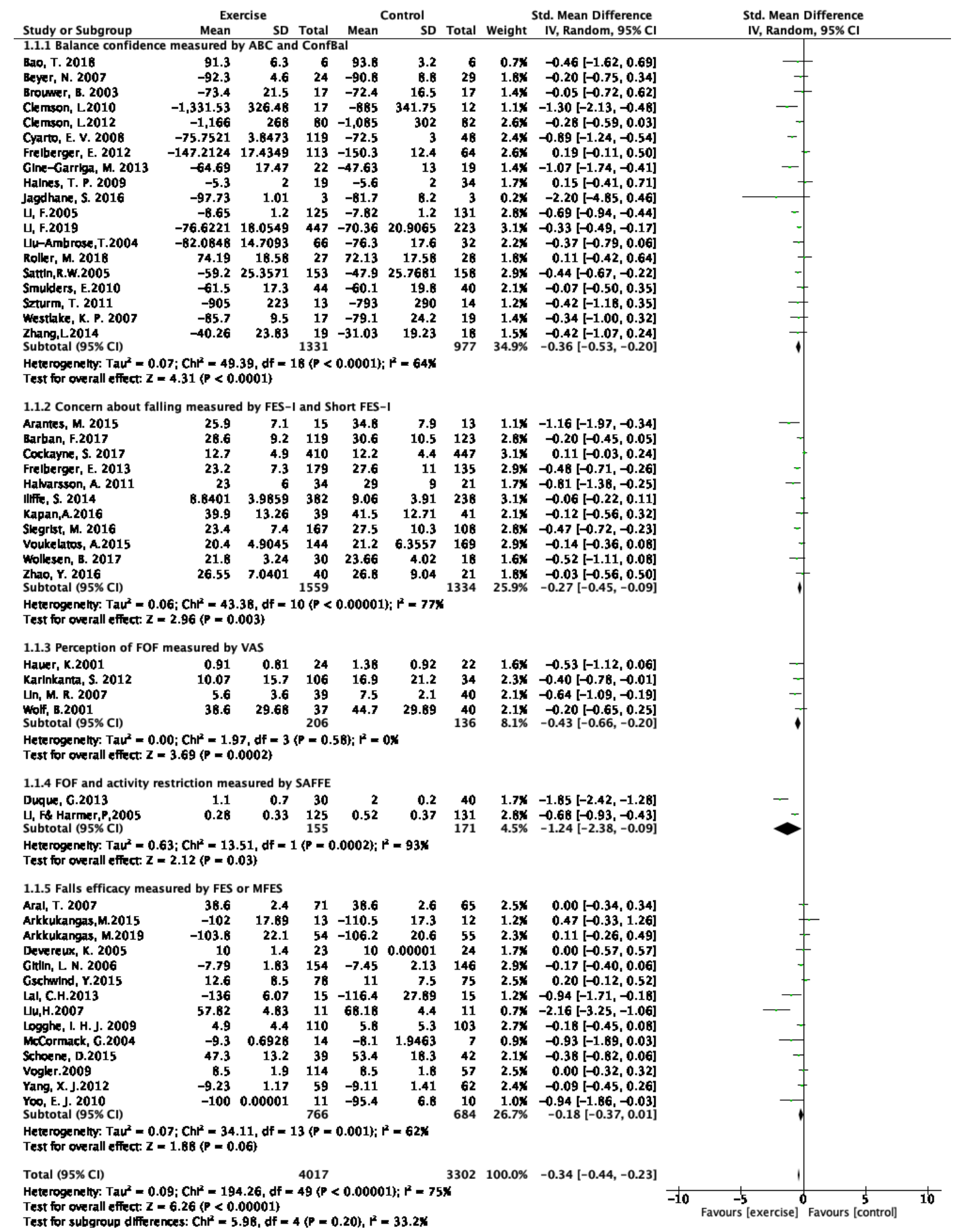

Figure 5: Subgroup analyses by outcome measures using post-intervention data 


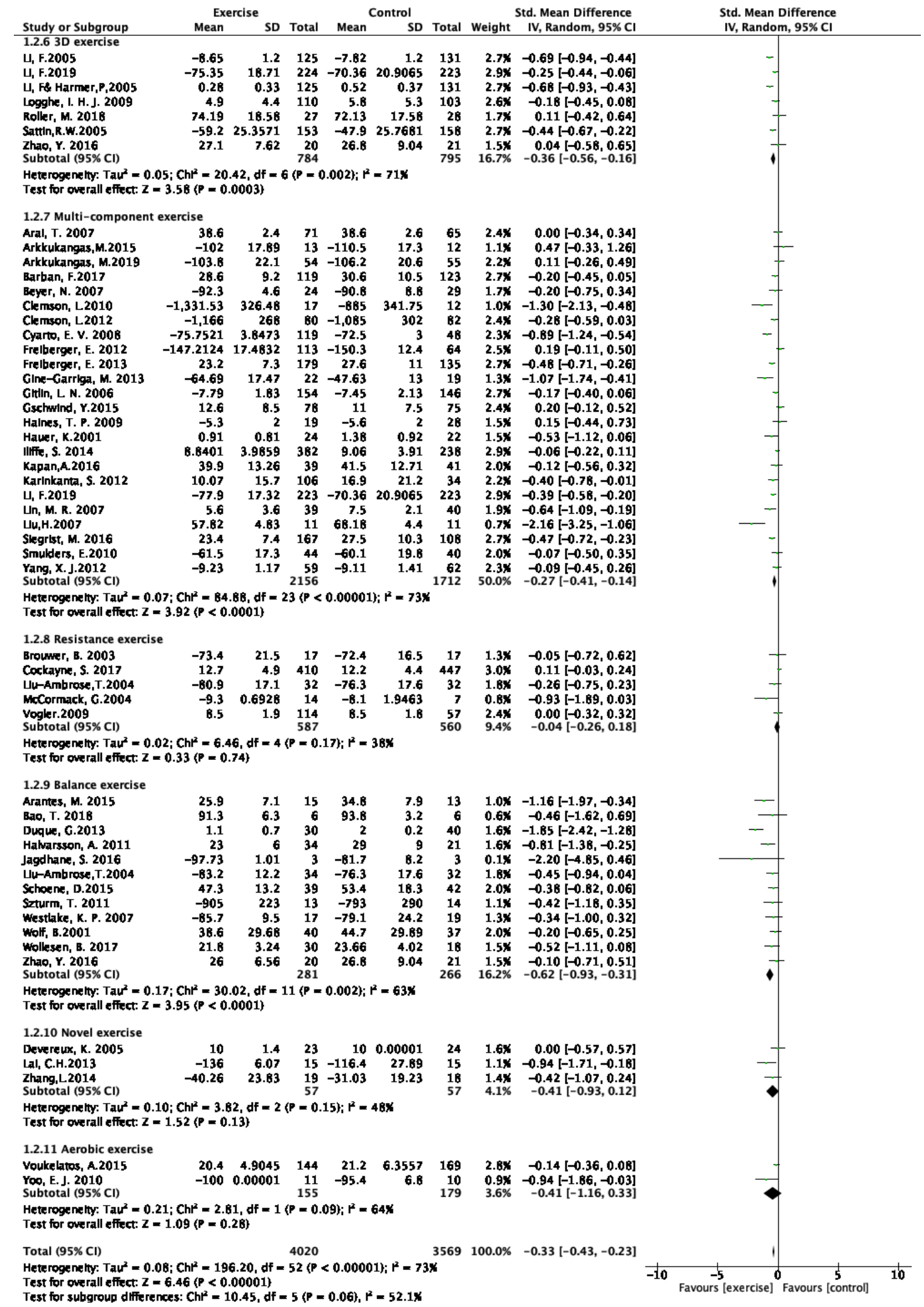

Figure 6: Subgroup analyses by types of exercise interventions using post-intervention data 


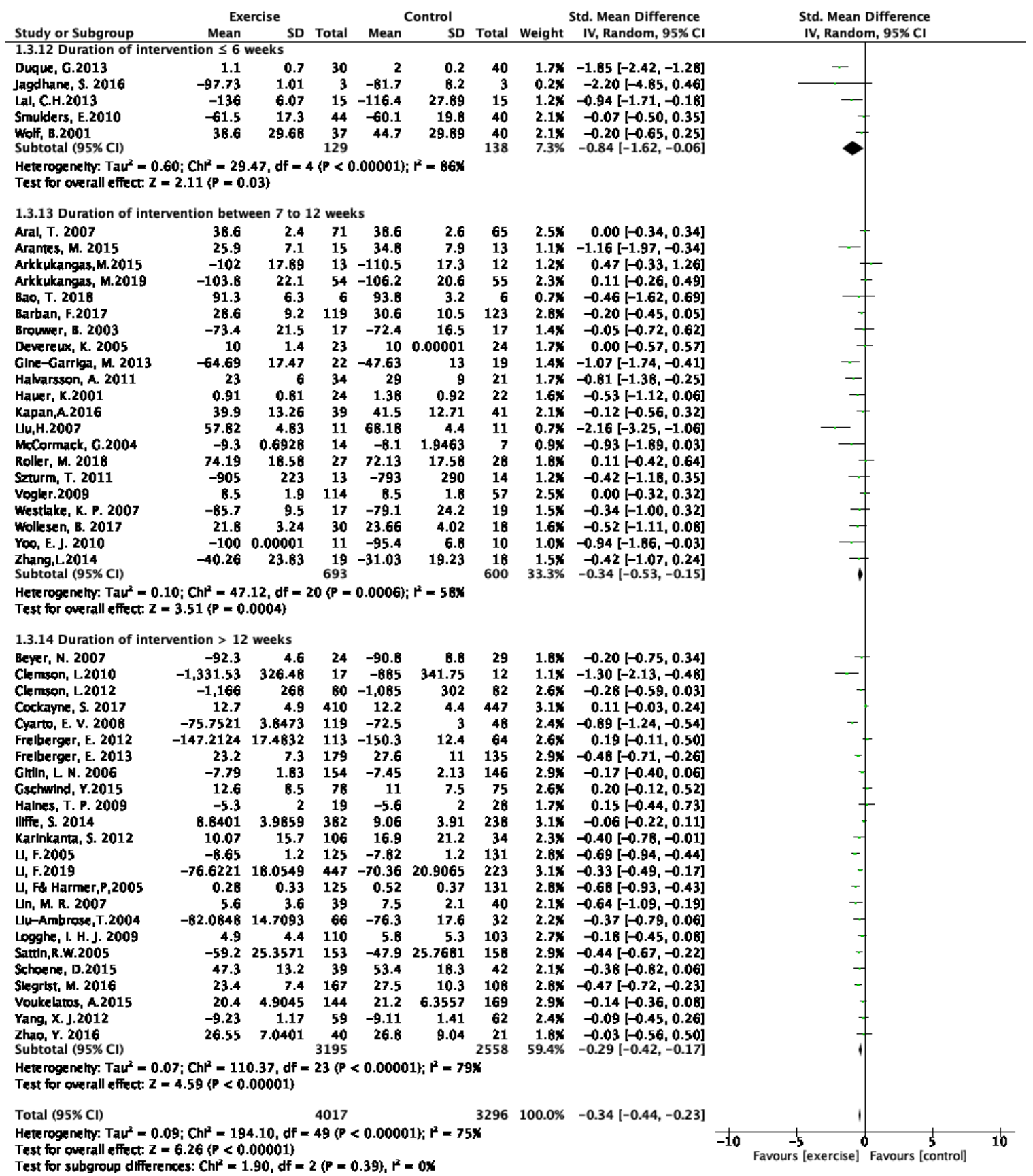

Figure 7: Subgroup analyses by the duration of intervention using post-intervention data 


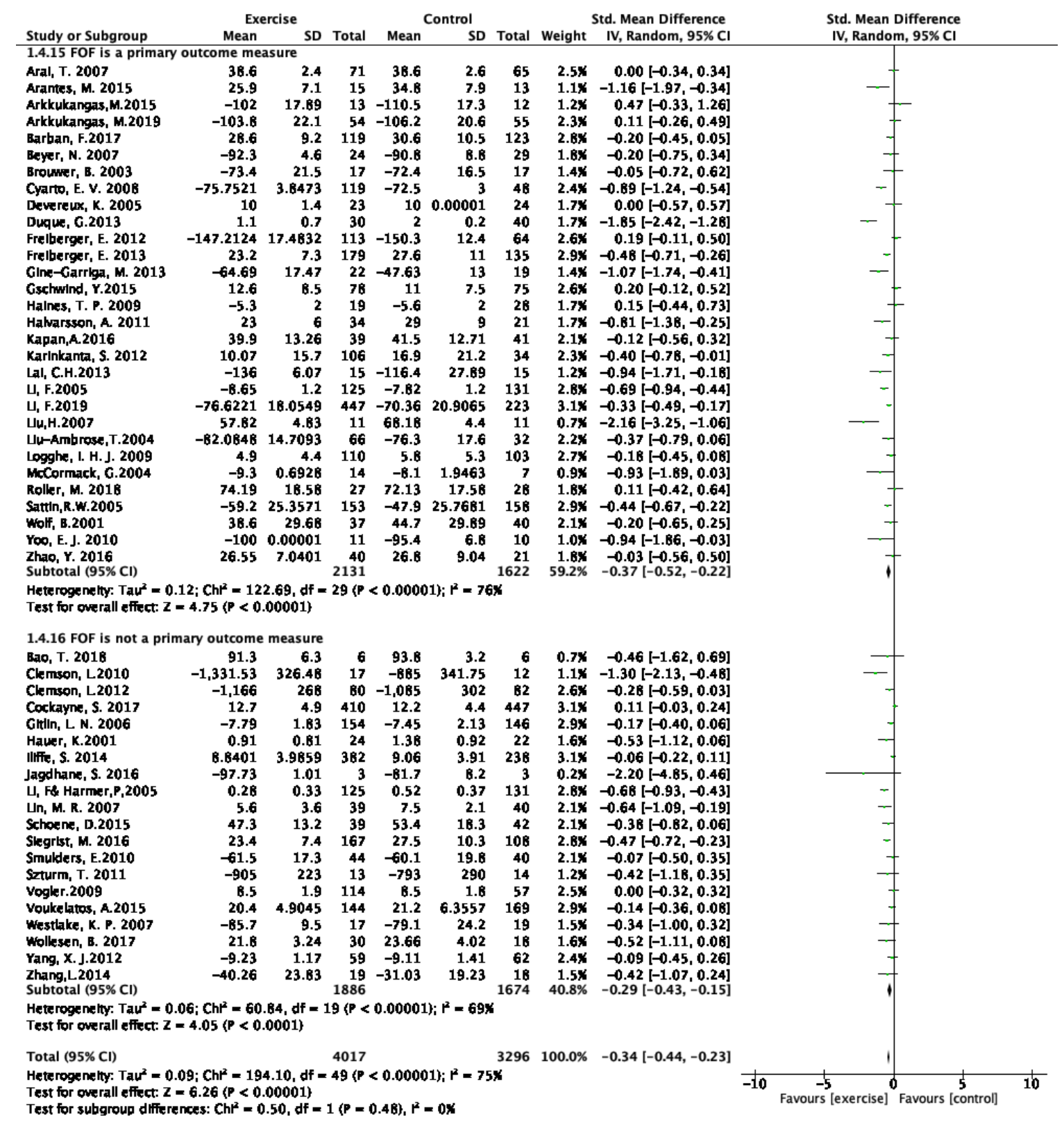

Figure 8: Subgroup analyses by whether FOF is primary or secondary outcome measures using post-intervention data 


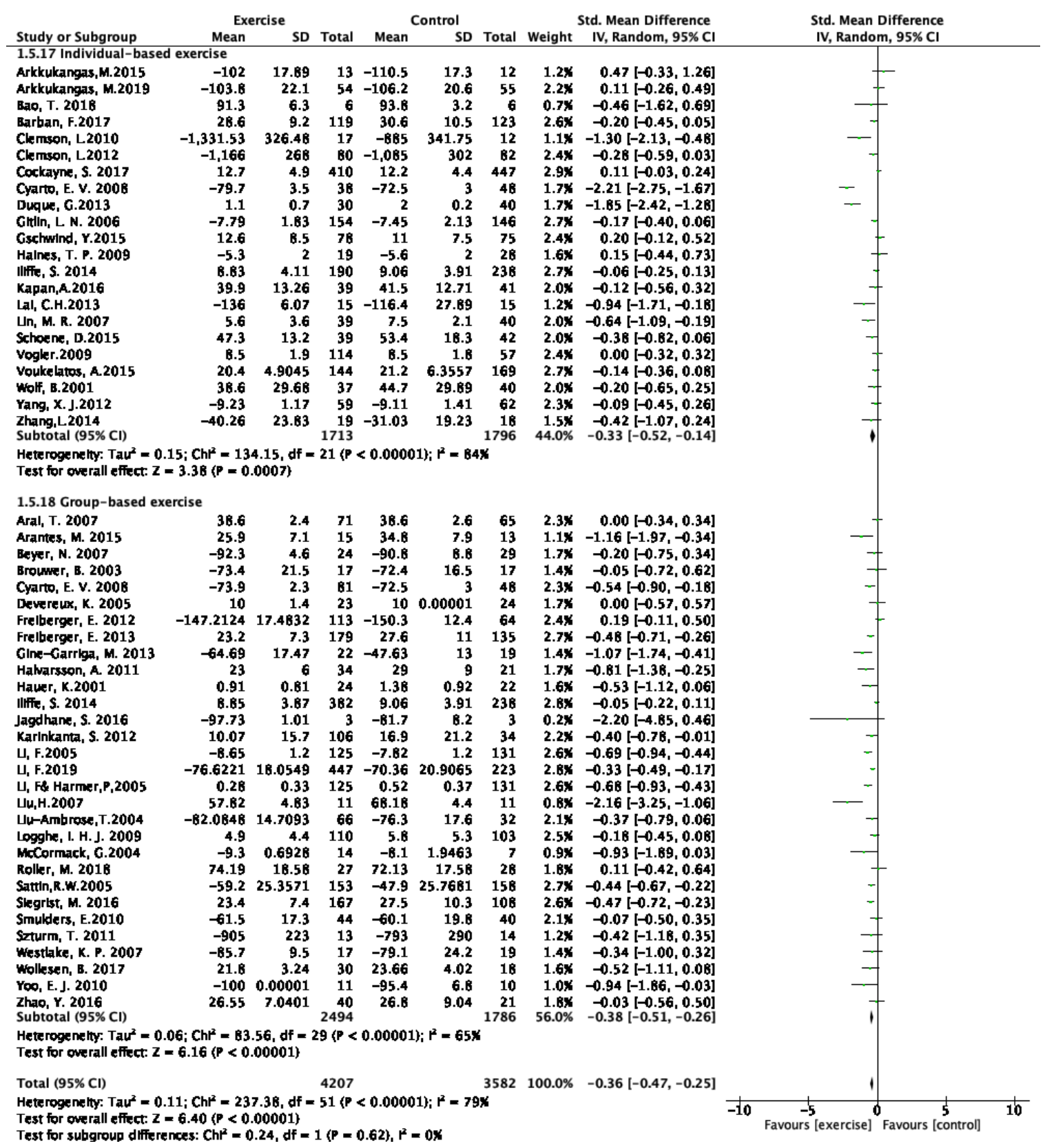

Figure 9: Subgroup analyses by whether the intervention was individual or group-based using post-intervention data

\subsubsection{Sensitivity Analysis}

The effect of study quality was tested. The pooled effect size $(\mathrm{SMD}=-0.34 ; 95 \% \mathrm{CI}=-0.44$ to -0.23$)$ of 50 studies in which post-intervention values were analyzed decreased to $-0.22(95 \% \mathrm{CI}=$ -0.36 to -0.8 ) after removing trials with PEDro Scale scores of $<6$. The pooled effect size decreased 
to $-0.25(95 \% \mathrm{CI}=-0.37$ to -0.13$)$ after removing trials with a sample size of $<100$. However, the results remained significant after the removal of studies with a fair PEDro score or a small sample size.

The influence of using change-from-baseline instead of post-intervention data was also tested in the sensitivity analysis. The meta-analysis of 52 studies using change-from-baseline values (Figure 10) showed that the pooled effect size of exercise interventions on reducing FOF was slightly smaller than the pooled effect size using post-intervention data, but still statistically significant ( $\mathrm{SMD}=-0.28$; $95 \% \mathrm{CI}=-0.37$ to -0.19$)$.

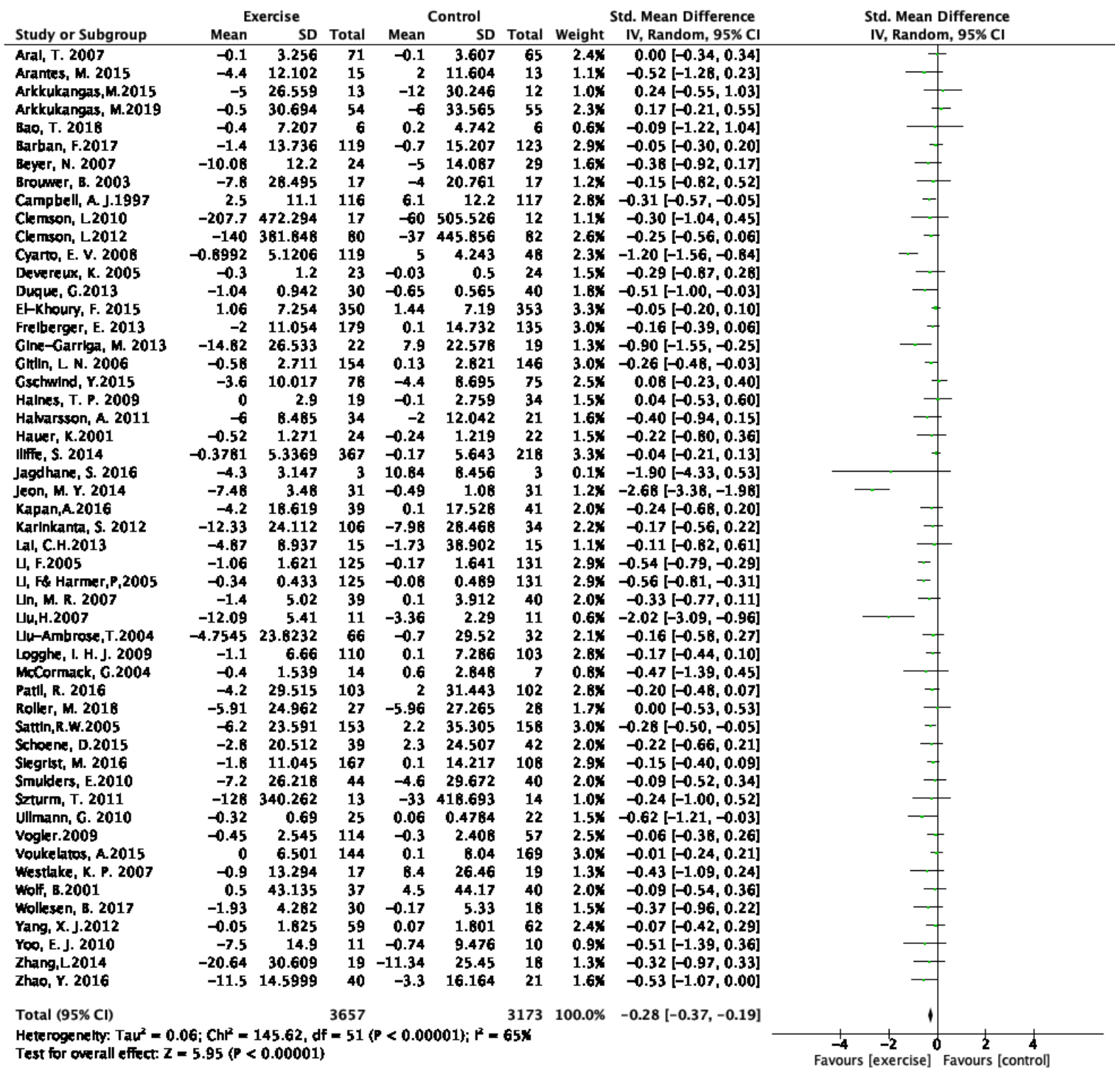

Figure 10: The pooled effect of exercise interventions on FOF using change-from-baseline values $(\mathbf{n}=52)$ 


\subsubsection{Publication Bias}

Visual inspection of the funnel plot (Figure 10) of studies using post-intervention data revealed an asymmetric plot, indicative of the possibility of publication bias.

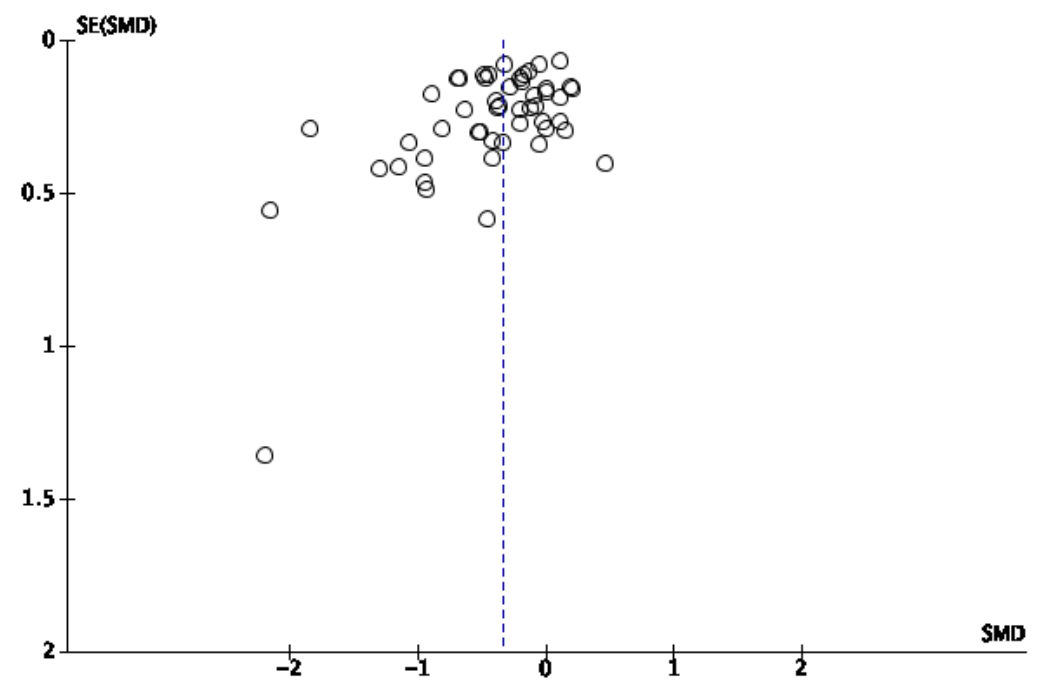

Figure 11. Funnel plot using post-intervention data 


\subsection{References}

1. Iliffe S, Kendrick D, Morris R, et al. Multicentre cluster randomised trial comparing a community group exercise programme and home-based exercise with usual care for people aged 65 years and over in primary care. Health Technology Assessment (Winchester, England). 2014;18(49):vii-xxvii.

2. Halvarsson A, Franzen E, Faren E, Olsson E, Oddsson L, Stahle A. Long-term effects of new progressive group balance training for elderly people with increased risk of falling: a randomized controlled trial. Clinical Rehabilitation. 2012;27(5):450-458.

3. Barnett A, Smith B, Lord SR, Williams M, Baumand A. Community-based group exercise improves balance and reduces falls in at-risk older people: a randomised controlled trial. Age \& Ageing. 2003;32(4):407-414.

4. Kim S, Lockhart T, Roberto K. The effects of eight-week balance training or weight training: for the elderly on fear of falling measures and social activity levels. Quality in Ageing. 2009;10(4):37-48.

5. Shigematsu R, Okura T, Sakai T, Rantanen T. Square-stepping exercise versus strength and balance training for fall risk factors. Aging Clinical \& Experimental Research. 2008;20(1):1924.

6. Wolf SL, Barnhart HX, Kutner NG, et al. Selected as the best paper in the 1990s: reducing frailty and falls in older persons: an investigation of tai chi and computerized balance training. Journal of the American Geriatrics Society. 2003;51(12):1794-1803.

7. Yamada M, Tanaka B, Nagai K, Aoyama T, Ichihashi N. Rhythmic stepping exercise under cognitive conditions improves fall risk factors in community-dwelling older adults: preliminary results of a cluster-randomized controlled trial. Aging \& Mental Health. 2011;15(5):647-653.

8. Karinkanta S, Nupponen R, Heinonen A, et al. Effects of exercise on health-related quality of life and fear of falling in home-dwelling older women. Journal of Aging \& Physical Activity. 2012;20(2):198-214.

9. Lin MR, Wolf SL, Hwang HF, Gong SY, Chen CY. A randomized, controlled trial of fall prevention programs and quality of life in older fallers. Journal of the American Geriatrics Society. 2007;55(4):499-506.

10. Wolf B, Feys H, De Weerdt W, van der Meer J, Noom M, Aufdemkampe G. Effect of a physical therapeutic intervention for balance problems in the elderly: a single-blind, randomized, controlled multicentre trial. Clinical Rehabilitation. 2001;15(6):624-636.

11. Duque G, Boersma D, Loza-Diaz G, et al. Effects of balance training using a virtual-reality system in older fallers. Clin Interv Aging. 2013;8:257-263.

12. Li F, Fisher K, Harmer P, McAuley E. Falls self-efficacy as a mediator of fear of falling in an exercise intervention for older adults. Journals of Gerontology Series B Psychological Sciences \& Social Sciences. 2005;60(1):34-40.

13. Arai $\mathrm{T}$, Obuchi $\mathrm{S}$, Inaba $\mathrm{Y}$, et al. The effects of short-term exercise intervention on falls selfefficacy and the relationship between changes in physical function and falls self-efficacy in Japanese older people: a randomized controlled trial. American Journal of Physical Medicine \& Rehabilitation. 2007;86(2):133-141.

14. Arantes PM, Dias JMD, Fonseca FF, et al. Effect of a program based on balance exercises on gait, functional mobility, fear of falling, and falls in Prefrail older women. Topics in Geriatric Rehabilitation. 2015;31(2):113-120.

15. Arkkukangas M, Johnson ST, Hellström K, Söderlund A, Eriksson S, Johansson A-C. A feasibility study of a randomised controlled trial comparing fall prevention using exercise with or without the support of motivational interviewing. Preventive Medicine Reports. 2015;2:134-140.

16. Arkkukangas M, Söderlund A, Eriksson S, Johansson AC. Fall preventive exercise with or without behavior change support for community-dwelling older adults: a randomized controlled trial with short-term follow-up. J Geriatr Phys Ther. 2019;42(1):9-17. 
17. Bao T, Carender WJ, Kinnaird C, et al. Effects of long-term balance training with vibrotactile sensory augmentation among community-dwelling healthy older adults: a randomized preliminary study. Journal of Neuroengineering \& Rehabilitation. 2018;15(1):5.

18. Barban F, Annicchiarico R, Melideo M, et al. Reducing fall risk with combined motor and cognitive training in elderly fallers. Brain Sciences. 2017;7(2):19.

19. Beyer N, Simonsen L, Bulow J, et al. Old women with a recent fall history show improved muscle strength and function sustained for six months after finishing training. Aging-Clinical \& Experimental Research. 2007;19(4):300-309.

20. Boongird C, Keesukphan P, Phiphadthakusolkul S, Rattanasiri S, Thakkinstian A. Effects of a simple home-based exercise program on fall prevention in older adults: a 12-month primary care setting, randomized controlled trial. Geriatrics \& Gerontology International. 2017;17(11):2157-2163.

21. Brouwer BJ, Walker C, Rydahl SJ, Culham EG. Reducing fear of falling in seniors through education and activity programs: a randomized trial. Journal of the American Geriatrics Society. 2003;51(6):829-834.

22. Campbell AJ, Robertson MC, Gardner MM, Norton RN, Tilyard MW, Buchner DM. Randomised controlled trial of a general practice programme of home based exercise to prevent falls in elderly women. BMJ. 1997;315(7115):1065-1069.

23. Clemson L, Singh MAF, Bundy A, et al. Integration of balance and strength training into daily life activity to reduce rate of falls in older people (the LiFE study): randomised parallel trial. BMJ. 2012;345.

24. Clemson L, Singh MF, Bundy A, et al. LiFE Pilot Study: A randomised trial of balance and strength training embedded in daily life activity to reduce falls in older adults. Australian Occupational Therapy Journal. 2010;57(1):42-50.

25. Cockayne S, Adamson J, Clarke A, et al. Cohort randomised controlled trial of a multifaceted podiatry intervention for the prevention of falls in older people. PLOS ONE. 2017;12(1):e0168712.

26. Covill LG, Utley C, Hochstein C. Comparison of Ai Chi and impairment-based aquatic therapy for older adults with balance problems: a clinical study. Journal of Geriatric Physical Therapy. 2017;40(4):204-213.

27. Cyarto EV, Brown WJ, Marshall AL, Trost SG. Comparative effects of home- and groupbased exercise on balance confidence and balance ability in older adults: cluster randomized trial. Gerontology. 2008;54(5):272-280.

28. Devereux K, Robertson D, Briffa NK. Effects of a water-based program on women 65 years and over: a randomised controlled trial. Australian Journal of Physiotherapy. 2005;51(2):102108.

29. Donath L, Faude O, Bridenbaugh SA, et al. Transfer effects of fall training on balance performance and spatiotemporal gait parameters in healthy community-dwelling older adults: a pilot study. Journal of Aging \& Physical Activity. 2014;22(3):324-333.

30. El-Khoury F, Cassou B, Latouche A, Aegerter P, Charles MA, Dargent-Molina P. Effectiveness of two year balance training programme on prevention of fall induced injuries in at risk women aged 75-85 living in community: Ossebo randomised controlled trial. BMJ. 2015;351:h3830.

31. Freiberger E, Blank WA, Salb J, et al. Effects of a complex intervention on fall risk in the general practitioner setting: a cluster randomized controlled trial. Clinical Interventions in Aging. 2013;8:1079-1088.

32. Freiberger E, Haberle L, Spirduso WW, Zijlstra GA. Long-term effects of three multicomponent exercise interventions on physical performance and fall-related psychological outcomes in community-dwelling older adults: a randomized controlled trial. Journal of the American Geriatrics Society. 2012;60(3):437-446.

33. Gallo E, Stelmach M, Frigeri F, Ahn D-H. Determining whether a dosage-specific and individualized home exercise program with consults reduces fall risk and falls in communitydwelling older adults with difficulty walking: a randomized control trial. Journal of Geriatric Physical Therapy. 2018;41(3):161-172. 
34. Gine-Garriga M, Guerra M, Unnithan VB. The effect of functional circuit training on selfreported fear of falling and health status in a group of physically frail older individuals: a randomized controlled trial. Aging-Clinical \& Experimental Research. 2013;25(3):329-336.

35. Gitlin LN, Winter L, Dennis MP, Corcoran M, Schinfeld S, Hauck WW. A randomized trial of a multicomponent home intervention to reduce functional difficulties in older adults. Journal of the American Geriatrics Society. 2006;54(5):809-816.

36. Gschwind YJ, Eichberg S, Ejupi A, et al. ICT-based system to predict and prevent falls (iStoppFalls): results from an international multicenter randomized controlled trial. European Review of Aging and Physical Activity. 2015;12(1):10.

37. Haines TP, Russell T, Brauer SG, et al. Effectiveness of a video-based exercise programme to reduce falls and improve health-related quality of life among older adults discharged from hospital: a pilot randomized controlled trial. Clinical Rehabilitation. 2009;23(11):973-985.

38. Halvarsson A, Oddsson L, Olsson E, Faren E, Pettersson A, Stahle A. Effects of new, individually adjusted, progressive balance group training for elderly people with fear of falling and tend to fall: a randomized controlled trial. Clinical Rehabilitation. 2011;25(11):1021-1031.

39. Hauer K, Rost B, Rütschle K, et al. Exercise training for rehabilitation and secondary prevention of falls in geriatric patients with a history of injurious falls. Journal of the American Geriatrics Society. 2001;49(1):10-20.

40. Henwood TR, Riek S, Taaffe DR. Strength versus muscle power-specific resistance training in community-dwelling older adults. Journals of Gerontology Series A-Biological Sciences \& Medical Sciences. 2008;63(1):83-91.

41. Jagdhane S, Kanekar N, Aruin AS. The effect of a four-week balance training program on anticipatory postural adjustments in older adults: a pilot feasibility study. Current Aging Science. 2016;9(4):295-300.

42. Jeon MY, Jeong H, Petrofsky J, Lee H, Yim J. Effects of a randomized controlled recurrent fall prevention program on risk factors for falls in frail elderly living at home in rural communities. Medical Science Monitor. 2014;20:2283-2291.

43. Josephs S, Pratt ML, Calk Meadows E, Thurmond S, Wagner A. The effectiveness of Pilates on balance and falls in community dwelling older adults. Journal of Bodywork \& Movement Therapies. 2016;20(4):815-823.

44. Kapan A, Luger E, Haider S, et al. Fear of falling reduced by a lay led home-based program in frail community-dwelling older adults: a randomised controlled trial. Arch Gerontol Geriatr. 2017;68:25-32.

45. Kyrdalen IL, Moen K, Røysland AS, Helbostad JL. The Otago exercise program performed as group training versus home training in fall-prone older people: a randomized controlled trial. Physiotherapy Research International. 2014;19(2):108-116.

46. Lai C-H, Peng C-W, Chen Y-L, Huang C-P, Hsiao Y-L, Chen S-C. Effects of interactive video-game based system exercise on the balance of the elderly. Gait \& posture. 2013;37(4):511-515.

47. LaStayo P, Marcus R, Dibble L, Wong B, Pepper G. Eccentric versus traditional resistance exercise for older adult fallers in the community: a randomized trial within a multicomponent fall reduction program. BMC Geriatrics. 2017;17(1):149.

48. Li F, Harmer P, Fisher KJ, et al. Tai Chi and fall reductions in older adults: a randomized controlled trial. The Journals of Gerontology Series A: Biological Sciences and Medical Sciences. 2005;60(2):187-194.

49. Li F, Harmer P, Chou LS. Dual-Task Walking Capacity Mediates Tai Ji Quan impact on physical and cognitive function. Med Sci Sports Exerc. 2019;51(11):2318-2324.

50. Liu H, Rainey J, Zabel R, Quiben MU, Kehayov A, Boswell J. Comparison of two exercise programs using the Falls Efficacy Scale, Berg Balance Scale and ankle dorsiflexor strength in older adults. Physical \& Occupational Therapy in Geriatrics. 2007;26(2):23-42.

51. Liu YW, Tsui CM. A randomized trial comparing Tai Chi with and without cognitivebehavioral intervention (CBI) to reduce fear of falling in community-dwelling elderly people. Archives of Gerontology \& Geriatrics. 2014;59(2):317-325. 
52. Liu-Ambrose T, Khan KM, Eng JJ, Lord SR, McKay HA. Balance confidence improves with resistance or agility training. Increase is not correlated with objective changes in fall risk and physical abilities. Gerontology. 2004;50(6):373-382.

53. Logghe IHJ, Zeeuwe PEM, Verhagen AP, et al. Lack of effect of Tai Chi Chuan in preventing falls in elderly people living at home: a randomized clinical trial. Journal of the American Geriatrics Society. 2009;57(1):70-75.

54. McCormack G, Lewin G, McCormack B, Helmes E, Rose E, Naumann F. Pilot study comparing the influence of different types of exercise intervention on the fear of falling in older adults. Australasian Journal on Ageing. 2004;23(3):131-135.

55. Oh S, Lim JM, Kim Y, Kim M, Song W, Yoon B. Comparison of the effects of water- and land-based exercises on the physical function and quality of life in community-dwelling elderly people with history of falling: a single-blind, randomized controlled trial. Archives of Gerontology \& Geriatrics. 2014;60(2):288-293.

56. Okubo Y, Osuka Y, Jung S, et al. Walking can be more effective than balance training in fall prevention among community-dwelling older adults. Geriatrics \& Gerontology International. 2016;16(1):118-125.

57. Patil R, Karinkanta S, Tokola K, Kannus P, Sievanen H, Uusi-Rasi K. Effects of vitamin D and exercise on the wellbeing of older community-wwelling women: a randomized controlled trial. Gerontology. 2016;62(4):401-408.

58. Plummer-D'Amato P, Cohen Z, Daee NA, Lawson SE, Lizotte MR, Padilla A. Effects of once weekly dual-task training in older adults: a pilot randomized controlled trial. Geriatrics \& Gerontology International. 2012;12(4):622-629.

59. Pollock RD, Martin FC, Newham DJ. Whole-body vibration in addition to strength and balance exercise for falls-related functional mobility of frail older adults: a single-blind randomized controlled trial. Clinical Rehabilitation. 2012;26(10):915-923.

60. Roller M, Kachingwe A, Beling J, Ickes DM, Cabot A, Shrier G. Pilates reformer exercises for fall risk reduction in older adults: a randomized controlled trial. Journal of Bodywork \& Movement Therapies. 2017;22(4):983-998.

61. Sattin RW, Easley KA, Wolf SL, Chen Y, Kutner MH. Reduction in fear of falling through intense tai chi exercise training in older, transitionally frail adults. Journal of the American Geriatrics Society. 2005;53(7):1168-1178.

62. Schoene D, Valenzuela T, Toson B, et al. Interactive cognitive-motor step training improves cognitive risk factors of falling in older adults: a randomized controlled trial. PLoS one. 2015;10(12):e0145161.

63. Siegrist M, Freiberger E, Geilhof B, et al. Fall prevention in a primary care setting. Deutsches Arzteblatt International. 2016;113(21):365-372.

64. Smulders E, Weerdesteyn V, Groen BE, et al. Efficacy of a short multidisciplinary falls prevention program for elderly persons with osteoporosis and a fall history: a randomized controlled trial. Archives of Physical Medicine and Rehabilitation. 2010;91(11):1705-1711.

65. Szturm T, Betker AL, Moussavi Z, Desai A, Goodman V. Effects of an interactive computer game exercise regimen on balance impairment in frail community-dwelling older adults: a randomized controlled trial. Physical Therapy. 2011;91(10):1449-1462.

66. Ullmann G, Williams HG, Hussey J, Durstine JL, McClenaghan BA. Effects of Feldenkrais exercises on balance, mobility, balance confidence, and gait performance in communitydwelling adults age 65 and older. Journal of Alternative \& Complementary Medicine. 2010;16(1):97-105.

67. Vogler CM, Sherrington C, Ogle SJ, Lord SR. Reducing risk of falling in older people discharged from hospital: a randomized controlled trial comparing seated exercises, weightbearing exercises, and social visits. Archives of Physical Medicine and Rehabilitation. 2009;90(8):1317-1324.

68. Voukelatos A, Merom D, Sherrington C, Rissel C, Cumming RG, Lord SR. The impact of a home-based walking programme on falls in older people: the easy steps randomised controlled trial. Age and Ageing. 2015;44(3):377-383. 
69. Westlake KP, Culham EG. Sensory-specific balance training in older adults: effect on proprioceptive reintegration and cognitive demands. Physical Therapy. 2007;87(10):12741283.

70. Wetherell JL, Bower ES, Johnson K, Chang DG, Ward SR, Petkus AJ. Integrated exposure therapy and exercise reduces fear of falling and avoidance in older adults: a randomized pilot study. American Journal of Geriatric Psychiatry. 2018;26(8):849-859.

71. Wollesen B, Schulz S, Seydell L, Delbaere K. Does dual task training improve walking performance of older adults with concern of falling? BMC Geriatrics. 2017;17(1):213.

72. Wu G, Keyes L, Callas P, Ren X, Bookchin B. Comparison of telecommunication, community, and home-based Tai Chi exercise programs on compliance and effectiveness in elders at risk for falls. Archives of Physical Medicine \& Rehabilitation. 2010;91(6):849-856.

73. Yang XJ, Hill K, Moore K, et al. Effectiveness of a targeted exercise intervention in reversing older people's mild balance dysfunction: a randomized controlled trial. Physical Therapy. 2012;92(1):24-37.

74. Yoo EJ, Jun TW, Hawkins SA. The effects of a walking exercise program on fall-related fitness, bone metabolism, and fall-related psychological factors in elderly women. Research in Sports Medicine. 2010;18(4):236-250.

75. Zhang L, Weng C, Liu M, Wang Q, Liu L, He Y. Effect of whole-body vibration exercise on mobility, balance ability and general health status in frail elderly patients: a pilot randomized controlled trial. Clinical Rehabilitation. 2014;28(1):59-68.

76. Zhao Y, Chung PK, Tong TK. Effectiveness of a community-based exercise program on balance performance and fear of falling in older nonfallers at risk for falling: a randomized, controlled study. Journal of Aging \& Physical Activity. 2016;24(4):516-524.

77. Higgins JP, Thomas J, Chandler J, et al. Cochrane Handbook for Systematic Reviews of Interventions. John Wiley \& Sons; 2019. 


\section{Chapter 5}

\section{Discussion}

\subsection{Reporting of Principles of Exercise Training and FITT Components}

This thesis investigated the extent to which the principles of exercise training and FITT components were reported for FOF exercise interventions in previous RCTs. Among 75 included trials, most of the exercise principles (i.e., overload, reversibility, diminishing return, and initial value) and one of the FITT components (i.e., intensity) were not sufficiently reported, and $63 \%$ of the trials reported adherence to exercise interventions. These results resonate with similar work in other populations. A review that assessed the application of exercise principles in people with stroke found that $89.2 \%$ of included RCTs reported specificity and $75.7 \%$ reported progression, while less than $50 \%$ reported on other principles. ${ }^{1}$ I will discuss each of the principles in the following sections.

\subsubsection{Specificity}

The exercise interventions should be designed to be specific for the intended outcomes. In our study, five out of 75 trials did not report sufficient data to comply with the specificity principle. These trials used Tai Chi, video games, walking and whole-body vibration exercises aiming to reduce FOF; however, they did not describe which body systems and muscle groups were targeted to meet the training goals. Without this information, it is difficult to determine the essential ingredients that make interventions effective.

\subsubsection{Progression}

Twenty-eight percent of the reviewed trials did not report on the principle of progression. This result was similar to another study in which $28 \%$ of RCTs did not consider the progression principle in designing breast cancer exercise interventions for women. ${ }^{2}$ The exercise progression of resistance and aerobic exercises was well explained by the physical stress theory of Mueller and Maluf, whereby exercise is prescribed to improve one's physical performance by using mechanical load to trigger 
physiological and tissue adaptations. ${ }^{3}$ When this adaptation accumulates to a certain degree, changes in our body structure and function can be expected. A continuous change of body structure and function relies on a gradual progression of exercise dosage. Sometimes meaningful changes in outcomes cannot be detected if the adaptation stops due to a constant exercise dosage. This theory might explain why some exercise programs that did not apply the principle of progression in our included trials did not find significant outcomes. ${ }^{4,5}$ Finally, the progression in nonconventional exercises such as Tai Chi was less reported than in the resistance and aerobic exercises in our reviewed trials. ${ }^{5-11}$ This gap is essential to consider when developing new guidelines for nonconventional exercises, especially on how to progress the exercise.

\subsubsection{Overload}

A sufficient load is another variable that can cause predictable physiological and tissue adaptations. ${ }^{3}$ The question is, how much load is enough? Evidence has shown that underloading will not cause predictable adaptations, whereas overloading leads to maladaptation such as tissue injury, fatigue, and loss of exercise motivation. ${ }^{12}$ Therefore, applying overload needs to consider the heterogeneity of a participant's baseline capacity. An optimal adaptation occurs when the load is maintained at a level at which it is challenging for the participants. Sixty-nine percent of trials in our study did not report the principle of overload. This gap might be due to the barriers of applying exercise tolerance tests to determine the baseline intensity level for each individual and making a personally tailored plan in group settings.

Despite the inconvenience of implementation of exercise tolerance tests and individually tailored intervention in group settings, it is possible to use a standardized training protocol based on the average baseline test scores while adjusting the training dosage for those individuals with extreme baseline test scores. Furthermore, few included trials in this study reported any maladaptation of exercise training among the participants. Particularly, reporting the dose-provoked side effects in a trial will provide valuable information regarding the maximum exercise load those older adults with FOF can tolerate. A relatively low exercise tolerance might be present among older adults with FOF and fall risks since 
balance impairment and sarcopenia are common risk factors for FOF and fall risks. Despite the challenges of applying the overload principle for older adults with FOF, individual-tailored exercise load based on exercise tolerance tests for each type of exercise should be considered in future research that employs exercise interventions.

\subsubsection{Initial Value}

The initial value was the least reported exercise principle. All trials measured the baseline outcomes, but only four trials compared the training effect between participants with low baseline levels and those with high baseline levels. Reporting the impact of a baseline value on training response can help tailor an exercise program for subgroups of participants with higher or lower functioning levels. Arai et al. found a significant correlation between baseline FES score and the magnitude of change in maximum walking velocity and knee extensor strength in the exercise intervention group. ${ }^{13}$ This finding indicated that combined progressive resistance and balance training was more effective with respect to the physical performance outcomes for the participants with lower FES scores than those with higher scores. ${ }^{13}$

\subsubsection{Diminishing Return}

Reporting the principle of diminishing return was also infrequent ( $21 \%$ of trials). Knowing when the peak adaptation occurs in participants due to the exercise interventions is an important indicator for the progression of exercise dosage. This principle requires us to continuously monitor the training responses of each individual during the intervention so that adequate doses can be given to maintain the training effect. The pattern of normal training response follows a nonlinear progression. The magnitude of training response can increase exponentially at the early training stage following a period of stagnation. Awareness of this trend helps us develop training strategies to sustain the training benefits. In trials in which the diminishing return principle was applied, key outcomes were measured at least once during the period of intervention. ${ }^{6,8,11,14-26}$ However, none of those trials showed rapid improvement in outcomes at the mid-intervention assessment. An explanation for this result might be the ceiling effect of FOF 
outcome measures. ${ }^{14,27}$ It is also possible that many existing FOF measures are not sensitive enough to detect clinically meaningful changes in a short period. ${ }^{28}$

\subsubsection{Reversibility}

Sixty-eight percent of trials in this study did not report the exercise principle of reversibility. This principle requires performing at least one follow-up assessment after the intervention is completed. The follow-up assessment is not always a feasible option in research due to time and financial limitations or the burden on the participants. However, the absence of follow-up assessments leads to uncertainty about the retention effect of exercise interventions. Also, when training ceases, a considerable decline of fitness level happens as early as two weeks, and a return to pretraining states appears between ten weeks and eight months. ${ }^{29}$ Therefore, sustainability should be considered a key component when designing and selecting exercise programs.

\subsubsection{FITT Components}

The FITT components are the main variables that can be manipulated to follow the exercise principles and generate desired training effects. For example, progression can be applied by increasing either frequency, intensity, or time of exercises. If the FITT components are not reported in detail, it makes it difficult to replicate the exercise interventions in clinical practices to compare the effectiveness of exercise interventions across studies where similar interventions were implemented, and to provide exercise prescription guidelines for older adults suffering from FOF.

Similar to previous literature, ${ }^{1,2}$ intensity was the least reported FITT component in this review. Intensity is a crucial component in the exercise prescription, and it reflects how challenging an exercise task is felt by a participant. Older adults with FOF often have low self-efficacy ${ }^{30}$, and a person's selfefficacy level is mainly influenced by his/her experience in successfully performing certain tasks such as exercises. ${ }^{31}$ If the intensity of an exercise task is too high, the person might fail to perform the task, leading to a decrease in self-efficacy.

In this study, most trials (44\%) used multicomponent exercise interventions (resistance, balance, aerobic etc.), which added complexity to measure the intensity. Additionally, there are well-established 
tools that measure participants' intensity levels for endurance and resistance exercises, such as 1RM and maximum rate of oxygen consumption, while there is an absence of validated intensity measures for balance exercises.

One study in this review used the level of difficulty of tasks to quantify the balance exercise intensity. ${ }^{32}$ Nevertheless, a limitation of using this method is that the challenge of the task cannot be quantified to a level that matches an individual's balance capability. Farlie et al. recently developed the Balance Intensity Scales (BIS) to measure balance intensity relative to the balance capacity of the individual to maintain balance, including a self-rate scale and an objective scale rated by therapists. ${ }^{33}$ However, the reliability and validity of the BIS among larger samples of high-intensity tasks and more diverse older adult populations are yet to be tested. Despite the limitations of existing balance intensity measurement tools, researchers are encouraged to use any accessible tools to report balance intensity in their studies or indicate the performance duration of each balance activity until a well-validated instrument is established for measuring balance intensity.

Given that the effectiveness of an exercise intervention relies heavily on participant adherence to the prescribed exercises, it is important to report whether the prescribed exercise dosage was performed. In our study, due to the insufficient report of adherence to exercise dosage, the adherence to program interventions was rated using the percentage or number of total attended exercise sessions. Adherence to exercise dosage refers to the number or percentage of participants who are completely or partially compliant with the prescribed exercise program regarding the frequency, intensity, time, type, and exercise progression. Future research involving exercise interventions is recommended to report adherence to exercise dosage in order to inform clinicians about the proper amount of dosage to retain the acceptability and popularity of different evidence-based exercise programs.

\subsection{The Overall Effect of FOF Exercise Intervention}

Aligned with previous meta-analyses, ${ }^{34-36}$ results in this study showed an overall small-tomoderate effect size ( $\mathrm{SMD}=-0.34 ; 95 \% \mathrm{CI}=-0.44$ to -0.23 ) of exercise interventions in reducing FOF . However, the overall effect size of exercise interventions on FOF reduction decreased to $-0.22(95 \% \mathrm{CI}$ 
$=-0.36$ to -0.8$)$ and to $0.25(95 \% \mathrm{CI}=-0.37$ to -0.13$)$ when studies with only good methodological quality (PEDro Scale score of $\geq 6$ ) and studies with large sample size ( $\mathrm{n} \geq 100$ ) were analyzed, respectively. Research shows that RCTs with poor methodological quality and small sample sizes tend to exaggerate or overestimate the effect size. ${ }^{37-39}$ Therefore, we should take the risk of bias into account when interpreting the effect estimate of FOF exercise interventions in this study.

Additionally, a sensitivity analysis using change-from-baseline values to check the robustness of the result in this review showed a slightly decreased overall effect estimate of exercise interventions in reducing FOF ( $\mathrm{SMD}=-0.28 ; 95 \% \mathrm{CI}=-0.37$ to -0.19 ). This discrepancy might be due to the differences in included studies in each meta-analysis using different approaches.

\subsection{Comparing Results with Previous Reviews on FOF Intervention}

\subsubsection{FOF Exercise Interventions}

The effectiveness of exercise intervetions in reducing FOF might be explained by Bandura's selfefficacy theory. Mastery experience (successfully performing exercises without falling) are the most valuable source of efficacy information since they provide evidence that an individual can achieve success. This success builds a robust belief in individual's self-effecacy to avoid falling which in turn reduce his/her FOF.

In parallel with the study of Kruisbrink et $\mathrm{al},{ }^{40}$ this study showed that group-based exercise interventions ( $\mathrm{SMD}=-0.38 ; 95 \% \mathrm{CI}=-0.51$ to -0.26 ) had a slightly larger effect size than individualbased exercise interventions ( $\mathrm{SMD}=-0.33 ; 95 \% \mathrm{CI}=-0.52$ to -0.14 ) in reducing FOF. This was also underlined in a previous study, which showed that group exercises have additional psychosocial health benefits through social interaction. ${ }^{41}$

In terms of the impact of types of exercise interventions on FOF reduction, the finding of the present study varies from Kruisbrink et al.'s study. In Kruisbrik et al.'s study, researchers examined the pooled effect of all types of interventions in reducing FOF, including exercise interventions across 49 studies and found that 3D exercises (i.e., Tai Chi, yoga, or pilates) had the largest effect size (SMD = $0.823 ; 95 \% \mathrm{CI}=-1.255$ to -0.392$).{ }^{40}$ However, findings in this study showed that balance exercises 
yielded the largest effect size ( $\mathrm{SMD}=-0.62 ; 95 \% \mathrm{CI}=-0.93$ to -0.31$)$ among all other types of exercise interventions. This inconsistency might be due to the differences in inclusion criteria since the previous study included a broader range of interventions. Having all FITT components reported in the future will facilitate the comparison of different studies and explain different findings.

Unlike other meta-analyses ${ }^{34,35,40}$ showing that the effect size was not associated with the primary aim of the study, the current meta-analyses revealed that studies with FOF as the primary outcome measure (SMD $=-0.37 ; 95 \% \mathrm{CI}=-0.52$ to -0.22 ) had a larger effect size than those with FOF as secondary outcome measures $(\mathrm{SMD}=-0.29 ; 95 \% \mathrm{CI}=-0.43$ to -0.15$)$. This finding might reflect the important role of the specificity principle in designing FOF exercise interventions. For instance, an exercise program to treat FOF should explicitly address FOF-related risk factors. If FOF is not the principal outcome expected to be influenced by an exercise program, the effectiveness of the exercise program may be compromised.

\subsubsection{Other Types of FOF Interventions}

In addition to exercise interventions being effective at reducing FOF among community-dwelling older adults, other types of intervention have been comparatively less researched but may also help reduce FOF. Among them, CBT has recently gained popularity in the field of FOF intervention research due to its direct impact on a person's beliefs and behaviours. Two systematic reviews and meta-analyses by $\mathrm{Liu}^{42}$ and $\mathrm{Chua}^{43}$ indicated that the immediate effect size of CBT and CBT-based multi-factorial interventions on FOF reduction were an SMD of 0.25 and -0.28 , respectively. The effect sizes of CBTbased interventions in $\mathrm{Liu}^{42}$ and Chua's ${ }^{43}$ studies are smaller than the effects sizes of FOF exercise interventions in this review and Kumar's review. ${ }^{35}$ Although FOF is a psychological construct, functional impairments are the most common modifiable risk factors for FOF. This might explain how exercise interventions can be more effective in reducing FOF than CBT-based interventions. To illustrate, an indirect effect of exercise interventions may lead to a reduction in FOF and an increase in balance confidence and fall-efficacy via improved dynamic and static balance, functional mobility, and muscle strength. 
While exercise interventions appear to be more effective than CBT in reducing FOF immediately after the intervention, the CBT might be a more effective intervention in the long term. Interestingly, the effect sizes of CBT-based interventions in Liu et al. ${ }^{42}$ and Chua et al.'s ${ }^{43}$ studies increased to an SMD of 0.37 and -0.30 beyond the end of the interventions ( 6 to 12 months post-intervention). While in Kumar's study, ${ }^{35}$ the retention effect of exercise interventions in reducing FOF decreased significantly after six months post-intervention. This might be explained by the reversibility effect of exercise training on individuals' physiological adaptations, which might also impact their psychological adaptions. Once the physiological adaptions stop and return to the original level, individuals' belief in their ability to avoid falls and maintain balance will also gradually return to the baseline level.

CBT might be effective in tackling FOF for older adults who have FOF without actual functional impairments, but CBT intervention alone might not be sufficient to target older adults who are both fearful about falling and have actual functional impairments such as poor balance and sarcopenia. That is why many current CBT-based interventions were integrated with exercises, as demonstrated in a recent review. ${ }^{43}$ Therefore, an ideal FOF intervention might be a combination of these two approaches.

Some fall prevention programs that attempted to address risk factors of falling also showed effectiveness in reducing FOF. For example, evidence from a systematic review by Sjosten and colleagues seems to support the benefits of multifactorial fall-prevention programs and Tai Chi as a single-component fall-prevention program for FOF. ${ }^{44}$ Yoshikawa et al.'s meta-analysis also showed that the effect size of A Matter of Balance Volunteer Lay Leader (AMOB/ALL) model fall-prevention program on FOF measured by affective construct was an SMD of -0.29 (9 studies, CI: $-0.4,-0.19$ ) and on FOF measured by cognitive construct was SMD of 0.51 (10 studies, CI: $0.42,0.60) .{ }^{36}$ These effect estimates were comparable with those in the present study. However, their findings should be interpreted with extra caution, given that most of the included studies in their review were a quasi-experimental design which might overestimate the program effects.

FOF and falls share many overlapping risk factors, so fall prevention programs might be able to reduce FOF by managing those shared risk factors. ${ }^{45}$ However, an exercise program should be targeted to 
a specific group of people likely to benefit most from the intervention. ${ }^{46}$ Fall prevention programs may not be specific enough for older adults who experience FOF without having actual fall risks.

Consequently, we should distinguish older adults with actual fall risks from those with FOF only when planning a fall prevention program in a community to prevent wasting resources.

\subsection{Implications for Future Research, Practice and Policy}

\subsubsection{Research Implications}

Researchers in current FOF exercise intervention research have not paid sufficient attention to reporting measures of exercise prescription. Particularly, principles of exercise training including overload, initial value, reversibility and diminishing return, and intensity in FITT components were reported in less than $50 \%$ of the included trials. This insufficient reporting of measures of exercise prescription might be a barrier to research reproduction and knowledge mobilization. To address this gap, future research involving exercise interventions should report the application of exercise principles and FITT components more transparently. The Consensus on Exercise Reporting Template (CERT) is a good tool to help researchers document the essential components of exercise intervention in various study designs. $^{47}$

Given the critical role of balance exercise in addressing the issue of FOF in older adults, there is a need for the establishment of reliable instruments to measure the intensity of balance exercises. More studies should focus on testing the dose-response effect of exercise interventions to identify the minimum doses required for effective interventions to address FOF. Furthermore, most trials in this study were focused on the causal effect of an exercise intervention on FOF alleviation, but little is known about the underlying mechanisms. Therefore, more research needs to explore the interaction between exercise dosage, physical performance, and FOF reduction. Given the significant long-term effect of CBT-based intervention, researchers should expand studies comparing the effects of CBT intervention alone on FOF reduction among older adults with a high level of functional impairment to the effects on older adults with a low level of functional impairment. Finally, to prolong the benefits of exercise interventions, 
researchers should develop more sustainable exercise programs, meaning that participants should be given adequate support to continue the exercise programs after the end of the interventions.

\subsubsection{Practice Implications}

This study showed that exercise interventions in previous RCTs that used balance exercises or were implemented in group settings have larger effect sizes than other types or one-to-one exercises. Regarding the dose of FOF exercises, most of the interventions with significant effects on FOF reduction used a frequency $\geq 3$ times per week for at least 12 weeks, a duration $\geq 30$ minutes for each session, and moderate-intensity (RPE from 12 to 13, HRmax from 64\% to 76\%, 1RM from 60\% to $70 \%$ ). Therefore, balance exercise or integrating a balance component into an exercise program should be emphasized for older adults who are at risk of FOF. Finally, any exercise program at moderate intensity at least three times per week for 30 minutes each time is recommended for community-dwelling older adults with FOF.

\subsubsection{Policy Implication}

In light of the high prevalence and adverse impact of FOF in community-dwelling older adults, policymakers should emphasize the FOF issue by supporting screening tools, identifying patients at risk of FOF and providing resources to develop effective interventions to cope with FOF. First, general physicians are uniquely positioned to identify older adults at risk of FOF and facilitate exercise participation. It has been reported that older adults who receive advice and support about physical activity from their physicians are more likely to participate in a regular physical activity program. ${ }^{48}$ To raise awareness of the FOF issue in older adults, an educational brochure that provides an overview of concepts, risk factors, consequences, and recommended interventions of FOF can be distributed to general physicians as well as other healthcare providers. Secondly, simple assessment tools such as FES-I, ABC, SAFE, or single-item questions can be used to identify older adults likely to benefit from an exercise program aimed at reducing FOF in primary care settings. Finally, an exercise program with an emphasis on the balance component and proper dosage that is implemented in a community group setting can be an effective intervention to reduce FOF and improve physical function for older adults. To this end, grant 
funding should be made available to create a community-based exercise program specifically to address FOF.

\subsection{Strengths and Limitations}

This study included 75 RCTs in the qualitative review and 50 RCTs in the meta-analysis. It is the largest and the first comprehensive overview to date of the effect of exercise interventions on reducing FOF based on the exercise principles and FITT components. To reduce the risk of publication bias, a comprehensive searching strategy was established with the assistance of a health science librarian, and a wide range of databases was searched without restricting publication dates and languages. Ensuring a rigorous systematic review, the PRISMA and AMSTAR2 checklists and Cochrane guidelines were followed when conducting and reporting this study. Two reviewers conducted a pilot test of dataextracting sheets independently to ensure systematic data collection. This study considered the impact of a sample size of the included RCTs, the methodological quality of the trials and the use of a different data set (chang-from-baseline values) when estimating the effect of exercise interventions in FOF reduction. With subgroup analyses, this study helped gain insight into the effectiveness of FOF exercise interventions regarding the characteristics of exercise prescription.

However, this study includes several possible limitations. In particular, the exclusion of trials focusing on condition-specific clinical populations such as participants with stroke and long-term care residents has limited the generalizability to all older adults with FOF. Furthermore, due to the discrepancies of follow-up reports after exercise interventions in reviewed studies, the long-term effects of FOF exercise interventions were not investigated in this study. Additionally, concrete evidence on how variables related to exercise prescriptions such as intensity and supervised or non-supervised delivery of exercises impact the effectiveness of FOF exercise interventions is yet to be clarified. The inadequate reports of exercise principles and parameters undermine efforts to thoroughly examine the optimal dosage and progression for FOF exercise prescription. Trials included in this study also showed a high risk of performance bias since no trials masked participants and therapists. However, it should be noted that masking participants and therapists for exercise interventions is extremely difficult in such studies. 


\subsection{Conclusion}

Previous RCTs did not fully and consistently report the measures of exercise prescriptions. In the reviewed trials, most principles of exercise training (overload, initial values, reversibility, and diminishing return) and intensity in FITT components were not sufficiently reported. Exercise interventions in previous RCTs had an overall small-to-moderate effect size on reducing FOF in community-dwelling older adults, and balance exercise had the largest effect size of all types of exercise interventions (i.e., multi-component, resistance, aerobic, 3D and novel exercises). Furthermore, although most of the trials had good methodological quality, the risks of performance, detection and selection biases were relatively high across trials. Future research should provide a more comprehensive reporting of the exercise principles and FITT components to translate robust research findings into clinical practice. The present author recommends that community-dwelling older adults with FOF participate in moderate-intensity group exercise programs with a balance exercise component at least three times per week for 30 minutes in each session. Authorities should make these programs available for older adults at risk of FOF. 


\subsection{References}

1. Ammann BC, Knols RH, Baschung P, De Bie RA, de Bruin ED. Application of principles of exercise training in sub-acute and chronic stroke survivors: a systematic review. BMC Neurology. 2014;14(1):167.

2. Neil-Sztramko SE, Winters-Stone KM, Bland KA, Campbell KL. Updated systematic review of exercise studies in breast cancer survivors: attention to the principles of exercise training. British Journal of Sports Medicine. 2019;53(8):504.

3. Mueller MJ, Maluf KS. Tissue adaptation to physical stress: a proposed "physical stress theory" to guide physical therapist practice, education, and research. Physical Therapy. 2002;82(4):383-403.

4. Devereux K, Robertson D, Briffa NK. Effects of a water-based program on women 65 years and over: a randomised controlled trial. Australian Journal of Physiotherapy. 2005;51(2):102-108.

5. Logghe IHJ, Zeeuwe PEM, Verhagen AP, et al. Lack of effect of Tai Chi Chuan in preventing falls in elderly people living at home: a randomized clinical trial. Journal of the American Geriatrics Society. 2009;57(1):70-75.

6. Li F, Fisher K, Harmer P, McAuley E. Falls self-efficacy as a mediator of fear of falling in an exercise intervention for older adults. Journals of Gerontology Series $B$ Psychological Sciences \& Social Sciences. 2005;60(1):34-40.

7. Li F, Harmer P, Chou LS. Dual-task walking capacity mediates Tai Ji Quan impact on physical and cognitive function. Medicine and Science in Sports and Exercise. 2019;51(11):2318-2324.

8. Li F, Harmer P, Fisher KJ, et al. Tai Chi and fall reductions in older adults: a randomized controlled trial. The Journals of Gerontology Series A: Biological Sciences and Medical Sciences. 2005;60(2):187-194.

9. Liu YW, Tsui CM. A randomized trial comparing Tai Chi with and without cognitivebehavioral intervention (CBI) to reduce fear of falling in community-dwelling elderly people. Archives of Gerontology \& Geriatrics. 2014;59(2):317-325.

10. Wu G, Keyes L, Callas P, Ren X, Bookchin B. Comparison of telecommunication, community, and home-based Tai Chi exercise programs on compliance and effectiveness in elders at risk for falls. Archives of Physical Medicine \& Rehabilitation. 2010;91(6):849-856.

11. Sattin RW, Easley KA, Wolf SL, Chen Y, Kutner MH. Reduction in fear of falling through intense tai chi exercise training in older, transitionally frail adults. Journal of the American Geriatrics Society. 2005;53(7):1168-1178.

12. American College of Sports Medicine. ACSM's Guidelines for Exercise Testing and Prescription. Lippincott Williams \& Wilkins; 2013.

13. Arai T, Obuchi S, Inaba Y, et al. The effects of short-term exercise intervention on falls self-efficacy and the relationship between changes in physical function and falls self-efficacy in Japanese older people: a randomized controlled trial. American Journal of Physical Medicine \& Rehabilitation. 2007;86(2):133-141.

14. Bao T, Carender WJ, Kinnaird C, et al. Effects of long-term balance training with vibrotactile sensory augmentation among community-dwelling healthy older adults: a randomized preliminary study. Journal of Neuroengineering \& Rehabilitation. 2018;15(1):5.

15. Barban F, Annicchiarico R, Melideo M, et al. Reducing fall risk with combined motor and cognitive training in elderly fallers. Brain Sciences. 2017;7(2):19.

16. Boongird C, Keesukphan P, Phiphadthakusolkul S, Rattanasiri S, Thakkinstian A. Effects of a simple home-based exercise program on fall prevention in older adults: a 
12-month primary care setting, randomized controlled trial. Geriatrics \& Gerontology International. 2017;17(11):2157-2163.

17. Clemson L, Singh MF, Bundy A, et al. LiFE pilot study: a randomised trial of balance and strength training embedded in daily life activity to reduce falls in older adults. Australian Occupational Therapy Journal. 2010;57(1):42-50.

18. Freiberger E, Haberle L, Spirduso WW, Zijlstra GA. Long-term effects of three multicomponent exercise interventions on physical performance and fall-related psychological outcomes in community-dwelling older adults: a randomized controlled trial. Journal of the American Geriatrics Society. 2012;60(3):437-446.

19. Gallo E, Stelmach M, Frigeri F, Ahn D-H. Determining whether a dosage-specific and individualized Home Exercise Program with consults reduces fall risk and falls in community-dwelling older adults with difficulty walking: a randomized control trial. Journal of Geriatric Physical Therapy. 2018;41(3):161-172.

20. Haines TP, Russell T, Brauer SG, et al. Effectiveness of a video-based exercise programme to reduce falls and improve health-related quality of life among older adults discharged from hospital: a pilot randomized controlled trial. Clinical Rehabilitation. 2009;23(11):973-985.

21. Henwood TR, Riek S, Taaffe DR. Strength versus muscle power-specific resistance training in community-dwelling older adults. Journals of Gerontology Series ABiological Sciences \& Medical Sciences. 2008;63(1):83-91.

22. Patil R, Karinkanta S, Tokola K, Kannus P, Sievanen H, Uusi-Rasi K. Effects of vitamin $\mathrm{D}$ and exercise on the wellbeing of older community-dwelling women: a randomized controlled trial. Gerontology. 2016;62(4):401-408.

23. Roller M, Kachingwe A, Beling J, Ickes DM, Cabot A, Shrier G. Pilates reformer exercises for fall risk reduction in older adults: a randomized controlled trial. Journal of Bodywork \& Movement Therapies. 2017;22(4):983-998.

24. Wetherell JL, Bower ES, Johnson K, Chang DG, Ward SR, Petkus AJ. Integrated exposure therapy and exercise reduces fear of falling and avoidance in older adults: a randomized pilot study. American Journal of Geriatric Psychiatry. 2018;26(8):849859.

25. Zhang L, Weng C, Liu M, Wang Q, Liu L, He Y. Effect of whole-body vibration exercise on mobility, balance ability and general health status in frail elderly patients: a pilot randomized controlled trial. Clinical Rehabilitation. 2014;28(1):59-68.

26. Zhao Y, Chung PK, Tong TK. Effectiveness of a community-based exercise program on balance performance and fear of falling in older nonfallers at risk for falling: a randomized, controlled study. Journal of Aging \& Physical Activity. 2016;24(4):516524.

27. McCormack G, Lewin G, McCormack B, Helmes E, Rose E, Naumann F. Pilot study comparing the influence of different types of exercise intervention on the fear of falling in older adults. Australasian Journal on Ageing. 2004;23(3):131-135.

28. Jørstad EC, Hauer K, Becker C, Lamb SE, Group obotP. Measuring the psychological outcomes of falling: a systematic review. Journal of the American Geriatrics Society. 2005;53(3):501-510.

29. Rivera-Brown AM, Frontera WR. Principles of exercise physiology: responses to acute exercise and long-term adaptations to training. Pm\&r. 2012;4(11):797-804.

30. Denkinger MD, Lukas A, Nikolaus T, Hauer K. Factors associated with fear of falling and associated activity restriction in community-dwelling older adults: a systematic review. The American Journal of Geriatric Psychiatry. 2015;23(1):72-86.

31. McAuley E, Mihalko SL, Rosengren K. Self-efficacy and balance correlates of fear of falling in the elderly. Journal of Aging and Physical Activity. 1997;5(4):329-340. 
32. Duque G, Boersma D, Loza-Diaz G, et al. Effects of balance training using a virtualreality system in older fallers. Clinical Interventions in Aging. 2013;8:257-263.

33. Farlie MK, Keating JL, Molloy E, et al. The Balance Intensity Scales for therapists and exercisers measure balance exercise intensity in older adults: initial validation using Rasch analysis. Physical Therapy. 2019;99(10):1394-1404.

34. Kendrick D, Kumar A, Carpenter H, et al. Exercise for reducing fear of falling in older people living in the community. Cochrane Library. 2014;2015(11):CD009848CD009848.

35. Kumar A, Delbaere K, Zijlstra G, et al. Exercise for reducing fear of falling in older people living in the community: Cochrane systematic review and meta-analysis. Age and Ageing. 2016;45(3):345-352.

36. Yoshikawa A, Ramirez G, Smith ML, Lee S, Ory MG. Systematic review and metaanalysis of fear of falling and fall-related efficacy in a widely disseminated community-based fall prevention program. Archives of Gerontology and Geriatrics. 2020;91:104235.

37. Dechartres A, Trinquart L, Boutron I, Ravaud P. Influence of trial sample size on treatment effect estimates: meta-epidemiological study. BMJ. 2013;346.

38. Zlowodzki M, Poolman RW, Kerkhoffs GM, Tornetta III P, Bhandari M, Group IEBOSW. How to interpret a meta-analysis and judge its value as a guide for clinical practice. Acta Orthopaedica. 2007;78(5):598-609.

39. Savović J, Jones HE, Altman DG, et al. Influence of reported study design characteristics on intervention effect estimates from randomized, controlled trials. Annals of Internal Medicine. 2012;157(6):429-438.

40. Kruisbrink M, Delbaere K, Kempen GI, et al. Intervention characteristics associated with a reduction in fear of falling among community-dwelling older people: a systematic review and meta-analysis of randomized controlled trials. The Gerontologist. 2020.

41. Hayashi T, Kondo K, Kanamori S, et al. Differences in falls between older adult participants in group exercise and those who exercise alone: a cross-sectional study using Japan Gerontological Evaluation Study (JAGES) data. International Journal of Environmental Research and Public Health. 2018;15(7):1413.

42. Liu T-W, Ng GY, Chung RC, Ng SS. Cognitive behavioural therapy for fear of falling and balance among older people: a systematic review and meta-analysis. Age and Ageing. 2018;47(4):520-527.

43. Chua CHM, Jiang Y, Lim DS, Wu VX, Wang W. Effectiveness of cognitive behaviour therapy-based multicomponent interventions on fear of falling among community-dwelling older adults: a systematic review and meta-analysis. Journal of Advanced Nursing. 2019;75(12):3299-3315.

44. Sjösten N, Vaapio S, Kivelä S-L. The effects of fall prevention trials on depressive symptoms and fear of falling among the aged: a systematic review. Aging and Mental Health. 2008;12(1):30-46.

45. Young WR, Williams AM. How fear of falling can increase fall-risk in older adults: applying psychological theory to practical observations. Gait \& Posture. 2015;41(1):7-12.

46. Barnett A, Smith B, Lord SR, Williams M, Baumand A. Community-based group exercise improves balance and reduces falls in at-risk older people: a randomised controlled trial. Age \& Ageing. 2003;32(4):407-414.

47. Slade SC, Dionne CE, Underwood M, Buchbinder R. Consensus on Exercise Reporting Template (CERT): explanation and elaboration statement. British Journal of Sports Medicine. 2016;50(23):1428-1437. 
48. Booth ML, Bauman A, Owen N, Gore CJ. Physical activity preferences, preferred sources of assistance, and perceived barriers to increased activity among physically inactive Australians. Preventive Medicine. 1997;26(1):131-137. 


\section{Appendix A Search History from EMBASE}

\begin{tabular}{|c|c|c|}
\hline \multicolumn{2}{|r|}{ EMBASE } & \multirow[b]{2}{*}{ Results } \\
\hline \# & Searches & \\
\hline 1 & Fear/ & 30559 \\
\hline 2 & exp Psychological Trauma/ & 962 \\
\hline 3 & Resilience, Psychological/ & 5016 \\
\hline 4 & exp Accidental Falls/ & 22988 \\
\hline 5 & or/1-3 & 36412 \\
\hline 6 & 4 and 5 & 761 \\
\hline 7 & exp Exercise/ or exp Exercise Therapy/ & 215658 \\
\hline 8 & train*. mp. & 537699 \\
\hline 9 & 7 or 8 & 700952 \\
\hline 10 & 6 and 9 & 216 \\
\hline 11 & $\begin{array}{l}\text { exp Randomized Controlled Trials as Topic/ or exp Clinical Trials } \\
\text { as Topic/ or Treatment Outcome/ }\end{array}$ & 1286713 \\
\hline 12 & exp Humans/ & 18104851 \\
\hline 13 & 11 or 12 & 18139621 \\
\hline 14 & 10 and 13 & 216 \\
\hline 15 & limit 14 to "all aged (65 and over)" & 196 \\
\hline
\end{tabular}




\section{Appendix B Search History from PsycINFO}

\begin{tabular}{|l|l|r|}
\hline \multicolumn{2}{|c|}{ PsycINFO } \\
\hline$\#$ & Searches & Results \\
\hline 1 & falls/ & 22988 \\
\hline 2 & Fear/ & 30559 \\
\hline 3 & 1 and 2 & 759 \\
\hline 4 & exp Exercise/ & 185066 \\
\hline 5 & exp Exercise Therapy/ & 47935 \\
\hline 6 & 4 or 5 & 215658 \\
\hline 7 & 3 and 6 & 131605 \\
\hline 8 & exp Randomized Controlled Trials as Topic/ & 583362 \\
\hline 9 & exp controlled clinical trial/ & 707209 \\
\hline 10 & 8 or 9 & 69 \\
\hline 11 & 7 and 10 & \\
\hline
\end{tabular}




\section{Appendix C Search History from Medline}

\begin{tabular}{|c|c|c|}
\hline \multicolumn{3}{|c|}{ Medline } \\
\hline$\#$ & Searches & Results \\
\hline 1 & (fear adj5 fall*).mp. & 1702 \\
\hline 2 & (concern* adj5 fall*).mp. & 645 \\
\hline 3 & (afraid adj5 fall*).mp. & 55 \\
\hline 4 & (psychol* adj5 fall*).mp. & 255 \\
\hline 5 & (self efficacy adj5 fall*).mp & 215 \\
\hline 6 & (balance adj5 confiden*).mp. & 966 \\
\hline 7 & or/1-6 & 3364 \\
\hline 8 & exercis*.mp & 366553 \\
\hline 9 & training.mp. & 417366 \\
\hline 10 & $\begin{array}{l}\text { exp exercise therapy/ or endurance training/ or motion therapy, } \\
\text { continuous passive/or muscle stretching exercises/ or plyometric } \\
\text { exercise/ or resistance training/ }\end{array}$ & 47935 \\
\hline 11 & exp exercise/or muscle stretching exercises/ & 185066 \\
\hline 12 & or/8-11 & 762913 \\
\hline 13 & exp Nervous System Diseases/ & 2438570 \\
\hline 14 & exp Musculoskeletal Diseases/ & 1056304 \\
\hline 15 & 13 or 14 & 3273144 \\
\hline 16 & 7 and 12 & 1160 \\
\hline 17 & 16 not 15 & 776 \\
\hline 18 & exp controlled clinical trial/or exp randomized controlled trial/ & 583362 \\
\hline 19 & 17 and 18 & 195 \\
\hline
\end{tabular}


Appendix D Search History from CINAHL

\begin{tabular}{|c|c|c|c|c|}
\hline \multicolumn{5}{|c|}{ CINAHL } \\
\hline$\#$ & Query & Limiters/Expanders & Last Run Via & Results \\
\hline S5 & S3 AND S4 & $\begin{array}{l}\text { Expanders - Apply } \\
\text { related words; Apply } \\
\text { equivalent subjects } \\
\text { Search modes - } \\
\text { Boolean/Phrase }\end{array}$ & $\begin{array}{l}\text { Interface - EBSCOhost } \\
\text { Research Databases } \\
\text { Search Screen - } \\
\text { Advanced Search } \\
\text { Database - CINAHL }\end{array}$ & 122 \\
\hline S4 & $\begin{array}{l}\text { (MH } \\
\text { "Therapeutic } \\
\text { Exercise+") }\end{array}$ & $\begin{array}{l}\text { Expanders - Apply related } \\
\text { words; Apply equivalent } \\
\text { subjects Search } \\
\text { Boolean/Phrase modes - }\end{array}$ & $\begin{array}{l}\text { Interface - EBSCOhost } \\
\text { Research Databases } \\
\text { Search Screen - } \\
\text { Advanced Search } \\
\text { Database - CINAHL }\end{array}$ & 47,762 \\
\hline S3 & S1 OR S2 & $\begin{array}{l}\text { Expanders - Apply related } \\
\text { words; Apply equivalent } \\
\text { subjects Search } \\
\text { Boolean/Phrase modes - } \\
\text { equivalent subjects Search } \\
\text { modes -Boolean/Phrase }\end{array}$ & $\begin{array}{l}\text { Interface - EBSCOhost } \\
\text { Research Databases } \\
\text { Search Screen - } \\
\text { Advanced Search } \\
\text { Database - CINAHL }\end{array}$ & 1,296 \\
\hline S2 & $\begin{array}{l}\text { (MH } \\
\text { "Accidental } \\
\text { Falls/PF") }\end{array}$ & $\begin{array}{l}\text { Expanders - Apply related } \\
\text { words; Apply equivalent } \\
\text { subjects Search } \\
\text { Boolean/Phrase modes - } \\
\text { equivalent subjects Search } \\
\text { modes -Boolean/Phrase }\end{array}$ & $\begin{array}{l}\text { Interface - EBSCOhost } \\
\text { Research Databases } \\
\text { Search Screen - } \\
\text { Advanced Search } \\
\text { Database - CINAHL }\end{array}$ & 338 \\
\hline S1 & "fear of fall*" & $\begin{array}{l}\text { Expanders - Apply related } \\
\text { words; Apply equivalent } \\
\text { subjects Search modes - } \\
\text { Boolean/Phrase }\end{array}$ & $\begin{array}{l}\text { Interface - EBSCOhost } \\
\text { Research Databases } \\
\text { Search Screen - } \\
\text { Advanced Search } \\
\text { Database - CINAHL }\end{array}$ & 1,141 \\
\hline
\end{tabular}




\section{Appendix E Excluded Studies and Reasons for Exclusion}

\begin{tabular}{|c|c|c|c|}
\hline Author & Year & Title & reasons \\
\hline Clemson, L & 2004 & $\begin{array}{l}\text { The Effectiveness of a Community-Based Program for Reducing the Incidence of Falls in the Elderly: A } \\
\text { Randomized Trial }\end{array}$ & Multi-component intervention \\
\hline Gawler, S & 2016 & Reducing falls among older people in general practice: The ProAct65+ exercise intervention trial & Identical data source \\
\hline Gitlin, L & 2008 & Variation in response to a home intervention to support daily function by age, race, sex, and education & non-RCT \\
\hline Hinman & 2002 & Comparison of Two Short-term Balance Training Programs for Community-dwelling Older Adults & age $<65$ \\
\hline Lajoie, Y. & 2004 & Effect of computerized feedback postural training on posture and attentional demands in older adults & non-RCT \\
\hline Lin, M. R. & 2006 & Community-based tai chi and its effect on injurious falls, balance, gait, and fear of falling in older people & non-RCT \\
\hline Montero-Alía, P & 2019 & Controlled trial of balance training using a video game console in community-dwelling older adults & non-RCT \\
\hline Nguyen, $\mathrm{M}$ & 2012 & $\begin{array}{l}\text { A randomized controlled trial of Tai chi for balance, sleep quality and cognitive performance in elderly } \\
\text { Vietnamese }\end{array}$ & age $<65$ \\
\hline Pirauá, A & 2019 & $\begin{array}{l}\text { Effect of 24-week strength training on unstable surfaces on mobility, balance, and concern about falling in } \\
\text { older adults }\end{array}$ & age $<65$ \\
\hline Reinsch, S. & 1992 & Attempts to prevent falls and injury: a prospective community study & age $<65$ \\
\hline Rendon, A. A. & 2012 & The effect of virtual reality gaming on dynamic balance in older adults & age $<65$ \\
\hline Resnick, B. & 2008 & Testing the Senior Exercise Self-efficacy Project (SESEP) for use with urban dwelling minority older adults & non-exercise intervention \\
\hline Robertson, M. C. & 2001 & $\begin{array}{l}\text { Effectiveness and economic evaluation of a nurse delivered home exercise programme to prevent falls. 1: } \\
\qquad \text { Randomised controlled trial }\end{array}$ & no FOF outcome measures \\
\hline Sihvonen, S. & 2004 & Fall incidence in frail older women after individualized visual feedback-based balance training & $\begin{array}{l}\text { Participants were } \\
\text { institutionalized }\end{array}$ \\
\hline Sihvonen, S. E. & 2004 & $\begin{array}{c}\text { Changes in postural balance in frail elderly women during a 4-week visual feedback training: a randomized } \\
\text { controlled trial }\end{array}$ & $\begin{array}{l}\text { Participants were } \\
\text { institutionalized }\end{array}$ \\
\hline
\end{tabular}




\begin{tabular}{|c|c|c|c|}
\hline Author & Year & Title & reasons \\
\hline Tiedemann, A. & 2013 & $\begin{array}{c}\text { A 12-week Iyengar yoga program improved balance and mobility in older community-dwelling people: a pilot } \\
\text { randomized controlled trial }\end{array}$ & age $<65$ \\
\hline Tiedemann, A. & 2012 & Can yoga improve balance in older people?: A randomised controlled trial & age $<65$ \\
\hline Tinetti, $\mathrm{M}$ & 1994 & A multifactorial intervention to reduce the risk of falling among elderly people living in the community & non-RCT \\
\hline Vind, A & 2010 & $\begin{array}{l}\text { Effect of a program of multifactorial fall prevention on health-related quality of life, functional ability, fear of } \\
\text { falling and psychological well-being. A randomized controlled trial }\end{array}$ & Multi-component intervention \\
\hline Vrantsidis, F. & 2009 & Getting Grounded Gracefully: effectiveness and acceptability of Feldenkrais in improving balance & age $<65$ \\
\hline Wallsten, S & 2006 & $\begin{array}{c}\text { The Effect of Tai Chi Chuan on Confidence and Lower Extremity Strength and Balance in Residents Living } \\
\text { Independently at a Continuing Care Retirement Community }\end{array}$ & age $<65$ \\
\hline Weerdesteyn, V. & 2006 & A five-week exercise program can reduce falls and improve obstacle avoidance in the elderly & non-RCT \\
\hline Yates, $\mathrm{S}$ & 2001 & $\begin{array}{l}\text { Evaluating the effectiveness of a home-based fall risk reduction program for rural community-dwelling older } \\
\text { adults }\end{array}$ & Non-exercise intervention \\
\hline Lin, M. R. & 2006 & Community-based tai chi and its effect on injurious falls, balance, gait, and fear of falling in older people & non-RCT \\
\hline Reinsch, S. & 1992 & Attempts to prevent falls and injury: a prospective community study & age $<65$ \\
\hline Zhang, J. G. & 2006 & $\begin{array}{l}\text { The effects of Tai Chi Chuan on physiological function and fear of falling in the less robust elderly: an } \\
\text { intervention study for preventing falls }\end{array}$ & age $<65$ \\
\hline Donat, $\mathrm{H}$. & 2007 & $\begin{array}{l}\text { Comparison of the effectiveness of two programmes on older adults at risk of falling: unsupervised home } \\
\text { exercise and supervised group exercise }\end{array}$ & $\begin{array}{l}\text { Participants were } \\
\text { institutionalized }\end{array}$ \\
\hline Frandin, $\mathrm{K}$. & 2009 & $\begin{array}{l}\text { A Nordic multi-center study on physical and daily activities for residents in nursing home settings: design of a } \\
\text { randomized, controlled trial }\end{array}$ & $\begin{array}{l}\text { Participants were } \\
\text { institutionalized }\end{array}$ \\
\hline Frandin, K. & 2016 & $\begin{array}{l}\text { Long-Term Effects of Individually Tailored Physical Training and Activity on Physical Function, Well-Being } \\
\text { and Cognition in Scandinavian Nursing Home Residents: A Randomized Controlled Trial }\end{array}$ & $\begin{array}{l}\text { Participants were } \\
\text { institutionalized }\end{array}$ \\
\hline Furtado, G & 2016 & $\begin{array}{l}\text { Effects of a chair-yoga exercises on stress hormone levels, daily life activities, falls and physical fitness in } \\
\text { institutionalized older adults }\end{array}$ & $\begin{array}{l}\text { Participants were } \\
\text { institutionalized }\end{array}$ \\
\hline
\end{tabular}




\begin{tabular}{|c|c|c|c|}
\hline Author & Year & Title & reasons \\
\hline Gusi, N. & 2012 & $\begin{array}{l}\text { Balance training reduces fear of falling and improves dynamic balance and isometric strength in } \\
\qquad \text { institutionalised older people: a randomised trial }\end{array}$ & $\begin{array}{l}\text { Participants were } \\
\text { institutionalized }\end{array}$ \\
\hline Hauer, K. & 2003 & $\begin{array}{l}\text { Two years later: a prospective long-term follow-up of a training intervention in geriatric patients with a } \\
\text { history of severe falls }\end{array}$ & $\begin{array}{l}\text { Participants were } \\
\text { institutionalized }\end{array}$ \\
\hline Halvarsson, A & 2012 & $\begin{array}{l}\text { Long-term effects of new progressive group balance training for elderly people with increased risk of falling - } \\
\text { a randomized controlled trial }\end{array}$ & Identical data source \\
\hline Hewitt, J & 2018 & $\begin{array}{l}\text { Progressive Resistance and Balance Training for Falls Prevention in Long-Term Residential Aged Care: A } \\
\text { Cluster Randomized Trial of the Sunbeam Program }\end{array}$ & $\begin{array}{l}\text { Participants were } \\
\text { institutionalized }\end{array}$ \\
\hline Hewitt, J. & 2014 & $\begin{array}{l}\text { Does progressive resistance and balance exercise reduce falls in residential aged care? Randomized controlled } \\
\text { trial protocol for the SUNBEAM program }\end{array}$ & $\begin{array}{l}\text { Participants were } \\
\text { institutionalized }\end{array}$ \\
\hline Huang, T & 2016 & $\begin{array}{l}\text { Evaluation of a combined cognitive-behavioural and exercise intervention to manage fear of falling among } \\
\text { elderly residents in nursing homes }\end{array}$ & $\begin{array}{l}\text { Participants were } \\
\text { institutionalized }\end{array}$ \\
\hline Rossano, C & 2016 & $\begin{array}{l}\text { Visually- guided gait training in paretic patients during the first rehabilitation phase: study protocol for a } \\
\text { randomized controlled trial }\end{array}$ & $\begin{array}{l}\text { Participants were } \\
\text { institutionalized }\end{array}$ \\
\hline Sanchez - Padilla, M & 2016 & Effectiveness of a Proprioceptive Exercise Program in Nursing Home Residents & $\begin{array}{l}\text { Participants were } \\
\text { institutionalized }\end{array}$ \\
\hline Schoenfelder, D. P & 2000 & A fall prevention program for elderly individuals. Exercise in long-term care settings & $\begin{array}{l}\text { Participants were } \\
\text { institutionalized }\end{array}$ \\
\hline Schoenfelder, D. P. & 2004 & An exercise program to improve fall-related outcomes in elderly nursing home residents & $\begin{array}{l}\text { Participants were } \\
\text { institutionalized }\end{array}$ \\
\hline Tousignant, $\mathrm{M}$. & 2012 & $\begin{array}{l}\text { The effect of supervised Tai Chi intervention compared to a physiotherapy program on fall-related clinical } \\
\text { outcomes: a randomized clinical trial }\end{array}$ & $\begin{array}{l}\text { Participants were } \\
\text { institutionalized }\end{array}$ \\
\hline Underwood, $\mathrm{M}$. & 2011 & $\begin{array}{l}\text { The OPERA trial: protocol for a randomised trial of an exercise intervention for older people in residential } \\
\text { and nursing accommodation }\end{array}$ & $\begin{array}{l}\text { Participants were } \\
\text { institutionalized }\end{array}$ \\
\hline
\end{tabular}




\begin{tabular}{|c|c|c|c|}
\hline Author & Year & Title & reasons \\
\hline Aibar-Almazán, A & 2019 & Effects of Pilates on fall risk factors in community-dwelling elderly women: A randomized, controlled trial & age $<65$ \\
\hline Azizan, A & 2015 & Elders' Exercise and Behavioral Program: Effects on Balance and Fear of Falls & age $<65$ \\
\hline Beauvais, A & 2014 & Reducing the Fear of Falling Through a Community Evidence-Based Intervention & non-RCT \\
\hline Boon Chong, K & 2016 & $\begin{array}{l}\text { Effects of Wii Active exercises on fear of falling and functional outcomes in community-dwelling older } \\
\text { adults: a randomised control trial }\end{array}$ & age $<65$ \\
\hline Britten, L & 2017 & $\begin{array}{l}\text { Dancing in time: feasibility and acceptability of a contemporary dance programme to modify risk factors for } \\
\qquad \text { falling in community dwelling older adults }\end{array}$ & age $<65$ \\
\hline Brovold, T. & 2012 & $\begin{array}{l}\text { The efficacy of counseling and progressive resistance home-exercises on adherence, health-related quality of } \\
\text { life and function after discharge from a geriatric day-hospital }\end{array}$ & age $<65$ \\
\hline Chen, $\mathrm{J}$ & 2018 & The Effects of Tae Kwon Do-Based Exercise vs. Standard Ba lance Exercises on Fall Risk in Older Adults & non-RCT \\
\hline de, Carvalho Fonseca & 2018 & $\begin{array}{c}\text { Effect of the Auricular Acupoint Associated with Physical Exercise in Elderly People: A Randomized Clinical } \\
\text { Test }\end{array}$ & age $<65$ \\
\hline Delbaere, $\mathrm{K}$ & 2006 & A home-based multidimensional exercise program reduced physical impairment and fear of falling & non-RCT \\
\hline Gomes, G. C. V. & 2018 & $\begin{array}{l}\text { Feasibility, safety, acceptability, and functional outcomes of playing Nintendo Wii Fit PlusTM for frail older } \\
\qquad \text { adults: A randomized feasibility clinical trial }\end{array}$ & age $<65$ \\
\hline Halvarsson, A & 2015 & $\begin{array}{l}\text { Taking balance training for older adults one step further: the rationale for and a description of a proven } \\
\text { balance training programme }\end{array}$ & non-RCT \\
\hline Hamrick, I. & 2017 & Yoga's effect on falls in rural, older adults & age $<65$ \\
\hline Hita-Contreras F & 2016 & Fall prevention in postmenopausal women: the role of Pilates exercise training & non-RCT \\
\hline Huang, T. T. & 2011 & $\begin{array}{l}\text { Reducing the fear of falling among community-dwelling elderly adults through cognitive-behavioural } \\
\text { strategies and intense Tai Chi exercise: a randomized controlled trial }\end{array}$ & age $<65$ \\
\hline Iliffe, $\mathrm{S}$ & 2015 & Promoting physical activity in older people in general practice: ProAct65+ cluster randomised controlled trial & \\
\hline Kuo, S. L. & 2011 & Effect of exercise intervention on balance and fear of falling in elderly subjects & non-RCT \\
\hline
\end{tabular}




\begin{tabular}{|c|c|c|c|}
\hline Author & Year & Title & reasons \\
\hline Kwok, B. C. & 2016 & $\begin{array}{l}\text { Effects of WiiActive exercises on fear of falling and functional outcomes in community-dwelling older adults: } \\
\qquad \text { a randomised control trial }\end{array}$ & age $<65$ \\
\hline Kwon, M. S. & 2011 & $\begin{array}{l}\text { [Effects of a fall prevention program on physical fitness and psychological functions in community dwelling } \\
\text { elders] }\end{array}$ & non-RCT \\
\hline Lin, M. R. & 2006 & Community-based tai chi and its effect on injurious falls, balance, gait, and fear of falling in older people & non-RCT \\
\hline Mihay, L. M. & 2006 & The effect of Tai Chi inspired exercise compared to strength training: a pilot study & non-RCT \\
\hline Padala, Kalpana P. & 2017 & $\begin{array}{l}\text { Efficacy of Wii-Fit on Static and Dynamic Balance in Community Dwelling Older Veterans: A Randomized } \\
\text { Controlled Pilot Trial }\end{array}$ & age $<65$ \\
\hline Pata, Rachel W. & 2014 & $\begin{array}{l}\text { e effect of Pilates based exercise on mobility, postural stability, and balance in order to decrease fall risk in } \\
\text { older adults }\end{array}$ & age $<65$ \\
\hline Prata, Melina Galleti & 2015 & $\begin{array}{l}\text { Effects of strength and balance training on the mobility, fear of falling and grip strength of elderly female } \\
\text { fallers }\end{array}$ & age $<65$ \\
\hline Robinson, James B. & 2018 & An Interdisciplinary Intervention for Fear of Falling: Lessons Learned from Two Case Studies & non-RCT \\
\hline Sá, César & 2019 & $\begin{array}{l}\text { Results of an Aquatic Exercise Program on Balance, Risk of Falls, Fear of Falling, and Quality of Life in } \\
\text { Older Adults }\end{array}$ & age $<65$ \\
\hline Sales, M. & 2017 & A Novel Exercise Initiative for Seniors to Improve Balance and Physical Function & age $<65$ \\
\hline Schilling, B. K. & 2009 & Effects of unstable surface training on measures of balance in older adults & age $<65$ \\
\hline Schwarting, A. E. & 2002 & The effectiveness of an intervention plan in decreasing fear of falling & non-RCT \\
\hline Singh, D. K. & 2012 & Participating in a virtual reality balance exercise program can reduce risk and fear of falls & age $<65$ \\
\hline Skinner, Elizabeth H. & 2016 & $\begin{array}{l}\text { An Ai Chi-based aquatic group improves balance and reduces falls in community-dwelling adults: A pilot } \\
\text { observational cohort study }\end{array}$ & non-RCT \\
\hline Taggart, Hm & 2002 & Effects of Tai Chi exercise on balance, functional mobility, and fear of falling among older women & non-RCT \\
\hline Takai, I & 2010 & $\begin{array}{c}\text { [Influence of balance exercises during an attention task on fear of falling among frail elderly fallen]. } \\
\text { [Japanese] }\end{array}$ & $\begin{array}{l}\text { Participants were } \\
\text { institutionalized }\end{array}$ \\
\hline
\end{tabular}




\begin{tabular}{|c|c|c|c|}
\hline Author & Year & Title & reasons \\
\hline Tisher, K. & 2019 & $\begin{array}{l}\text { Functional measures show improvements after a home exercise program following supervised balance } \\
\text { training in older adults with elevated fall risk }\end{array}$ & age $<65$ \\
\hline Toronjo-Hornillo, L & 2018 & $\begin{array}{l}\text { Effects of the Application of a Program of Adapted Utilitarian Judo (JUA) on the Fear of Falling Syndrome } \\
\qquad \text { (FOF) for the Health Sustainability of the Elderly Population }\end{array}$ & non-RCT \\
\hline Wetherell, Jl & 2016 & Activity, balance, learning, and exposure (ABLE): a new intervention for fear of falling & non-RCT \\
\hline $\mathrm{Wu}, \mathrm{G}$ & 2006 & Group tele-exercise for improving balance in elders & non-RCT \\
\hline Yan, T. & 2009 & Results from the Healthy Moves for Aging Well program: changes of the health outcomes & non-RCT \\
\hline Yang, $\mathrm{F}$ & 2015 & Controlled whole-body vibration training reduces risk of falls among community-dwelling older adults & non-RCT \\
\hline Yeung, Py & 2015 & $\begin{array}{c}\text { A community-based Falls Management Exercise Programme (FaME) improves balance, walking speed and } \\
\text { reduced fear of falling }\end{array}$ & age $<65$ \\
\hline Yoo, J. S. & 2013 & Effects of a Fall Prevention Program on Falls in Frail Elders Living at Home in Rural Communities & non-RCT \\
\hline Zhang, J. G. & 2006 & $\begin{array}{l}\text { The effects of Tai Chi Chuan on physiological function and fear of falling in the less robust elderly: an } \\
\text { intervention study for preventing falls }\end{array}$ & age $<65$ \\
\hline
\end{tabular}




\section{Appendix F Subgroup Analyses for Studies Using Change-from-baseline Values}

Subgroups by outcome measures

\begin{tabular}{|c|c|c|c|c|c|c|c|c|}
\hline \multirow[b]{2}{*}{ Study or Subgroup } & \multicolumn{3}{|c|}{ Exercise } & \multicolumn{3}{|c|}{ Control } & \multicolumn{2}{|r|}{ Std. Mean Difference } \\
\hline & Mean & SD & Total & Mean & SD & Total & Weight & IV, Random, $95 \% \mathrm{CI}$ \\
\hline \multicolumn{9}{|c|}{ 1.1.1 Balance confidence measured by $\mathrm{ABC}$ and ConfBal } \\
\hline Bao, T. 2018 & -0.4 & 7.207 & 6 & 0.2 & 4.742 & 6 & $0.6 \times$ & $-0.09[-1.22,1.04]$ \\
\hline Beyer, N. 2007 & -10.08 & 12.2 & 24 & -5 & 14.087 & 29 & $1.6 \%$ & $-0.3 B[-0.92,0.17]$ \\
\hline Broumer & -7.8 & 28.495 & 17 & -4 & 20.761 & 17 & $1.2 \%$ & $.82,0.52]$ \\
\hline Clemson, L2010 & -207.7 & 472.294 & 17 & -60 & 505.526 & 12 & $1.1 \mathrm{x}$ & $-0.30[-1.04,0.45]$ \\
\hline Clemson, L2012 & -140 & 3B1.84B & BO & -37 & & B2 & $2.6 \times$ & $-0.56,0.06]$ \\
\hline $\mathrm{Cya}_{\mathrm{a}}$ & -0.8992 & & 119 & 5 & & 48 & $2.3 \%$ & -1.2 \\
\hline Garrkg, M. 2013 & -14.82 & 26.533 & 22 & 7.9 & 22.5 & 19 & $1.3 \%$ & -0.90[ \\
\hline & & 2.9 & 19 & -0.1 & & 34 & $1.5 \%$ & \\
\hline Jagdh & -4.3 & 3.147 & 3 & 10.84 & B.456 & 3 & $0.1 \%$ & -1 \\
\hline $\mathrm{U}, \mathrm{F}$ & -1.06 & 1.621 & 125 & -0.17 & 1.641 & 131 & $2.9 \%$ & $-0.54[-0.79,-0.29]$ \\
\hline rose, T.2004 & -4.7545 & 23.8232 & 66 & -0.7 & 29.52 & 32 & $2.1 \%$ & $58,0.27]$ \\
\hline (n) & -5.91 & 24.962 & 27 & -5.96 & 27.265 & 28 & $1.7 \%$ & $0.53]$ \\
\hline t.w.2005 & -6.2 & 23.591 & 153 & 2.2 & 35.305 & $15 B$ & $3.0 \times$ & $0.50,-0.05]$ \\
\hline Smukders, E.2010 & -7.2 & 26.218 & 44 & -4.6 & 29.672 & 40 & $2.0 \mathrm{x}$ & $2,0.34]$ \\
\hline Szturm, T. 2011 & $-12 B$ & 340.262 & 13 & -33 & 418.693 & 14 & $1.0 \times$ & $0.52]$ \\
\hline ke, K. P. 2007 & -0.9 & 13.294 & 17 & $B .4$ & 26.46 & 19 & $1.3 \%$ & $09,0.24]$ \\
\hline Zhang, L 2014 & -20.64 & 30.609 & 19 & -11.34 & 25.45 & 18 & $1.3 \times$ & $2[-0.97,0.33]$ \\
\hline & & & 771 & & & & & \\
\hline & & & & & & & & \\
\hline
\end{tabular}

1.1.2 Concern about falling measured by FES-I and Short FES-I

\begin{tabular}{|c|c|c|c|c|c|c|c|c|}
\hline Arantes, M. 2015 & -4.4 & 12.102 & 15 & 2 & 11.604 & 13 & $1.1 \%$ & $-0.52[-1.28,0.23]$ \\
\hline Barban, F.2017 & -1.4 & 13.736 & 119 & -0.7 & 15.207 & 123 & $2.9 \times$ & $-0.05[-0.30,0.20]$ \\
\hline Er-Khoury, F. 2015 & 1.06 & 7.254 & 350 & 1.44 & 7.19 & 353 & 3.37 & $-0.05[-0.20,0.10]$ \\
\hline Frelberger, E. 2013 & -2 & 11.054 & 179 & 0.1 & 14.732 & 135 & $3.0 \%$ & $-0.16[-0.39,0.06]$ \\
\hline Halvarsson, A. 2011 & -6 & 8.485 & 34 & -2 & 12.042 & 21 & $1.6 \times$ & $-0.40[-0.94,0.15]$ \\
\hline Illffe, S. 2014 & -0.3781 & 5.3369 & 367 & -0.17 & 5.643 & $21 B$ & 3.37 & $-0.04[-0.21,0.13]$ \\
\hline Kapan,A.2016 & -4.2 & 18.619 & 39 & 0.1 & 17.528 & 41 & $2.0 \%$ & $-0.24[-0.68,0.20]$ \\
\hline Pattl, R. 2016 & -4.2 & 29.515 & 103 & 2 & 31.443 & 102 & $2.8 \%$ & $-0.20[-0.4 B, 0.07]$ \\
\hline Slegrist, M. 2016 & -1.8 & 11.045 & 167 & 0.1 & 14.217 & 108 & $2.9 \times$ & $-0.15[-0.40,0.09]$ \\
\hline Voukelatos, A.2015 & 0 & 6.501 & 144 & 0.1 & B.04 & 169 & $3.0 \%$ & $-0.01[-0.24,0.21]$ \\
\hline Wollesen, B. 2017 & -1.93 & $4.2 \mathrm{B2}$ & 30 & -0.17 & 5.33 & 18 & $1.5 \%$ & $-0.37[-0.96,0.22]$ \\
\hline Zhao, Y. 2016 & -11.5 & 14.5999 & $\begin{array}{r}40 \\
487\end{array}$ & -3.3 & 16.164 & 21 & $1.6 \%$ & $-0.53[-1.07,0.00]$ \\
\hline abtotal $(95 \% \mathrm{Cl})$ & & & 1587 & & & 1322 & $28.8 \%$ & $-0.11[-0.18,-0.03]$ \\
\hline
\end{tabular}

Test for overall efiect: $Z=2.85(\mathrm{P}=0.004)$

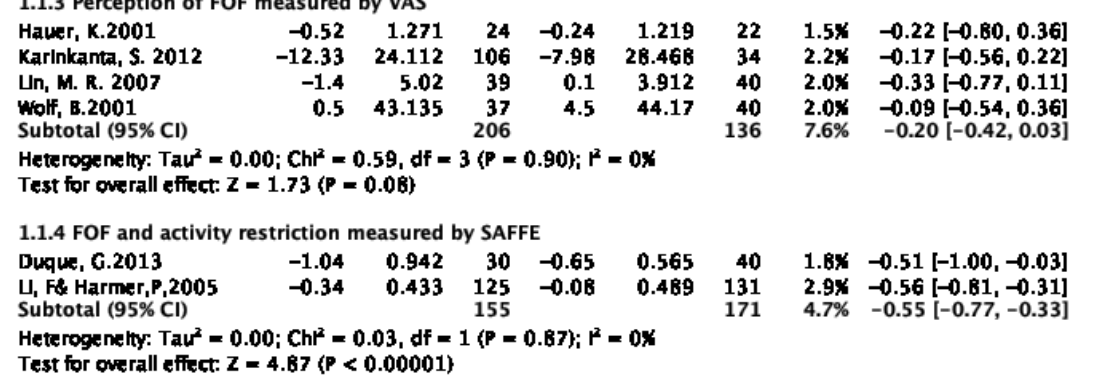

1.1.5 Falls efficacy measured by FES or MFES

\begin{tabular}{|c|c|c|c|c|c|c|c|c|}
\hline Aral, T. 2007 & -0.1 & 3.256 & 71 & -0.1 & 3.607 & 65 & $2.4 \%$ & $0.00[-0.34,0.34]$ \\
\hline Arkkukangas, M. 2015 & -5 & 26.559 & 13 & -12 & 30.246 & 12 & $1.0 \%$ & $0.24[-0.55,1.03]$ \\
\hline Arkkukangas, M.2019 & -0.5 & 30.694 & 54 & -6 & 33.565 & 55 & $2.3 \mathbf{x}$ & $0.17[-0.21,0.55]$ \\
\hline Campbell, A. J.1997 & 2.5 & 11.1 & 116 & 6.1 & 12.2 & 117 & 2.8X & $-0.31[-0.57,-0.05]$ \\
\hline Devereux, K. 2005 & -0.3 & 1.2 & 23 & -0.03 & 0.5 & 24 & $1.5 \%$ & $-0.29[-0.07,0.2 B]$ \\
\hline Gittln, L N. 2006 & -0.58 & 2.711 & 154 & 0.13 & 2.821 & 146 & $3.0 \mathrm{x}$ & $-0.26[-0.48,-0.03]$ \\
\hline Gschwind, Y.2015 & -3.6 & 10.017 & 78 & -4.4 & B.695 & 75 & 2.5\% & $0.0 B[-0.23,0.40]$ \\
\hline Jeon, M. Y. 2014 & -7.48 & 3.48 & 31 & -0.49 & 1.08 & 31 & $1.2 \%$ & $-2.68[-3.38,-1.98]$ \\
\hline Lal, C.H.2013 & -4.87 & B.937 & 15 & -1.73 & 38.902 & 15 & $1.1 \times$ & $-0.11[-0.82,0.61]$ \\
\hline ปи, H.2007 & -12.09 & 5.41 & 11 & -3.36 & 2.29 & 11 & $0.6 \times$ & $-2.02[-3.09,-0.96]$ \\
\hline he, I. H. J. 2009 & -1.1 & 6.66 & 110 & 0.1 & 7.286 & 103 & 2.BX & $-0.17[-0.44,0.10]$ \\
\hline Mocormack, G.2004 & -0.4 & 1.539 & 14 & 0.6 & 2.848 & 7 & $0 . \mathbf{B x}$ & $-0.47[-1.39,0.45]$ \\
\hline Schoene, D.2015 & -2.8 & 20.512 & 39 & 2.3 & 24.507 & 42 & $2.0 \%$ & $-0.22[-0.66,0.21]$ \\
\hline Ullmann, G. 2010 & -0.32 & 0.69 & 25 & 0.06 & 0.4784 & 22 & $1.5 \%$ & $-0.62[-1.21,-0.03]$ \\
\hline er.2009 & -0.45 & 2.545 & 114 & -0.3 & 2.408 & 57 & $2.5 \%$ & $-0.06[-0.38,0.26]$ \\
\hline Yang, X. J.2012 & -0.05 & 1.825 & 59 & 0.07 & 1.801 & 62 & $2.4 \%$ & $-0.07[-0.42,0.29]$ \\
\hline Yo, E. J. 2010 & -7.5 & 14.9 & 11 & -0.74 & 9.476 & 10 & $0.9 \%$ & $-0.51[-1.39,0.36]$ \\
\hline Subt & & & 938 & & & 854 & $1.3 \%$ & $-0.33[-0.55,-0.10]$ \\
\hline
\end{tabular}

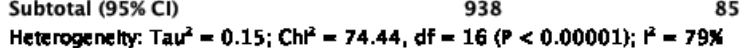

Heterogenelty: Taur $=0.15 ; \mathrm{ChH}^{2}=74.44, d f$
Test for overall effect: $\mathrm{Z}=2.87(\mathrm{P}=0.004)$

Total $(95 \% \mathrm{Cl}) \quad 3657 \quad 3173 \quad 100.0 \% \quad-0.28[-0.37,-0.19]$

Heterogenelty: $\mathrm{Tau}^{2}=0.06 ; \mathrm{Ch}^{2}=145.62, \mathrm{df}=51(\mathrm{P}<0.00001) ; \mathrm{I}^{2}=65 \%$

Test for overall effect: $Z=5.95(P<0.00001)$

Test for subgroup differences: $\mathrm{Ch}^{2}=20.24, \mathrm{df}=4(\mathrm{P}=0.0004), \mathrm{I}^{2}=80.2 \%$ 
Subgroups by type of exercise

\begin{tabular}{lrrrrrrrr} 
& \multicolumn{2}{c}{ Exercise } & \multicolumn{3}{c}{ Control } & \multicolumn{2}{c}{ Std. Mean Difference } \\
Study or Subgroup & Mean & SD & Total & Mean & SD & Total & Weight & IV, Random, 95\% CI \\
\hline 1.2.6 3D exercise & & & & & & & & \\
U, F.2005 & -1.06 & 1.621 & 125 & -0.17 & 1.641 & 131 & $2.8 \%$ & $-0.54[-0.79,-0.29]$ \\
U, F\& Harmer,P, 2005 & -0.34 & 0.433 & 125 & -0.08 & 0.489 & 131 & $2.8 \%$ & $-0.56[-0.81,-0.31]$ \\
Logghe, I. H. J. 2009 & -1.1 & 6.66 & 110 & 0.1 & 7.286 & 103 & $2.7 \%$ & $-0.17[-0.44,0.10]$ \\
Roller, M. 2018 & -5.91 & 24.962 & 27 & -5.96 & 27.265 & 28 & $1.6 \%$ & $0.00[-0.53,0.53]$ \\
Sattin,R.W.2005 & -6.2 & 23.591 & 153 & 2.2 & 35.305 & 158 & $2.9 \%$ & $-0.28[-0.50,-0.05]$ \\
Zha, Y. 2016 & -14.4 & 12.812 & 20 & -3.3 & 16.164 & 21 & $1.3 \%$ & $-0.74[-1.38,-0.11]$ \\
Subtotal (95\% Cl) & & & 560 & & & 572 & $14.2 \%$ & $-0.38[-0.56,-0.20]$
\end{tabular}

Heterogenelty: $\mathrm{Tau}^{2}=0.02 ; \mathrm{Ch}^{2}=10.03, \mathrm{df}=5(\mathrm{P}=0.07) ; \mathrm{r}^{2}=50 \mathrm{X}$

Test for overall effect: $Z=4.15(P<0.0001)$

\begin{tabular}{|c|c|c|c|c|c|}
\hline Aral, T. 2007 & -0.1 & 3.256 & 71 & -0.1 & 3.607 \\
\hline Arkkukangas,M.2015 & -5 & 26.559 & 13 & -12 & 30.246 \\
\hline Arkkukangas, M.2019 & -0.5 & 30.694 & 54 & -6 & 33.565 \\
\hline Barban, F.2017 & -1.4 & 13.736 & 119 & -0.7 & 15.207 \\
\hline Beyer, N. 2007 & -10.08 & 12.2 & 24 & -5 & 14.087 \\
\hline Campbell, A.J.1997 & 2.5 & 11.1 & 116 & 6.1 & 12.2 \\
\hline Clemson, L2010 & -207.7 & 472.294 & 17 & -60 & 505.526 \\
\hline Clemson, L2012 & -140 & 381.848 & 80 & -37 & 445.856 \\
\hline Cyarto, E. v. 2008 & -0.8992 & 5.1206 & 119 & 5 & 4.243 \\
\hline Frelberger, E. 2013 & -2 & 11.054 & 179 & 0.1 & 14.732 \\
\hline Gine-Garriga, M. 2013 & -14.82 & 26.533 & 22 & 7.9 & 22.578 \\
\hline Gitiln, L N. 2006 & -0.58 & 2.711 & 154 & 0.13 & 2.821 \\
\hline Gschwind, Y.2015 & 3.6 & 10.017 & 78 & 4.4 & B.695 \\
\hline Halnes, T. P. 2009 & 0 & 2.9 & 19 & -0.1 & 2.759 \\
\hline Haler, K.2001 & -0.52 & 1.271 & 24 & -0.24 & 1.219 \\
\hline Ilffe, S. 2014 & -0.3781 & 5.3369 & 367 & -0.17 & 5.643 \\
\hline Jeon, M. Y. 2014 & -7.48 & $3.4 \mathrm{~B}$ & 31 & -0.49 & 1.08 \\
\hline Kapan,A.2016 & -4.2 & 18.619 & 39 & 0.1 & 17.528 \\
\hline Karinkanta, S. 2012 & -12.33 & 24.112 & 106 & -7.98 & 28.468 \\
\hline Un, M. R. 2007 & -1.4 & 5.02 & 39 & 0.1 & 3.912 \\
\hline Uи,н.2007 & -12.09 & 5.41 & 11 & -3.36 & 2.29 \\
\hline Pattl, R. 2016 & -4.2 & 29.515 & 103 & 2 & 31.443 \\
\hline Siegrist, M. 2016 & -1.8 & 11.045 & 167 & 0.1 & 14.217 \\
\hline Smulders, E.2010 & -7.2 & 26.218 & 44 & -4.6 & 29.672 \\
\hline $\begin{array}{l}\text { Yang, X. J. } 2012 \\
\text { Subtotal }(95 \% \mathrm{Cl})\end{array}$ & -0.05 & 1.825 & $\begin{array}{r}59 \\
2055\end{array}$ & 0.07 & 1.801 \\
\hline
\end{tabular}

Heterogenelty: $\mathrm{Tau}^{2}=0.10 ; \mathrm{ChI}^{2}=109.36, \mathrm{df}=24(\mathrm{P}<0.00001) ; \mathrm{P}^{2}=7 \mathrm{BH}$

Test for overall effect: $Z=3.89(P=0.0001)$

1.2.8 Resistance exercise

$\begin{array}{lrrrrrrrr}\text { Broumer, B. 2003 } & -7.8 & 28.495 & 17 & -4 & 20.761 & 17 & 1.2 \% & -0.15[-0.82,0.52] \\ \text { Uu-Ambrose,T.2004 } & -4.6 & 28.42 & 32 & -0.7 & 29.52 & 32 & 1.7 \% & -0.13[-0.62,0.36] \\ \text { MeCormack, G.2004 } & -0.4 & 1.539 & 14 & 0.6 & 2.848 & 7 & 0.8 \% & -0.47[-1.39,0.45] \\ \text { Vogler.2009 } & -0.45 & 2.545 & 114 & -0.3 & 2.408 & 57 & 2.5 \% & -0.06[-0.38,0.26] \\ \text { Subtotal }(95 \% \mathrm{Cl}) & & & 177 & & & 113 & 6.2 \% & -0.12[-0.36,0.12]\end{array}$

Subtotal $(95 \% \mathrm{Cl})$

$\begin{array}{llllllll}-0.45 & 2.545 & 114 & -0.3 & 2.408 & 57 & 2.5 \% & -0.06[-0.38,0.26] \\ & & 177 & & & 113 & 6.2 \% & -0.12[-0.36,0.12]\end{array}$

Heterogenelty: $\mathrm{Tau}^{2}=0.00 ; \mathrm{Ch}^{2}=0.70, \mathrm{df}=3(\mathrm{P}=0.87) ; \mathrm{H}^{2}=0 \mathrm{X}$

Test for overall effect: $Z=0.95$ (P $=0.34$ )

1.2.9 Balance exercise

$\begin{array}{lrr}\text { Arantes, M. 2015 } & -4.4 & 12.102 \\ \text { Bao, T. 201B } & -0.4 & 7.207 \\ \text { Duque, G.2013 } & -1.04 & 0.942 \\ \text { E-Khoury, F. 2015 } & 1.06 & 7.254 \\ \text { Halwarsson, A. 2011 } & -6 & 8.485 \\ \text { Jagdhane, S. 2016 } & -4.3 & 3.147 \\ \text { Uu-Ambrose,T.2004 } & -4.9 & 18.95 \\ \text { Schoene, D.2015 } & -2.8 & 20.512 \\ \text { Szturm, T. 2011 } & -128 & 340.262 \\ \text { Westlake, K. P. 2007 } & -0.9 & 13.294 \\ \text { Wolf, B.2001 } & 0.5 & 43.135 \\ \text { Wollesen, B. 2017 } & -1.93 & 4.282 \\ \text { Zhao, Y. 2016 } & -8.6 & 15.099\end{array}$

$\begin{array}{lrr}\text { Whas Y. 2016 } & -1.93 & 4.2 \mathrm{B2} \\ \text { Zhao, } & -8.6 & 15,099\end{array}$

Subtotal $(95 \% \mathrm{Cl})$

Heterogenelty: $\mathrm{Tau}^{2}=0.00 ; \mathrm{Ch}^{2}=9.23, \mathrm{df}=12(\mathrm{P}=0.68) ; \mathrm{P}^{2}=0 \mathrm{X}$

Test for overall effect: $Z=2.63(\mathrm{P}=0.00 \mathrm{~B})$

1.2.10 Novel exercise

$\begin{array}{lrrrrrrrr}1.2 .10 \text { Novel exercise } & & & & & & \\ \text { Devereux, K. 2005 } & -0.3 & 1.2 & 23 & -0.03 & 0.5 & 24 & 1.5 \% & -0.29[-0.87,0.28] \\ \text { Lal, C.H.2013 } & -4.87 & 8.937 & 15 & -1.73 & 38.902 & 15 & 1.1 \% & -0.11[-0.82,0.61] \\ \text { Ullmann, G. 2010 } & -0.32 & 0.69 & 25 & 0.06 & 0.4784 & 22 & 1.4 \% & -0.62[-1.21,-0.03] \\ \text { Zhang, L2014 } & -20.64 & 30.609 & 19 & -11.34 & 25.45 & 18 & 1.2 \% & -0.32[-0.97,0.33] \\ \text { Subtotal (95\% Cl) } & & & 82 & & & 79 & 5.2 \% & -0.36[-0.67,-0.04]\end{array}$

Shang, L2014

Heterogenelty: $\mathrm{Tau}^{2}=0.00 ; \mathrm{Ch}^{2}=1.31, \mathrm{df}=3(\mathrm{P}=0.73) ; \mathrm{r}^{2}=0 \mathrm{x}$

2.4\% $\quad 0.00[-0.34,0.34]$

$2.2 \times \quad 0.17[-0.21,0.55]$

$2.8 \%-0.05[-0.30,0.20]$

$1.5 \%-0.38[-0.92,0.17]$

$2.8 \%-0.31[-0.57,-0.05]$

$1.0 \times-0.30[-1.04,0.45]$

$2.58-0.25[-0.56,0.06]$

$[-1.56,-0.84]$

$2.9 \times-0.16[-0.39,0.06]$

$2.9 \times-0.26[-0.48,-0.03]$

$2.5 \%-0.08[-0.40,0.23]$

$1.5 \% \quad 0.04[-0.53,0.60]$

$1.5 \%-0.04[-0.53,0.60]$

$3.2 \%-0.04[-0.21,0.13]$

$1.1 \times-2.68[-3.38,-1.98]$

$1.9 \%-0.24[-0.68,0.20]$

$2.2 \%-0.17[-0.56,0.22]$

$1.9 \%-0.33[-0.77,0.11]$

$0.6 \times-2.02[-3.09,-0.96]$

$2.7 \times-0.20[-0.48,0.07]$

$2.9 \times-0.15[-0.40,0.09]$

$2.0 \%-0.09[-0.52,0.34]$

$2.3 \%-0.07[-0.42,0.29]$

$51.8 \%-0.30[-0.46,-0.15]$

Test for overall effect: $Z=2.24(P=0.03)$

1.2.11 aerobic exercise

Voukelatos, A.2015

Yoo, E.J. 2010

Subtotal $(95 \% \mathrm{Cl})$

$\begin{array}{rrrrrrrr}0 & 6.501 & 144 & 0.1 & 8.04 & 169 & 3.0 \times & -0.01[-0.24,0.21]\end{array}$

$1.0 \times-0.52[-1.28,0.23]$

$0.5 \%-0.09[-1.22,1.04]$

$1.8 \times-0.51[-1.00,-0.03]$

$3.3 \times-0.05[-0.20,0.10]$

$1.5 \%-0.40[-0.94,0.15]$

$0.1 \times-1.90[-4.33,0.53]$

$1.8 \times-0.17[-0.65,0.32]$

$1.9 \%-0.22[-0.66,0.21]$

$1.0 \times-0.24[-1.00,0.52]$

$1.2 \%-0.43[-1.09,0.24]$

$1.9 \%-0.09[-0.54,0.36]$

$1.4 \times-0.37[-0.96,0.22]$

$1.3 \%-0.00[-0.61,0.61]$

Std. Mean Difference

Heterogenelty: $\mathrm{Tau}^{2}=0.02 ; \mathrm{Ch}^{2}=1.1 \mathrm{~B}$, df $=1(\mathrm{P}=0.2 \mathrm{~B}) ; \mathrm{P}^{2}=16 \mathrm{~K}$

Test for overall effect: $Z=0.47(\mathrm{P}=0.64)$

Total $(95 \% \mathrm{Cl})$ 3657

$3226100.0 \%-0.28[-0.37,-0.19]$

Heterogenelty: $\mathrm{Tau}^{2}=0.06 ; \mathrm{Ch}^{2}=144.66, \mathrm{df}=53(\mathrm{P}<0.00001) ; \mathrm{P}^{2}=63 \mathrm{x}$

Test for overall effect $Z=6.09(\mathrm{P}<0.00001)$

Test for subgroup differences: $\mathrm{Ch}^{2}=7.79$, df $=5(\mathrm{P}=0.17), \mathrm{I}^{2}=35.9 \mathrm{X}$ 
Subgroups by duration of intervention

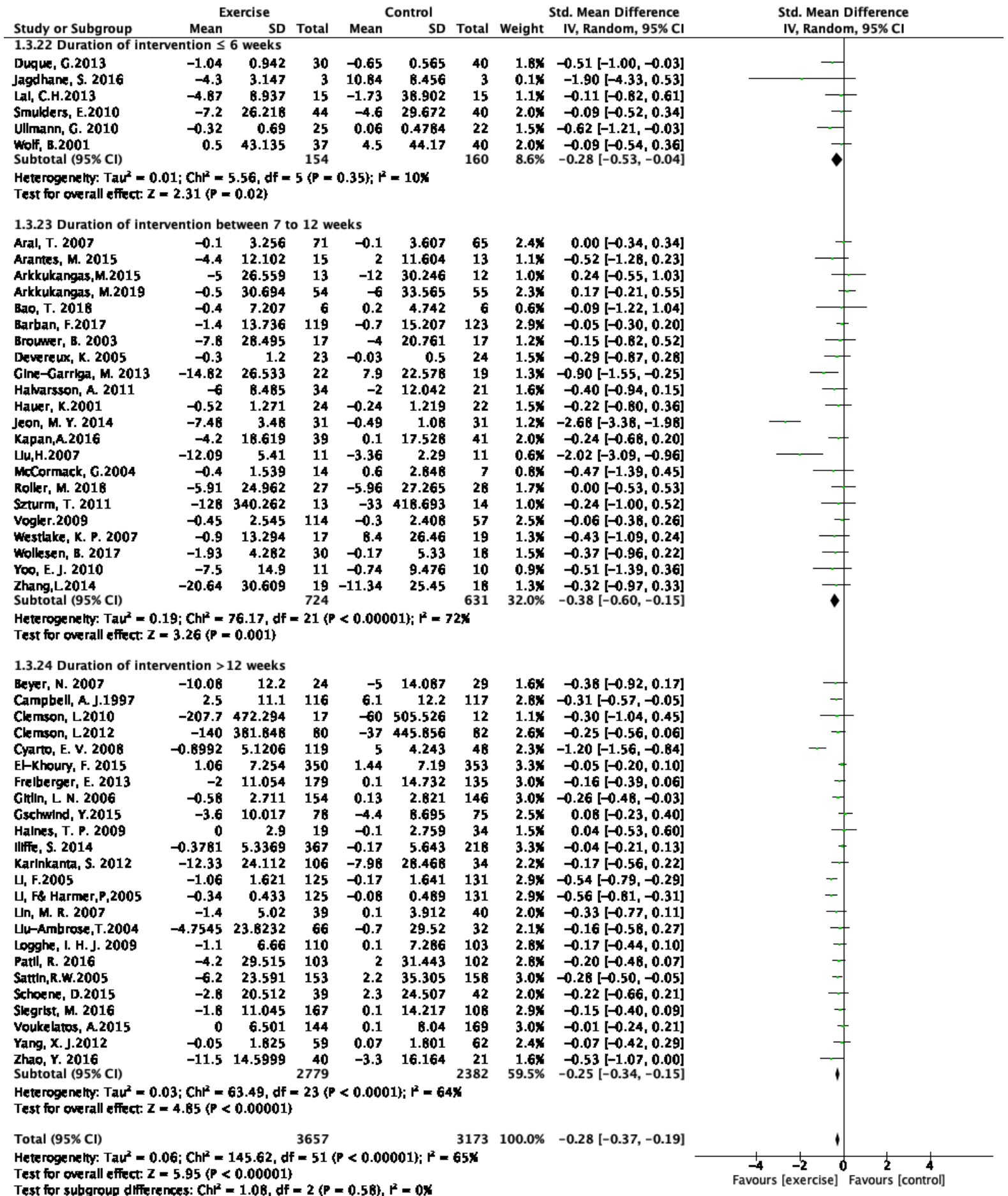


Subgroups by primary or secondary outcome measures

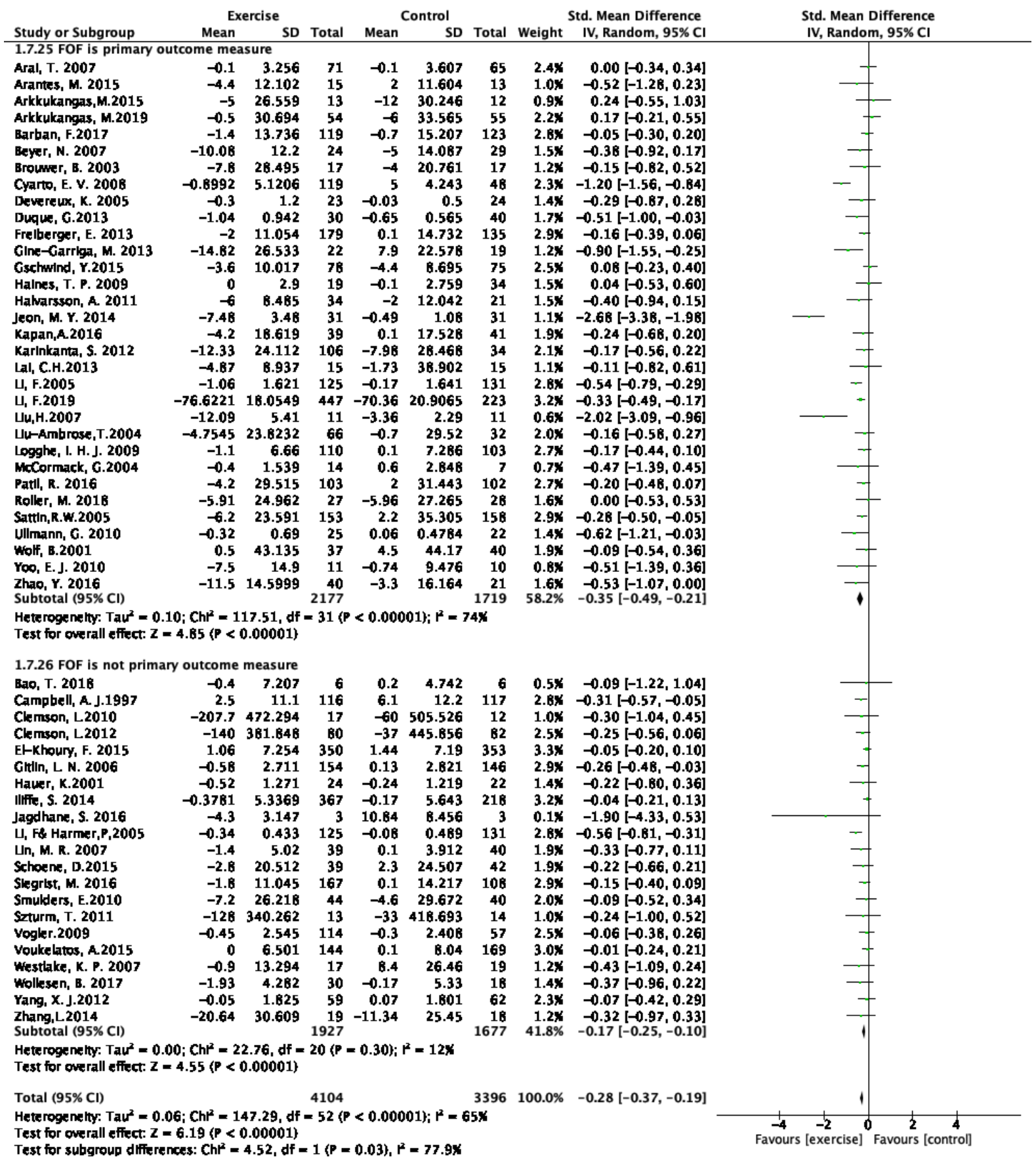


Subgroups by individual or group-based exercise

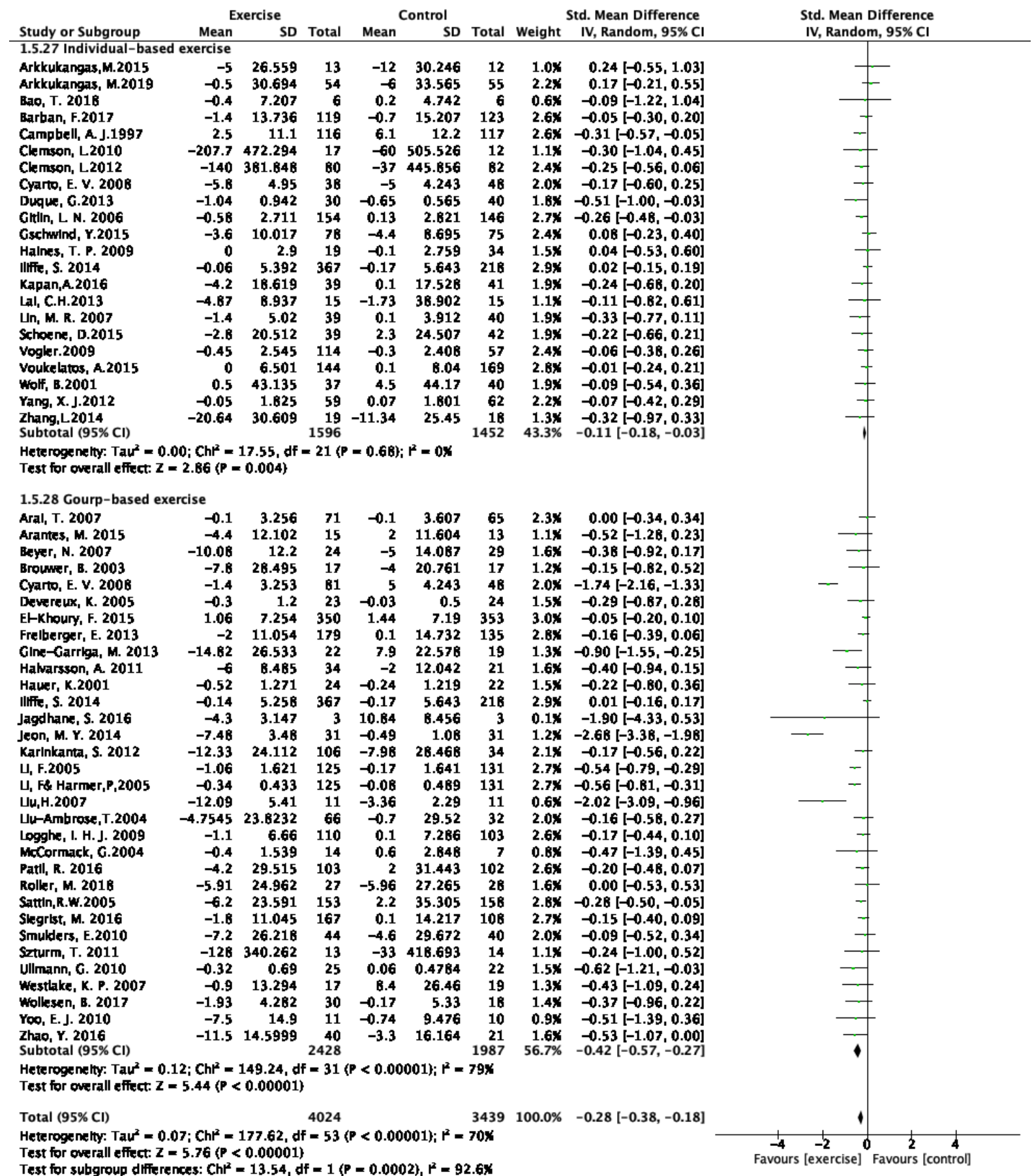




\section{Appendix G PRISMA Checklist}

\begin{tabular}{|c|c|c|c|}
\hline $\begin{array}{l}\text { Section and } \\
\text { Topic }\end{array}$ & $\begin{array}{l}\text { Item } \\
\#\end{array}$ & Checklist item & $\begin{array}{l}\text { Location } \\
\text { where item is } \\
\text { reported }\end{array}$ \\
\hline \multicolumn{4}{|l|}{ TITLE } \\
\hline Title & 1 & Identify the report as a systematic review. & Cover page \\
\hline \multicolumn{4}{|l|}{ ABSTRACT } \\
\hline Abstract & 2 & See the PRISMA 2020 for Abstracts checklist. & Page ii \\
\hline \multicolumn{4}{|c|}{ INTRODUCTION } \\
\hline Rationale & 3 & Describe the rationale for the review in the context of existing knowledge. & Page 13-19 \\
\hline Objectives & 4 & Provide an explicit statement of the objective(s) or question(s) the review addresses. & Page 19-20 \\
\hline \multicolumn{4}{|l|}{ METHODS } \\
\hline $\begin{array}{l}\text { Eligibility } \\
\text { criteria }\end{array}$ & 5 & Specify the inclusion and exclusion criteria for the review and how studies were grouped for the syntheses. & Page 47-48 \\
\hline $\begin{array}{l}\text { Information } \\
\text { sources }\end{array}$ & 6 & $\begin{array}{l}\text { Specify all databases, registers, websites, organisations, reference lists and other sources searched or consulted to } \\
\text { identify studies. Specify the date when each source was last searched or consulted. }\end{array}$ & Page 47 \\
\hline $\begin{array}{l}\text { Search } \\
\text { strategy }\end{array}$ & 7 & Present the full search strategies for all databases, registers and websites, including any filters and limits used. & Page 47 \\
\hline $\begin{array}{l}\text { Selection } \\
\text { process }\end{array}$ & 8 & $\begin{array}{l}\text { Specify the methods used to decide whether a study met the inclusion criteria of the review, including how many } \\
\text { reviewers screened each record and each report retrieved, whether they worked independently, and if applicable, } \\
\text { details of automation tools used in the process. }\end{array}$ & Page 47-51 \\
\hline $\begin{array}{l}\text { Data collection } \\
\text { process }\end{array}$ & 9 & $\begin{array}{l}\text { Specify the methods used to collect data from reports, including how many reviewers collected data from each } \\
\text { report, whether they worked independently, any processes for obtaining or confirming data from study investigators, } \\
\text { and if applicable, details of automation tools used in the process. }\end{array}$ & Page 47-51 \\
\hline \multirow[t]{2}{*}{ Data items } & $10 a$ & $\begin{array}{l}\text { List and define all outcomes for which data were sought. Specify whether all results that were compatible with each } \\
\text { outcome domain in each study were sought (e.g. for all measures, time points, analyses), and if not, the methods } \\
\text { used to decide which results to collect. }\end{array}$ & Page 48 \\
\hline & $10 \mathrm{~b}$ & $\begin{array}{l}\text { List and define all other variables for which data were sought (e.g. participant and intervention characteristics, } \\
\text { funding sources). Describe any assumptions made about any missing or unclear information. }\end{array}$ & Page 48-52 \\
\hline $\begin{array}{l}\text { Study risk of } \\
\text { bias } \\
\text { assessment }\end{array}$ & 11 & $\begin{array}{l}\text { Specify the methods used to assess risk of bias in the included studies, including details of the tool(s) used, how } \\
\text { many reviewers assessed each study and whether they worked independently, and if applicable, details of } \\
\text { automation tools used in the process. }\end{array}$ & Page 50-51 \\
\hline $\begin{array}{l}\text { Effect } \\
\text { measures }\end{array}$ & 12 & $\begin{array}{l}\text { Specify for each outcome the effect measure(s) (e.g. risk ratio, mean difference) used in the synthesis or } \\
\text { presentation of results. }\end{array}$ & Page 51-52 \\
\hline $\begin{array}{l}\text { Synthesis } \\
\text { methods }\end{array}$ & $13 a$ & $\begin{array}{l}\text { Describe the processes used to decide which studies were eligible for each synthesis (e.g. tabulating the study } \\
\text { intervention characteristics and comparing against the planned groups for each synthesis (item \#5)). }\end{array}$ & Page 48-50 \\
\hline
\end{tabular}




\begin{tabular}{|c|c|c|c|}
\hline $\begin{array}{l}\text { Section and } \\
\text { Topic }\end{array}$ & $\begin{array}{l}\text { Item } \\
\text { \# }\end{array}$ & Checklist item & $\begin{array}{l}\text { Location } \\
\text { where item is } \\
\text { reported }\end{array}$ \\
\hline & $13 b$ & $\begin{array}{l}\text { Describe any methods required to prepare the data for presentation or synthesis, such as handling of missing } \\
\text { summary statistics, or data conversions. }\end{array}$ & Page 51-52 \\
\hline & $13 c$ & Describe any methods used to tabulate or visually display results of individual studies and syntheses. & Page 51 \\
\hline & $13 d$ & $\begin{array}{l}\text { Describe any methods used to synthesize results and provide a rationale for the choice(s). If meta-analysis was } \\
\text { performed, describe the model(s), method(s) to identify the presence and extent of statistical heterogeneity, and } \\
\text { software package(s) used. }\end{array}$ & Page 51-52 \\
\hline & $13 e$ & $\begin{array}{l}\text { Describe any methods used to explore possible causes of heterogeneity among study results (e.g. subgroup } \\
\text { analysis, meta-regression). }\end{array}$ & Page 51-52 \\
\hline & $13 f$ & Describe any sensitivity analyses conducted to assess robustness of the synthesized results. & Page 52 \\
\hline $\begin{array}{l}\text { Reporting bias } \\
\text { assessment }\end{array}$ & 14 & $\begin{array}{l}\text { Describe any methods used to assess risk of bias due to missing results in a synthesis (arising from reporting } \\
\text { biases). }\end{array}$ & Page 52 \\
\hline $\begin{array}{l}\text { Certainty } \\
\text { assessment }\end{array}$ & 15 & Describe any methods used to assess certainty (or confidence) in the body of evidence for an outcome. & Page 52 \\
\hline \multicolumn{4}{|l|}{ RESULTS } \\
\hline \multirow[t]{2}{*}{$\begin{array}{l}\text { Study } \\
\text { selection }\end{array}$} & $16 a$ & $\begin{array}{l}\text { Describe the results of the search and selection process, from the number of records identified in the search to the } \\
\text { number of studies included in the review, ideally using a flow diagram. }\end{array}$ & Page 55 \\
\hline & $16 \mathrm{~b}$ & $\begin{array}{l}\text { Cite studies that might appear to meet the inclusion criteria, but which were excluded, and explain why they were } \\
\text { excluded. }\end{array}$ & Page 55 \\
\hline $\begin{array}{l}\text { Study } \\
\text { characteristics }\end{array}$ & 17 & Cite each included study and present its characteristics. & Page 58-65 \\
\hline $\begin{array}{l}\text { Risk of bias in } \\
\text { studies }\end{array}$ & 18 & Present assessments of risk of bias for each included study. & Page 67-72 \\
\hline $\begin{array}{l}\text { Results of } \\
\text { individual } \\
\text { studies }\end{array}$ & 19 & $\begin{array}{l}\text { For all outcomes, present, for each study: (a) summary statistics for each group (where appropriate) and (b) an } \\
\text { effect estimate and its precision (e.g. confidence/credible interval), ideally using structured tables or plots. }\end{array}$ & Page 87 \\
\hline \multirow{4}{*}{$\begin{array}{l}\text { Results of } \\
\text { syntheses }\end{array}$} & $20 a$ & For each synthesis, briefly summarise the characteristics and risk of bias among contributing studies. & Page 87-95 \\
\hline & $20 b$ & $\begin{array}{l}\text { Present results of all statistical syntheses conducted. If meta-analysis was done, present for each the summary } \\
\text { estimate and its precision (e.g. confidence/credible interval) and measures of statistical heterogeneity. If comparing } \\
\text { groups, describe the direction of the effect. }\end{array}$ & Page 87-95 \\
\hline & $20 c$ & Present results of all investigations of possible causes of heterogeneity among study results. & Page 87-95 \\
\hline & $20 d$ & Present results of all sensitivity analyses conducted to assess the robustness of the synthesized results. & Page 93-95 \\
\hline $\begin{array}{l}\text { Reporting } \\
\text { biases }\end{array}$ & 21 & $\begin{array}{l}\text { Present assessments of risk of bias due to missing results (arising from reporting biases) for each synthesis } \\
\text { assessed. }\end{array}$ & Page 95 \\
\hline
\end{tabular}




\begin{tabular}{|c|c|c|c|}
\hline $\begin{array}{l}\text { Section and } \\
\text { Topic }\end{array}$ & $\begin{array}{l}\text { Item } \\
\text { \# }\end{array}$ & Checklist item & $\begin{array}{l}\text { Location } \\
\text { where item is } \\
\text { reported }\end{array}$ \\
\hline $\begin{array}{l}\text { Certainty of } \\
\text { evidence }\end{array}$ & 22 & Present assessments of certainty (or confidence) in the body of evidence for each outcome assessed. & Page 87-94 \\
\hline \multicolumn{4}{|l|}{ DISCUSSION } \\
\hline \multirow[t]{4}{*}{ Discussion } & $23 a$ & Provide a general interpretation of the results in the context of other evidence. & $\begin{array}{l}\text { Page 101, } \\
105-108\end{array}$ \\
\hline & $23 b$ & Discuss any limitations of the evidence included in the review. & Page 110-111 \\
\hline & $23 c$ & Discuss any limitations of the review processes used. & Page 110-111 \\
\hline & $23 d$ & Discuss implications of the results for practice, policy, and future research. & Page 109-110 \\
\hline \multicolumn{4}{|c|}{ OTHER INFORMATION } \\
\hline \multirow[t]{3}{*}{$\begin{array}{l}\text { Registration } \\
\text { and protocol }\end{array}$} & $24 a$ & $\begin{array}{l}\text { Provide registration information for the review, including register name and registration number, or state that the } \\
\text { review was not registered. }\end{array}$ & N/A \\
\hline & $24 \mathrm{~b}$ & Indicate where the review protocol can be accessed, or state that a protocol was not prepared. & N/A \\
\hline & $24 c$ & Describe and explain any amendments to information provided at registration or in the protocol. & N/A \\
\hline Support & 25 & $\begin{array}{l}\text { Describe sources of financial or non-financial support for the review, and the role of the funders or sponsors in the } \\
\text { review. }\end{array}$ & N/A \\
\hline $\begin{array}{l}\text { Competing } \\
\text { interests }\end{array}$ & 26 & Declare any competing interests of review authors. & Page 111 \\
\hline $\begin{array}{l}\text { Availability of } \\
\text { data, code and } \\
\text { other materials }\end{array}$ & 27 & $\begin{array}{l}\text { Report which of the following are publicly available and where they can be found: template data collection forms; } \\
\text { data extracted from included studies; data used for all analyses; analytic code; any other materials used in the } \\
\text { review. }\end{array}$ & Page 115-137 \\
\hline
\end{tabular}




\section{Appendix H AMSTAR2}

1. Did the research questions and inclusion criteria for the review include the components of PICO?

\section{For Yes:}
$\square$ Population
I. Intervention
$\square$ Comparator group
$\square$ Outcome

2. Did the report of the review contain an explicit statement that the review methods were established prior to the conduct of the review and did the report justify any significant deviations from the protocol?

\section{For Partial Yes:}

The authors state that they had a written protocol or guide that included ALL the following:
$\square$ review question(s)
$\square$ a search strategy
v inclusion/exclusion criteria
$\square$ a risk of bias assessment

\section{For Yes:}

As for partial yes, plus the protocol should be registered and should also have specified:

$$
\begin{aligned}
& \square \text { a meta-analysis/synthesis plan, } \\
& \text { if appropriate, and } \\
& \square \text { a plan for investigating causes } \\
& \text { of heterogeneity } \\
& \square \text { justification for any deviations }
\end{aligned}
$$$$
\text { Q Yes }
$$$$
\text { ․ No }
$$

3. Did the review authors explain their selection of the study designs for inclusion in the review?

For Yes, the review should satisfy ONE of the following:
$\square$ Explanation for including only RCTs
O OR Explanation for including only NRSI
$\square$ Yes
․ No

OR Explanation for including both RCTs and NRSI

4. Did the review authors use a comprehensive literature search strategy?

For Partial Yes (all the following): $\quad$ For Yes, should also have (all the

v searched at least 2 databases (relevant to research question)

$\square$ provided key word and/or search strategy

Q justified publication restrictions (e.g. language) following):
(v) searched the reference lists / bibliographies of included studies
$\square$ searched trial/study registries
$\square$ included/consulted content experts in the field
$\square$ where relevant, searched for grey literature
$\square$ conducted search within 24 months of completion of the review

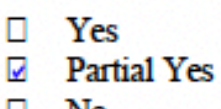
$\square$ No

5. Did the review authors perform study selection in duplicate?

For Yes, either ONE of the following:

Q at least two reviewers independently agreed on selection of eligible studies and achieved consensus on which studies to include

OR two reviewers selected a sample of eligible studies and achieved good 
6. Did the review authors perform data extraction in duplicate?

For Yes, either ONE of the following:

$\square$ at least two reviewers achieved consensus on which data to extract from

$\square$ Yes included studies

$\square$ OR two reviewers extracted data from a sample of eligible studies and achieved good agreement (at least 80 percent), with the remainder extracted by one reviewer.

7. Did the review authors provide a list of excluded studies and justify the exclusions?

For Partial Yes:

$\square$ provided a list of all potentially relevant studies that were read in full-text form but excluded For Yes, must also have: from the review

Q Justified the exclusion from the review of each potentially relevant study
$\square$ Yes
[ Partial Yes
․ No

8. Did the review authors describe the included studies in adequate detail?

For Partial Yes (ALL the following): $\quad$ For Yes, should also have ALL the following:

$\square$ described populations

Q. described interventions

$\square$ described comparators

『 described outcomes

$\square$ described research designs

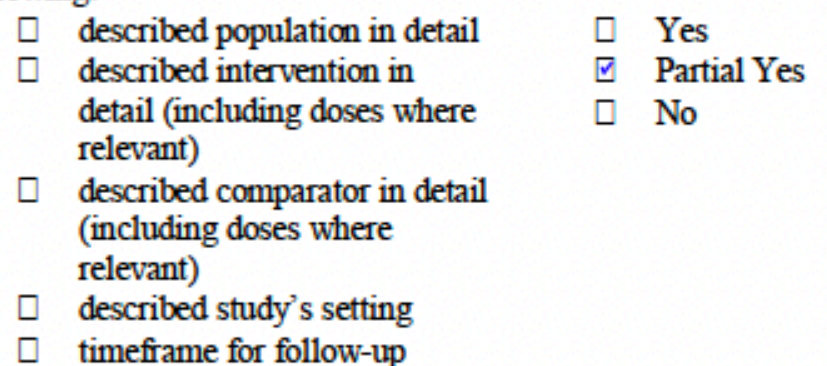

9. Did the review authors use a satisfactory technique for assessing the risk of bias (RoB) in individual studies that were included in the review?

\section{RCTs}

For Partial Yes, must have assessed RoB from

$\square$ unconcealed allocation, and

$\square$ lack of blinding of patients and assessors when assessing outcomes (unnecessary for objective outcomes such as allcause mortality)

NRSI

For Partial Yes, must have assessed RoB:

- from confounding, and

$\square$ from selection bias
For Yes, must also have assessed RoB from:

$\square \quad$ allocation sequence that was not truly random, and

v selection of the reported result from among multiple measurements or analyses of a specified outcome
区 Yes

[ Partial Yes

․ No

- Includes only NRSI
For Yes, must also have assessed RoB:

$\square$ methods used to ascertain exposures and outcomes, and

- selection of the reported result from among multiple measurements or analyses of a specified outcome

$$
\begin{array}{ll}
\square & \text { Yes } \\
\square & \text { Partial Yes } \\
\square & \text { No } \\
\square & \text { Includes only } \\
& \text { RCTs }
\end{array}
$$

10. Did the review authors report on the sources of funding for the studies included in the review? For Yes

Must have reported on the sources of funding for individual studies included in the review. Note: Reporting that the reviewers looked for this information $\square$ Yes but it was not reported by study authors also qualifies 
11. If meta-analysis was performed did the review authors use appropriate methods for statistical combination of results?

\section{RCTs}

For Yes:

(]) The authors justified combining the data in a meta-analysis

『 AND they used an appropriate weighted technique to combine study results and adjusted for heterogeneity if present.

Q. AND investigated the causes of any heterogeneity

For NRSI

For Yes:

$\square$ The authors justified combining the data in a meta-analysis

$\begin{array}{ll}\text { Y } & \text { Yes } \\ \square & \text { No } \\ \text { T } & \begin{array}{l}\text { No meta-analysis } \\ \text { conducted }\end{array}\end{array}$

AND they used an appropriate weighted technique to combine study results, adjusting for heterogeneity if present

AND they statistically combined effect estimates from NRSI that

$\square$ Yes

(]) No

․ No meta-analysis conducted were adjusted for confounding, rather than combining raw data, or justified combining raw data when adjusted effect estimates were not available

$\square$ AND they reported separate summary estimates for RCTs and NRSI separately when both were included in the review

12. If meta-analysis was performed, did the review authors assess the potential impact of RoB in individual studies on the results of the meta-analysis or other evidence synthesis?

For Yes:

$\square$ included only low risk of bias RCTs

$\square \mathrm{OR}$, if the pooled estimate was based on RCTs and/or NRSI at variable

$\mathrm{RoB}$, the authors performed analyses to investigate possible impact of

RoB on summary estimates of effect.

$\begin{array}{ll}\square & \text { Yes } \\ \square & \text { No } \\ \square & \text { No meta-analysis } \\ \text { conducted }\end{array}$

13. Did the review authors account for RoB in individual studies when interpreting/ discussing the results of the review?

For Yes:
included only low risk of bias RCTs
$\square$ OR, if RCTs with moderate or high RoB, or NRSI were included the
『 Yes
review provided a discussion of the likely impact of RoB on the results
$\square$ No

14. Did the review authors provide a satisfactory explanation for, and discussion of, any heterogeneity observed in the results of the review?

For Yes:

There was no significant heterogeneity in the results

$\square \quad O R$ if heterogeneity was present the authors performed an investigation of sources of any heterogeneity in the results and discussed the impact of this on the results of the review

15. If they performed quantitative synthesis did the review authors carry out an adequate investigation of publication bias (small study bias) and discuss its likely impact on the results of the review?

For Yes:

$\square$ performed graphical or statistical tests for publication bias and discussed the likelihood and magnitude of impact of publication bias
ए Yes
( No
․ No meta-analysis conducted


16. Did the review authors report any potential sources of conflict of interest, including any funding they received for conducting the review?

For Yes:

$\square$ The authors reported no competing interests $O R$

$\square$ The authors described their funding sources and how they managed

$\square$ Yes potential conflicts of interest

․ No

No 